\title{
The antithrombotic management of atrial fibrillation
}

Citation for published version (APA):

Pisters, R. (2012). The antithrombotic management of atrial fibrillation. [Doctoral Thesis, Maastricht University]. Datawyse / Universitaire Pers Maastricht. https://doi.org/10.26481/dis.20120323rp

Document status and date:

Published: 01/01/2012

DOI:

10.26481/dis.20120323rp

Document Version:

Publisher's PDF, also known as Version of record

\section{Please check the document version of this publication:}

- A submitted manuscript is the version of the article upon submission and before peer-review. There can be important differences between the submitted version and the official published version of record.

People interested in the research are advised to contact the author for the final version of the publication, or visit the DOI to the publisher's website.

- The final author version and the galley proof are versions of the publication after peer review.

- The final published version features the final layout of the paper including the volume, issue and page numbers.

Link to publication

\footnotetext{
General rights rights.

- You may freely distribute the URL identifying the publication in the public portal. please follow below link for the End User Agreement:

www.umlib.nl/taverne-license

Take down policy

If you believe that this document breaches copyright please contact us at:

repository@maastrichtuniversity.nl

providing details and we will investigate your claim.
}

Copyright and moral rights for the publications made accessible in the public portal are retained by the authors and/or other copyright owners and it is a condition of accessing publications that users recognise and abide by the legal requirements associated with these

- Users may download and print one copy of any publication from the public portal for the purpose of private study or research.

- You may not further distribute the material or use it for any profit-making activity or commercial gain

If the publication is distributed under the terms of Article $25 \mathrm{fa}$ of the Dutch Copyright Act, indicated by the "Taverne" license above, 


\section{The Antithrombotic Management of Atrial Fibrillation}


ISBN 9789461591289

Production: I.Magine

Alle rechten voorbehouden.

Niets uit deze uitgave mag worden verveelvoudigd, opgeslagen in een geautomatiseerd gegevensbestand en/of openbaar gemaakt in enige vorm of op enige wijze, hetzij elektronisch, mechanisch, door fotokopieën, opnamen of op enige andere manier zonder voorafgaande schriftelijke toestemming van de uitgever. 


\section{The Antithrombotic Management of Atrial Fibrillation}

\section{PROEFSCHRIFT}

ter verkrijging van de graad van doctor aan de Universiteit Maastricht, op gezag van de Rector Magnificus, Prof. mr. G.P.M.F. Mols,

volgens het besluit van het College van Decanen,

in het openbaar te verdedigen,

op vrijdag 23 maart 2012 om 16.00 uur

door

Ronny Pisters

geboren op 27 augustus 1982 te Heerlen

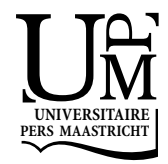




\section{Promotor}

Prof. dr. H.J.G.M. Crijns

\section{Beoordelingscommissie}

Prof. dr. H. ten Cate (voorzitter)

Prof. dr. M.A. Allessie

Prof. dr. I.C. van Gelder, University Medical Centre Groningen

Prof. dr. G.Y.H. Lip, University of Birmingham, United Kingdom

Prof. dr. R.J. van Oostenbrugge

Financial support by Stichting Hartsvrienden RESCAR for the publication of this thesis is gratefully acknowledged.

Additional financial support by Bayer Health Care B.V., Boehringer-Ingelheim B.V. and Merck Sharp \& Dohme B.V. is similarly appreciated. 
Voor iedereen met AF, of die iemand met AF kent 



\section{Content}

$\begin{array}{ll}\text { Introduction } & 9\end{array}$

Section I - Risk of stroke $\quad 19$

$\begin{array}{lll}\text { Chapter } 1 & \text { Refining clinical risk stratification for predicting stroke and } & 21\end{array}$ thromboembolism in atrial fibrillation using a novel risk factorbased approach: the euro heart survey on atrial fibrillation. Chest 2010;137;:263-72.

Letter to the Editor by Daniel E. Singer, Margret C. Fang and Alan S.Go and response Chest 2010;138; 1020-1021.

Letter to the Editor by Karen G. Johnson and Douglas C. Johnson and response Chest 2010;138; 239-240.

Section II - Risk of major bleeding

Chapter 2 Clopidogrel plus aspirin in atrial fibrillation N Engl J Med 2009;361(13);1314-5.

Chapter 3 A novel user-friendly score (HAS-BLED) to assess 1-year risk of 49 major bleeding in patients with atrial fibrillation: the Euro Heart Survey. Chest Chest 2010; 138(5);1093-100.

Editorial by Giusepper Boriani, Igor Diemberger, Mauro Biffi and Christian Martignani Chest 2010;138(5):1032-3.

Letter to the Editor by Eduardo Vázquez and Carmen SánchezPerales and response Chest 2011;139(5):1248-50.

Letter to the Editor by Ullise Corbanese and response 72 Chest 2011;139(5):1247-8. 
Chapter 4 The likelihood of decreasing strokes in atrial fibrillation patients by strict application of guidelines Europace 2010;12(6):779-84.

Editorial by Laurent Fauchier and Gregory Y.H. Lip Europace 2010;12(6):761-3.

Chapter 5 Use and underuse of oral anticoagulation for stroke prevention in atrial fibrillation: old an new paradigms Semin Thromb Hemost 2009;35(6);554-9.

$\begin{array}{lll}\text { Chapter } 6 & \text { Improving antithrombotic management in patients with atrial } & 109\end{array}$ fibrillation: current status and perspectives.

Semin Thromb Hemost 2009;35(6)527-42.

Chapter 7 Clinical correlaters of immediate success and outcome at one year follow-up of real world cardioversion of atrial fibrillation: The Euro Heart Survey Europace 2012 Jan 5. [Epub ahead of print] PMID:22223715

Chapter 8 Effect of dronedarone on clinical endpoints in patients with atrial fibrillation and coronary heart disease: insights from the ATHENA trial

Submitted

Discussion and future directions

Summary / Samenvatting $\quad 199$

$\begin{array}{ll}\text { Dankwoord } & 201\end{array}$

$\begin{array}{ll}\text { Curriculum vitae } & 203\end{array}$

List of publications 205 
Introduction 


\section{Atrial fibrillation}

Atrial fibrillation (AF) is the most common sustained cardiac arrhythmia. In the Netherlands alone there are an estimated 300,000 patients with AF. The prevalence of atrial fibrillation is age dependent, reflected by the impressive numerical rise of $1 \%$ among the overall population to $>8 \%$ of the individuals aged 80 or above. ${ }^{1}$ Also staggering is the lifetime risk of developing AF of nearly $25 \%$ at 55 years of age. ${ }^{1}$ Other important and common risk factors for the development of AF are obesity and hypertension. ${ }^{2,3}$ Given the current conditions of the Western society, it is therefore easily foreseeable that the prevalence of $A F$ is heading towards true epidemic proportions within the next decades. ${ }^{4}$

If a disease would cause little to no inconvenience, or would be easy to treat or even cure - a (strong) rising prevalence per se does not have to be disturbing. However, labeling AF as a benign, harmless arrhythmia could not be farther away from the truth. First of all, next to an irregular (rapid) heartbeat - probably the hallmark of the arrhythmia - AF usually causes a variety of symptoms which disrupt a normal social life and prompt patients to seek medical attention. Furthermore, on top of the doubled mortality rate ${ }^{5}$ and increased risk of developing heart failure, $\mathrm{AF}$ patients have an increased thromboembolic risk. ${ }^{6}$ Most feared is the occurrence of an ischemic stroke, for which AF patients - irrespective of the clinical type of AF have an average risk of $5 \%$ per year: two to seven times higher compared to individuals without the arrhythmia. ${ }^{6,7}$ This risk is even further increased in the presence of several cardiovascular risk factors. ${ }^{8}$ Apart from being more prone to develop a stroke, AF patients also have the disadvantage that the impact of the stroke is more severe compared to non-AF related strokes. ${ }^{9}$

Physicians treating AF patients face one particular important, somehow confusing issue. There is no benefit regarding prevention of mortality or stroke for a strategy where all efforts are made to maintain sinus rhythm over one where merely (lenient) rate control is applied. ${ }^{10-12}$ Fortunately, antithrombotic regimens are available which substantially reduce the chance of dying and the risk of thromboembolic events in general and ischemic stroke in particular. ${ }^{13}$ However, hurdles for its widespread implementation in every day practice are all around. ${ }^{14,15}$ Introduction of antithrombotic agents inherently comes at the cost of an increased risk of major bleeding and introduces the pivotal aspect of iatrogenic harm. Short-term focus on rhythm management allows old paradigms to withstand time and certain drug specific aspects, e.g. the need for intensive monitoring of the anticoagulation effects, cripple the antithrombotic readiness for battle, in this example of vitamin $\mathrm{K}$ antagonists (VKAs).

Altogether, this translates into a somewhat vicious, sustained inadequate antithrombotic management of AF patients. ${ }^{15,16}$ Which subsequently leads to unneces- 
sary strokes, major bleedings and loss of life. ${ }^{17}$ This is especially alarming considering the forecasted burden of the arrhythmia.

\section{Clinical aspects of the antithrombotic management of atrial fibrillation}

\subsection{Identifying the arrhythmia}

Atrial fibrillation, as the name suggests, is an arrhythmia that takes places in the atria of the heart. As the clinical presentation of many supraventricular tachycardias (SVTs) can mimic AF or create suspicion of its existence, electrocardiographic diagnosis is warranted for discriminative reasons. In particular considering the potential horrific sequelae associated with AF, opposed to the 'benign' natural history of most other SVTs. Unlike for instance the atrial repolarization, identifying AF on an electrocardiogram (ECG) is not compromised by the ventricles cancelling out the electrical forces of their smaller counterparts. In fact, absence of distinct atrial activity ( $P$ waves) is one of AF's key diagnostic ECG features together with totally irregular R-R intervals during the recording of a 12-lead ECG or 30 seconds on a rhythm strip. ${ }^{18}$

From a clinical point of view AF has been divided into four categories. First detected $A F$ represents the first documented episode and can turn out to be either one of the following types. Paroxysmal AF refers to spontaneously converting episodes with a duration of up to 7 days, whereas persistent AF is unable to convert without medical intervention and by definition lasts longer than a week. Permanent AF, finally, depicts mutual agreement between patient and physician upon acceptance of the arrhythmia - predominantly following failed attempts to restore sinus rhythm whether or not in combination with no or minimal symptoms - and thereby its continuous presence on the ECG. ${ }^{19,20}$

The above mentioned clinical classification points out the two most important clinical hurdles in detecting AF. First, the arrhythmia does not have to be 'around' all the time, but can be present for (brief) paroxysms making it hard to 'catch'. ${ }^{21}$ ${ }^{22}$ Second, from the permanent AF scenario it is important to note that even long standing (persistent) or continuous (permanent) presence of AF is not synonymous to 'easy' detection if the patient is (virtually) asymptomatic. ${ }^{23}$ Thus, although AF related symptoms impair social life, the (completely) asymptomatic patients are likely posed with the biggest health threat. This is reflected by nearly $20 \%$ of newly diagnosed $A F$ in recent stroke patients. ${ }^{24}$ Also, patients who suffered from a stroke of unknown origin, so-called cryptogenic, stroke might have underlying paroxysmal AF which has simply not been caught (yet). This is exemplified by increased AF detection rate when extended monitoring is applied, being between 1-23\% depending on the type of monitoring and definitions used. ${ }^{25-28}$ 


\subsection{Identifying the risk of ischemic stroke}

In the mid 1980's recognition of the significant increased thromboembolic risk associated with AF triggered a series of large randomized clinical trials. ${ }^{29-34}$ They tested the hypothesis whether oral anticoagulation would be beneficial compared to care as usual - at that time being no antithrombotic therapy - regarding primary and secondary prevention of thromboembolism in patients with AF. The so-called 'big five' set a milestone in medicine and revolutionized the treatment of AF with a to this date (!) unprecedented, unanimous risk reduction with oral anticoagulation. ${ }^{13}$ However, the contribution to today's common knowledge was not limited to the antithrombotic armamentarium. Important information on stroke risk factors were derived from a pooled analysis of the placebo control arms of these studies. ${ }^{8}$ For the first time, clinical stroke risk factors in AF patients were described: advanced age, heart failure, history of hypertension, diabetes mellitus and previous stroke or transient ischemic attack. In time, supportive evidence of the latter risk factors became available as well as less consistent identification of additional stroke risk factors, such as female gender and coronary artery disease. The notion of styling this information into a clinically usable format led to the development of several stroke risk stratification schemas of which the $\mathrm{CHADS}_{2}$ score ${ }^{35}$ probably is the most renowned and used. $\mathrm{CHADS}_{2}$ is an acronym based scoring system which rewards one point for the presence of each of the following risk factors Congestive heart failure, $\underline{H}$ ypertension, $\underline{A g e} \geq 75$ years, $\underline{D}$ iabetes mellitus and two points in case the patient already suffered from a transient ischemic attack, $\underline{S}$ troke or other thromboembolism. Simply add up the points (maximum of 6 ) and the resulting score correlates with an annual stroke risk which can be used to further classify patients into low, intermediate and high thrombo-embolic risk and guide antithrombotic treatment. ${ }^{35}$

\subsection{Identifying the risk of major bleeding}

Like most milestones, the antithrombotic breakthrough in the management of AF patients proofed to be a double edged sword. It is not hard to imagine that VKAs carry a bleeding risk, considering the strategic position of the vitamin $\mathrm{K}$ dependent clotting factors - II, VII, IX and X - of which they irreversibly distort the normal structure and thereby function. Again, insights from the initial large randomized trials showed a risk of major bleeding with VKA use of approximately $1 \%$. Taking into account the more contemporary studies, the risk of major bleeding associated with the use of oral anticoagulation should be considered to be in the range of 3-4\%. ${ }^{36-38}$ Important to note, however, is that aspirin also carries a substantial risk of major bleeding. ${ }^{39,40}$ The risk of intracranial hemorrhage, the most feared complication of antithrombotic therapy, is doubled in patients who are treated with VKA compared to aspirin users. However, the numerical difference is small: $0.2 \%$ for VKA and $0.1 \%$ for aspirin use. ${ }^{13}$ Risk factors of this feared complication have been studied in the 
past and advanced age, an excessively high international normalized ratio (INR) and a previous ischemic stroke have been identified as its main independent predictors. ${ }^{41,42}$ As for the stroke risk, attempts have been made to create a risk stratification schema for the occurrence of major bleeding across several settings. The HEM$\mathrm{ORR}_{2} \mathrm{HAGES}$ score ${ }^{43}$, from the same group as the $\mathrm{CHADS}_{2}$ index, is probably the best alternative. HEMORR ${ }_{2} \mathrm{HAGES}$ is also an acronym based scoring system and repre-

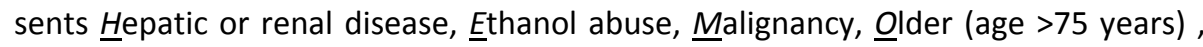
Reduced platelet count or function, $\underline{R}$ e-bleeding risk (2 points), Hypertension (uncontrolled), $\underline{A}$ nemia, Genetic factors, Excessive fall and Stroke. Apart from a previous major bleeding (re-bleeding) presence of the other risk factors adds one point. The resulting maximum score is 12 and an increasing score relates to an increasing risk of major bleeding. ${ }^{43}$ However, it is not as commonly applied as the $\mathrm{CHADS}_{2}$ score, in part due to inferior user-friendliness related to the incorporation of not readily available risk factors, nor is it represented in the 2006 ACC/AHA/ESC Joined guidelines on the management of atrial fibrillation. ${ }^{18}$

\section{Translating the risk of stroke (and bleeding) into an antithrombotic regimen}

At the starting point of this thesis, September 2006, a full revision of the first joined international management guidelines for AF was released. ${ }^{18}$ The available evidence on stroke risk factors and efficacy of antithrombotic regimens was translated into recommendations displayed in Figure 1 as a picture is worth a thousand words. Important to note, however, is that many schemas (and especially the widespread used $\mathrm{CHADS}_{2}$ score) classify the majority of patients at 'intermediate' risk. ${ }^{44}$ This leaves patients and physicians in doubt whether to choose between the inferior (aspirin) or superior (VKAs) drug. ${ }^{13,18}$ Furthermore, a considerable number of patients are withheld from effective antithrombotic therapy based on their 'low' risk profile, but still suffer from a thromboembolic event. Finally, straightforward guidance regarding the risk of major bleeding was lacking at that time, reflected by the absence of a dedicated section in the document. 


\begin{tabular}{|c|c|c|c|}
\hline \multicolumn{2}{|c|}{$\begin{array}{l}\text { No Risk factors } \\
\text { One moderate-risk factor } \\
\text { Any high-risk factor or more than } 1 \text { moderate-risk factor }\end{array}$} & \multicolumn{2}{|c|}{$\begin{array}{l}\text { Aspirin, } 81-325 \mathrm{mg} \text { daily } \\
\text { Aspirin, } 81-325 \mathrm{mg} \text { daily, or warfarin (INR 2.0-3.0, target 2.5) } \\
\text { Warfarin (INR 2.0-3.0, target 2.5) }\end{array}$} \\
\hline \multicolumn{4}{|c|}{ Risk Factors } \\
\hline Less Validated/Weaker & Moderate & & High-Risk \\
\hline $\begin{array}{l}\text { Female sex } \\
\text { Age } 65-74 \\
\text { Coronary artery disease } \\
\text { Thyrotoxicosis }\end{array}$ & $\begin{array}{l}\text { Age } \geq 75 \text { y } \\
\text { Hypertension } \\
\text { Heart Failure } \\
\text { Diabetes Mell }\end{array}$ & / LVEF $\leq 35 \%$ & $\begin{array}{l}\text { Prior stroke, TIA or embolism } \\
\text { Mitral stenosis } \\
\text { Prosthetic heart valve* }\end{array}$ \\
\hline
\end{tabular}

Figure 1 - 2006 Recommendations for the antithrombotic management of patients with atrial fibrillation

To summarize,

$\mathrm{AF}$ is the most common arrhythmia in the world. Yet, paradoxically, identifying individuals at risk of developing (or suffering from) the arrhythmia is challenging at least, but of the utmost importance to allow adequate antithrombotic therapy and thereby save lives.

$\mathrm{AF}$ (unfortunately) is often only regarded as an electrocardiographic phenomenon, i.e. an arrhythmia, and treated accordingly. Yet, morbidity and mortality on the long run are similar for a rhythm and rate control strategy which lets physicians get the wrong end of the stick, neglecting the patients (long term) thromboembolic risk.

AF carries an increased thromboembolic risk which can be classified by several (user-friendly) stroke risk schemas. Yet, these schemas fail to successfully identify patients at truly low risk and provide considerable opportunity to 'bailout' on the use of oral anticoagulation.

AF poses a serious health threat through the increased risk of ischemic stroke, which is known and successfully manageable to a certain level. Yet, inappropriate antithrombotic treatment is still common practice.

Antithrombotic management of AF patients is associated with an increased risk of major bleeding. Yet, a user-friendly counterpart to assess the bleeding risk is lacking.

\section{Aims and outline of this thesis}

The aim of this thesis was to maintain focus on the essential pillar of the AF management: dealing with the increased stroke risk by portraying real life pitfalls (Chapters 2, 4-7). To improve present clinical antithrombotic treatment of AF patients by developing new and fine-tuning available tools (Chapter 1 and 3). Finally, to promote similar advantageous proceedings in the nearby future by identifying unusual 
suspects as potential allies in the battle against thromboembolic events in AF patients (Chapter 8).

\section{References}

1. Heeringa J, van der Kuip DA, Hofman A, Kors JA, van Herpen G, Stricker BH, Stijnen T, Lip GY, Witteman JC. Prevalence, incidence and lifetime risk of atrial fibrillation: the Rotterdam study. Eur Heart J 2006;27:949-953.

2. Wang TJ, Parise H, Levy D, D'Agostino RB, Sr., Wolf PA, Vasan RS, Benjamin EJ. Obesity and the risk of new-onset atrial fibrillation. Jama 2004;292:2471-2477.

3. Wachtell K, Lehto M, Gerdts E, Olsen MH, Hornestam B, Dahlof B, Ibsen H, Julius S, Kjeldsen SE, Lindholm LH, Nieminen MS, Devereux RB. Angiotensin II receptor blockade reduces new-onset atrial fibrillation and subsequent stroke compared to atenolol: the Losartan Intervention For End Point Reduction in Hypertension (LIFE) study. J Am Coll Cardiol 2005;45:712-719.

4. Miyasaka Y, Barnes ME, Gersh BJ, Cha SS, Bailey KR, Abhayaratna WP, Seward JB, Tsang TS. Secular trends in incidence of atrial fibrillation in Olmsted County, Minnesota, 1980 to 2000, and implications on the projections for future prevalence. Circulation 2006;114:119-125.

5. Krahn AD, Manfreda J, Tate RB, Mathewson FA, Cuddy TE. The natural history of atrial fibrillation: incidence, risk factors, and prognosis in the Manitoba Follow-Up Study. Am J Med 1995;98:476-484.

6. Wolf PA, Abbott RD, Kannel WB. Atrial fibrillation as an independent risk factor for stroke: the Framingham Study. Stroke 1991;22:983-988.

7. Flegel KM, Shipley MJ, Rose G. Risk of stroke in non-rheumatic atrial fibrillation. Lancet 1987;1:526529.

8. Risk factors for stroke and efficacy of antithrombotic therapy in atrial fibrillation. Analysis of pooled data from five randomized controlled trials. Arch Intern Med 1994;154:1449-1457.

9. Steger C, Pratter A, Martinek-Bregel M, Avanzini M, Valentin A, Slany J, Stollberger C. Stroke patients with atrial fibrillation have a worse prognosis than patients without: data from the Austrian Stroke registry. Eur Heart J 2004;25:1734-1740.

10. Van Gelder IC, Hagens VE, Bosker HA, Kingma JH, Kamp O, Kingma T, Said SA, Darmanata JI, Timmermans AJ, Tijssen JG, Crijns HJ. A comparison of rate control and rhythm control in patients with recurrent persistent atrial fibrillation. N Engl J Med 2002;347:1834-1840.

11. Wyse DG, Waldo AL, DiMarco JP, Domanski MJ, Rosenberg Y, Schron EB, Kellen JC, Greene HL, Mickel MC, Dalquist JE, Corley SD. A comparison of rate control and rhythm control in patients with atrial fibrillation. N Engl J Med 2002;347:1825-1833.

12. Roy D, Talajic M, Nattel S, Wyse DG, Dorian P, Lee KL, Bourassa MG, Arnold JM, Buxton AE, Camm AJ, Connolly SJ, Dubuc M, Ducharme A, Guerra PG, Hohnloser SH, Lambert J, Le Heuzey JY, O'Hara G, Pedersen OD, Rouleau JL, Singh BN, Stevenson LW, Stevenson WG, Thibault B, Waldo AL. Rhythm control versus rate control for atrial fibrillation and heart failure. N Engl J Med 2008;358:26672677.

13. Hart RG, Pearce LA, Aguilar MI. Meta-analysis: antithrombotic therapy to prevent stroke in patients who have nonvalvular atrial fibrillation. Ann Intern Med 2007;146:857-867.

14. Lip GY, Zarifis J, Watson RD, Beevers DG. Physician variation in the management of patients with atrial fibrillation. Heart 1996;75:200-205.

15. Nieuwlaat R, Capucci A, Lip GY, Olsson SB, Prins MH, Nieman FH, Lopez-Sendon J, Vardas PE, Aliot E, Santini M, Crijns HJ. Antithrombotic treatment in real-life atrial fibrillation patients: a report from the Euro Heart Survey on Atrial Fibrillation. Eur Heart J 2006;27:3018-3026.

16. Waldo AL, Becker RC, Tapson VF, Colgan KJ. Hospitalized patients with atrial fibrillation and a high risk of stroke are not being provided with adequate anticoagulation. I Am Coll Cardiol 2005;46:1729-1736. 
17. Gorin L, Fauchier L, Nonin E, de Labriolle A, Haguenoer K, Cosnay P, Babuty D, Charbonnier B. Antithrombotic treatment and the risk of death and stroke in patients with atrial fibrillation and a CHADS2 score=1. Thromb Haemost 103:833-840.

18. Fuster V, Ryden LE, Cannom DS, Crijns HJ, Curtis AB, Ellenbogen KA, Halperin JL, Le Heuzey JY, Kay GN, Lowe JE, Olsson SB, Prystowsky EN, Tamargo JL, Wann S, Smith SC, Jr., Jacobs AK, Adams CD, Anderson JL, Antman EM, Hunt SA, Nishimura R, Ornato JP, Page RL, Riegel B, Priori SG, Blanc JJ, Budaj A, Camm AJ, Dean V, Deckers JW, Despres C, Dickstein K, Lekakis J, McGregor K, Metra M, Morais J, Osterspey A, Zamorano JL. ACC/AHA/ESC 2006 guidelines for the management of patients with atrial fibrillation--executive summary: a report of the American College of Cardiology/American Heart Association Task Force on Practice Guidelines and the European Society of Cardiology Committee for Practice Guidelines (Writing Committee to Revise the 2001 Guidelines for the Management of Patients With Atrial Fibrillation). J Am Coll Cardiol 2006;48:854-906.

19. Gallagher MM, Camm J. Classification of atrial fibrillation. Am J Cardiol 1998;82:18N-28N.

20. Camm AJ, Kirchhof P, Lip GY, Schotten U, Savelieva I, Ernst S, Van Gelder IC, Al-Attar N, Hindricks G, Prendergast B, Heidbuchel H, Alfieri O, Angelini A, Atar D, Colonna P, De Caterina R, De Sutter J, Goette A, Gorenek B, Heldal M, Hohloser SH, Kolh P, Le Heuzey JY, Ponikowski P, Rutten FH. Guidelines for the management of atrial fibrillation: the Task Force for the Management of Atrial Fibrillation of the European Society of Cardiology (ESC). Eur Heart J 31:2369-2429.

21. Pisters R, de Vos CB, Dennert R, Crijns HJ. Undetected paroxysmal atrial fibrillation in chronic heart failure patients: is it clinically relevant to catch the atrial phantom? Europace 2009;11:1257-1259.

22. Savelieva I, Camm AJ. Silent atrial fibrillation--another Pandora's box. Pacing Clin Electrophysiol 2000;23:145-148.

23. Kerr C, Boone J, Connolly S, Greene M, Klein G, Sheldon R, Talajic M. Follow-up of atrial fibrillation: The initial experience of the Canadian Registry of Atrial Fibrillation. Eur Heart J 1996;17 Suppl C:4851.

24. Wolf PA, Kannel WB, McGee DL, Meeks SL, Bharucha NE, McNamara PM. Duration of atrial fibrillation and imminence of stroke: the Framingham study. Stroke 1983;14:664-667.

25. Tayal AH, Tian M, Kelly KM, Jones SC, Wright DG, Singh D, Jarouse J, Brillman J, Murali S, Gupta R. Atrial fibrillation detected by mobile cardiac outpatient telemetry in cryptogenic TIA or stroke. Neurology 2008;71:1696-1701.

26. Douen A, Pageau N, Medic S. Usefulness of cardiovascular investigations in stroke management: clinical relevance and economic implications. Stroke 2007;38:1956-1958.

27. Jabaudon D, Sztajzel J, Sievert K, Landis T, Sztajzel R. Usefulness of ambulatory 7-day ECG monitoring for the detection of atrial fibrillation and flutter after acute stroke and transient ischemic attack. Stroke 2004;35:1647-1651.

28. Reiffel JA, Schwarzberg R, Murry M. Comparison of autotriggered memory loop recorders versus standard loop recorders versus 24-hour Holter monitors for arrhythmia detection. Am J Cardiol 2005;95:1055-1059.

29. The effect of low-dose warfarin on the risk of stroke in patients with nonrheumatic atrial fibrillation. The Boston Area Anticoagulation Trial for Atrial Fibrillation Investigators. N Engl J Med 1990;323:1505-1511.

30. Stroke Prevention in Atrial Fibrillation Study. Final results. Circulation 1991;84:527-539.

31. Secondary prevention in non-rheumatic atrial fibrillation after transient ischaemic attack or minor stroke. EAFT (European Atrial Fibrillation Trial) Study Group. Lancet 1993;342:1255-1262.

32. Petersen P, Boysen G, Godtfredsen J, Andersen ED, Andersen B. Placebo-controlled, randomised trial of warfarin and aspirin for prevention of thromboembolic complications in chronic atrial fibrillation. The Copenhagen AFASAK study. Lancet 1989;1:175-179.

33. Connolly SJ, Laupacis A, Gent M, Roberts RS, Cairns JA, Joyner C. Canadian Atrial Fibrillation Anticoagulation (CAFA) Study. J Am Coll Cardiol 1991;18:349-355. 
34. Ezekowitz MD, Bridgers SL, James KE, Carliner NH, Colling CL, Gornick CC, Krause-Steinrauf H, Kurtzke JF, Nazarian SM, Radford MJ, et al. Warfarin in the prevention of stroke associated with nonrheumatic atrial fibrillation. Veterans Affairs Stroke Prevention in Nonrheumatic Atrial Fibrillation Investigators. N Engl J Med 1992;327:1406-1412.

35. Gage BF, Waterman AD, Shannon W, Boechler M, Rich MW, Radford MJ. Validation of clinical classification schemes for predicting stroke: results from the National Registry of Atrial Fibrillation. Jama 2001;285:2864-2870.

36. Connolly SJ, Ezekowitz MD, Yusuf S, Eikelboom J, Oldgren J, Parekh A, Pogue J, Reilly PA, Themeles E, Varrone J, Wang S, Alings M, Xavier D, Zhu J, Diaz R, Lewis BS, Darius H, Diener HC, Joyner CD, Wallentin L. Dabigatran versus warfarin in patients with atrial fibrillation. N Engl J Med 2009;361:1139-1151.

37. Granger CB, Alexander JH, McMurray JJ, Lopes RD, Hylek EM, Hanna M, Al-Khalidi HR, Ansell J, Atar D, Avezum A, Bahit MC, Diaz R, Easton JD, Ezekowitz JA, Flaker G, Garcia D, Geraldes M, Gersh BJ, Golitsyn S, Goto S, Hermosillo AG, Hohnloser SH, Horowitz J, Mohan P, Jansky P, Lewis BS, LopezSendon JL, Pais P, Parkhomenko A, Verheugt FW, Zhu J, Wallentin L. Apixaban versus warfarin in patients with atrial fibrillation. N Engl J Med 365:981-992.

38. Patel MR, Mahaffey KW, Garg J, Pan G, Singer DE, Hacke W, Breithardt G, Halperin JL, Hankey GJ, Piccini JP, Becker RC, Nessel CC, Paolini JF, Berkowitz SD, Fox KA, Califf RM. Rivaroxaban versus warfarin in nonvalvular atrial fibrillation. N Engl J Med 365:883-891.

39. Connolly SJ, Eikelboom J, Joyner C, Diener HC, Hart R, Golitsyn S, Flaker G, Avezum A, Hohnloser SH, Diaz R, Talajic M, Zhu J, Pais P, Budaj A, Parkhomenko A, Jansky P, Commerford P, Tan RS, Sim KH, Lewis BS, Van Mieghem W, Lip GY, Kim JH, Lanas-Zanetti F, Gonzalez-Hermosillo A, Dans AL, Munawar M, O’Donnell M, Lawrence J, Lewis G, Afzal R, Yusuf S. Apixaban in patients with atrial fibrillation. N Engl J Med 364:806-817.

40. Mant J, Hobbs FD, Fletcher K, Roalfe A, Fitzmaurice D, Lip GY, Murray E. Warfarin versus aspirin for stroke prevention in an elderly community population with atrial fibrillation (the Birmingham Atrial Fibrillation Treatment of the Aged Study, BAFTA): a randomised controlled trial. Lancet 2007;370:493-503.

41. Fang MC, Chang Y, Hylek EM, Rosand J, Greenberg SM, Go AS, Singer DE. Advanced age, anticoagulation intensity, and risk for intracranial hemorrhage among patients taking warfarin for atrial fibrillation. Ann Intern Med 2004;141:745-752.

42. Hylek EM, Singer DE. Risk factors for intracranial hemorrhage in outpatients taking warfarin. Ann Intern Med 1994;120:897-902.

43. Gage BF, Yan Y, Milligan PE, Waterman AD, Culverhouse R, Rich MW, Radford MJ. Clinical classification schemes for predicting hemorrhage: results from the National Registry of Atrial Fibrillation (NRAF). Am Heart J 2006;151:713-719.

44. Poli D, Testa S, Antonucci E, Grifoni E, Paoletti O, Lip GY. Bleeding and Stroke Risk in a Real-world Prospective Primary Prevention Cohort of Patients With Atrial Fibrillation. Chest 140:918-924. 

Section I

Risk of Stroke 



\section{Chapter 1}

Refining Clinical Risk Stratification for Predicting Stroke and Thromboembolism in Atrial Fibrillation Using a Novel Risk FactorBased Approach: The Euro Heart Survey on Atrial Fibrillation

Gregory Y. H. Lip, MD; Robby Nieuwlaat, PhD; Ron Pisters, MD; Deirdre A. Lane, PhD; and Harry J. G. M. Crijns, MD 


\section{ABSTRACT}

Background: Contemporary clinical risk stratification schemata for predicting stroke and thromboembolism (TE) in patients with atrial fibrillation (AF) are largely derived from risk factors identified from trial cohorts. Thus, many potential risk factors have not been included.

Methods: We refined the 2006 Birmingham/National Institute for Health and Clinical Excellence (NICE) stroke risk stratification schema into a risk factor-based approach by reclassifying and/or incorporating additional new risk factors where relevant. This schema was then compared with existing stroke risk stratification schema in a real-world cohort of patients with AF $(n=51,084)$ from the Euro Heart Survey for AF.

Results: Risk categorization differed widely between the different schemes compared. Patients classified as high risk ranged from $10.2 \%$ with the Framingham schema to $75.7 \%$ with the Birmingham 2009 schema. The classic CHADS $_{2}$ (Congestive heart failure, Hypertension, Age.75, Diabetes, prior Stroke/transient ischemic attack) schema categorized the largest proportion (61.9\%) into the intermediaterisk strata, whereas the Birmingham 2009 schema classified 15.1\% into this category. The Birmingham 2009 schema classified only 9.2\% as low risk, whereas the Framingham scheme categorized $48.3 \%$ as low risk. Calculated C-statistics suggested modest predictive value of all schema for TE. The Birmingham 2009 schema fared marginally better (C-statistic, 0.606) than $\mathrm{CHADS}_{2}$. However, those classified as low risk by the Birmingham 2009 and NICE schema were truly low risk with no TE events recorded, whereas TE events occurred in $1.4 \%$ of low-risk $\mathrm{CHADS}_{2}$ subjects. When expressed as a scoring system, the Birmingham 2009 schema $\left(\mathrm{CHA}_{2} \mathrm{DS}_{2}\right.$-VASc acronym) showed an increase in TE rate with increasing scores ( $P$ value for trend $=.003$ ).

Conclusion: Our novel, simple stroke risk stratification schema, based on a risk factor approach, provides some improvement in predictive value for TE over the $\mathrm{CHADS}_{2}$ schema, with low event rates in low-risk subjects and the classification of only a small proportion of subjects into the intermediate-risk category. This schema could improve our approach to stroke risk stratification in patients with AF. 


\section{INTRODUCTION}

Atrial fibrillation is the most common sustained cardiac rhythm disorder, which is associated with a substantial risk of mortality and morbidity from stroke and thromboembolism (TE). A substantial evidence base is in favor of anticoagulants with the vitamin $\mathrm{K}$ antagonists (VKAs, e.g., warfarin), which reduce the risk by twothirds, whereas antiplatelet therapy only reduces the risk by $22 \% .{ }^{1}$ Vitamin $\mathrm{K}$ antagonists are clearly superior to aspirin for stroke prevention even in patients with $A F$ aged $\geq 75$ years. For example, in the Birmingham Atrial Fibrillation Treatment of the Aged (BAFTA) Study, the use of VKA (INR 2-3) reduced the primary end point of TE by $52 \%$ compared with aspirin $75 \mathrm{mg}$ daily, with no difference in major bleeding events between VKA or aspirin. ${ }^{2}$ Even in low- risk subjects with AF, aspirin may be no better than control for reducing TE events, with a tendency to more adverse effects (especially bleeding) with aspirin. ${ }^{3}$

The risk of stroke and TE in AF is not homogeneous, and various clinical and echocardiographic features have been identified to help stratify risk into high-, intermediate-, or low-risk categories. ${ }^{1}$ How- ever, contemporary clinical risk stratification schema for predicting stroke, transient ischemic attack (TIA), or TE for patients with $\mathrm{AF}$ are largely derived from risk factors identified from non-VKA arms of trial cohorts, and one cohort study (Framingham). Thus, many potential risk factors have not been adequately assessed, as not all potential risk factors have been systematically documented in the clinical trial populations. The Stroke in AF Working Group4 performed a systematic review of these stroke risk factors and concluded that only four clinical features (prior stroke/TIA, advancing age, hypertension, and diabetes) were consistent independent risk factors. Also, existing stroke risk stratification schema have widely varying proportions categorized into high-, intermediate-, and low-risk strata, and are generally of modest predictive value in predicting stroke and TE (C-statistics of approximately 0.6 ). ${ }^{5}$ Again, some of the validation studies comparing the performance of different schema are limited by having been performed in anticoagulated trial cohorts, ${ }^{6}$ retrospective analyses of anticoagulated AF registries, ${ }^{7}$ and in some, non-VKA arms of trial cohorts whereby antiplatelet therapy and/or subtherapeutic VKA (e.g., INR , 1.5) were used. $^{8}$

Other data on "real life" AF populations were provided in the ATRIA study, ${ }^{9}$ but this study did not compare some contemporary risk stratification schema as used in current guidelines. ${ }^{10-12}$

Nonetheless, there are increasing data that other risk factors should be considered in refining stroke and TE risk stratification for AF. For example, female gender increased TE risk in the Euro Heart Survey and other cohorts. ${ }^{13-15}$ Also, vascular diseases, includ- ing myocardial infarction, peripheral artery disease, and complex aortic plaque, all increase TE risk in AF. ${ }^{16-20}$ Furthermore, stroke risk in AF increases at age . 65 years onwards, and age as a risk factor is not a yes/no phenomenon. 
Indeed, the BAFTA trial showed that VKA was clearly superior thrombo-prophylaxis to aspirin in elderly (aged $\geq 75$ years) subjects with AF in a primary care setting, which shows that the frequently reported fear of bleeding as an excuse for not prescribing warfarin to elderly patients is not justified. ${ }^{1,2}$

In 2006, the Birmingham stroke risk stratification schema was compared against the $\mathrm{CHADS}_{2}$ (Congestive heart failure, Hypertension, Age $\geq 75$, Diabetes, prior Stroke/transient ischemic attack) schema in a cohort of 994 patients with AF, and it was found that the accuracy of both clinical risk stratification schemes was similar for predicting ischemic strokes and vascular events. ${ }^{8}$ The Birmingham schema was subsequently refined for the evidence-based UK National Institute for Health and Clinical Excellence (NICE) guidelines on AF management, which formulated an algorithm-based approach to stroke risk stratification. ${ }^{12}$ Since 2006, it is apparent that stroke risk stratification needs to be simple, yet consider new data on other risk factors (female gender, age, vascular disease, and so forth) that have emerged, and recognize that an artificial categorization into high-, intermediate-, and low-risk categories per se may be less helpful. Current treatment guidelines recommend VKA for high-risk subjects and (usually) aspirin for low- risk subjects, but for intermediate risk, many guide- lines state "either warfarin or aspirin" can be used. ${ }^{10-12}$ The latter can sometimes cause uncertainty for clinicians managing such patients, especially if a large proportion of a particular cohort of patients with AF are classified into this intermediate-risk category. This "either warfarin or aspirin" recommendation is also sometimes used as an excuse not to prescribe warfarin in intermediate-risk patients. Also, clinicians need reassurance that those classified as low risk are truly low risk, with no TE events in such patients.

The objective of this analysis is to refine the 2006 Birmingham/NICE stroke risk stratification schema into a risk factor-based approach, by reclassifying and/or incorporating additional new risk factors as relevant. This novel schema (Birmingham 2009) was then compared with existing schema in a real world AF patient cohort in the Euro Heart Survey for AF, where longitudinal data on outcomes have previously been published. ${ }^{21}$

\section{METHODS}

\section{Validation Cohort}

To test the predictive ability of the refined Birmingham schema, and to compare this with the performance of other schema, we used the Euro Heart Survey on AF population. Survey methods, center participation, patient characteristics, management and definitions of the baseline and follow-up survey of the Euro Heart Survey on AF have previously been described. ${ }^{21,22}$ In summary, 5,333 ambulant and hospi- 
talized patients with AF were enrolled from the cardiology practices of 182 hospitals among 35 countries in 2003 to 2004. Patients were enrolled if they were $>18$ years old and if they had an ECG or Holter recording showing AF during the qualifying admission/consultation or in the preceding 12 months. A follow-up was performed to assess mortality and incidence of major adverse events during 1 year.

For the current analysis we selected 1,577 patients without mitral stenosis or previous heart valve surgery and who did not use either VKA or heparin at discharge of the qualifying visit. We had survival status during 1 year for 1,150 (73\%) of these patients and the TE status for 1,084 (69\%). Compared with patients with known survival status at follow-up, patients with unknown survival status were at baseline of similar age ( 66615 vs. 66614 years; $P=.624$ ), were as often female (45\% vs. $40 \%$; $P=.103$ ), and equally as often had diabetes (15\% vs. $17 \% ; P=.244$ ) or a prior stroke/TIA (9\% vs. $8 \% ; P=.359)$, whereas they more often had heart failure (41\% vs. $24 \% ; P<.001)$ and less often vascular disease (35\% vs. $42 \% ; P=.015)$ and hypertension (62\% vs. $67 \% ; P=.032$ ). Patients with known survival status at follow-up but unknown TE status were more often deceased compared with patients who had both survival and TE status known ( $24 \%$ vs. $4 \%$; $P<.001)$.

\section{Description of Stroke Risk Stratification Schema}

The various stroke risk schema compared and/or validated in this real world European cohort are summarized in Table 1 . In case of multiple available schema, we chose to use the most recent one: for example, the Stroke Prevention in Atrial Fibrillation (SPAF) 1999 schema (rather than the SPAF 1995 schema), 23 the second American College of Cardiology/American Heart Association/ European Society of Cardiology (ACC/AHA/ESC) guidelines (2006), ${ }^{11}$ and the eighth American College of Chest Physicians (ACCP) guidelines (2008). ${ }^{10}$ We did use the AF Investigators 1994 schema, ${ }^{24}$ since the 1998 analysis explored the additional value of echocardiography parameters, but did not explicitly recommend a new schema. The Framingham and $\mathrm{CHADS}_{2}$ schema are point-based scores, with the Framingham based on a mathematical equation ${ }^{25}$ and the $\mathrm{CHADS}_{2}$ based on one point for $\mathrm{CHAD}$ and two points for stroke/TIA. ${ }^{26}$

In order to compare their predictive ability with other schema for distinguishing low, intermediate, and high risk, we categorized the scores into three groups. We defined the $\mathrm{CHADS}_{2}$ score in two ways: (1) classic, whereby scores of 05 low, 1 to 2 $=$ intermediate, ${ }^{25}$ high risk; or (2) revised, whereby scores of $0=$ low, 1 = intermediate, $>2$ = high risk. We categorized the Framingham score in a similar manner to that proposed by Fang et al, ${ }^{9}$ as follows: score 0 to $7=$ low, 8 to $15=$ intermediate, 16 to 31 = high risk. In addition to these categorized definitions (commonly used in clinical practice), the Framingham and $\mathrm{CHADS}_{2}$ scores were also tested as continuous variables. 
Table 1 - Risk stratification schemes used to predict thromboembolism in atrial fibrillation

\begin{tabular}{|c|c|c|c|}
\hline Risk Scheme & Low risk & Intermediate risk & High Risk \\
\hline AFI Investigators (1994) ${ }^{24}$ & $\begin{array}{l}\text { Age }>65 \text { y and no risk } \\
\text { factors }\end{array}$ & $\begin{array}{l}\text { Age }>65 \text { y and no other risk } \\
\text { factors }\end{array}$ & $\begin{array}{l}\text { Prior stroke/TIA, hypertension, } \\
\text { diabetes }\end{array}$ \\
\hline SPAF investigators ${ }^{23}$ & No risk factors & Hypertension, diabetes & $\begin{array}{l}\text { Prior stroke/TIA, women . } 75 \text { y, } \\
\text { men }>75 \text { y with hypertension }\end{array}$ \\
\hline CHADS 2 (2001)-classic ${ }^{26}$ & Score 0 & Score 1-2 & Score 3-6 \\
\hline CHADS 2 -revised & Score 0 & Score 1 & Score 2-6 \\
\hline Framingham $(2003)^{25}$ & Score $0-7$ & Score 8-15 & Score 16-31 \\
\hline NICE guidelines $(2006)^{12}$ & $\begin{array}{l}\text { Age } \geq 65 \text { y with no } \\
\text { moderate/high-risk } \\
\text { factors }\end{array}$ & $\begin{array}{l}\text { Age } \geq 65 \text { y with no high-risk } \\
\text { factors } \\
\text { Age , } 75 \text { y with hyperten- } \\
\text { sion, } \\
\text { diabetes, or vascular dis- } \\
\text { ease a }\end{array}$ & $\begin{array}{l}\text { Age } \geq 75 \text { y with hypertension, } \\
\text { diabetes, or } \\
\text { vascular disease } \\
\text { Clinical evidence of valve disease } \\
\text { or } \\
\text { heart failure, or impaired left } \\
\text { ventricular function }\end{array}$ \\
\hline $\begin{array}{l}\text { ACC/AHA/ESC } \\
\text { guidelines }(2006)^{11}\end{array}$ & No risk factors & $\begin{array}{l}\text { Age }>75 \text { y, or hypertension, } \\
\text { or heart } \\
\text { failure, or } \operatorname{LVEF} \leq 35 \% \text {, or } \\
\text { diabetes }\end{array}$ & $\begin{array}{l}\text { Previous stroke, TIA or embo- } \\
\text { lism, } \\
\text { or } \geq 2 \text { moderate risk factors: age } \\
\geq 75 \text { y, } \\
\text { hypertension, heart failure, LVEF } \\
\leq 35 \% \text {, } \\
\text { diabetes }\end{array}$ \\
\hline $\begin{array}{l}\text { Eighth ACCP } \\
\text { guidelines }(2008)^{10}\end{array}$ & No risk factors & $\begin{array}{l}\text { Age } 75 \text { y, or hypertension, } \\
\text { or } \\
\text { moderately or severely } \\
\text { impaired } \\
\text { LVEF and/or heart failure, } \\
\text { or diabetes }\end{array}$ & $\begin{array}{l}\text { Previous stroke, TIA or embo- } \\
\text { lism, } \\
\text { or } \geq 2 \text { moderate risk factors: age } \\
\geq 75 \text { y, } \\
\text { hypertension, moderately or } \\
\text { severely } \\
\text { impaired LVEF and/or heart } \\
\text { failure, } \\
\text { diabetes }\end{array}$ \\
\hline Birmingham (2009) & No risk factors & $\begin{array}{l}\text { One combination risk } \\
\text { factor: heart } \\
\text { failure/LVEF } \leq 40 \text {, hyperten- } \\
\text { sion, } \\
\text { diabetes, vascular disease, a }\end{array}$ & $\begin{array}{l}\text { Previous stroke, TIA or embo- } \\
\text { lism, or } \\
\text { age } \geq 75 \text { y, or } \geq 2 \text { combination risk } \\
\text { factors: heart failure/LVEF } \leq 40 \text {, } \\
\text { ahypertension, diabetes, vascular }\end{array}$ \\
\hline & & $\begin{array}{l}\text { female } \\
\text { gender, age } 65-74\end{array}$ & $\begin{array}{l}\text { disease, a } \\
\text { female gender, age } 65-74\end{array}$ \\
\hline
\end{tabular}

$\mathrm{ACC}=$ American College of Cardiology; $\mathrm{ACCP}=$ American College of Chest Physicians; $\mathrm{AFI}=\mathrm{Atrial}$ Fibrillation Investigators; $\mathrm{AHA}=$ American Heart Association; CHADS 2 = Congestive heart failure, Hypertension, Age $>75$, Diabetes, prior Stroke/TIA; ESC = European Society of Cardiology; LVEF = left ventricular ejection fraction; NICE = National Institute for Health and Clinical Excellence; SPAF = Stroke Prevention in Atrial Fibrillation; TIA = transient ischemic attack.

${ }^{a}$ Myocardial infarction, peripheral artery disease, or aortic plaque.

We refined the 2006 Birmingham (or NICE) TE risk schema into a risk factor-based approach, by defining definitive risk factors (previous stroke/TIA/TE and age $\geq 75$ 
years) and combination risk factors (heart failure/moderate-severe cardiac dysfunction, hypertension, diabetes, vascular disease, female gender, and age 65-74 years). If we wished to artificially categorize these subjects, high risk was defined as one definitive or two or more combination risk factors, intermediate risk was essentially defined as one combination risk factor, and low risk was defined as no risk factors being present. This refined (2009) Birmingham schema was also tested with a pointbased scoring system, the CHA2DS2-VASc score (see Table 2 for definition), whereby scores of $0=$ low, 1 = intermediate, and $>2=$ high risk.

Table 2 - The 2009 Birmingham Schema Expressed as a Point-Based Scoring System, With the Acronym CHA 2 DS 2 -VASC

\begin{tabular}{ll}
\hline Risk Factor & Score \\
\hline Congestive heart failure/LV dysfunction & 1 \\
Hypertension & 1 \\
Áge $\geq 75$ y & 2 \\
Diabetes mellitus & 1 \\
$\underline{\text { Stroke/TIA/TE }}$ Vascular disease (prior myocardial infarction, peripheral artery & 2 \\
disease, or aortic plaque) & 1 \\
$\underline{\text { Age 65-74 y }}$ & \\
$\underline{\text { Sex category (ie female gender) }}$ & 1 \\
\hline
\end{tabular}

$\mathrm{LV}=$ left ventricular; TE = thromboembolism. See Table 1 for expansion of other abbreviations.

\section{Definitions of End Points and Risk Factors}

Ischemic stroke was defined as a focal neurologic deficit of sudden onset as diagnosed by a neurologist, lasting $>24 \mathrm{~h}$ and caused by ischemia. TIA was defined as a focal neurologic deficit of sudden onset as diagnosed by a neurologist, lasting $>24 \mathrm{~h}$. Peripheral embolism was defined as TE outside the brain, heart, eyes, and lungs. Pulmonary embolism was defined by the responsible physician. TE as outcome variable of the validation analysis was defined as either an ischemic stroke, peripheral embolism, or pulmonary embolism. Definitions of risk factors, such as diabetes, hypertension, heart failure, peripheral artery disease, and so forth, are pro- vided in the online supplement.

\section{Statistical Analysis}

We used descriptive analyses with proportions and means (6SD) to describe the validation cohort, categorization of the three risk groups per schema, and the event rates per risk group. We calculated the $95 \% \mathrm{Cl}$ of event rates using the binomial approximation. We performed logistic regression with each schema, containing three risk groups, as independent variable and TE during 1 year as dependent vari- 
able. The probability that this model predicted the correct classification of each patient (TE or not) was saved. Following this we plotted this probability in a receiver- operating characteristic (ROC) curve against TE as dependent variable. The area under the curve for this ROC curve represents the ability of a schema to correctly classify risk for TE, which is also referred to as the C-statistic (Harrell's C). As a subsidiary analysis, we also ran the same analyses on 843 patients within this group who were not on anticoagulation at both baseline and 1-year follow-up.

To assess the effect of individual risk factors on the occurrence of TE in this cohort, we performed multivariable logistic regression with the following independent variables: age, gender, diabetes, coronary artery disease, heart failure, hypertension, prior stroke/TIA, prior other thromboembolism, and peripheral vascular disease. To assess whether the effect of systolic blood pressure at baseline was different than that of hypertension, we performed the same analysis while replacing systolic blood pressure for hypertension and we report these results in the text only. Further, since recent echocardiography was not available for 400 (37\%) patients, we repeated the initial analysis with the addition of left ventricular ejection fraction to assess its effect and whether other effects were changed by this addition. Variables were removed stepwise from the model when the $P$ value exceeded $<.10$. Variables with $P$ value $<0.05$ in the final model were considered to be significant contributors to TE prediction and we report the net odds ratio (OR), $95 \% \mathrm{Cl}$, and $P$ value for these variables. Variables in the final model were tested for interaction(s), if any.

\section{RESULTS}

The 1,084 patients with nonvalvular AF, who were not on anticoagulation at baseline and for whom we knew TE status at 1 year, were on average 66 years old and $40.8 \%$ were women (Table 3). Hypertension was the most prevalent stroke risk factor (67.3\%), followed by coronary artery disease (38.4\%). Antiplatelet drugs were taken by $74.0 \%$. In univariate analyses, female gender, history of vascular disease, prior stroke/TIA, and diabetes were associated with an increased incidence of TE (all $P<.05$; Table 4). When assessing the independent effect of all potential risk factors on TE occurrence in multivariate analysis, female gender (OR52.53 [1.08-5.92]; $P=$.029) was the only significant associated factor, whereas the effect of vascular disease was near significant (OR 52.27 [0.94-5.46]; $P=.064$ ) (Table 4). Taking into account systolic blood pressure at baseline, rather than the diagnosis of hypertension, showed that also systolic blood pressure was not significantly associated with TE occurrence (OR=0.99 [0.97-1.01] per $\mathrm{mm}$ Hg increase; $P=.319$ ). 
Table 3 - Clinical Characteristics of 1,084 Non-valvular Atrial Fibrillation Patients Not Receiving Oral Anticoagulation and Heparin at Discharge of the Baseline Euro Heart Survey and With Known Thromboembolic Follow-up Status During 1 Year

\begin{tabular}{ll}
\hline Clinical Characteristic & No. (\%) or Mean 6 SD \\
\hline Age, y & $66 \pm 14$ \\
Age $\geq 75$ y & $309(28.5)$ \\
Women & $442(40.8)$ \\
Past medical history & \\
Stroke & $45(4.2)$ \\
TIA & $46(4.3)$ \\
Other systemic embolism & $6(0.6)$ \\
CAD & $412(38.4)$ \\
Peripheral vascular disease & $62(5.8)$ \\
Hypertension & $729(67.3)$ \\
Diabetes & $187(17.3)$ \\
Heart failure & $253(23.5)$ \\
Systolic blood pressure, mm Hg & $139 \pm 23$ \\
LVEF, \% & $53 \pm 14 \pm$ \\
Drugs & \\
ACEI & $480(44.3)$ \\
ARB & $139(12.8)$ \\
ACEI/ARB & $607(56.0)$ \\
Statins & $252(23.2)$ \\
Antiplatelet drugs & $802(74.0)$ \\
\hline ACE ACE inhitor &
\end{tabular}

ACEI = ACE inhibitor; ARB = angiotensin II receptor blocker; $C A D$ = coronary artery disease. See Table 1 for expansion of other abbreviations.

Table 4 - Univariate and Multivariate Predictive Power of Risk Factors for Thromboembolic Events

\begin{tabular}{llllll}
\hline & $\begin{array}{l}\text { Event Rate With } \\
\text { Risk Factor }\end{array}$ & $\begin{array}{l}\text { Event Rate Without Univariate } \\
\text { Risk Factor }\end{array}$ & OR a & $\begin{array}{l}\text { Multivariate } \\
\text { P Value }\end{array}$ \\
\hline Age>75 & $11(3.6)$ & $14(1.8)$ & .083 & $1.46(0.63-3.35)$ & .383 \\
Female & $16(3.6)$ & $9(1.4)$ & .017 & $2.53(1.08-5.92)$ & .029 \\
Stroke/TIA/TE & $5(5.9)$ & $20(2.0)$ & .023 & $2.22(0.78-6.35)$ & .163 \\
Hypertension & $19(2.6)$ & $6(1.7)$ & .349 & $1.01(0.38-2.66)$ & .992 \\
Diabetes & $8(4.3)$ & $17(1.9)$ & .048 & $1.79(0.73-4.40)$ & .220 \\
Heart failure & $6(2.4)$ & $19(2.3)$ & .967 & $0.72(0.27-1.88)$ & .493 \\
LVEF <40 & $1(0.8)$ & $12(2.1)$ & .335 & $0.34(0.04-2.73)$ & .243 \\
Vascular disease b & $16(3.6)$ & $9(1.5)$ & .022 & $2.27(0.94-5.46)$ & .063 \\
\hline
\end{tabular}

$\mathrm{OR}=$ odds ratio. See Tables 1 and 2 for expansion of other abbreviations.

${ }^{a}$ All results other than LVEF from model without LVEF.

${ }^{b}$ Coronary artery disease, peripheral vascular disease, or a previous thromboembolism other than stroke/TIA.

The proportions of patients categorized as high, intermediate or low risk are shown in Table 5. Risk categorization differed widely between the different schemes. Pa- 
tients classified as high risk ranged from $10.2 \%$ with the Framingham schema to 75.7\% with the Birmingham 2009 schema. The classic $\mathrm{CHADS}_{2}$ categorized the largest proportion (61.9\%) of subjects into the intermediate-risk strata, whereas the AF Investigators and Birmingham 2009 schema classified 12.2\% and 15.1\%, respectively, into this category.

Table 5 - Risk Categorization, Incidence of TE, a and Predictive Ability for Contemporary Risk Stratification Schema Among Euro Heart Survey Patients Who Did not Receive Anticoagulation at Baseline

\begin{tabular}{|c|c|c|c|c|c|}
\hline & Categorization & & & Predictive Ability & \\
\hline & Low & Intermediate & High & C Statistic $(95 \% \mathrm{Cl})$ & P Value \\
\hline AFI 1994 & & & & & .209 \\
\hline$\%$ in risk category & 16.7 & 12.2 & 71.1 & 0.573 & \\
\hline TE events, No. (\%) & $1(0.6)$ & $4(3.0)$ & $20(2.6)$ & $(0.470-0.676)$ & \\
\hline SPAF 1999 & & & & & .405 \\
\hline$\%$ in risk category & 26.2 & 44.8 & 29.0 & 0.549 & \\
\hline TE events, No. (\%) & $5(1.8)$ & $11(2.3)$ & 9 (2.9) & $(0.435-0.662)$ & \\
\hline CHADS 2 -classic & & & & & .296 \\
\hline$\%$ in risk category & 20.4 & 34.9 & 44.7 & $0.586 \mathrm{~b}$ & \\
\hline TE events, No. (\%) & $3(1.4)$ & $7(1.9)$ & $15(3.1)$ & $(0.477-0.695)$ & \\
\hline Framingham & & & & & .018 \\
\hline$\%$ in risk category & 48.3 & 41.5 & 10.2 & $0.638 \mathrm{~b}$ & \\
\hline TE events, No. (\%) & $6(1.2)$ & $14(3.2)$ & $5(4.6)$ & $(0.532-0.744)$ & \\
\hline NICE 2006 & & & & & .094 \\
\hline$\%$ in risk category & 13.1 & 39.2 & 47.7 & 0.598 & \\
\hline TE events, No. (\%) & $0(0.0)$ & $13(3.1)$ & $12(2.3)$ & $(0.498-0.698)$ & \\
\hline ACC/AHA/ESC 2006 & & & & & .228 \\
\hline$\%$ in risk category & 19.6 & 33.4 & 47.0 & 0.574 & \\
\hline TE events, No. (\%) & $3(1.4)$ & $7(1.9)$ & $15(3.0)$ & $(0.465-0.683)$ & \\
\hline Birmingham 2009 & & & & & .070 \\
\hline$\%$ in risk category & 9.2 & 15.1 & 75.7 & 0.606 & \\
\hline TE events, No. (\%) & $0(0.0)$ & $1(0.6)$ & $24(3.0)$ & $(0.513-0.699)$ & \\
\hline
\end{tabular}

See Tables 1 and 2 for expansion of abbreviations.

aschemic stroke, pulmonary embolism, or peripheral embolism.

${ }^{\mathrm{b}}$ The $\mathrm{C}$ statistics for the Framingham and $\mathrm{CHADS}_{2}$ scores, if tested as continuous variables, are as follows: Framingham: $0.693(0.603-0.784) ; \mathrm{P}=.001$; and $\mathrm{CHADS}_{2}: 0.602(0.486-0.718) ; \mathrm{P}=.081$.

The Birmingham 2009 schema classified only 9.2\% as low risk, whereas the Framingham scheme categorized $48.3 \%$ as low risk.

The C-statistics all suggested modest predictive value of all schema for TE, with C-statistics ranging from 0.549 (SPAF) to 0.638 (Framingham), whereby the Framingham schema was the only one to predict TE better than chance in this cohort. If Framingham and $\mathrm{CHADS}_{2}$ scores were tested as continuous variables a slightly improved C-statistic was obtained compared with their respective categorized scores. 
The Birmingham 2009 schema fared marginally better (C-statistic, 0.606) than $\mathrm{CHADS}_{2}$, whether classic $(0.561)$ or revised $(0.586)$, or as a continuous variable (0.602) (Table 5).

Those classified as low risk by Birmingham 2009 and the NICE schema were truly low risk, with no TE events recorded, whereas TE events occurred in $1.4 \%$ of lowrisk CHADS subjects and $1.8 \%$ of SPAF low-risk subjects. Also, where most intermediate-risk groups had an event rate around 3\%, the intermediate- risk group using the Birmingham 2009 schema had only 1 event (0.6\%). When expressed as a scoring system (Table 6), the Birmingham 2009 schema (with the $\mathrm{CHA}_{2} \mathrm{DS}_{2}$-VASc acronym) showed an increase in TE rate with increasing scores ( $P$ value for trend $=.003$ ); those with a score of 0 (i.e., low risk) had no TE events, whereas a score of 1 (i.e., intermediate risk) had TE events in $0.6 \%$.

Table 6 - Stroke or Other TE at 1 Year Based on the 2009 Birmingham (CHA 2 DS 2 -VASc) Scoring System

\begin{tabular}{lllll}
\hline $\begin{array}{l}\text { CHA } 2 \text { DS 2 -VASc } \\
\text { Score }\end{array}$ & No. & $\begin{array}{l}\text { Number of } \\
\text { TE Events }\end{array}$ & TE Rate During 1 y $\mathbf{( 9 5 \% ~ C l )}$ & $\begin{array}{l}\text { TE Rate During } 1 \text { y, Adjusted } \\
\text { for Aspirin Prescription, }{ }^{\text {a }}\end{array}$ \\
\hline 0 & 103 & 0 & $0 \%(0-0)$ & 0 \\
1 & 162 & 1 & $0.6 \%(0.0-3.4)$ & 0.7 \\
2 & 184 & 3 & $1.6 \%(0.3-4.7)$ & 1.9 \\
3 & 203 & 8 & $3.9 \%(1.7-7.6)$ & 4.7 \\
4 & 208 & 4 & $1.9 \%(0.5-4.9)$ & 2.3 \\
5 & 95 & 3 & $3.2 \%(0.7-9.0)$ & 3.9 \\
6 & 57 & 2 & $3.6 \%(0.4-12.3)$ & 4.5 \\
7 & 25 & 2 & $8.0 \%(1.0-26.0)$ & 10.1 \\
8 & 9 & 1 & $11.1 \%(0.3-48.3)$ & 14.2 \\
9 & 1 & 1 & $100 \%(2.5-100)$ & 100 \\
Total & 1,084 & 25 & P Value for trend 0.003 & \\
\hline
\end{tabular}

See Tables 1 and 2 for expansion of abbreviations.

${ }^{a}$ Theoretical TE rates without therapy: corrected for the \% of patients receiving aspirin within each group, assuming that aspirin provides a $22 \%$ reduction in TE risk, based on Hart et al. ${ }^{28}$

A secondary analysis of a cohort of subjects who were not treated with anticoagulation at baseline and at follow-up are presented in the online supplement, and accepting the caveat of lower study numbers, this does not substantially change our observations.

\section{DISCUSSION}

In this article, we have provided a validation for a novel risk factor-based approach to stroke risk stratification (Birmingham 2009), in comparison with other published schema, in a real world European cohort. This Birmingham 2009 schema considers 
patients with a prior stroke/TIA or patients $\geq 75$ years as high risk and as candidates for warfarin. Further- more, a combination of at least two risk factors from hypertension, heart failure, diabetes, age 65 to 75, female gender, and vascular disease are also considered to be high risk; we provide strong evidence from the Euro Heart Survey for the addition of the latter two risk factors. To aid risk scoring, we also provide a risk score for the Birmingham 2009 schema, using the $\mathrm{CHA}_{2} \mathrm{DS}_{2}$-VASc acronym, with a clear increase in stroke risk with an increasing score, whereas those with a score of 0 to 1 (that is, low to moderate risk) had low event rates. We also confirm the results of recent comparisons ${ }^{5-9,14}$ showing a modest predictive value of older published stroke risk stratification schema for stroke and TE in patients with $A F$, but extend this work by showing the modest performance of the most recent ACC/AHA/ESC, ACCP, and NICE schemata.

There is some justification for the addition of female gender, vascular disease, and age 65 to 74 years into the combination risk factor category. The impact of female gender on stroke and TE risk has recently been reviewed by us. ${ }^{15}$ Compared with men, women are more likely to suffer a TE event or ischemic stroke when not taking warfarin, but when they are prescribed warfarin they have comparable INR control, are not more likely to suffer a major bleed, and demonstrate a greater TE risk reduction.15 The impact of vascular disease, particularly myocardial infarction, on increasing TE risk in AF has also been systematically reviewed. ${ }^{16-19}$ Furthermore, the presence of $A F$ in association with peripheral artery disease is associated with a substantial mortality and morbidity, and the impact of atherothrombotic disease is also clearly illustrated by the presence of complex aortic plaque on the descending aorta being an independent predictor for stroke and TE in AF. ${ }^{17,20}$ Last, stroke incidence increases with advancing age, and in AF this is no exception. Given that age is not a yes/no effect on stroke, and that anticoagulation has marked benefit in elderly subjects 2 our proposal is that age $\geq 75$ years is a definitive (high) risk factor, and age 65 to 74 plus one additional combination risk factor also merits anticoagulation, thus improving thromboprophylaxis for large absolute numbers of AF patients who would otherwise be at risk. Our proposal is supported by data that the relative ischemic stroke risk reduction of antiplatelet drugs decreases with aging, whereas oral anticoagulation maintains its preventive power. ${ }^{27}$

The Framingham schema ${ }^{25}$ had the highest C-statistic (0.638) but is based on a complicated mathematical formula and has not been incorporated into current treatment guidelines. In addition, it classified most patients of our cohort into low and moderate risk categories. Thus, many patients could have been denied VKA treatment on this basis, exposing them to the risk of stroke and TE. The AF Investigators schema ${ }^{24}$ is based on the original (and now, historical) placebo-controlled trials of warfarin vs control, and again, represents historical interest given that many schema (e.g., Birmingham/NICE and $\mathrm{CHADS}_{2}$ ) have since evolved from this schema. Similarly, the SPAF risk stratification schema is of historical interest and the $\mathrm{CHADS}_{2}$ 
schema was an amalgamation of the AF Investigators and SPAF schema, but the SPAF schema was the only one to have previously included female gender as a risk factor. ${ }^{23}$ Since publication of the Stroke in AF Working Group analysis, ${ }^{5}$ the eighth ACCP guidelines have been published, ${ }^{10}$ and the current analysis provides a comparison of this against other schema. Because the eighth ACCP schema is broadly similar to the revised $\mathrm{CHADS}_{2}$ schema (score 1 as intermediate risk group), it is unsurprising that the performance of this schema is comparable to $\mathrm{CHADS}_{2}$.

The $\mathrm{CHADS}_{2}$ schema is widely used due to its simplicity and ease. The $\mathrm{CHADS}_{2}$ schema has been validated in its classic form, and we are unaware of a formal validation or comparison against other published schema with its revised $(0,1,>1)$ form. ${ }^{9,26}$ As our analysis (and that of others ${ }^{5-9}$ ) has shown, the classic $\mathrm{CHADS}_{2}$ version generated a large intermediate risk group (>60\%) for whom it is unclear which treatment (warfarin or aspirin) to apply. The revised $\mathrm{CHADS}_{2}$ provided some improvement, with a low proportion classified as intermediate risk, but with the addition of vascular disease, female gender, or age 65 to 74 years to a risk factor-based schema (Birmingham 2009) there was further refinement of TE risk stratification for AF with an improved C-statistic.

Current guidelines divide subjects into high-, intermediate-, and low-risk strata, but one advantage of a risk factor-based approach as proposed in the current analysis is the possibility to state "consider anti- coagulation if AF present with one or more TE risk factors." Indeed, the presence of one definitive factor merits oral anticoagulation with (for example) an oral VKA (to a target INR 2-3). Patients with two or more combination risk factors should all be considered for oral anticoagulation. Thus, those with one definitive factor or two or more combination risk factors represent the old-style high-risk category. The small group of patients with one combination risk factor (15\% of this cohort) would represent the old-style intermediaterisk category and should be managed with antithrombotic therapy, either as oral anticoagulation therapy (e.g., VKA, target INR 2-3) or as aspirin 75 to $325 \mathrm{mg}$ daily, although the recent ACCP guidelines suggest considering a VKA rather than aspirin if possible. ${ }^{10}$ In Figure 1, we propose a clinical flowchart, based on the Birmingham 2009 schema. Our refined schema can thus be presented in three ways: (1) in a narrative manner (high risk is one definitive risk factor, or two or more combination risk factors), (2) scoring system (CHA2DS2-VASc score $>2$ is high risk), or (3) as a algorithm-based flow diagram.

Where possible, patients at intermediate risk should be considered for oral anticoagulation rather than aspirin, since undertreatment is more harmful than overtreatment. ${ }^{28,29}$ Full discussion with the patient with one combination risk factor would enable agreement to use oral anticoagulation instead of aspirin to allow greater protection against ischemic stroke, especially if these patients value stroke prevention much more than the (theoretical) lower risk of hemorrhage with aspirin and the inconvenience of anti- coagulation monitoring. ${ }^{10}$ As mentioned, the BAFTA 
trial found no difference in major bleeding between warfarin (INR 2-3) and aspirin $75 \mathrm{mg}$ in an elderly AF population in primary care, ${ }^{2}$ and aspirin cannot be regarded as a much safer alternative to VKA.

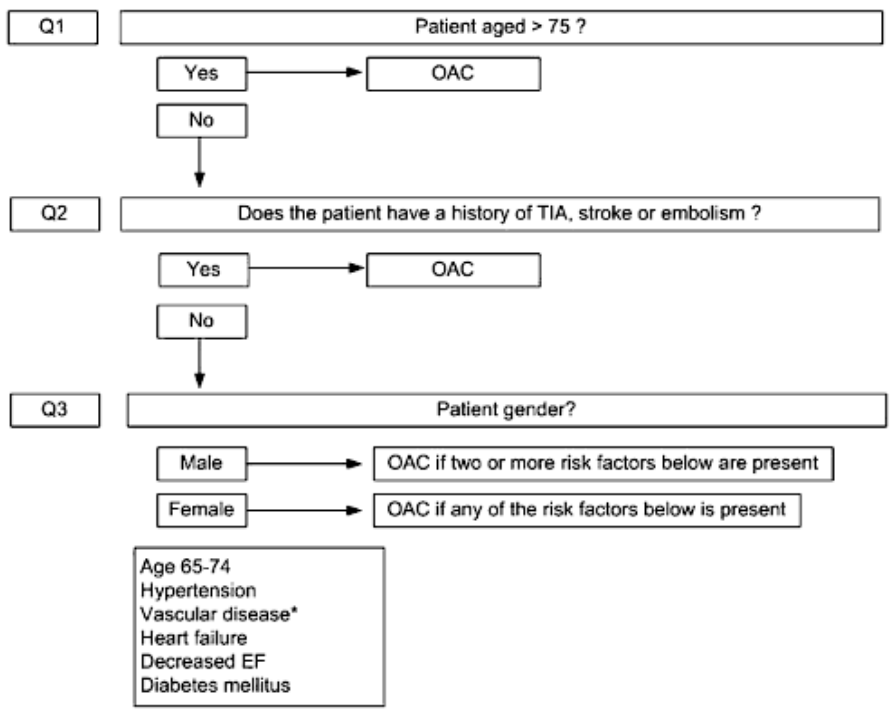

"Myocardial infarction, peripheral artery disease or aortic plaque

Figure 1 - Proposed clinical flowchart for the use of oral anticoagulation for stroke prevention in atrial fibrillation.

Patients with no risk factors are at low risk (essentially patients aged $<65$ years with lone AF, with none of the risk factors, whether high, moderate, or less validated), as confirmed by the absence of TE events in this group in our analysis, and can be managed with aspirin 75 to $325 \mathrm{mg}$ daily or no anti- thrombotic therapy, given the limited data on the benefits of aspirin in this patient group (that is, lone AF) and the potential for adverse effects. ${ }^{3}$ Indeed, the $22 \%$ reduction in stroke risk with antiplatelet therapy in the latest meta-analysis is largely driven by the SPAF-I clinical trial, in which internal inconsistencies in TE events with the aspirin vs. control arms are apparent.30 Also, it is likely that the magnitude of aspirin effect is related to the stroke prevention seen by giving antiplatelet therapy in patients with vascular disease. $^{1,27,31}$ It is notable that if trials with aspirin alone (and not other antiplatelet drugs) are considered in the recent meta-analysis by Hart et al, $^{28}$ the $95 \%$ confidence intervals of the aspirin effect also include zero. Interestingly, more recent trials in vascular disease have not shown any significant benefit for aspirin in the primary prevention of vascular disease. ${ }^{32,33}$

Hesitance to prescribe VKA to patients at high or intermediate risk is substantially related to the need for monitoring VKA and the many interactions of food and 
drugs with VKAs. These limitations can cause a patient to spend a low proportion of time within the therapeutic target INR range, which is associated with an increase TE risk. ${ }^{34}$ Implementation of methods shown to improve quality of VKA management, such as an anticoagulation clinic, and the development of new oral anticoagulants that can be given as a fixed dose with few food/drug interactions and no requirement for monitoring, provide an opportunity for guidelines to adopt this risk factor-based approach to simply state "consider oral anticoagulation if AF is present with one or more TE risk factors" (i.e., $\mathrm{CHA}_{2} \mathrm{DS}_{2}$-VASc score of 1 or more). The Birmingham 2009 schema also allows identification of a truly low-risk population, in whom no TE events were recorded in the low-risk subjects classified as no risk factors (i.e., $\mathrm{CHA}_{2} \mathrm{DS}_{2}$-VASc score $=0$ ) and such patients may not need any antithrombotic therapy.

This analysis is limited by its dependence upon a survey database, and although we have made efforts to ensure accurate coding and validation, all possible sources of bias and recording errors cannot be excluded. An important limitation is the absence of information on TE occurrence during 1 year for $31 \%$ of patients from the baseline survey. Also, we have based our primary analysis on 1,084 subjects who were not anticoagulated at baseline, but during the 1 year of follow-up, a small proportion (18\%) were started on VKA, which could have influenced TE end points. However, confining our analysis to a secondary cohort of subjects who were not treated with anti- coagulation at baseline or during follow-up does not change our conclusions. Also, these analyses may have included some patients who were not started on VKA because of comorbidities, poor compliance (or inability to have adequate monitoring), and/or intolerance of anticoagulation, and furthermore, the numbers of end points in this subset are much lower. We recognize our modest follow-up period (1 year) in a contemporary real life clinical practice survey, but follow-up durations in other analyses are only marginally better. For example, the (older) $\mathrm{CHADS}_{2}$ validation exercise only had an average of 1.25 years of follow-up. ${ }^{26}$

In conclusion, our novel, simple stroke risk stratification schema, based on a risk factor approach, pro- vides some improvement in predictive value for TE over the CHADS2 schema, with low event rates in low risk subjects and the classification of only a small proportion of subjects into the intermediate risk category. This schema could improve our approach to stroke risk stratification in patients with AF. Ongoing validations of the Birmingham 2009 risk schema in other AF populations from different race/ethnic groups will confirm its true value. 


\section{ACKNOWLEDGEMENTS}

Author contributions: Dr Lip: contributed to study design and hypothesis, data interpretation, and drafting and revisions of the manuscript. Dr Nieuwlaat: contributed to statistical analyses, data interpretation, and drafting of the manuscript.

Dr Pisters: contributed to drafting and revision of the manuscript. Dr Lane: contributed to drafting and revision of the manuscript. Dr Crijns: contributed to drafting and revision of the manuscript. Financial/nonfinancial disclosures: The authors have reported to CHEST the following conflicts of interest: Dr Lip has served as a consultant for Bayer, Astellas, Merck, AstraZeneca, Sanofi, Aryx, and Boehringher and has been on the speakers bureau for Bayer, Boehringher, and Sanofi. Dr Pisters has served on the Roche advisory board. Dr Lane has received assistance to travel to the European Society of Cardiology from AstraZeneca. Drs Nieuwlaat and Crijns have reported no potential conflicts of interest exist with any companies/organizations whose products or services may be discussed in this article.

Other contributions: We thank the Euro Heart Survey team, national coordinators, investigators, and data collection officers for performing the survey.

\section{REFERENCES}

1. Lip GY, Lim HS. Atrial fibrillation and stroke prevention. Lancet Neurol.2007;6(11):981993.

2. Mant J, Hobbs FD, Fletcher K, et al; BAFTA investigators; Midland Research Practices Network (MidReC). Warfarin versus aspirin for stroke prevention in an elderly commu- nity population with atrial fibrillation (the Birmingham Atrial Fibrillation Treatment of the Aged Study, BAFTA): a randomised controlled trial. Lancet. 2007;370(9586):493-503.

3. Sato H, Ishikawa K, Kitabatake A, et al; Japan Atrial Fibrillation Stroke Trial Group. Low-dose aspirin for prevention of stroke in low-risk patients with atrial fibrillation: Japan Atrial Fibrillation Stroke Trial. Stroke. 2006;37(2):447-451.

4. Stroke Risk in Atrial Fibrillation Working Group. Independent predictors of stroke in patients with atrial fibrillation: a sys- tematic review. Neurology. 2007;69(6):546-554.

5. Stroke Risk in Atrial Fibrillation Working Group. Comparison of 12 risk stratification schemes to predict stroke in patients with nonvalvular atrial fibrillation. Stroke. 2008;39(5):1901-1910.

6. Baruch L, Gage BF, Horrow J, et al. Can patients at elevated risk of stroke treated with anticoagulants be further risk strati- fied? Stroke. 2007;38(9):2459-2463.

7. Poli D, Antonucci E, Grifoni E, Abbate R, Gensini GF, Prisco D. Stroke risk in atrial fibrillation patients on warfa- rin. Predictive ability of risk stratification schemes for primary and secondary prevention. Thromb Haemost. 2009;101(2): 367-372.

8. Lip GY, Lane D, Van Walraven C, Hart RG. Additive role of plasma von Willebrand factor levels to clinical factors for risk stratification of patients with atrial fibrillation. Stroke. 2006;37(9):2294-2300.

9. Fang MC, Go AS, Chang Y, Borowsky L, Pomernacki NK, Singer DE; ATRIA Study Group. Comparison of risk strati- fication schemes to predict thromboembolism in people with nonvalvular atrial fibrillation. J Am Coll Cardiol. 2008; 51(8):810-815.

10. Singer DE, Albers GW, Dalen JE, et al; American College of Chest Physicians. Antithrombotic therapy in atrial fibrilla- tion: American College of Chest Physicians evidence-based clinical practice guidelines (8th edition). Chest. 2008;133 (6 suppl):546S-592S. 
11. Fuster V, Rydén LE, Cannom DS, et al; Task Force on Practice Guidelines, American College of Cardiology/American Heart Association; Committee for Practice Guidelines, European Society of Cardiology; European Heart Rhythm Association; Heart Rhythm Society. ACC/AHA/ESC 2006 guidelines for the management of patients with atrial fibrillation-executive summary: a report of the American College of Cardiology/ American Heart Association Task Force on Practice Guidelines and the European Society of Cardiology Committee for Practice Guidelines (Writing Committee to Revise the 2001 Guidelines for the Management of Patients with Atrial Fibrillation). Eur Heart J. 2006;27(16):1979-2030.

12. National Collaborating Centre for Chronic Conditions. Atrial Fibrillation: National Clinical Guideline for Management in Primary and Secondary Care. London: Royal College of Physicians; 2006.

13. Dagres N, Nieuwlaat R, Vardas PE, et al. Gender-related differences in presentation, treatment, and outcome of patients with atrial fibrillation in Europe: a report from the Euro Heart Survey on Atrial Fibrillation. J Am Coll Cardiol. 2007;49(5):572-577.

14. Fang $M C$, Singer $D E$, Chang $Y$, et al. Gender differences in the risk of ischemic stroke and peripheral embolism in atrial fibrillation: the AnTicoagulation and Risk factors In Atrial fibrillation (ATRIA) study. Circulation. 2005;112(12): 1687-1691.

15. Lane DA, Lip GYH. Female gender is a risk factor for stroke and thromboembolism in atrial fibrillation patients. Thromb Haemost. 2009;101(5):802-805.

16. Schmitt J, Duray G, Gersh BJ, Hohnloser SH. Atrial fibrilla- tion in acute myocardial infarction: a systematic review of the incidence, clinical features and prognostic implications. Eur Heart $J$. 2009;30(9):1038-1045.

17. Conway DS, Lip GY. Comparison of outcomes of patients with symptomatic peripheral artery disease with and without atrial fibrillation (the West Birmingham Atrial FibrillationProject). Am J Cardiol. 2004;93(11):1422-1425., A10.

18. Siu $\mathrm{CW}$, Jim $\mathrm{MH}, \mathrm{Ho} \mathrm{HH}$, et al. Transient atrial fibrillation complicating acute inferior myocardial infarction: implications for future risk of ischemic stroke. Chest. 2007;132(1):44-49.

19. Lip GYH. Coronary artery disease and ischemic stroke in atrial fibrillation. Chest. 2007;132(1):8-10.

20. The Stroke Prevention in Atrial Fibrillation Investigators Committee on Echocardiography. Transesophageal echocar- diographic correlates of thromboembolism in high-risk patients with nonvalvular atrial fibrillation. Ann Intern Med. 1998;128(8):639-647.

21. Nieuwlaat R, Prins MH, Le Heuzey JY, et al. Prognosis, dis- ease progression, and treatment of atrial fibrillation patients during 1 year: follow-up of the Euro Heart Survey on atrial fibrillation. Eur Heart J. 2008;29(9):1181-1189.

22. Nieuwlaat R, Capucci A, Lip GY, et al; Euro Heart Survey Investigators. Antithrombotic treatment in real-life atrial fibrillation patients: a report from the Euro Heart Survey on Atrial Fibrillation. Eur Heart J. 2006;27(24):3018-3026.

23. Hart R, Pearce L, McBride R, Rothbart R, Asinger R. Factors associated with ischemic stroke during aspirin therapy in atrial fibrillation: analysis of 2012 participants in the SPAF I-III clinical trials. Stroke. 1999;30(6):1223-1229.

24. Atrial Fibrillation Investigators. Risk factors for stroke and efficacy of antithrombotic therapy in atrial fibrillation analysis of pooled data from five randomised clinical trials. Arch Intern Med. 1994;154(13):1449-1457.

25. Wang TJ, Massaro JM, Levy D, et al. A risk score for predict- ing stroke or death in individuals with new-onset atrial fibrilla- tion in the community: the Framingham Heart Study. JAMA. 2003;290(8):1049-1056.

26. Gage BF, van Walraven $C$, Pearce $L$, et al. Selecting patients with atrial fibrillation for anticoagulation: stroke risk stratifi- cation in patients taking aspirin. Circulation. 2004;110(16): 2287-2292.

27. van Walraven C, Hart RG, Connolly S, et al. Effect of age on stroke prevention therapy in patients with atrial fibrillation.

28. The Atrial Fibrillation Investigators. Stroke. 2009;40(4): 1410-1416. H 
29. Hart RG, Pearce LA, Aguilar MI. Meta-analysis: antithrom- botic therapy to prevent stroke in patients who have nonvalvu- lar atrial fibrillation. Ann Intern Med. 2007;146(12):857-867.

30. Nieuwlaat R, Olsson SB, Lip GY, et al; Euro Heart Survey Investigators; The Euro Heart Survey on Atrial Fibrillation. Guideline-adherent antithrombotic treatment is associated with improved outcomes compared with undertreatment in high-risk patients with atrial fibrillation. Am Heart J. 2007; 153(6):1006-1012.

31. Stroke Prevention in Atrial Fibrillation investigators. A differ- ential effect of aspirin in prevention of stroke on atrial fibrilla- tion. J Stroke Cerebrovasc Dis. 1993;3(X):181-188. Antithrombotic Trialists' Collaboration. Collaborative meta- analysis of randomised trials of antiplatelet therapy for pre- vention of death, myocardial infarction, and stroke in high risk patients. BMJ. 2002;324(7329):71-86.

32. Belch J, MacCuish A, Campbell I, et al; Prevention of Progression of Arterial Disease and Diabetes Study Group; Diabetes Registry Group; Royal College of Physicians Edinburgh. The prevention of progression of arterial disease and diabetes (POPADAD) trial: factorial randomised placebo controlled trial of aspirin and antioxidants in patients with diabetes and asymptomatic peripheral arterial disease. BMJ. 2008;337:a1840.

33. Ogawa $\mathrm{H}$, Nakayama M, Morimoto $\mathrm{T}$, et al; Japanese Primary Prevention of Atherosclerosis With Aspirin for Diabetes (JPAD) Trial Investigators. Low-dose aspirin for primary prevention of atherosclerotic events in patients with type 2 diabetes: a randomized controlled trial. JAMA. 2008;300(18): 2134-2141.

34. Connolly SJ, Pogue J, Eikelboom J, et al; ACTIVE W Investigators. Benefit of oral anticoagulant over antiplatelet therapy in atrial fibrillation depends on the quality of interna- tional normalized ratio control achieved by centers and coun- tries as measured by time in therapeutic range. Circulation. 2008;118(20):2029-2037. 


\section{$\mathrm{CHA}_{2} \mathrm{DS}_{2}$-VASc Risk Scheme Not Ready for Clinical Use}

To the Editor:

In a recent issue of CHEST (February 2010), Lip et al ${ }^{1}$ assert that their "novel . . . schema could improve our approach to stroke risk stratification in patients with AF [atrial fibrillation]." We respectfully disagree because the following limitations, among others, substantially undercut this assertion:

1. Most importantly, the scheme's predictive ability was poor, with a C statistic of 0.606. Although the authors suggest that their model was better than the widely used $\mathrm{CHADS}_{2}$ (an acronym for Congestive heart failure, Hypertension, Age $\geq 75$, Diabetes, prior Stroke/TIA (transient ischemic attack) scheme, they provide no evidence that the two were statistically significantly different. Indeed, in one analysis, the authors note that their scheme did not predict thromboembolism "better than chance." The study's clearest finding was that the Framingham scheme performed best in their limited cohort.

2. Modern prognostic model building demands validation of the exact model to avoid deterioration in performance when used outside the original data. ${ }^{2}$ The authors claim that their study provides a validation for their Birmingham 2009 scheme. However, we were unable to identify any formal validation of the model (e.g., through testing in an independent sample). The authors should make clear what they mean by validation.

3. The statistical approach described in "Methods" was not followed in the analyses. The "Methods" state, "Variables were removed stepwise from the model when the $P$ value exceeded $<10$." In the final model, six of the eight variables included did not meet the $P<.10$ criterion.

4. The authors claim that a distinctive feature of their scoring system is that their low-risk patients sustained no strokes during follow-up. They report a rate of 0 with a $\mathrm{Cl}$ of $(0-0)$. First, we note that this is an impossibly precise $\mathrm{Cl}$. The true upper bound actually includes stroke rates $>3 \%$ per year. The low observed rate is largely the consequence of setting a very low threshold for categorizing patients as more than low risk. As a result, the scheme also categorizes $75 \%$ of their patients as high risk. It is particularly important to validate the performance of these thresholds since the threshold can be chosen post hoc.

5. The Euro Heart Survey had limitations that could bias the reported analyses. Most importantly, follow-up for thromboembolism was missing for a substantial (31\%) portion of the cohort. An earlier report from Euro Heart conceded that some patients might have been lost because of stroke events. ${ }^{3}$ 
In sum, we need better stroke-risk prediction schemes for patients with AF, but the analysis reported by Lip et al is too pre- mature for clinical application.

Daniel E. Singer MD Boston MA, Margret C. Fang MD MPH, San Francisco CA, Alan S. Go MD Oakland, CA.

\section{REFERENCES}

1. Lip GYH, Nieuwlaat R, Pisters R, Lane DA, Crijns HJGM. Refining clinical risk stratification for predicting stroke and thromboembolism in atrial fibrillation using a novel risk factor- based approach: the Euro Heart Survey on atrial fibrillation. Chest. 2010;137(2):263-272.

2. Harrell FE Jr, Lee KL, Mark D. Multivariable prognostic models: issues in developing models, evaluating assumptions and adequacy, and measuring and reducing errors. Stat Med. 1996;15(4):361-387.

3. Nieuwlaat R, Prins $M H$, Le Heuzey JY, et al. Prognosis, disease progression, and treatment of atrial fibrillation patients during 1 year: follow-up of the Euro Heart Survey on atrial fibrillation. Eur Heart J. 2008;29(9):1181-1189.

\section{RESPONSE}

DOI: 10.1378/chest.10-0938

To the Editor:

Singer et al feel that the $\mathrm{CHA}_{2} \mathrm{DS}_{2}$-VASc (Cardiac failure or dysfunction, Hypertension, Age $\geq 75$ [Doubled], Diabetes, Stroke Doubled] - Vascular disease, Age 65-74 and Sex category [Female]) (Birmingham 2009) schema is too premature for clinical application, but our schema is essentially an adaptation/refinement of the widely applied 2006 American College of Cardiology (ACC)/American Heart Association (AHA)/European Society of Cardiology (ESC) guidelines risk schema1 that takes into account recent research evidence.

Recent schema largely incorporates the same risk factors, and small differences in $\mathrm{C}$ statistics are shown by $\mathrm{us}^{2}$ and Fang et al. ${ }^{3}$ Differences might only be statistically different when using a very large cohort, especially when correcting for multiple comparisons. Our aim was to fine-tune risk stratification by adding evidence from our cohort (and other recent research) to current known-risk factors in a practically useful schema. The desirable large $C$ statistic improvements might only be expected when making a schema substantially more complex or adding multiple biomarkers/genes. Although the Framingham score performed better than chance when (artificially) categorized into three risk strata, this schema requires a risk calculator, categorizes many as low $(48.3 \%)$ or intermediate $(41.5 \%)$ risk, and is impractical for everyday use. 
We have "validated" the schema in the sense that we used a combination of the existing $\mathrm{CHADS}_{2}$ score added to gender, age 65 to 74 years, and vascular disease (all already listed in the 2006 ACC/AHA/ESC guidelines as "less validated" moderate risk factors). In keeping with new data, the $\mathrm{CHA}_{2} \mathrm{DS}_{2}$-VASc score recognizes the importance of age $\geq 75$ years as a major risk factor.

We stated that ongoing validations of the $\mathrm{CHA}_{2} \mathrm{DS}_{2}$-VASc score in other populations will confirm its true value, and one presented analysis in $>80,000$ atrial fibrillation (AF) patients confirms the usefulness of $\mathrm{CHA}_{2} \mathrm{DS}_{2}$-VASc. ${ }^{4}$ We initially used the stepwise approach to test which factors were significantly associated with thromboembolism in the Euro Heart Survey "derivation cohort," which were gender and vascular disease. However, in the final analysis of the $\mathrm{CHA}_{2} \mathrm{DS}_{2}$-VASc score, we kept all risk factors in the model and reported their performance in Table 4 (no stepwise method was applied).

We apologize for the typo in the $95 \% \mathrm{Cl}$ of $(0-0)$ in Table 6; the correct $95 \% \mathrm{Cl}$ should read (0.0-3.5), which reflects the modest statistical power of our analysis. For everyday clinical use, it is still preferable to have a small intermediate-risk group (avoiding the "aspirin or warfarin" uncertainty) and to be better at filtering out the "truly low-risk" patients who will receive less benefit from antithrombotic therapy (with potential harm from bleeding).

We have already acknowledged that a major limitation was the absence of information on thromboembolism for $31 \%$ of the patients, but a strength of our analysis was its prospective nature, which allowed better standardization of definitions and identification of events, compared with retrospective record linkage data. Patients lost to follow-up were more diseased and, if anything, we have probably underestimated the overall thromboembolic event rate.

Overall, a valuable risk stratification tool should have good predictive ability, be practically useful, and take into account acceptable absolute event rates and the net risk-benefit for linking risk scores to treatment recommendations. Regarding the last, most patients in randomized trials that show the efficacy of oral anticoagulation have only one or two stroke risk factors, and in clinical practice, more of such patients are being considered for anticoagulant therapy. We feel the $\mathrm{CHA}_{2} \mathrm{DS}_{2}-\mathrm{VASC}$ score improves identification of "truly low-risk" patients, without increasing the "intermediate-risk" category (with the uncertainty of "warfarin or aspirin"), and will assist in delivering oral anticoagulation (especially with new agents on the horizon) to more patients with AF who are likely to benefit. 


\section{REFERENCES}

1. Fuster V, Rydén LE, Cannom DS, et al.; Task Force on Practice Guidelines, American College of Cardiology/American Heart Association; Committee for Practice Guidelines, European Society of Cardiology; European Heart Rhythm Association; Heart Rhythm Society. ACC/AHA/ESC 2006 guidelines for the management of patients with atrial fibrillation-executive summary: a report of the American College of Cardiology/American Heart Association Task Force on Practice Guidelines and the European Society of Cardiology Committee for Prac-tice Guidelines (Writing Committee to Revise the 2001 Guide- lines for the Management of Patients with Atrial Fibrillation). Eur Heart J. 2006;27(16):1979-2030.

2. Lip GYH, Nieuwlaat R, Pisters R, Lane DA, Crijns HJGM. Refining clinical risk stratification for predicting stroke and thromboembolism in atrial fibrillation using a novel risk factor- based approach: the Euro Heart Survey on atrial fibrillation. Chest. 2010;137(2):263:272.

3. Fang MC, Go AS, Chang Y, Borowsky L, Pomernacki NK, Singer DE; ATRIA Study Group. Comparison of risk stratifi- cation schemes to predict thromboembolism in people with non- valvular atrial fibrillation. J Am Coll Cardiol. 2008;51(8):810-815.

4. van Staa TP, Zhang B, Setakis E, Lane D, Lip GY. Comparison of risk stratification schemes for stroke in atrial fibrillation. Circulation. 2009;120:S521.

Daniel E. Singer MD Boston MA, Margret C. Fang MD MPH, San Francisco CA, Alan S. Go MD Oakland, $C A$

\section{Obstructive Sleep Apnea Is a Risk Factor for Stroke and Atrial Fibrillation}

To the Editor:

In a recent issue of CHEST (February 2010), the study by Lip et al. ${ }^{1}$ helps with the assessment of risk for stroke and thromboembolism in patients with atrial fibrillation (AF). Unfortunately, the Euro Heart Survey did not evaluate patients for obstructive sleep apnea (OSA), which we believe is a significant risk factor.

OSA is believed to increase the risk of stroke through endothelial damage and hypercoagulability as well as to increase the risk of AF. OSA with an apneahypopnea index $(\mathrm{AHI})<5$ is an independent risk factor for stroke, with a hazard ratio of 1.97 when adjusted for race, sex, smoking, alcohol use, BMI, diabetes, AF, hypertension, and lipids. ${ }^{2}$ In a meta-analysis of studies on stroke and sleep apnea, we found that $72 \%$ of patients with stroke and transient ischemic attack (TIA) have OSA with an $\mathrm{AHI}<5$, and $38 \%$ have OSA with an $\mathrm{AHI}<20 .{ }^{3}$ Further, we cite studies finding that treatment with continuous positive airway pressure (CPAP) reduces the rate of recurrent stroke and mortality in patients with OSA.

Among the Sleep Heart Health Study cohort, $4.8 \%$ of patients with OSA $(\mathrm{AHI}<5)$ have AF compared with only $0.9 \%$ of patients without OSA.4 OSA increases the 12 month recurrence of AF after cardioversion from $53 \%$ of patients without OSA to 
$82 \%$ of patients with untreated OSA vs. $42 \%$ of those treated with CPAP. ${ }^{5}$ OSA could increase the risk of paroxysmal AF.

OSA is thought to predispose patients to AF because of effects on the parasympathetic and sympathetic nervous systems that occur in the setting of hypoxemia, acidosis, apneas, and arousals. Additionally, mechanical effects of negative intrathoracic pressure promote cardiac stretch, which may predispose arrhythmias through mechanical-electrical feedback mechanisms. ${ }^{4}$

Given the increased risk of stroke and TIA in patients with AF and in patients with OSA, a strong case can be made that patients with both AF and OSA are at high risk and should receive oral anticoagulation for stroke prevention. Further studies are needed to better assess this risk.

Karin G. Johnson, MD Springfield, MA Douglas C. Johnson, MD Boston, MA

\section{REFERENCES}

1. Lip GYH, Nieuwlaat R, Pisters R, Lane DA, Crijns HJGM. Refining clinical risk stratification for predicting stroke and thromboembolism in atrial fibrillation using a novel risk factor- based approach: the Euro Heart Survey on atrial fibrillation. Chest. 2010;137(2):263-272.

2. Yaggi HK, Concato J, Kernan WN, Lichtman JH, Brass LM, Mohsenin V. Obstructive sleep apnea as a risk factor for stroke and death. N Engl J Med. 2005;353(19):2034-2041.

3. Johnson KG, Johnson DC. Frequency of sleep apnea in stroke and TIA patients: a meta-analysis. J Clin Sleep Med. 2010; 6(2):131-137.

4. Mehra R, Benjamin EJ, Shahar E, et al; Sleep Heart Health Study. Association of nocturnal arrhythmias with sleep- disordered breathing: The Sleep Heart Health Study. Am J Respir Crit Care Med. 2006;173(8):910-916.

5. Kanagala R, Murali NS, Friedman PA, et al. Obstructive sleep apnea and the recurrence of atrial fibrillation. Circulation. 2003;107(20):2589-2594.

\section{RESPONSE}

To the Editor:

Johnson and Johnson suggest the routine use of oral anticoagulation (OAC) in patients with both atrial fibrillation (AF) and obstructive sleep apnea (OSA) because they consider these patients to be at high risk for stroke. Although we lack data on OSA in the Euro Heart Survey on AF, the use of OAC in these patients is more likely to be highly prevalent, given the associated comorbidities, such as hypertension, in this population. Although the OSA-related pathophysiologic mechanisms pointed out by Johnson and Johnson might influence the risk of stroke, there is no evidence that OSA is an independent risk factor for stroke in AF. 
In the article by Yaggi et al., ${ }^{1}$ the hazard ratio of 1.97 does not hold true for OSA in relation to stroke but for the composite end point of stroke and death from any cause. Considering fatality was the major contributor of the combined end point, OSA was no longer a significant predictor of death as the single end point after correction for known confounders. ${ }^{1}$

Emphasis should lie on the high prevalence of OSA in general and its coexistence with underlying cardiovascular disease. ${ }^{2}$ Apart from OSA leading to hypertension3 no causal data exist; it is, therefore, much more likely that a "compromised" cardiovascular patient results in OSA than vice versa. ${ }^{4}$ Thus, the underlying cardiovascular conditions reflect the risk of stroke.

The novel CHA2DS2-VASc score, a point-based acronym to assess stroke risk in patients with AF (consisting of congestive heart failure, hypertension, age $\geq 75$ years [2 points], diabetes, stroke [2 points], vascular disease [coronary artery disease, peripheral vessel disease], age [65-74 years], and sex category [female]) takes the broad spectrum of cardiovascular disease and risk factors into account. ${ }^{5}$ As mentioned previously, considering the vast prevalence of under- lying heart disease among patients with $\mathrm{AF}^{6}$ and of OSA in cardio- vascular disease, patients are more likely to have an OAC-qualifying $\mathrm{CHA}_{2} \mathrm{DS}_{2}$-VASc score of $\geq 2$, reducing the additive value of OSA in antithrombotic decision making in patients with $A F$ to nil.

Ron Pisters, MD Robby Nieuwlaat, PhD Maastricht, The Netherlands Deirdre A. Lane, PhD Birmingham, England Harry J. G. M. Crijns, MD Maastricht, The Netherlands Gregory Y. H. Lip, MD Birmingham, England

\section{REFERENCES}

1. Yaggi HK, Concato J, Kernan WN, Lichtman JH, Brass LM, Mohsenin V. Obstructive sleep apnea as a risk factor for stroke and death. N Engl J Med. 2005;353(19):2034-2041.

2. Young T, Palta M, Dempsey J, Skatrud J, Weber S, Badr S. The occurrence of sleep-disordered breathing among middle- aged adults. N Engl J Med. 1993;328(17):1230-1235.

3. Peppard PE, Young T, Palta M, Skatrud J. Prospective study of the association between sleepdisordered breathing and hypertension. N Engl J Med. 2000;342(19):1378-1384.

4. Porthan KM, Melin JH, Kupila JT, Venho KKK, Partinen MM. Prevalence of sleep apnea syndrome in lone atrial fibril- lation: a case-control study. Chest. 2004;125(3):879-885.

5. Lip GYH, Nieuwlaat R, Pisters R, Lane DA, Crijns HJGM. Refining clinical risk stratification for predicting stroke and thromboembolism in atrial fibrillation using a novel risk factor- based approach: the Euro Heart Survey on atrial fibrillation. Chest. 2010;137(2):263-272.

6. Nieuwlaat R,Capucci A,Camm AJ, et al.;European Heart Survey Investigators. Atrial fibrillation management: a prospective survey in ESC member countries: the Euro Heart Survey on Atrial Fibrillation. Eur Heart J. 2005;26(22):2422-2434. 
Section II

Risk of Major Bleeding 

Chapter 2

Clopidogrel plus Aspirin in Atrial Fibrillation

N Engl J Med Sept 242009 361;13 
The investigators of ACTIVE (Atrial Fibrillation Clopidogrel Trial with Irbesartan for Prevention of Vascular Events) (May 14 issue) ${ }^{1}$ address the pivotal clinical question, "Will the addition of clopidogrel to aspirin reduce the risk of vascular events in highrisk patients with atrial fibrillation for whom vitamin K antagonists are unsuitable?" The notion of the unsuitability of vitamin $\mathrm{K}$ antagonists warrants explanation, since the vast majority of patients in ACTIVE A (the part of the trial comparing clopidogrel plus aspirin with aspirin alone in patients with atrial fibrillation) did not have a risk factor for bleeding. Instead, "a physician's judgment that a vitamin K antagonist was inappropriate for the patient" (for $50 \%$ of the patients) and "the patient's preference not to take a vitamin K antagonist" (26\%) dominated enrollment. Unfortunately, the authors do not provide a detailed explanation of the "physician's judgment" and "patient's preference" designations. ${ }^{2}$ It is noteworthy that $8.5 \%$ of the patients were receiving vitamin $\mathrm{K}$ antagonists at inclusion, but this treatment was discontinued due to the unsuitability of these agents. Also, $10 \%$ of the patients switched to vitamin $\mathrm{K}$ antagonists during follow-up after discontinuing the study drug. Was this switch due to unreported stroke that occurred while the patient was receiving placebo or clopidogrel? In summary, the meaning of the unsuitability of vitamin $\mathrm{K}$ antagonists in ACTIVE $\mathrm{A}$ is unclear, and the article may cause physicians to avoid vitamin $\mathrm{K}$ antagonists inappropriately.

Ron Pisters, M.D. Trang Dinh, M.D. Harry J. Crijns, M.D., Ph.D.

1. The ACTIVE Investigators. Effect of clopidogrel added to as- pirin in patients with atrial fibrillation. $\mathrm{N}$ Engl J Med 2009;360: 2066-78.

2. Nieuwlaat R, Capucci A, Lip GY, et al. Antithrombotic treat- ment in real-life atrial fibrillation patients: a report from the Euro Heart Survey on Atrial Fibrillation. Eur Heart J 2006;27:3018-26.

The Authors Reply:

Pisters et al. raise the issue of how physicians decide whether warfarin is un- suitable for patients with atrial fibrillation. As we pointed out in our article, only about $50 \%$ of high-risk patients with atrial fibrillation receive warfarin. Many patients are unable or unwilling to make the considerable commitment required for safe warfarin therapy. Many patients cannot take adjusted-dose warfarin because of a lack of access to good anticoagulation monitoring, be- cause of widely fluctuating or poorly controlled INRs, or because of other contraindications. Inter- national guidelines provide little specific guidance on how to assess the benefits and risks of warfarin treatment, and physicians must use their clinical judgment, weighing many factors. 


\section{Chapter 3}

\section{A Novel User-Friendly Score (HAS-BLED) to}

\section{Assess 1-Year Risk of Major Bleeding in}

Patients with Atrial Fibrillation:

\section{The Euro Heart Survey}

Ron Pisters, MD; Deirdre A. Lane, PhD; Robby Nieuwlaat, PhD; Cees B. de Vos, MD; Harry J. G. M. Crijns, MD; and Gregory Y. H. Lip, MD 


\section{ABSTRACT}

Objective: Despite extensive use of oral anticoagulation (OAC) in patients with atrial fibrillation (AF) and the increased bleeding risk associated with such OAC use, no handy quantification tool for assessing this risk exists. We aimed to develop a practical risk score to estimate the 1-year risk for major bleeding (intracranial, hospitalization, hemoglobin decrease $.2 \mathrm{~g} / \mathrm{L}$, and/or transfusion) in a cohort of real-world patients with AF.

Methods: Based on 3,978 patients in the Euro Heart Survey on AF with complete follow-up, all univariate bleeding risk factors in this cohort were used in a multivariate analysis along with historical bleeding risk factors. A new bleeding risk score termed HAS-BLED (Hypertension, Abnormal renal/liver function, Stroke, Bleeding history or predisposition, Labile international normalized ratio, Elderly (. 65 years), Drugs/alcohol concomitantly) was calculated, incorporating risk factors from the derivation cohort.

Results: Fifty-three (1.5\%) major bleeds occurred during 1-year follow-up. The annual bleeding rate increased with increasing risk factors. The predictive accuracy in the overall population using significant risk factors in the derivation cohort ( $C$ statistic 0.72 ) was consistent when applied in several subgroups. Application of the new bleeding risk score (HAS-BLED) gave similar C statistics except where patients were receiving antiplatelet agents alone or no antithrombotic therapy, with $\mathrm{C}$ statistics of 0.91 and 0.85 , respectively.

Conclusion: This simple, novel bleeding risk score (HAS-BLED) provides a practical tool to assess the individual bleeding risk of real-world patients with $A F$, potentially supporting clinical decision making regarding antithrombotic therapy in patients with AF. 


\section{INTRODUCTION}

Atrial fibrillation (AF) is associated with a well known increase in ischemic stroke risk, ${ }^{1}$ which is further increased by individual conditions such as heart failure, hypertension, diabetes, and prior thromboembolism. ${ }^{2}$ Oral anticoagulation (OAC) dramatically reduces this risk ${ }^{3}$ and is therefore recommended in patients with $\mathrm{AF}$ at moderate-high risk of stroke and thromboembolism. ${ }^{4}$ The increasing incidence and prevalence of AF increases the likelihood of OAC use in the AF population, which is usually elderly, and comorbidities commonly coexist. ${ }^{5-7}$ Indeed, clinical decision making about whether or not OAC is justified based on stroke risk is supported by various practical stroke risk classification schema which incorporate known clinical risk factors. ${ }^{4,8}$

However, stroke risk is also closely related to bleeding risk, ${ }^{9}$ and OAC prescription needs to balance the benefit from stroke prevention against the risk from bleeding. Thus, there is often suboptimal implementation of thromboprophylaxis amongst AF patients, ${ }^{9,10}$ which may be partly due to the lack of a validated bleeding risk stratification schema that is user-friendly. ${ }^{11-13}$ This is further reflected by the absence of recommendations on bleeding risk assessment in current antithrombotic guidelines for AF management. ${ }^{4,12}$ The available schemas estimating the risk of bleeding associated with use of OAC either do not focus on AF patients in particular, ${ }^{14,15}$ address a (very) specific subgroup among AF patients, ${ }^{16}$ or incorporate routinely unavailable risk factors which also overlap significantly with stroke risk factors. ${ }^{17}$ Furthermore, all published schema are based on 'historic' cohorts of patients and consequently may not reflect advancements in medical care over time (for example, OAC monitoring) and treatment of underlying heart disease. ${ }^{14-17}$

Our aim was to develop a practical risk score to estimate the one-year risk of major bleeding (intracranial, hospitalization, hemoglobin drop $>2 \mathrm{~g} / \mathrm{L}$ and/or transfusion) in a contemporary, 'real world' cohort of AF patients.

\section{METHODS}

We used the large population database of the prospective Euro Heart Survey on AF, with data collected between 2003 and 2004. A detailed study outline of the Euro Heart Survey on AF at baseline ${ }^{5}$ and follow-up assessment ${ }^{18}$ has been previously described. In summary, 5,333 ambulatory and hospitalized AF patients from 182 university, non- university, and specialized hospitals among 35 member countries of the European Society of Cardiology (ESC) were enrolled. Patients had to be 18 years or older and have an ECG or Holter proven diagnosis of AF during the qualifying admission or in the preceding year. A one year follow-up assessment was performed to determine survival and major adverse cardiovascular events, such as 
major bleeding. Medical records and/or medical information systems were used to populate the dataset.

We defined major bleeding as any bleeding requiring hospitalization and/or causing a decrease in hemoglobin level of more than $2 \mathrm{~g} / \mathrm{L}$ and or requiring blood transfusion, which was not a hemorrhagic stroke. Hemorrhagic stroke was defined as a focal neurologic deficit of sudden onset, diagnosed by a neurologist, lasting longer than 24 hours and caused by bleeding. Presence of chronic dialysis or renal transplantation or serum creatinine $\geq 200 \mu \mathrm{mol} / \mathrm{L}$ was classified as abnormal kidney function. Abnormal liver function was defined as chronic hepatic disease (e.g. cirrhosis) or biochemical evidence of significant hepatic derangement (e.g. bilirubin $>2 x$ upper limit of normal, in association with AST/ALT/ALP >3x upper limit normal, etc.). Finally, valvular heart disease was defined as the presence of any regurgitation or gradient over a valve with hemodynamic significance and/or related symptoms.

\section{Statistical analysis and design of a new bleeding risk score}

Data analysis was performed with SPSS (SPSS Inc., Version 16.0). The presence of any differences between the groups with and without a major bleeding during one year follow-up was tested by Fisher's exact test for categorical variables and by independent samples T-test for continuous variables.

All potential bleeding risk factors identified from the univariate analyses of the derivation cohort with a p-value $<0.10$ (age $>65$, female gender, diabetes mellitus, heart failure, chronic obstructive pulmonary disease, valvular heart disease (VHD), kidney failure, prior major bleeding episode and clopidogrel use), were used in the multivariate logistic regression analyses along with more 'historical' bleeding risk factors: OAC, alcohol use, and hypertension. We disregarded thyroid disease $(p=0.039$ ) because of difficulties with interpretation (only $n=10$ bleeding events) and this had not been identified as a bleeding risk in prior systematic reviews. ${ }^{11-13}$ Given the persistent nature of the evidence of OAC, hypertension, age $>65$, renal failure, alcohol abuse and prior major bleed as bleeding risk factors, these variables were kept in the model at all times. The other, less strongly linked, variables were removed stepwise from the model when the $P$-value exceeded 0.10 . Variables with $P<0.05$ in the final model were considered to be significant contributors and were checked for interaction effects, which did not exist.

In recognition of the limited number of major bleeds and relatively short followup period in the Euro Heart Survey on AF, we also added consistent risk factors for major bleeding(stroke, alcohol use, systolic blood pressure $>160 \mathrm{mmHg}$, etc.) identified in recent systematic reviews ${ }^{11,13}$ to use the data from the derivation cohort to test a new bleeding risk score (HAS-BLED, see below) in final statistical model, accepting the lack of statistical significance of some variables in our derivation cohort. For each of the variables in the final model the regression coefficient, net odds ratio 
(OR) and its $95 \%$ confidence interval $(\mathrm{Cl})$ and $P$-value are reported (Table 1 ). We then calculated the c- statistic as a measure of the predictive accuracy of the model incorporating bleeding risk factors from the derivation cohort (that is, prior major bleeding, age $>65$, clopidogrel use and kidney failure), where based on their respective multivariate regression coefficients, two points were awarded for prior major bleeding and one point for each of the other bleeding risk factors. In addition, we report the c-statistics in a subgroup analysis of individuals discharged with OAC monotherapy, OAC combined with an antiplatelet drug, an antiplatelet drug alone, or no antithrombotic therapy.

Table 1 - Baseline characteristics*

\begin{tabular}{|c|c|c|c|}
\hline Characteristic & $\begin{array}{l}\text { Major bleeding } \\
(n=49)\end{array}$ & $\begin{array}{l}\text { No major bleeding } \\
(n=1,087)\end{array}$ & $P$ value \\
\hline Mean (SD) age, y & $70.7(6.4)$ & $67.9(8.5)$ & 0.005 \\
\hline Female & $17(34)$ & $386(36)$ & 1.00 \\
\hline Mean (SD) BMI, kg/m² & $27.2(4.1)$ & $28.1(4.5)$ & 0.21 \\
\hline Mean (SD) SBP, mmHg & $136.9(18.3)$ & $139.5(20.1)$ & 0.37 \\
\hline Current smoker & $6(12)$ & $163(15)$ & 0.84 \\
\hline Total AF history, days & & & 0.73 \\
\hline Median & 400 & 506 & \\
\hline Interquartile range & 183-1891 & $171-1618$ & \\
\hline \multicolumn{4}{|l|}{ Medical history } \\
\hline Mean (SD) $\mathrm{CHADS}_{2}$ score & $0.90(1.12)$ & $1.03(1.01)$ & 0.19 \\
\hline Hypertension & $14(29)$ & $402(37)$ & 0.29 \\
\hline Coronary artery disease & $8(17)$ & $181(17)$ & 1.00 \\
\hline Diabetes mellitus & $2(4)$ & $119(11)$ & 0.16 \\
\hline Congestive heart failure & $7(14)$ & $193(18)$ & 0.70 \\
\hline Stroke/TIA & $4(8)$ & $97(9)$ & 1.00 \\
\hline Previous major bleeding & $6(12)$ & $33(3)$ & 0.005 \\
\hline Alcohol abuse & $1(2)$ & $18(2)$ & 0.57 \\
\hline
\end{tabular}

Abbreviations: AF, atrial fibrillation; DBP, diastolic blood pressure; SBP, systolic blood pressure TIA, transient ischemic attack. $\mathrm{CHADS}_{2}$ : congestive heart failure, hypertension, age $\geq 75$ years, previous stroke or transient ischemic attack ( 2 points).

"Data are presented as No. (\%) or unless otherwise specified. Fisher exact test for comparison of categorical outcomes and Unless otherwise specified Students t-test between two and three groups.

A new bleeding risk score (acronym HAS-BLED: Hypertension, Abnormal renal/liver function, Stroke, Bleeding history or predisposition, Labile INR, Elderly (>65), Drugs/alcohol concomitantly) was calculated, incorporating risk factors from the derivation cohort as well as significant risk factors of major bleeding found in the literature from systematic reviews. ${ }^{11,13}$ HAS-BLED is an acronym for Hypertension [uncontrolled, $>160 \mathrm{mmHg}$ systolic), Abnormal renal/liver function (1 point for presence of renal or liver impairment, maximum 2 points), Stroke (previous history, particularly lacunar), Bleeding history or predisposition [anemia], Labile INR [i.e. 
therapeutic time in range $<60 \%$ ], Elderly (>65 years), Drugs/alcohol concomitantly (antiplatelet agents, non- steroidal anti-inflammatory drugs; 1 point for drugs plus 1 point for alcohol excess, maximum 2 points) as shown in Table 2.

Table 2 - Uni- and multivariate analyses of risk factors of major bleeding

\begin{tabular}{lllllll}
\hline & \multicolumn{2}{l}{ Event rate (\%) } & & & & \\
Risk factor present & Univariate analysis & \multicolumn{2}{l}{ Multivariate analysis } \\
Risk factor & Yes & No & HR (95\% Cl) & p value & HR (95\% Cl) & p value \\
\hline Previous major bleeding & 15.4 & 3.9 & $4.36(1.85-10.26)$ & 0.001 & $4.70(1.99-11.08)$ & $<.001$ \\
Age $\geq 75$ y & 5.8 & 3.9 & $1.52(0.81-2.87)$ & 0.20 & $1.39(0.72-2.68)$ & 0.32 \\
Hypertension & 3.4 & 4.9 & $0.68(0.36-1.26)$ & 0.22 & $0.72(0.39-1.34)$ & 0.30 \\
Alcohol abuse & 5.3 & 4.3 & $1.26(0.17-9.14)$ & 0.82 & $1.70(0.23-12.61)$ & 0.60 \\
Renal dysfunction & 8.3 & 4.2 & $1.97(0.61-6.32)$ & 0.26 & $2.21(0.68-7.19)$ & 0.19 \\
Congestive heart failure & 3.5 & 4.5 & $0.80(0.36-1.78)$ & 0.59 & $0.83(0.36-1.91)$ & 0.67 \\
Female & 4.2 & 4.4 & $0.98(0.54-1.76)$ & 0.95 & $1.10(0.60-2.02)$ & 0.76 \\
Previous stroke/TIA & 4.0 & 4.3 & $0.91(0.33-2.54)$ & 0.86 & $0.94(0.33-2.64)$ & 0.91 \\
Smoking & 3.6 & 4.4 & $0.81(0.35-1.91)$ & 0.63 & $0.80(0.34-1.89)$ & 0.62 \\
Aspirin use & 5.3 & 4.3 & $1.21(0.17-8.74)$ & 0.85 & $1.32(0.18-9.68)$ & 0.79 \\
Diabetes mellitus & 1.7 & 4.6 & $0.38(0.09-1.55)$ & 0.18 & $0.14(0.08-1.40)$ & 0.14 \\
Coronary artery disease & 4.2 & 4.2 & $1.04(0.49-2.21)$ & 0.93 & $(0.44-2.10)$ & 0.93 \\
\hline
\end{tabular}

In order to compare the predictive accuracy of our novel bleed risk score (HASBLED) with the previously proposed HEMOR2RHAGES scheme, patients were classified accordingly ${ }^{17}$; however, we considered 'uncontrolled' hypertension to be $>160$ $\mathrm{mmHg}$ systolic, a 'history of malignancy' to be similar to 'current malignancy' and we classified $\geq 8$ units alcoholic consumption per week as 'ethanol abuse'. Relevant genetic and laboratory data (required for calculation of the HEMOR ${ }_{2}$ RHAGES schema), apart from serum creatinine, were not available for the Euro Heart Survey on AF cohort.

\section{RESULTS}

Of the 5272 AF patients in the Euro Heart Survey of AF who were discharged alive5, $3456(66 \%)$ patients without mitral valve stenosis or valvular surgery had one year follow-up status regarding major bleeding. The overall mean (SD) age was 66.8 (12.8) years and the majority were male (59\%). Fifty-three (1.5\%) patients experienced a major bleed during the first year, including $9(17 \%)$ cases of intracerebral hemorrhage (ICH). The baseline demographic and clinical characteristics of the 3456 patients are presented in Table 3. 
Table 3 - Major bleeding rates by HAS-BLED score

\begin{tabular}{lll}
\hline HAS-BLED score & Patients with particular score $^{*}$ & Number of major bleedings $^{\dagger}$ \\
\hline 0 & $218(19.2)$ & $8(3.7)$ \\
1 & $532(46.8)$ & $21(3.9)$ \\
2 & $324(28.5)$ & $15(4.6)$ \\
3 & $51(4.49)$ & $4(7.8)$ \\
4 & $10(0.9)$ & $1(10.0)$ \\
5 & $1(0.1)$ & $0(0)$ \\
& C statistic=0.61; p value for trend 0.27 & \\
\hline
\end{tabular}

Values are $n$ (\%). "Percentage of column total. ${ }^{\dagger}$ Percentage of row total. HAS-BLED: Hypertension, Abnormal Renal/Liver Function, Stroke, Bleeding History or Predisposition, Labile INR, Elderly, Drugs/Alcohol Concomitantly

Of all discharged patients, 2242 (64.8\%) were on OAC (286 (12.8\%) of whom also received aspirin and/or clopidogrel), 828 (24.0\%) received antiplatelet therapy alone (aspirin and/or clopidogrel) and 352 (10.2\%) received no antithrombotic therapy. The distribution of the risk factors for major bleeding within one year among the different antithrombotic treatment regimens in the derivation cohort is depicted in Table 4. The risk of major bleeding within one year in AF patients in the Euro Heart Survey determined by the novel bleeding risk score, HAS-BLED, is shown in Table 5. The annual bleeding rate increased with the addition of each risk factor from the derivation cohort (Table 5).

Table 4 - Risk factors for major bleeding according to the HAS-BLED score

\begin{tabular}{|c|c|c|c|c|c|c|c|c|}
\hline \multirow[b]{2}{*}{ Risk factor } & \multirow[b]{2}{*}{$\begin{array}{l}\text { RACE I/II } \\
\text { cohort definition }\end{array}$} & \multirow[b]{2}{*}{ RF+ } & \multicolumn{2}{|l|}{$\begin{array}{l}\text { Major } \\
\text { bleeding }\end{array}$} & \multicolumn{2}{|l|}{$\begin{array}{l}\text { Univariate } \\
\text { analyses }\end{array}$} & \multicolumn{2}{|l|}{$\begin{array}{l}\text { Multivariate } \\
\text { analyses }\end{array}$} \\
\hline & & & RF+ & RF- & $\mathrm{HR}(95 \% \mathrm{CI})$ & $\begin{array}{l}P \\
\text { value }\end{array}$ & HR (95\% Cl) & $\begin{array}{l}\mathbf{P} \\
\text { value }\end{array}$ \\
\hline Hypertension & $\begin{array}{l}\mathrm{SBP}>160 \mathrm{mmHg} \text { at } \\
\text { entry }\end{array}$ & $133(11.7)$ & $5(3.8)$ & $44(4.4)$ & & & & \\
\hline $\begin{array}{l}\text { Abnormal } \\
\text { renal function }\end{array}$ & $\begin{array}{l}\text { Serum creatinine } \\
>200 \text { or dialysis }\end{array}$ & $36(3.2)$ & $3(8.3)$ & $46(4.2)$ & & & & \\
\hline Stroke & Yes/no & $27(2.4)$ & $0(0)$ & $49(4.4)$ & & & & \\
\hline $\begin{array}{l}\text { Bleeding } \\
\text { predisposition }\end{array}$ & $\begin{array}{l}\text { Prior major bleed- } \\
\text { ing/anemia }\end{array}$ & $56(4.9)$ & $6(10.7)$ & $43(4.0)$ & & & & \\
\hline Labile INR & TTR $<60 \%$ & $353(31.3)$ & $15(4.2)$ & $34(4.3)$ & & & & \\
\hline \multirow[t]{2}{*}{ Elderly } & $>65$ years at entry & $735(64.7)$ & $36(4.9)$ & $13(3.2)$ & & & & \\
\hline & $>75$ years at entry & $224(19.7)$ & $13(5.8)$ & $36(3.9)$ & & & & \\
\hline \multirow[t]{2}{*}{ Drugs } & Aspirin use & $19(1.7)$ & $1(5.3)$ & $48(4.3)$ & & & & \\
\hline & Alcohol >8U/week & $19(1.7)$ & $1(5.3)$ & $48(4.3)$ & & & & \\
\hline
\end{tabular}


Table 5 - Predictive value of contemporary bleeding risk schemas in patients on oral anticoagulation

\begin{tabular}{|c|c|c|c|c|}
\hline Bleeding risk score (Ref. \#) & Low & Moderate & High & C-statistic $(95 \% \mathrm{Cl})$ \\
\hline \multicolumn{5}{|l|}{ HAS-BLED } \\
\hline$\%$ in risk category & $218(19.2)$ & $856(75.4)$ & $62(5.5)$ & $0.61(0.53-0.68)$ \\
\hline \multicolumn{5}{|l|}{ Bleeding events, n (\%) } \\
\hline \multicolumn{5}{|l|}{ Shireman et al. } \\
\hline$\%$ in risk category & $1069(94.1)$ & $66(5.8)$ & $1(0.1)$ & $0.68(0.60-0.75)$ \\
\hline \multicolumn{5}{|l|}{ Bleeding events, n (\%) } \\
\hline \multicolumn{5}{|l|}{$\mathrm{HEMORR}_{2} \mathrm{HAGES}$} \\
\hline$\%$ in risk category & $1032(90.8)$ & $98(8.6)$ & $6(0.5)$ & $0.62(0.53-0.70)$ \\
\hline \multicolumn{5}{|l|}{ Bleeding events, n (\%) } \\
\hline \multicolumn{5}{|l|}{ Beyth } \\
\hline$\%$ in risk category & $361(31.8)$ & $771(67.9)$ & $4(0.4)$ & $0.59(0.52-0.67)$ \\
\hline \multicolumn{5}{|l|}{ Bleeding events, n (\%) } \\
\hline \multicolumn{5}{|l|}{ Kuijer } \\
\hline$\%$ in risk category & $162(14.3)$ & $941(82.8)$ & $33(2.9)$ & $0.58(0.50-0.66)$ \\
\hline Bleeding events, n (\%) & & & & \\
\hline
\end{tabular}

The corresponding unadjusted bleeding rates in patients with OAC, antiplatelet therapy alone, or no antithrombotic treatment were $1.75,0.97$, and 1.42 bleeds per 100 patient years, respectively. The predictive accuracy in the overall population using significant risk factors in the derivation cohort (c-statistic 0.72) was consistent when applied in several subgroups, as shown in Table 6. Application of the new bleeding risk score (HAS-BLED) gave similar c-statistics to that derived in the derivation cohort overall $(0.72)$, or when patients were established on OAC at baseline (0.69) or where patients were on 'OAC plus antiplatelet therapy' at baseline $(0,78)$. HAS-BLED substantially improved the predictive accuracy of bleeding risk where AF patients were receiving antiplatelet therapy alone or in those who were not on antithrombotic therapy at all (with c-statistics of 0.91 and 0.85 , respectively). The $\mathrm{HEMOR}_{2}$ RHAGES bleeding scheme had a lower predictive accuracy compared to the new HAS-BLED score, overall or in relation to antithrombotic therapy use, except in the 'OAC plus antiplatelet therapy' subgroup (Table 6).

Of all the 33 bleeding events in patients discharged with OAC because of a $\mathrm{CHADS}_{2}$ score $\geq 1,4$ (12\%) patients had a HAS-BLED-based bleeding risk that outweighed their individual stroke risk. Conversely, of all 1580 patients discharged with $\mathrm{OAC}$ because of a $\mathrm{CHADS}_{2}$ score $\geq 1$ who did not suffer a major bleed within one year, only 34 (2.2\%) had a HAS-BLED-based bleeding risk that outweighed their individual stroke risk. Of all 21 patients with a $\mathrm{CHADS}_{2}$ score $\geq 1$ discharged without OAC who suffered a stroke within one year of follow-up, only one had a HAS-BLED score outweighing the individual stroke risk. Of the $\mathrm{CHADS}_{2}$ score $\geq 1$ patients discharged without OAC with a higher HAS-BLED bleeding risk score, all three patients suffered a major bleed. 
Table 6 - Predictive power of the bleeding risk scores used to assess risk of major bleeding within one year in atrial fibrillation patients

\begin{tabular}{llll}
\hline Antithrombotic treatment & Bleeding risk score $^{*}$ & N & C-statistic (CI) \\
\hline Overall group & Derivation cohort $^{*}$ & 3381 & $0.72(0.64-0.79)$ \\
& HAS-BLED $^{* *}$ & 3071 & $0.72(0.65-0.79)$ \\
Oral anticoagulation alone & HEMORRHAGES $^{* * *}$ & 3040 & $0.66(0.57-0.74)$ \\
& Derivation cohort $^{*}$ & 1947 & $0.68(0.58-0.78)$ \\
& HAS-BLED $^{* *}$ & 1722 & $0.69(0.59-0.80)$ \\
OAC + antiplatelet therapy & HEMORRHAGES $^{* * *}$ & 1706 & $0.64(0.53-0.75)$ \\
& Derivation cohort $^{*}$ & 240 & $0.80(0.68-0.93)$ \\
\multirow{3}{*}{ Antiplatelet therapy alone } & HAS-BLED $^{* *}$ & 239 & $0.78(0.65-0.91)$ \\
& HEMORRHAGES $^{* * *}$ & 235 & $0.83(0.74-0.91)$ \\
& ${\text { Derivation } \text { cohort }^{*}}^{*}$ & 788 & $0.74(0.52-0.97)$ \\
& HAS-BLED $^{* *}$ & 753 & $0.91(0.83-1.00)$ \\
No antithrombotic therapy & HEMORRHAGES $^{* * *}$ & 728 & $0.83(0.68-0.98)$ \\
& Derivation cohort $^{*}$ & 348 & $0.75(0.51-0.99)$ \\
& HAS-BLED $^{* *}$ & 315 & $0.85(0.00-1.00)$ \\
& HEMORRHAGES $^{* * *}$ & 311 & $0.81(0.00-1.00)$ \\
\hline
\end{tabular}

$\mathrm{N}$, number of patients included in analysis; $\mathrm{Cl}$, confidence interval; OAC, oral anticoagulation).

*Derivation cohort risk factors: Bleeding history, Age $>65$ years, Clopidogrel use and Kidney failure

**HAS-BLED, acronym: Hypertension [uncontrolled, $>160 \mathrm{mmHg}$ systolic), Abnormal renal/liver function, Stroke, Bleeding history or predisposition [anemia], Labile INR [i.e. therapeutic time in range $<60 \%$ ], Elderly (>65 years) and Drugs/alcohol concomitantly [antiplatelet agents, non-steroidal antiinflammatory drugs;

${ }^{* * *}$ HEMOR2RHAGES, acronym: Hepatic or renal disease, Ethanol abuse, Malignancy, Older age (>75years), Re-bleeding, Reduced platelet count or function, Hypertension (uncontrolled), Anemia, Genetic factors, Excessive fall risk and Stroke.

[NB. Classifying bleeding risk by antithrombotic therapy use with the HEMOR2RHAGES model resulted in mean scores of 1.17, 1.17, 1.31, 1.24 and 1.07, respectively.]

\section{DISCUSSION}

Using a derivation cohort based on the large, 'real-world' population of the Euro Heart Survey on AF, we identified four independent risk factors of major bleeding within one year (prior major bleeding, age $>65$, clopidogrel use and kidney failure). Incorporating these risk factors with other established risk factors from systematic reviews and multivariate analyses, ${ }^{11,13,19}$ we developed and tested a novel, userfriendly bleeding risk score, HAS-BLED, which demonstrated a good predictive accuracy in the overall Euro Heart survey cohort (c-statistic 0.72 ) but performed particularly well in predicting bleeding risk where antiplatelet therapy was used alone (cstatistic 0.91), or no antithrombotic therapy at all (c-statistic 0.85). Assessment of both stroke and bleeding risk using the $\mathrm{CHADS}_{2}$ and HAS-BLED schemas, respectively, in the Euro Heart Survey on AF population would have resulted in withholding OAC therapy in $12 \%$ of the patients who suffered a major bleeding within one 
year and the initiation of OAC in 95\% of the patients at high risk for stroke who were discharged without OAC and had suffered a stroke within one year.

With the previously published HEMOR ${ }_{2}$ RHAGES schema ${ }^{17}$ and others, ${ }^{11,19}$ the concept of a risk score for major bleeding in AF patients is not new. However, our novel proposed HAS-BLED score has several key advantages over the abovementioned bleeding risk stratification method. First, the shorter acronym means that physicians have less risk factors to memorize when using the HAS-BLED score, thereby increasing the user- friendliness and subsequent clinical application. Further, in contrast to certain risk factors incorporated into the HEMOR ${ }_{2}$ RHAGES score which require laboratory parameters or even genetic testing ${ }^{17}$, all risk factors of the HAS-BLED score are either readily available from the clinical medical history or routinely tested in (new) AF patients. This characteristic strongly supports its use in all health care settings and is another significant contributor to its superior userfriendliness. Because less does not necessarily mean more, it is important to note that the predictive accuracy of the HAS-BLED score is broadly similar when compared to the HEMOR ${ }_{2}$ RHAGES model in the overall population (c- statistic of 0.72 vs. 0.66 , respectively). ${ }^{17}$ However, the HAS-BLED score was particularly useful when antiplatelet therapy was used alone or no antithrombotic therapy used at all (cstatistics of 0.91 and 0.85 , respectively). Whilst the HAS-BLED score and the HEM$\mathrm{OR}_{2}$ RHAGES model were broadly similar in subjects who were not taking antithrombotic therapy at baseline (c-statistics of 0.85 vs. 0.81 , respectively), the HAS- BLED score is simpler. This score would be particularly useful in everyday clinical practice, when making decisions on whether OAC can be initiated in a newly diagnosed AF patient who is not taking any antithrombotic therapy ${ }^{12}$, or where antiplatelet therapy (or NSAIDs) use is being considered, for example, in the setting or coronary artery disease. $^{20}$

As mentioned previously, balancing the individual risk of bleeding and stroke is difficult $^{21}$ but of the utmost importance to maximize appropriate antithrombotic therapy and minimize adverse events in AF patients, resulting in a net clinical benefit for the treated patient. In daily clinical practice, the $\mathrm{CHADS}_{2}$ index ${ }^{8}$ is a widely used tool to stratify stroke risk in AF patients. For now, the HEMOR ${ }_{2}$ RHAGES score is the only suitable counterpart available to assess the risk of bleeding. ${ }^{17}$ Closer examination of the risk factors comprising the $\mathrm{CHADS}_{2}$ and $\mathrm{HEMOR}_{2}$ RHAGES schemas, reveals an extensive overlap between risk factors for bleeding and stroke, which has obvious drawbacks. ${ }^{8,17}$ Indeed, the patients at highest stroke and thromboembolic risk are - paradoxically - more likely to sustain bleeding complications. This may lead to confusion when trying to decide on the most appropriate antithrombotic regimen, to balance the risks of bleeding against the risk of stroke, thereby limiting the applicability of such schemas.

The 'trade off' in terms of the benefits and risks of OAC using the $\mathrm{CHADS}_{2}$ index and HAS-BLED score demonstrates that in the vast majority of AF patients who re- 
quire $\mathrm{OAC}\left(\mathrm{CHADS}_{2}\right.$ index $\left.\geq 2\right)$ the risk of bleeding outweighs the potential benefit of OAC if the HAS-BLED bleed score exceeds the individual $\mathrm{CHADS}_{2}$ index. In case of a $\mathrm{CHADS}_{2}$ score of 1 the HAS-BLED score must exceed two for the potential harm caused by OAC use to offset its beneficial effect on stroke risk reduction. Appropriate use of this practical 'rule' in the Euro Heart Survey on AF population could have prevented more than one out of every ten (4/33) of the major bleeds. However, $34 / 1580$ (2.2\%) of the patients with a $\mathrm{CHADS}_{2}$ score $\geq 1$ discharged with OAC who did not suffer a major bleed within one year would have been denied OAC because of a HAS-BLED bleed risk outweighing their stroke risk.

The potential impact on current clinical practice of the novel HAS-BLED score is underlined by the recently published Atrial Fibrillation Clopidogrel Trial with Irbesartan for Prevention of Vascular Events (ACTIVE)-A trial. ${ }^{22}$ This large randomized clinical trial was designed to compare the preventive effect on all cause vascular events of clopidogrel plus aspirin vs. aspirin alone in AF patients deemed unsuitable for OAC treatment. In half $\left(n^{\sim} 3,500\right)$ of these AF patients with a high stroke risk, the most common applied classification was 'unsuitable for $\mathrm{OAC}^{\prime}$, which was solely based on physician clinical judgment, without the presence of any predefined risk factor of bleeding or other objective risk scoring. Perhaps this reflects physician's uncertainty about what to consider as true risk factors of bleeding and their fear of potential iatrogenic harm caused by OAC use.

Given the recent promising results of the RE-LY trial ${ }^{23}$, patients assessed as being at higher bleeding risk using the novel HAS-BLED score could be prescribed the lower dose $(110 \mathrm{mg}$ bid) of the oral direct thrombin inhibitor, dabigatran, which demonstrated a significant reduction in major bleeding compared to warfarin, with a similar stroke risk reduction to warfarin, whilst those at lower bleeding risk could be prescribed dabigatran $150 \mathrm{mg}$ bid which offers superior efficacy but with a similar major bleeding risk to warfarin ${ }^{24}$. Further, the HAS-BLED score could also be used to identify patients who may benefit from a left atrial appendage occlusion device ${ }^{25}$, i.e. patients at high risk of ischemic stroke who have such an increased risk of bleeding that OAC is contraindicated. Thus, future clinical decisions by physicians deciding on initiating OAC (whether with the VKAs or new oral anticoagulants, such as dabigatran) in an AF patient could use the HAS-BLED score to assess the potential bleeding risk and feel more confident in prescribing OAC where appropriate or refer for implantation of a left atrial appendage occlusion device. Indeed, bleeding risk scores should also be validated in dabigatran treated patients, as well as those being considered for left atrial appendage occlusion devices.

\section{LIMITATIONS}

The HAS-BLED score need to be validated in at least one other large contemporary cohort of AF patients before it can be widely implemented into daily practice. Po- 
tential selection bias might have occurred because of $25 \%$ missing data regarding the occurrence of major bleeding during the follow-up period. Patients who were lost to follow-up were likely to have been more comorbidities and transferred to nursing homes or even deceased, which might have led to underestimation of the overall bleeding rate. Also, we recognize that the limited number of major bleeds and the relatively short follow-up period make it possible that other important risk factors for bleeding were not identified. Indeed, bleeding may occur following changes to warfarin (e.g. for surgery or interventions such as pacemaker implant, etc.) with institution of 'bridging' therapy with low molecular heparin. We also did not consider thyroid disease in our model, as this had not been identified as a bleeding risk in prior systematic reviews ${ }^{11-13}$; however, some pathophysiological plausibility is possible, since hypothyroidism has been described to cause acquired von Willebrand disease associated with low Factor VIII levels and platelet dysfunction $^{26}$. Of note, there is an improved predictive power of the HAS-BLED score over the HEMOR ${ }_{2}$ RHAGES score in patients treated with antiplatelet therapy (or NSAIDs) or no antithrombotic therapy at all (Table 6).

The risk of major bleeding (especially intracranial hemorrhage) is increased with advanced age $e^{26,7,28}$. Of note, the risk of major hemorrhage can be similar amongst elderly patients receiving warfarin and aspirin ${ }^{29}$. The relatively small numbers of bleeding events and the modest size of the very elderly in our cohort makes it rather difficult to draw too many firm conclusions by introducing different weights to different age categories (e.g. 1 point for age 65-74, 2 points for age 75-84, 3 points for age $\geq 85$, etc.), as well as introducing additional complexity to our simple HASBLED scoring system. Also, age is a continuous (rather than categorized) risk for bleeding (as well as stroke). It must be stressed that in many instances, bleeding risk amongst the elderly is multifactorial ${ }^{30}$ and is often the result of associated comorbidities, high anticoagulation intensity and labile INRs in this population ${ }^{11-13}$. The HAS-BLED score already takes some of these aspects into account, allowing cumulative assessment of risk factors for bleeding. In the present analysis, the HAS-BLED score already outperforms the HEMOR ${ }_{2}$ RHAGES bleeding scheme, which was an attempt by Gage et al. ${ }^{17}$ to have a 'simple' method of bleeding assessment. Future validation and refinement of HAS- BLED amongst a huge elderly AF population with prolonged follow-up may address the issue of age as a continuous variable for bleeding risk.

Finally, data about INR control are obviously not available when having to decide on starting OAC for the first time in a patient. When on OAC, the INR is often elevated at the time of admission for a bleeding event, but it is unknown which measure of INR control best predicts bleeding in such a manner that clinical action could prevent the bleeding. We did not include actual INR values during follow-up, but acknowledge its importance as risk factor of bleeding. ${ }^{19}$ Of note, the current 
alternative ( $\mathrm{HEMOR}_{2}$ RHAGES model) was also developed without the availability of INR values. ${ }^{17}$

\section{CONCLUSION}

We propose a novel bleeding risk score, HAS-BLED, which provides an easy, practical tool to assess the individual bleeding risk of AF patients, potentially supporting clinical decision-making regarding antithrombotic therapy for stroke prevention.

\section{ACKNOWLEDGEMENTS}

We thank the Euro Heart Survey team, national co-ordinators, investigators, and data collection officers for performing the survey.

\section{Funding sources for the Euro Heart Survey}

Industry sponsors: main sponsor: AstraZeneca; major sponsor: Sanofi-Aventis; sponsor: Eucomed. Funding institutions: Austrian Heart Foundation, Austrian Society of Cardiology, French Federation of Cardiology, Hellenic Cardiological Society, Netherlands Heart Foundation, Portuguese Society of Cardiology, Spanish Cardiac Society, Swedish Heart and Lung Foundation and individual centres.

\section{Conflicts of interest}

None declared.

\section{Authors contributions}

$\mathrm{RP}, \mathrm{RN}$ - statistical analyses, data interpretation, drafting of manuscript DL, CV, HC - drafting, revision of manuscript GYHL - study design and hypothesis, concept of the HAS-BLED score (the 'Birmingham Atrial Fibrillation Bleeding schema'), data interpretation, drafting of manuscript, revisions.

\section{REFERENCES}

1. Wolf PA, Abbott RD, Kannel WB. Atrial fibrillation as an independent risk factor for stroke: the Framingham Study. Stroke 1991; 22:983-988

2. Risk factors for stroke and efficacy of antithrombotic therapy in atrial fibrillation. Analysis of pooled data from five randomized controlled trials. Arch Intern Med 1994; 154:1449-1457 
3. Hart RG, Pearce LA, Aguilar MI. Meta-analysis: antithrombotic therapy to prevent stroke in patients who have nonvalvular atrial fibrillation. Ann Intern Med 2007; 146:857-867

4. Fuster V, Ryden LE, Cannom DS, Crijns HJ, Curtis AB, Ellenbogen KA, Halperin JL, Le Heuzey JY, Kay GN, Lowe JE, Olsson SB, Prystowsky EN, Tamargo JL, Wann S, Smith SC, Jr., Jacobs AK, Adams CD, Anderson JL, Antman EM, Hunt SA, Nishimura R, Ornato JP, Page RL, Riegel B, Priori SG, Blanc JJ, Budaj A, Camm AJ, Dean V, Deckers JW, Despres C, Dickstein K, Lekakis J, McGregor K, Metra M, Morais J, Osterspey A, Zamorano JL. ACC/AHA/ESC 2006 guidelines for the management of patients with atrial fibrillation--executive summary: a report of the American College of Cardiology/American Heart Association Task Force on Practice Guidelines and the European Society of Cardiology Committee for Practice Guidelines (Writing Committee to Revise the 2001 Guidelines for the Management of Patients With Atrial Fibrillation). J Am Coll Cardiol 2006; 48:854-906

5. Nieuwlaat R, Capucci A, Camm AJ, Olsson SB, Andresen D, Davies DW, Cobbe S, Breithardt G, Le Heuzey JY, Prins MH, Levy S, Crijns HJ. Atrial fibrillation management: a prospective survey in ESC member countries: the Euro Heart Survey on Atrial Fibrillation. Eur Heart J 2005; 26:2422-2434

6. Heeringa J, van der Kuip DA, Hofman A, Kors JA, van Herpen G, Stricker BH, Stijnen T, Lip GY, Witteman JC. Prevalence, incidence and lifetime risk of atrial fibrillation: the Rotterdam study. Eur Heart J 2006; 27:949-953

7. Miyasaka Y, Barnes ME, Gersh BJ, Cha SS, Bailey KR, Abhayaratna WP, Seward JB, Tsang TS. Secular trends in incidence of atrial fibrillation in Olmsted County, Minnesota, 1980 to 2000, and implications on the projections for future prevalence. Circulation 2006; 114:119-125

8. Gage BF, Waterman AD, Shannon W, Boechler M, Rich MW, Radford MJ. Validation of clinical classification schemes for predicting stroke: results from the National Registry of Atrial Fibrillation. Jama 2001; 285:2864-2870

9. Nieuwlaat R, Capucci A, Lip GY, Olsson SB, Prins MH, Nieman FH, Lopez-Sendon J, Vardas PE, Aliot E, Santini $M$, Crijns HJ. Antithrombotic treatment in real-life atrial fibrillation patients: a report from the Euro Heart Survey on Atrial Fibrillation. Eur Heart J 2006; 27:3018-3026

10. Waldo AL, Becker RC, Tapson VF, Colgan KJ. Hospitalized patients with atrial fibrillation and a high risk of stroke are not being provided with adequate anticoagulation. J Am Coll Cardiol 2005; 46:1729-1736

11. Palareti G, Cosmi B. Bleeding with anticoagulation therapy - who is at risk, and how best to identify such patients. Thromb Haemost 2009; 102:268-278

12. National Collaborating Centre for Chronic Conditions. Atrial fibrillation: national clinical guideline for management in primary and secondary care. London: Royal College of Physicians.

13. Hughes M, Lip GY. Risk factors for anticoagulation-related bleeding complications in patients with atrial fibrillation: a systematic review. QJM 2007; 100:599-607

14. Beyth RJ, Quinn LM, Landefeld CS. Prospective evaluation of an index for predicting the risk of major bleeding in outpatients treated with warfarin. Am J Med 1998; 105:91-99

15. Kuijer PM, Hutten BA, Prins MH, Buller HR. Prediction of the risk of bleeding during anticoagulant treatment for venous thromboembolism. Arch Intern Med 1999; 159:457-460

16. Shireman TI, Howard PA, Kresowik TF, Ellerbeck EF. Combined anticoagulant- antiplatelet use and major bleeding events in elderly atrial fibrillation patients. Stroke 2004; 35:2362-2367

17. Gage BF, Yan Y, Milligan PE, Waterman AD, Culverhouse R, Rich MW, Radford MJ. Clinical classification schemes for predicting hemorrhage: results from the National Registry of Atrial Fibrillation (NRAF). Am Heart J 2006; 151:713-719

18. Nieuwlaat R, Prins MH, Le Heuzey JY, Vardas PE, Aliot E, Santini M, Cobbe SM, Widdershoven JW, Baur LH, Levy S, Crijns HJ. Prognosis, disease progression, and treatment of atrial fibrillation patients during 1 year: follow-up of the Euro Heart Survey on atrial fibrillation. Eur Heart J 2008; 29:11811189

19. Tay KH, Lane DA, Lip GY. Bleeding risks with combination of oral anticoagulation plus antiplatelet therapy: is clopidogrel any safer than aspirin when combined with warfarin? Thromb Haemost 2008; 100:955-957 
20. Lip GY, Huber K, Andreotti F, Arnesen H, Airaksinen KJ, Cuisset T, Kirchhof P, Marin F. Management of antithrombotic therapy in atrial fibrillation patients presenting with acute coronary syndrome and/or undergoing percutaneous coronary intervention/ stenting. Thromb Haemost; 2010; 103:1328

21. Lip GY, Zarifis J, Watson RD, Beevers DG. Physician variation in the management of patients with atrial fibrillation. Heart 1996; 75:200-205

22. Connolly SJ, Pogue J, Hart RG, Hohnloser SH, Pfeffer M, Chrolavicius S, Yusuf S. Effect of clopidogrel added to aspirin in patients with atrial fibrillation. N Engl J Med 2009; 360:2066-2078

23. Connolly SJ, Ezekowitz MD, Yusuf S, Eikelboom J, Oldgren J, Parekh A, Pogue J, Reilly PA, Themeles E, Varrone J, Wang S, Alings M, Xavier D, Zhu J, Diaz R, Lewis BS, Darius H, Diener HC, Joyner CD, Wallentin L; RE-LY Steering Committee and Investigators. Dabigatran versus warfarin in patients with atrial fibrillation. N Engl J Med 2009;361:1139-51

24. Fihn SD, Callahan CM, Martin DC, McDonell MB, Henikoff JG, White RH. The risk for and severity of bleeding complications in elderly patients treated with warfarin. The National Consortium of Anticoagulation Clinics. Ann Intern Med 1996; 124:970- 979

25. Holmes DR, Reddy VY, Turi ZG, Doshi SK, Sievert H, Buchbinder M, Mullin CM, Sick P. Percutaneous closure of the left atrial appendage versus warfarin therapy for prevention of stroke in patients with atrial fibrillation: a randomised non-inferiority trial. Lancet 2009; 374:534-542

26. Homoncik M, Gessl A, Ferlitsch A, Jilma B, Vierhapper H. Altered platelet plug formation in hyperthyroidism and hypothyroidism. J Clin Endocrinol Metab. 2007;92(8):3006-12.

27. Fang MC, Chang Y, Hylek EM, Rosand J, Greenberg SM, Go AS, Singer DE. Advanced age, anticoagulation intensity, and risk for intracranial hemorrhage among patients taking warfarin for atrial fibrillation. Ann Intern Med. 2004;141(10):745-52.

28. Van Walraven C, Hart RG, Connolly S, Austin PC, Mant J, Hobbs FD, Koudstaal PJ, Petersen P, PerezGomez F, Knottnerus JA, Boode B, Ezekowitz MD, Singer DE.

29. Effect of age on stroke prevention therapy in patients with atrial fibrillation: the atrial fibrillation investigators. Stroke 2009;40:1410-6

30. Mant J, Hobbs FDR, Fletcher K, Roalfe A, Fitzmaurice D, Lip GY, Murray E; BAFTA investigators; Midland Research Practices Network (MidReC). Warfarin versus aspirin for stroke prevention in an elderly community population with atrial fibrillation (the Birminigham Atrial Fibrillation Treatment of the Aged Study, BAFTA): a randomized controlled trial. Lancet 2007;370:493-503

31. Arboix A, Vall-Llosera A, Garcia-Eroles L, Massons J, Oliveres M, Targa C. Clinical features and functional outcome of intracerebral hemorrhage in patients aged 85 and older. J Am Geriatr Soc 2002;50:449-54. 


\title{
Balancing the Risk of Hemorrhage vs Thromboembolism in Patients With Atrial Fibrillation : How To Navigate Between Scylla and Charybdis?
}

\author{
Giuseppe Boriani, Igor Diemberger, Mauro Biffi and Cristian Martignani \\ Chest 2010;138;1032-1033 DOI 10.1378/chest.10-0808
}

According to mythology, Scylla and Charybdis were two sea monsters placed on opposite sides of the Strait of Messina, between Calabria and Sicily in Italy. Sailors' navigation was extremely difficult since these monsters were very close to each other and attempts to avoid Scylla implied passing very closely to Charybdis and vice versa. This imaginary scenario well depicts the difficulties that a practicing physician may encounter when deciding on the intriguing trade-off between benefits and risks of antithrombotic prophylaxis in the challenging and complex setting of "realworld" patients affected by nonvalvular atrial fibrillation (AF). ${ }^{1}$

In this issue of CHEST (see page 1093), Pisters et al. ${ }^{2}$ report on the development of a novel, easy, and practical risk score to estimate the 1-year risk for major bleeding, which uses the acronym HAS-BLED (Hyper- tension, Abnormal renal/liver function, Stroke, Bleeding history or predisposition, Labile international normalized ratio, Elderly (>65 years), Drugs/alcohol concomitantly). The authors tested this score (also called the Birmingham AF Bleeding Risk Schema) on a cohort of 3,678 real-world patients enrolled in the Euro Heart Survey on AF. At discharge, around $65 \%$ of patients were on oral anticoagulation (OAC) treatment ( $13 \%$ of them also taking aspirin and/or clopidogrel), $24 \%$ on antiplatelet therapy alone, and $10 \%$ without any antithrombotic therapy, with unadjusted bleeding rates of $1.75 \%$, $0.97 \%$, and $1.42 \%$ per year, respectively.

This study is particularly interesting because the risk of bleeding was assessed on real-world patients with AF included in a registry, thus in a much-less- selected population than that represented in randomized clinical trials on OACs, where, quite often, up to one-third of patients with AF were not enrolled, mainly because they were judged to be at high risk of bleeding. ${ }^{3}$ During treatment with OACs, the absolute risk of major bleeding complications for patients followed by specialized anticoagulation services ranges from $0.32 \%$ to $2.1 \%$ per year, with a risk of fatal bleeding ranging from $0 \%$ to $0.25 \%$ per year, and this implies that the risk of major bleeding and the risk of intracranial hemorrhage are increased by $0.3 \%$ to $0.5 \%$ per year and by $0.2 \%$ per year, respectively, in comparison with controls. ${ }^{3,4}$

However, these data cannot necessarily be extrapolated to real-world clinical practice, where patients' care may be less accurate and rigorous. $4 \mathrm{~A}$ series of bleeding-risk stratification schemes have been previously developed and proposed to estimate the risk of major bleeding during OAC treatment, ${ }^{3,4}$ but most of them were not necessarily specific for patients with $A F$, were derived from historic cohorts without subsequent prospective validation, and did not appear to be user friend- 
ly.2-4 The study by Pisters et al 2 indicates that a very simple risk score, HAS-BLED, is able to predict the bleeding risk with consistent accuracy, performing better than the more complicated HEMOR2RAGES (Hepatic or renal disease, Ethanol abuse, Malignancy, Older age [ $<75$ years], Rebleeding, Reduced platelet count or function, Hypertension [uncontrolled], Anemia, Genetic factors, Excessive fall risk, and Stroke) scheme (which also requires genetic assessment4) when tested in the overall population and in all the subgroups of patients, apart from those receiving both OAC and antiplatelet treatments. ${ }^{2}$

While the HAS-BLED score is a very simple and useful tool to be applied in daily practice, the article also stimulates questions about how to further improve our prediction of the risk of bleeding. In our view, and according to what the authors reported, assessment of the bleeding risk in the elderly will merit further evaluation. Indeed, the use of antithrombotic treatments in the elderly is quite problematic but relevant given the increasing prevalence of $A F$ with age. ${ }^{1}$ However, biologic age is perhaps more relevant than chronologic age. For example, a frail 60-year-old patient with multiple comorbidities and polypharmacy would be at greater bleeding risk than a fit, healthy 90 -year-old subject with no previous illnesses who still goes ballroom dancing.

The risk of bleeding, and specifically the risk of intracranial hemorrhage, is particularly increased in the elderly. ${ }^{3-6}$ Whereas the prevalence of bleeding is reported to be $0.2 \%$ to $1.0 \%$ patient-years over- all among patients who are anticoagulated, this rate increases to $1.1 \%$ patient-years in patients aged $\geq 75$ years. ${ }^{3}$ Fang et al. ${ }^{5}$ reported an adjusted odds ratio of 2.5 for intracranial hemorrhage in patients aged $\geq 85$ vs. a reference group of patients aged 70 to 74 years. However, the risk of major bleeding is not limited to use of OACs, since the occurrence of major hemorrhage may be similar with both warfarin or aspirin use. ${ }^{7}$ The relatively small numbers of bleeding events and the limited number of very elderly patients in the study by Pisters et al. $^{2}$ suggest the need for collecting long-term data on larger populations of elderly patients with AF to assess how much the bleeding risk is increased at ages $>65$ years, thus providing further tools for improving decision making in the elderly. Perhaps a future refinement of HAS-BLED would address this.

A decision-making process based on balancing the individual risk of bleeding and the risk of stroke is difficult, and the risk factors for bleeding and stroke largely overlap. For example, a history of previous stroke is one of the determinants of the HAS-BLED risk score. The impact of bleeding in decision making is considerable because physicians are less likely to prescribe OACs to any patient after observing a case of major bleeding during treatment with these agents, but the same powerful influence does not appear to exist in the case of a thromboembolic stroke occurring in a patient without OAC prescription. ${ }^{8}$ Therefore, any method for predicting the risk of bleeding in an individual patient may be of special value. ${ }^{3}$ 
Now, how do we make decisions in balancing the risks of hemorrhage and thromboembolism? Stroke risk assessment is well served by many studies into stroke risk factors and the value of stroke risk stratification schema. Indeed, the same investigators recently proposed the CHA2DS2-VASc (Congestive heart failure, Hypertension, Age $\geq 75$ years, Diabetes mellitus, prior Stroke or transient ischemic attack, Vascular disease, Age 65-74 years, and Sex category [female]) score ${ }^{9}$ to improve identification of "truly low-risk" patients and to incorporate risk factors not included in the commonly used CHADS (Congestive heart failure, Stroke or transient ischemic attack) risk score. In our view, the availability of such simple stroke and bleedingrisk assessments is the basis for helping to improve "personalized care," but perhaps should also take into account the balance between risks and benefits of all the available treatments, the patient's context and comorbidities, the patient's cognitive state and likelihood of compliance to therapy, as well as the patient's values and preferences, where the problematic trade-off of stroke vs. hemorrhagic risk may not coincide with the physician's priorities. ${ }^{10}$ Thus, a dialogue between the patient, the patient's relatives, and a physician well aware of the complexity of this problem and of the potential options appears to be mandatory for appropriately directing the helm between Scylla and Charybdis.

Giuseppe Boriani, MD, PhD Igor Diemberger, MD, PhD Mauro Biffi, MD Cristian Martignani, MD, PhD Bologna, Italy

Affiliations: From the Institute of Cardiology, University of Bologna, Azienda Ospedaliera S. Orsola-Malpighi. Financial/nonfinancial disclosures: The authors have reported to CHEST that no potential conflicts of interest exist with any companies/organizations whose products or services may be dis-cussed in this article.

\section{REFERENCES}

1. Boriani G, Diemberger I, Martignani C, Biffi M, Branzi A. The epidemiological burden of atrial fibrillation: a challenge for clinicians and health care systems. Eur Heart J. 2006;27(8): 893-894.

2. Pisters R, Lane DA, Nieuwlaat R, et al. A novel user-friendly score (HAS-BLED) to assess 1-year risk of major bleeding in patients with atrial fibrillation: The Euro Heart Survey. Chest. 2010;138(5):10931100.

3. PalaretiG, CosmiB. Bleeding with anticoagulation therapy- who is at risk, and how best to identify such patients. Thromb Haemost. 2009;102(2):268-278.

4. Schulman S, Beyth RJ, Kearon C, Levine MN; American College of Chest Physicians. Hemorrhagic complications of anticoagulant and thrombolytic treatment: American College of Chest Physicians Evidence-Based Clinical Practice Guide- lines (8th Edition). Chest. 2008;133(6 Suppl):257S-298S.

5. Fang MC, Chang Y, Hylek EM, et al. Advanced age, anticoagulation intensity, and risk for intracranial hemorrhage among patients taking warfarin for atrial fibrillation. Ann Intern Med. 2004;141(10):745-752. 
6. DiMarco JP, Flaker G, Waldo AL, et al; AFFIRM Investigators. Factors affecting bleeding risk during anticoagulant therapy in patients with atrial fibrillation: observations from the Atrial Fibrillation Follow-up Investigation of Rhythm Management (AFFIRM) study. Am Heart J. 2005;149(4):650-656.

7. Mant J, Hobbs FD, Fletcher $\mathrm{K}$, et al; BAFTA investigators; Midland Research Practices Network (MidReC). Warfarin versus aspirin for stroke prevention in an elderly community population with atrial fibrillation (the Birmingham Atrial Fibrillation Treatment of the Aged Study, BAFTA): a randomised controlled trial. Lancet. 2007;370(9586):493-503.

8. Choudhry NK, Anderson GM, Laupacis A, Ross-Degnan D, Normand SL, Soumerai SB. Impact of adverse events on pre- scribing warfarin in patients with atrial fibrillation: matched pair analysis. BMJ. 2006;332(7534):141-145.

9. Lip GY,Nieuwlaat R,Pisters R,Lane DA,Crijns HJ.Refining clinical risk stratification for predicting stroke and thrombo- embolism in atrial fibrillation using a novel risk factor-based approach: the Euro Heart Survey on atrial fibrillation. Chest. 2010;137(2):263-272.

10. Devereaux PJ, Anderson DR, Gardner MJ, et al. Differences between perspectives of physicians and patients on anticoagulation in patients with atrial fibrillation: observational study. BMJ. 2001;323(7323):1218-1222. 


\section{Assessing the Performance of the HAS-BLED Score Is the C Statistic Sufficient?}

\section{To the Editor:}

I read with interest the article by Pisters et al. ${ }^{1}$ in CHEST (November 2010) that addresses the problem of major bleeding in patients with atrial fibrillation during treatment with oral anticoagulant drugs. The authors suggest a new user-friendly score in order to assess the risk of major bleeding and, possibly, to sup-port clinical decision making about antithrombotic therapy in patients with atrial fibrillation. They evaluated the predictive accuracy of the model by using the $\mathrm{C}$ statistic. Although the $C$ statistic should offer a simple and intuitive measure of the accuracy of predictions using a single test, several readers might not be so familiar with it. Conventionally, the evaluation of a new scoring system is performed using calibration, discrimination and, to a lesser extent, classification measures (mainly sensitivity and specificity), and likelihood ratios. ${ }^{2-4}$

The calibration is generally assessed with the Hosmer-Lemeshow goodness-offit test, ${ }^{5}$ which is a summary measure of the model's ability to predict outcome for groups of patients having different levels of risk. Patients are rank-ordered according to outcome probability; they then are divided into deciles of risk. Expected and observed outcomes are compared within each decile of risk. The results of comparisons for each cell of the contingency table are summed, and that result is compared with the $x 2$ distribution: $P$ values larger than .05 demonstrate adequate model calibration across the entire range of risks.

On the other hand, discrimination is commonly evaluated using the area under the receiver operating characteristic curve. ${ }^{2-4}$ The area under the receiver operating characteristic curve summarizes in a single number the overall discrimination across the range of risks, independently of disease prevalence and without loss of information due to the choice of a particular decision criterion, as happens for classification measures. ${ }^{2,3}$ The area can range from 0.5 to $1.0 ; 0.7$ is considered the minimal value acceptable in the validation of a model. Finally, although the role of classification measures in the assessment of the performance of scoring systems has been questioned, ${ }^{2,3}$ most readers are familiar with these measures, particularly with sensitivity and specificity. In my opinion, such an interesting article could have benefited if the authors had reported in a table at least some of the above- mentioned timehonored statistics, making easier the interpretation of the performance results of the model, as well as its comparison with other scoring systems.

Ulisse Corbanese, MD Conegliano, Italy 
Affiliations: From the Department of Anesthesia and Intensive Care, Ospedale S. Maria dei Battuti. Financial/nonfinancial disclosures: The author has reported to CHEST that no potential conflicts of interest exist with any companies/organizations whose products or services may be dis- cussed in this article.

DOI: 10.1378/chest.10-2995

\section{REFERENCES}

41. Pisters R, Lane DA, Nieuwlaat R, de Vos CB, Crijns HJGM, Lip GYH. A novel user-friendly score (HAS$B L E D)$ to assess 1-year risk of major bleeding in patients with atrial fibrilla- tion: the Euro Heart Survey. Chest. 2010;138(5):1093-1100.

42. Lemeshow S, Le Gall JR. Modeling the severity of illness of ICU patients. A systems update. JAMA. 1994;272(13): 1049-1055.

43. Lett RR, Hanley JA, Smith JS. The comparison of injury severity instrument performance using likelihood ratio and ROC curve analyses. J Trauma. 1995;38(1):142-148.

44. Sackett DL, Haynes RB, Tugwell P. Clinical Epidemiology: A Basic Science for Clinical Medicine. 1st ed. Boston, MA: Little, Brown \& Co; 1985:59-138.

45. Hosmer DW, Lemeshow S. Applied Logistic Regression. New York, NY: John Wiley \& Sons Inc; 1989.

\section{RESPONSE}

To the Editor:

Dr Corbanese raises the question as to whether the $C$ statistic suffices as a comprehensible measure of predictive accuracy of our novel bleeding risk model, HAS-BLED (hypertension, abnormal renal/liver function, stroke, bleeding history or predisposition, labile international normalized ratio, elderly [>65 years], drugs/alcohol concomitantly). We acknowledge that the $C$ statistic has its shortcomings, although it is used widely in many validation studies of risk-scoring systems. In addition, the moderate size of the Euro Heart Survey study population ${ }^{1}$ was reason not to apply the complex statistics proposed by $\mathrm{Dr}$ Corbanese in our analysis.

However, in a recent second validation of HAS-BLED, Lip et al. $^{2}$ tested the different statistical methods on the available bleeding risk models in a much larger clinical trial cohort (>7,000 patients). In this study, univariate Cox regression was used to estimate the hazard ratios and $95 \% \mathrm{Cls}$ for individual risk factors, with major bleeding as the dependent variable. All potential risk factors investigated in the univariate analyses were included in the multivariate Cox regression analyses; only those variables with $P$ values that remained significant at the $5 \%$ level in the presence of other selected variables were retained in the final model. Then, $\mathrm{C}$ statistics 
were estimated to quantify the predictive accuracy of the risk schemes, with $95 \%$ Cls obtained by bootstrapping analyses.

The Hosmer-Lemeshow test for calibration was also performed by Lip et al. ${ }^{2}$ in conjunction with all $C$ statistics, and none of the $P$ values was $>.05$ for any of the risk scores (i.e., lack of goodness of fit was not indicated). For HAS-BLED in particular, the $P$ values were .24 for all patients and .13 for the warfarin patient cohort. Furthermore, using multivariate Cox regression models, Lip et al. ${ }^{2}$ tested whether the HAS-BLED score added significantly to models already incorporating the four older scores, one at a time. In all four instances, HAS-BLED was associated with predictive improvement when inserted into models already incorporating the older scores. In contrast, none of the other four older scores added significantly when inserted one at a time into a model already including HAS-BLED. Thus, we hope we have clarified the interpretation of the predictive accuracy of the HAS-BLED model, as well as its comparison with the other bleeding risk models, in the second validation study, which had a much larger sample size and used other statistical methods beyond the C statistic, ${ }^{2}$ as suggested by Dr Corbanese.

Ron Pisters, MD Maastricht, The Netherlands Deirdre A. Lane, PhD Birmingham, England Robby Nieuwlaat, PhD Harry J. G. M. Crijns, MD Maastricht, The Netherlands Gregory Y. H. Lip, MD Birmingham, England

Affiliations: From the University of Birmingham Centre for Cardiovascular Sciences (Drs Pisters, Lane, and Lip), City Hospital: and the Department of Cardiology, Maastricht University Medical Centre (Drs Nieuwlaat and Crijns).

Financial/nonfinancial disclosures: The authors have reported to CHEST the following conflicts of interest: Dr Pisters has consulting fees from Bayer and Boehringer Ingelheim and lecture fees from Boehringer Ingelheim. Dr Lane is the recip- ient of an investigator-initiated educational grant from Bayer Healthcare and has received sponsorship to attend the European Society of Cardiology Congress 2009 from AstraZeneca. Dr Crijn has received consulting fees from Boehringer Ingelheim, SanofiAventis, and AstraZeneca; grant support from St. Jude Medical, Boston Scientific, Boehringer Ingelheim, Sanofi-Aventis, Medapharma, and Merck; and honoraria from Medtronic, Sanofi-Aventis, Medapharma, Merck, Boehringer Ingelheim, and Biosense Webster. Dr Lip has served as a consultant for Bayer, Astellas, Merck, AstraZeneca, Sanofi-Aventis, Aryx, Portola, Biotronic, and Boehringher Ingelheim, and has been on the speakers bureau for Bayer, Boehringher Ingelheim, and SanofiAventis. Dr Nieuwlaat has reported that no potential conflicts of interest exist with any companies/organizations whose products or services may be discussed in this article.

DOI: 10.1378/chest.11-0184 


\section{REFERENCES}

1. Pisters R, Lane DA, Nieuwlaat R, de Vos CB, Crijns HJGM, Lip GYH. A novel user-friendly score (HAS$B L E D)$ to assess 1-year risk of major bleeding in patients with atrial fibrilla- tion: the Euro Heart Survey. Chest. 2010;138(5):1093-1100.

2. Lip GY, Frison L, Halperin JL, Lane DA. Comparative vali- dation of a novel risk score for predicting bleeding risk in anticoagulated patients with atrial fibrillation: the HAS-BLED (hypertension, abnormal renal/liver function, stroke, bleeding history or predisposition, labile INR, elderly, drugs/alcohol concomitantly) score. J Am Coll Cardiol. 2011;57(2):173-180 


\section{The HAS-BLED Score and Renal Failure}

To the Editor:

In a recent issue of CHEST (November 2010), Pisters et al. ${ }^{1}$ published an interesting work that establishes a score to assess 1-year risk of major bleeding in patients with atrial fibrillation. In this article, kidney failure (defined as the presence of chronic dialysis or renal transplantation or serum creatinine $\geq 200 \mathrm{mmol} / \mathrm{L}$ ) is identified as a risk factor for major bleeding. The "Discussion" section of the article stated that in the vast majority of patients with atrial fibrillation who require oral anticoagulation (CHADS $_{2}$ [congestive heart failure, hypertension, age .75 years, diabetes mellitus, previous stroke/transient ischemic attack (doubled)] index $\geq 2$ ), the risk of bleeding outweighs the potential benefits of oral anticoagulation if the HAS-BLED (hypertension, abnormal renal/liver function, stroke, bleeding history or predisposition, labile international normalized ratio, elderly [ $>65$ years], drugs/alcohol concomitantly) score exceeds the individual $\mathrm{CHADS}_{2}$ index. As such, a 75-year-old man with hypertension and renal failure would have a $\mathrm{CHADS}_{2}$ index of 2 and HAS-BLED score of 3 , and the oral anticoagulant treatment should be discouraged. We believe that this recommendation does not take into account the impact of renal failure on thromboembolism risk in patients with atrial fibrillation. In all trials in which the benefit of oral anticoagulant in the prevention of thromboembolism in atrial fibrillation was established, the patients with end-stage renal failure were excluded, and in the European Heart Survey on atrial fibrillation, renal failure was not evaluated as a risk factor for thromboembolism. ${ }^{2}$ However, in the ATRIA (Anticoagulation and Risk Factors in Atrial Fibrillation) study, chronic kidney disease increased the risk of thromboembolism in atrial fibrillation independently of other risk factors ${ }^{3}$; in addition to this, studies carried out in our institution show that the patients with endstage renal disease and atrial fibrillation have a very high rate of thromboembolism. ${ }^{4,5}$ We believe that this excellent risk score should have considered that although renal failure can increase the bleeding risk, it can also increase the risk of thromboembolism.

Eduardo Vázquez, MD Carmen Sánchez-Perales, MD Jaén, Spain

Affiliations: From the Departments of Cardiology (Dr Vázquez) and Nephrology (Dr Sánchez-Perales), Complejo Hospitalario de Jaén. Financial/nonfinancial disclosures: The authors have reported to CHEST that no potential conflicts of interest exist with any companies/organizations whose products or services may be discussed in this article.

DOI: 10.1378/chest.10-2961 


\section{REFERENCES}

46. Pisters R, Lane DA, Nieuwlaat R, de Vos CB, Crijns HJGM, Lip GYH. A novel user-friendly score (HAS$B L E D)$ to assess 1-year risk of major bleeding in patients with atrial fibrilla- tion: the Euro Heart Survey. Chest. 2010;138(5):1093-1100.

47. Lip GYH, Nieuwlaat R, Pisters R, Lane DA, Crijns HJGM. Refining clinical risk stratification for predicting stroke and thromboembolism in atrial fibrillation using a novel risk factor-based approach: the Euro Heart Survey on atrial fibril- lation. Chest. 2010;137(2):263-272.

48. Go AS, Fang MC, Udaltsova N, et al; for the ATRIA Study Investigators. Impact of proteinuria and glomerular filtration rate on risk of thromboembolism in atrial fibrillation: the Anticoagulation and Risk Factors in Atrial Fibrillation (ATRIA) study. Circulation. 2009;119(10):1363-1369.

49. Vazquez E, Sanchez-Perales C, Garcia-Garcia F, et al. Atrial fibrillation in incident dialysis patients. Kidney Int. 2009; 76(3):324-330.

50. Sánchez-Perales C, Vázquez E, García-Cortés MJ, et al. Ischaemic stroke in incident dialysis patients. Nephrol Dial Transplant. 2010;25(10):3343-3348.

\section{RESPONSE}

To the Editor:

We thank Vázquez and Sánchez-Perales for their interest into our recent article in CHEST (November 2010). ${ }^{1}$ First, we emphasize our mutual agreement on the importance of chronic kidney failure (defined as the presence of chronic dialysis or renal transplantation or serum creatinine $\geq 200 \mathrm{mmol} / \mathrm{L}$ ) as a thromboembolic risk factor, as was highlighted in the article by Go et al. ${ }^{2}$ on the importance of decreased glomerular filtration rate and proteinuria as risk factors for stroke.

However, patients with chronic kidney failure represent a difficult treatment problem. Not only are these patients at high risk of thromboembolism, but they are also at high risk of bleeding, myocardial infarction, vascular events, and all-cause mortality. ${ }^{3}$ That the Euro Heart Survey on atrial fibrillation (AF) did high- light the absence of definitive evidence on chronic kidney failure or proteinuria is a limitation, as we did not have information on proteinuria in our survey. Nonetheless, patients with severe chronic kidney failure have not been adequately studied in clinical trials of stroke prevention in AF, and our proposal of using the HAS-BLED (Hypertension, Abnormal renal/liver function, Stroke, Bleeding history or predisposition, Labile international normalized ratio, Elderly (> 65 years), Drugs/alcohol concomitantly) score was meant to provide a simple, user-friendly score for use in everyday clinical practice that would be applicable for the majority of patients with AF. Indeed, one could informally apply an unwritten rule for guideline writing, where any recommendations would need to be applicable for $>80 \%$ of the time, in $>80 \%$ of the patient population. Vasquez and Sánchez-Perales challenge our statement in the discussion where we discourage the use of oral anticoagulation if the HAS-BLED 
score outweighs the $\mathrm{CHADS}_{2}$ (congestive heart failure, hypertension, age $\geq 75$ years, diabetes mellitus, previous stroke/transient ischemic attack [doubled]) score. ${ }^{1}$ Balancing the risk of stroke and bleeding solely based on this simplistic subtraction is tricky and fails to take into account significant (and important) differences in morbidity, mortality, and associated costs within the different types of major bleeding and compared with AF-related ischemic strokes. Indeed, a high HAS-BLED score is indicative of the need for caution and/or regular review of patients following the initiation of antithrombotic therapy, rather than the complete nonuse of oral anticoagulation. ${ }^{4}$ Despite the awareness of the above-mentioned shortcomings of our proposed "rule," we strongly believe its use is justified. Compared with a scenario where no practical guidance on balancing stroke and bleeding risks in patients with $\mathrm{AF}$ is available, large numbers of patients are automatically deemed unsuitable for oral anticoagulation. Given that poor guideline adherence has a significant impact on adverse outcomes, undertreatment can be reduced by applying decision rules, at the cost of a few cases where oral anticoagulation may be withheld. ${ }^{1}$ With regard to the scenario illustrated by Vázquez and Sánchez- Perales of a 75-year-old man with renal failure and hypertension, a history of hypertension is less of a risk compared with uncontrolled hypertension, in relation to bleeding. ${ }^{1}$ With the age of 75 and the presence of renal failure scoring, the patient's HAS-BLED score is 2. As his $\mathrm{CHADS}_{2}$ score is also 2, application of our rule in this specific case would actually favor the use of oral anticoagulation. Even if a particular patient has a HAS-BLED score of $>3$, this is an "alarm bell" for caution and a signal that correctable bleeding risk factors should be treated (e.g., cessation of concomitant aspirin use with oral anticoagulation, control of blood pressure, labile international normalized ratios, etc.) to lower the HAS-BLED score. ${ }^{4}$

Ron Pisters, MD Robby Nieuwlaat, PhD Maastricht, The Netherlands Deirdre A. Lane, PhD Birmingham, England Harry J. G. M. Crijns, MD Maastricht, The Netherlands Gregory Y. H. Lip, MD Birmingham, England

Affiliations: From the Department of Cardiology, Maastricht University Medical Centre (Drs Pisters, Nieuwlaat, and Crijns); and the University of Birmingham Centre for Cardiovascular Sci- ences, City Hospital (Drs Lane and Lip). Financial/nonfinancial disclosures: The authors have reported to CHEST the following conflicts of interest: Dr Pisters is on the American College of Chest Physicians guidelines panel on antithrombotic therapy. He was also a speaker at the Global Thrombosis Forum for the Thrombosis Research Institute. Dr Lip has served as a consultant for Bayer, Astellas, Merck, AstraZeneca, Sanofi, ARYx Therapeutics, Portola, Biotronic, and Boehringher, and has been on speaker bureaus for Bayer, Boehringher, and Sanofi. Dr Lane received an investigator-initiated educational grant from Bayer Healthcare. She also received a sponsorship to attend the ESC 2009 from Astra- 
Zeneca. Drs Nieuwlaat and Crijns have reported that no potential conflicts of interest exist with any companies/organizations whose products or services may be discussed in this article.

DOI: $10.1378 /$ chest.10-3237

\section{REFERENCES}

1. Pisters R, Lane DA, Nieuwlaat R, de Vos CB, Crijns HJGM, Lip GY. A novel user-friendly score (HAS$B L E D)$ to assess 1-year risk of major bleeding in patients with atrial fibrilla- tion: the Euro Heart Survey. Chest. 2010;138(5):1093-1100.

2. Go AS, Fang MC, Udaltsova N, et al; ATRIA Study Investigators. Impact of proteinuria and glomerular filtration rate on risk of thromboembolism in atrial fibrillation: the anticoagulation and risk factors in atrial fibrillation (ATRIA) study. Circulation. 2009;119(10):1363-1369.

3. Lip GYH. Chronic renal disease and stroke in atrial fibrillation: balancing the prevention of thromboembolism and bleeding risk. Europace. 2011;13(2):145-148.

4. Camm AJ, Kirchhof P, Lip GY, et al. European Heart Rhythm Association; European Association for Cardio-Thoracic Surgery; ESC Committee for Practice Guidelines. Guidelines for the management of atrial fibrillation: the Task Force for the Management of Atrial Fibrillation of the European Society of Cardiology (ESC). Europace. 2010;12(10):1360-1420. 

Section III

Clinical Anti-Thrombotic Management 



\section{Chapter 4}

\section{The Likelihood of Decreasing Strokes in Atrial Fibrillation Patients by Strict Application of Guidelines}

Ron Pisters ${ }^{1,2^{*}}$, Robert J. van Oostenbrugge ${ }^{2,3}$, Iris L.H. Knottnerus ${ }^{3}$, Cees B. de Vos ${ }^{1,2}$, Anita Boreas ${ }^{2,3}$, Jan Lodder ${ }^{2,3}$, Martin H. Prins ${ }^{4}$, Harry J.G.M. Crijns ${ }^{1,2}$, and Robert G. Tieleman $^{2,5}$

${ }^{1}$ Department of Cardiology, Maastricht University Medical Centre, ${ }^{2}$ Cardiovascular Research Institute Maastricht, Maastricht, Netherlands; ${ }^{3}$ Department of Neurology, Maastricht University Medical Centre, Maastricht, Netherlands; ${ }^{4}$ Department of Clinical Epidemiology, Maastricht University Medical Centre, Maastricht, Netherlands; and ${ }^{5}$ Department of Cardiology, Martini Hospital Groningen, Groningen, Netherlands

Europace 2010 Jun;12(6):779-84 


\section{ABSTRACT}

Aims: Despite the known increased stroke risk associated with $\mathrm{AF}$ and the benefit of oral anticoagulation (OAC) in high-risk patients, still $20 \%$ of all ischaemic strokes are atrial fibrillation (AF) related. We aimed to evaluate the frequency of inappropriate anticoagulation in all patients admitted with AF associated ischaemic stroke and calculate the theore- tical number of preventable strokes in case of proper guideline adherence and assess secondary stroke prevention at discharge.

Methods and results: In this cross-sectional study, all patients with ischaemic strokes admitted to our hospital during May 2003-August 2006 in whom the diagnosis AF was either known or established during hospital stay were identified. We studied if their admission and discharge antithrombotic therapy was in accordance with the published guidelines. Subsequently, we calculated the number of preventable strokes in case AF patients would have received adequate antithrombotic treatment on admission. On admission, in $51 \%$ of the OAC eligible known AF patients the drug was withheld. Improved antithrombotic guideline adherence potentially would have prevented 20 out of the 89 (22\%) ischaemic strokes. At discharge at least $10 \%$ of the patients were still insufficiently protected against recurrent stroke.

Conclusion: Many known AF patients admitted with ischaemic stroke lack adequate antithrombotic treatment on admission. Antithrombotic guideline adherence in these patients has the potential to prevent a substantial number strokes. Secondary stroke prevention at discharge is also suboptimal. 


\section{INTRODUCTION}

Atrial fibrillation (AF) is associated with an increased risk of ischaemic stroke and accounts for almost $20 \%$ of all ischaemic strokes. ${ }^{1}$ Stroke due to AF is often more severe and has a worse prognosis. ${ }^{2}$

The risk of AF related stroke can be lowered with adequate antithrombotic therapy (ATT). Stroke prevention with aspirin in AF patients with a low thromboembolic risk seems justified ${ }^{3}$, whereas in high-risk AF patients treatment with vita$\min \mathrm{K}$ antagonists is superior to placebo and aspirin. ${ }^{4,5}$ Despite over- whelming evidence antithrombotic guideline adherence in AF patients is suboptimal ${ }^{6,7}$ and treatment is not at all tailored to risk score ${ }^{8,9}$ resulting in undertreatment in primary and secondary stroke prevention, both quantitatively and qualitatively. ${ }^{10}$

However, mostly underuse of only oral anticoagulation (OAC) is considered in a numerical way without any indication of the associated clinical toll. Therefore, the aim of the present hospital based study among all admissions for AF related ischaemic strokes, is to assess primary and secondary quantitative antithrombotic under- treatment as a and estimate the possible decrease in numbers of strokes if antithrombotic guidelines are strictly applied.

\section{METHODS}

\section{Patients}

In this retrospective cross-sectional study, we included all consecutive patients admitted with a (first) CT or MRI proven ischaemic stroke to our hospital during the period May 2003-August 2006 in whom the diagnosis AF was either known or newly detected during hospital stay. Patients were identified using the Maastricht Stroke Registry: ${ }^{11}$ a registry of all consecutive stroke admissions.

We defined AF according the most recent guidelines as an episode of more than $30 \mathrm{~s}$ where consistent $\mathrm{P}$ waves are substituted by fibrillatory waves together with an irregular, often rapid ventricular response when atrioventricular conduction is in tact. ${ }^{3}$ Patients without an AF history prior to admission but an ECG with AF during

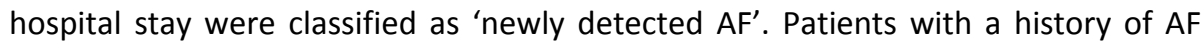
were considered 'known AF' patients. All ECG's retrieved from the hospitals electronic ECG database, were reviewed by two of us (R.P. and H.C.) to verify the diagnosis.

Using hospital chart review we retrieved medical history, admission and discharge medication. On the basis of medical history prior to the index stroke, the $\mathrm{CHADS}_{2}$ score was calculated. ${ }^{12}$ We use the phrase 'virtual CHADS2 score' to refer to 
patients exhibiting associated diseases without the diagnosis AF (prior to the index stroke).

The study was approved by the institutional review board at the University Maastricht Medical Centre.

Admission guideline adherence assessment As the period of observation stretched from 2003 to 2006 we used the ACC/AHA/ESC 2001 guidelines for the management of patients with AF to classify patients accordingly as high, medium, or low risk. ${ }^{13}$ Guideline adherent ATT consisted of OAC in patients with at least one high-risk factor or more than one inter- mediate risk factor and aspirin in low-risk patients. We defined undertreatment in case high-risk AF patients were not using $\mathrm{OAC}$ and whenever low-risk AF patients did not use aspirin.

We considered a documented history of malignancy or bleeding [gastrointestinal bleeding or intracranial haemorrhage $(\mathrm{ICH})]$, severe kidney or liver dysfunction (glomerular filtration rate , $30 \mathrm{~mL} / \mathrm{min}$, aspartate transaminase and alanine transaminase more than three times the upper limit, respectively), alcohol abuse or non-compliance (e.g. unwilling or dementia) to be contra- indications for OAC. In these cases any regimen (OAC, aspirin or no antithrombotic medication) was considered guideline adherent irrespective of stroke risk.

Discharge guideline adherence assessment Patients receiving OAC at discharge were considered to be treated according to the guidelines. In patients with either the above mentioned contraindications for the use of OAC, or a documented reason by the treating neurologist to withhold OAC (i.e. poor neurological outcome) any antithrombotic regimen was also considered guideline adherent. All other scenarios were classified as antithrombotic undertreatment.

\section{Calculation of the number of potential preventable ischaemic strokes}

Figure 1 displays the methods for calculating the theoretic number of preventable strokes with strict use of OAC. For example, assume that of 18 OAC eligible, AF related stroke patients six receive aspirin, four receive $\mathrm{OAC}$, and eight receive no antithrombotic medication. In theory, OAC prescription in this population could have prevented $6 \times 0.401 / 42.4$ strokes (benefit OAC vs. aspirin) ${ }^{5}$ plus $8 \times 0.601 / 44.8$ strokes (benefit OAC vs. placebo), ${ }^{5}$ in total 7.2 strokes per year. On the basis of the deduced population we took the additional cases of $\mathrm{OAC}$ associated $\mathrm{ICH}(0.4 \%)$ into account, ${ }^{14}$ producing a net number of preventable strokes. 


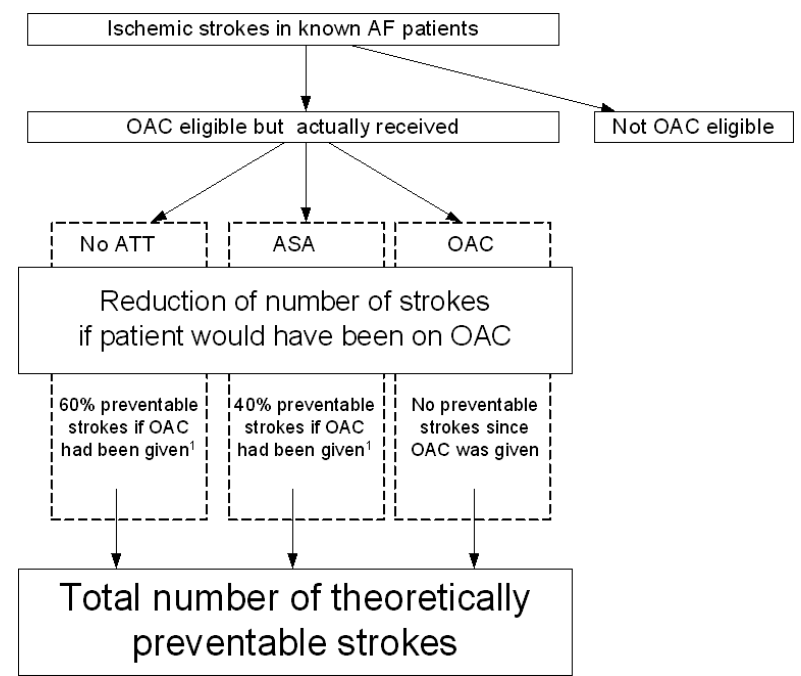

Figure 1 - Methods for calculating the theoretic number of preventable strokes with OAC; AF, atrial fibrillation; ASA, aspirin; ATT, antithrombotic therapy; OAC, oral anticoagulation.

\section{Statistical analysis}

Data analysis was performed with SPSS statistical software (release 15.0, SPSS Inc., Chicago, IL, USA). Results in Table 1 are reported as mean \pm standard deviation for age and $\mathrm{CHADS}_{2}$ score and as proportion within the column for the remaining variables. When testing continuous variables for differences between two groups we used the t-test, for detecting differences between categorical variables the $x 2$ statistic was used. A P-value $<0.05$ was considered statistically significant.

\section{RESULTS}

\section{Patient characteristics}

Of the 1120 stroke admissions, 163 (15\%) were associated with AF, of which 89 (55\%) were known AF and 74 (45\%) newly detected AF patients. In total, 138 patients (85\%) were discharged alive and thus survived the index stroke. Baseline characteristics are shown in Table 1 . The average CHADS2 score prior to the index stroke was 2.34 in the known AF patients and in the newly detected group 2.05. The CHADS2 score distribution is dis- played in Figure 2. Twelve of the known AF patients had a (relative) contraindication for OAC being either a history of malignancy ( $n=4$, two patients with colorectal cancer, one patient with bladder cancer, and another with prostate cancer) or bleeding $(n=8)$. 
Table I - Baseline characteristics of known and the newly detected atrial fibrillation patients admitted with a stroke

\begin{tabular}{|c|c|c|c|}
\hline Characteristic & Known $\mathrm{AF}^{*}(\mathrm{n}=89)$ & Newly detected AF $(n=74)$ & P value \\
\hline Age (yr) & $80 \pm 8$ & $80 \pm 9$ & 0.881 \\
\hline Female sex & $48(54)$ & $48(65)$ & 0.158 \\
\hline $\mathrm{CHADS}_{2}{ }^{\dagger}$ score & $2.3 \pm 1.4$ & $2.05 \pm 1.27^{\ddagger}$ & 0.221 \\
\hline History of heart failure & $13(15)$ & $6(8)$ & 0.209 \\
\hline History of hypertension & $42(48)$ & $40(55)$ & 0.372 \\
\hline History of diabetes mellitus & $19(21)$ & $11(15)$ & 0.306 \\
\hline History of ischemic stroke & $26(29)$ & $15(21)$ & 0.207 \\
\hline History of transient ischemic attack & $9(10)$ & $7(10)$ & 0.912 \\
\hline \multicolumn{4}{|l|}{ Contra indications for oral anticoagulation } \\
\hline History of bleeding & $8(9)$ & $2(3)$ & 0.100 \\
\hline History of malignancy & $4(5)$ & $9(12)$ & 0.072 \\
\hline \multicolumn{4}{|l|}{ Medication } \\
\hline Oral anticoagulation & $24(38)$ & $0(0)$ & $<0.001$ \\
\hline Acetyl salicylic acid & $33(37)$ & $28(38)$ & 0.760 \\
\hline Bèta blocker & $45(51)$ & $32(43)$ & 0.544 \\
\hline RAS $^{\S}$ inhibitor & $38(42)$ & $21(28)$ & 0.060 \\
\hline
\end{tabular}

Values are expressed as mean $\pm S D, \%$ of patients per group or absolute numbers of patients $(n)$. Analysis was by t-test and $\chi^{2}$ as appropriate. ${ }^{*} \mathrm{AF}$, atrial fibrillation; ${ }^{\dagger} \mathrm{CHADS}_{2}$, congestive heart failure, hypertension, age $>75$, diabetes mellitus and previous stroke / transient ischemic attack (doubled); ${ }^{\ddagger}$ This figure represents the virtual $\mathrm{CHADS}_{2}$ score: patients exhibiting associated diseases without the diagnosis AF; $\mathrm{RAS}^{\S}$, renin angiotensin aldosteron system.

\section{Virtual CHADS $_{2}$ score}

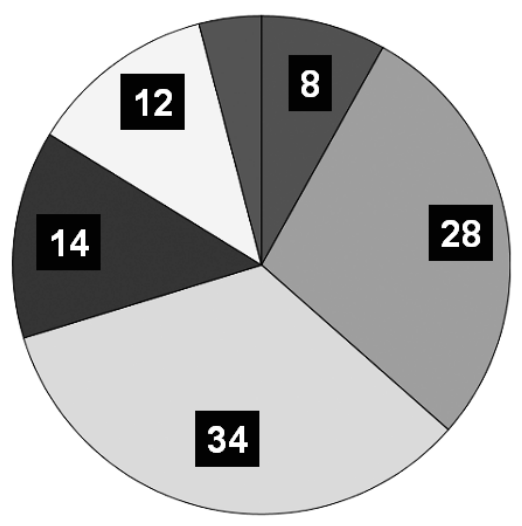

\section{$\mathrm{CHADS}_{2}$ score}

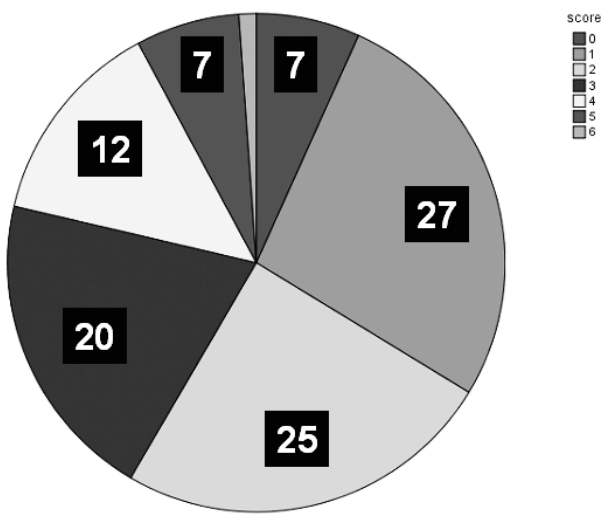

$\%$ Patients

Figure 2 - $\mathrm{CHADS}_{2}$ score distribution before index stroke of the known and newly detected AF patients; All values are expressed as \% of patients. ${ }^{*} \mathrm{CHADS}_{2}$, congestive heart failure, hypertension, age, diabetes mellitus and previous stroke / transient ischemic attack (doubled) 


\section{Potentially preventable ischaemic strokes}

Prior to admission, a total of 45 out of the 89 patients (51\%) with known AF were insufficiently protected against ischaemic stroke (Figure 3). In 41 (58\%) of the highrisk patients, OAC was unrightfully withheld, although 4 (67\%)of the low-risk patients did not receive aspirin.

The remaining 44 (49\%) patients did receive guideline adherent ATT (Figure 3). Taking into account the extra cases of ICH caused by the use of OAC, the total net number of potentially preventable strokes with guideline adherent ATT in the known AF patients was 20 out of 89 (22\%).

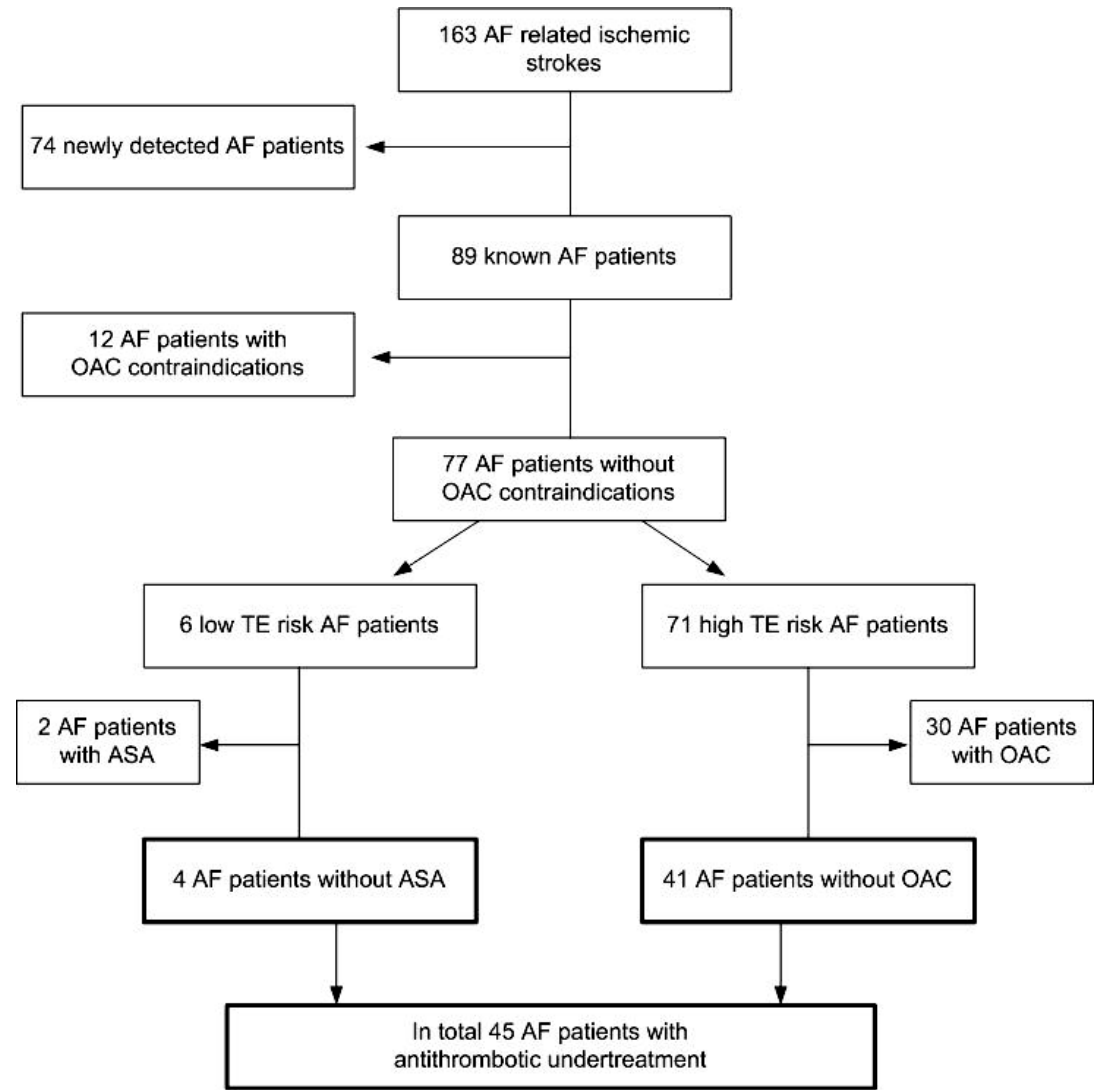

Figure 3 - Admission antithrombotic medication in the known AF patients; Values are expressed as number of patients $(n)$ or $\%$ of patients. OAC, oral anticoagulation. 


\section{Secondary stroke prevention}

Of all patients, survival status at discharge was missing in one case. We found no significant difference in the number of patients alive at discharge between the known AF patients and the newly detected AF group ( 83 vs. $87 \%, P=0.664$ ), nor between the undertreated and guideline adherently treated known AF patients ( 82 vs. $84 \%, \mathrm{P}=0.852$ ).

At discharge OAC was prescribed to $84(61 \%)$ patients. Of all $53(39 \%)$ patients not receiving OAC, 10 had a (relative) contraindication for OAC: being a history of bleeding $(n=3)$ or malignancy $(n=5)$, one case of alcohol abuse and one patient with severe dementia. In the 43 patients who did not have any OAC contra- indication, the decision was motivated in $28(65 \%)$ of the 43 patients. Poor neurological outcome was the main reason $(n=12)$, followed by excessive fall risk $(n=5)$, temporary aspirin use to prevent hemorrhagic transformation $(n=3)$, recent bleeding ( $n$ = 3; haematuria, rectal blood loss, unspecified bleeding condition), and high age ( $\mathrm{n}=$ 2). High blood pressure, presence of retinopathy, and type A aortic dissection were reasons to withhold OAC in the remaining three patients. Taking all this into account, at discharge at least $15(10 \%)$ patients were insufficiently protected against recurrent stroke.

\section{DISCUSSION}

We found more than $50 \%$ of the known AF patients admitted because of ischaemic stroke to have insufficient antithrombotic protection, with only 30 (42\%) of the eligible high-risk AF patients receiving OAC. Theoretically, one-fifth of these strokes could have been prevented just by prescribing guideline adherent antithrombotic medication. Secondary stroke prevention is also suboptimal since at least $10 \%$ of the AF patients admitted with an ischaemic stroke leave the hospital insufficiently protected against recurrent stroke.

The use of OAC as primary stroke prevention in our population of high-risk AF patients is in line with the recent report by Gladstone et al. ${ }^{10}$ Both are rather disappointingly low compared with the $68 \%$ of AF patients receiving OAC in clinical practice reported by Nieuwlaat et al. ${ }^{7}$ and considering the trend of increased OAC prescription. ${ }^{15,16}$ The high undertreatment is likely attributable to the advanced age of our population, which tends to discourage physicians to prescribe OAC.

\section{Potentially preventable strokes}

Antithrombotic undertreatment resulted in the highest absolute number of potentially preventable ischaemic strokes in the CHADS2 score 1 group (data not shown). This represents the prevention paradox: despite the lowest relative ischaemic 
stroke risk the majority of patients fall into the lower $\mathrm{CHADS}_{2}$ categories resulting in the highest absolute ischaemic stroke numbers. The latest, 2006, guidelines on the antithrombotic management of AF patients let patient and physician preference determine the use of either OAC or aspirin in the $\mathrm{CHADS}_{2}$ score 1 group ${ }^{3}$ whereas the 2001 version recommend $O A C$ in these patients. ${ }^{13}$ Our findings question the switch to a less vigorous OAC regimen because seemingly low-risk patients actually appear to have such a high ischaemic stroke risk that aspirin does not provide sufficient protection. This could in part be explained by the presence of other, currently infrequently used stroke risk increasing characteristics. The recent fine-tuning of the $\mathrm{CHADS}_{2}$ score by Lip et al. ${ }^{17}$ embodies this hypothesis. Beside re-evaluating age as a risk factor Lip et al. ${ }^{17}$ added female gender (Sc) and vascular disease (V) to the score, producing the acronym $\mathrm{CHA}_{2} \mathrm{DS}_{2}$ - VASc. Compared with conventional stroke risk schema the $\mathrm{CHA}_{2} \mathrm{DS}_{2}$-VASc score proved to be superior in correctly identifying $\mathrm{AF}$ patients with a truly low stroke risk. ${ }^{17}$ Together with recent evidence that treatment of patients with a $\mathrm{CHADS}_{2}$ score of 1 with OAC relates to a significantly better prognosis (combined end- point of stroke and all-cause mortality) compared with patients treated with only an antiplatelet agent ${ }^{18}$ and that the significant benefit of OAC in these individuals is offset by a limited increase in risk of bleeding ${ }^{19}$, advocates use of OAC in this 'grey area'. Finally, another opportunity to increase the potentially preventable strokes is hinted by the large number of stroke patients with heretofore undetected: AF screening programs. Particularly in individuals with a high 'virtual' CHA2DS2-VASc score, i.e. patients in whom the presence of AF necessitates use of $\mathrm{OAC}$, this might proof to be cost-effective on the long run.

Antithrombotic guideline adherence at discharge Considering ischaemic stroke is a strong independent risk factor for recurrent ischaemic stroke ${ }^{20}$ it is disappointing to find at least $10 \%$ of patients insufficiently protected against recurrent stroke at discharge. This percentage might even be higher because of the $90 \%$ guidelinetreated patients only 59\% actually received OAC (data not shown). In the remaining cases written documentation was provided why OAC was withheld. The validity of these reasons-as reported by the neurologists-could not be checked because of the retrospective nature of the study. However, based on evidence regarding risk of (intracerebral) bleeding in elderly AF patients on $\mathrm{OAC}^{21}$ and in patients with an excessive fall risk ${ }^{22,23}$ at least $6(21 \%)$ of the motivations not to prescribe OAC can be considered invalid.

\section{Limitations}

First, we did not dispose of admission international normalized ratio (INR) values of the patients on OAC. This is a missed opportunity to study the importance of qualitative guideline deviance. In a similar setting Gladstone et al. ${ }^{10}$ recently revealed that $75 \%$ of the AF patients using OAC as primary stroke prevention had subthera- 
peutic INR values at the time of the stroke, making (widespread) qualitative undertreatment among our population very likely. Another indication of subtherapeutic INR values on admission lies in the observed lack in survival difference of the index stroke between guideline adherent and undertreated patients, despite the known detrimental outcome of low INR values in this matter. ${ }^{24}$ However, our goal was to assess quantitative underuse of OAC. The probable presence of qualitative undertreatment only increases the percentage of undertreated patients and the number of potentially preventable strokes, underlining the message that still a lot of gain in stroke prevention lies in correct use of available drugs.

Secondly, the single, AF specialized university center nature makes extrapolation of our results both within and beyond the Netherlands difficult. However, our findings are in line with the multi-center study of Gladstone et al. ${ }^{10}$ and the EXAMINE-AF study found similar antithrombotic prescription in AF patients among Dutch general practitioners, internists, and cardiologists. ${ }^{6}$

Use of history of malignancy as risk factor of bleeding instead of active malignancy potentially overestimates rightful withholding OAC and thus underestimates the number of potentially preventable strokes.

\section{CONCLUSIONS}

Inadequate antithrombotic guideline adherence in AF patients leads to an unacceptably high annual number of potentially preventable strokes. Furthermore, even secondary prevention of AF related stroke at discharge is suboptimal.

Conflict of interest: none declared.

\section{Funding}

This work was supported by a grant of the Dutch Heart Foundation (grant number 2005B253).

\section{REFERENCES}

1. Bogousslavsky J, Cachin C, Regli F, Despland PA, Van Melle G, Kappenberger L. Cardiac sources of embolism and cerebral infarction-clinical consequences and vascular concomitants: the lausanne stroke registry. Neurology 1991;41:855 - 9.

2. Marini C, De Santis F, Sacco S, Russo T, Olivieri L, Totaro R et al. Contribution of atrial fibrillation to incidence and outcome of ischemic stroke: results from a population-based study. Stroke 2005;36:1115-9. 
3. Fuster V, Ryden LE, Cannom DS, Crijns HJ, Curtis AB, Ellenbogen KA et al. ACC/ AHA/ESC 2006 guidelines for the management of patients with atrial fibrillation-executive summary: a report of the American college of cardiology/ American heart association task force on practice guidelines and the European society of cardiology committee for practice guidelines (writing committee to revise the 2001 guidelines for the management of patients with atrial fibrillation). J Am Coll Cardiol 2006;48:854-906.

4. Hart RG, Pearce LA, Miller VT, Anderson DC, Rothrock JF, Albers GW et al. Car- dioembolic vs. noncardioembolic strokes in atrial fibrillation: frequency and effect of antithrombotic agents in the stroke prevention in atrial fibrillation studies. Cerebrovasc Dis 2000;10:39 - 43.

5. Hart RG, Pearce LA, Aguilar MI. Meta-analysis: antithrombotic therapy to prevent stroke in patients who have nonvalvular atrial fibrillation. Ann Intern Med 2007; 146:857 - 67.

6. Dinh T, Nieuwlaat R, Tieleman RG, Buller HR, van Charante NA, Prins MH et al. Antithrombotic drug prescription in atrial fibrillation and its rationale among general practitioners, internists and cardiologists in the netherlands-the examine-af study. A questionnaire survey. Int J Clin Pract 2007;61:24-31.

7. Nieuwlaat R, Capucci A, Camm AJ, Olsson SB, Andresen D, Davies DW et al. Atrial fibrillation management: a prospective survey in esc member countries: the euro heart survey on atrial fibrillation. Eur Heart J 2005;26:2422-34.

8. Nieuwlaat R, Capucci A, Lip GY, Olsson SB, Prins MH, Nieman FH et al. Anti- thrombotic treatment in real-life atrial fibrillation patients: $A$ report from the euro heart survey on atrial fibrillation. Eur Heart J 2006;27:3018-3026.

9. Waldo AL, Becker RC, Tapson VF, Colgan KJ. Hospitalized patients with atrial fibrillation and a high risk of stroke are not being provided with adequate anticoagulation. J Am Coll Cardiol 2005;46:1729-36.

10. Gladstone DJ, Bui E, Fang J, Laupacis A, Lindsay MP, Tu JV et al. Potentially preventable strokes in high-risk patients with atrial fibrillation who are not adequately anticoagulated. Stroke 2009;40:235-240.

11. de Jong G, van Raak L, Kessels F, Lodder J. Stroke subtype and mortality. A follow-up study in 998 patients with a first cerebral infarct. J Clin Epidemiol 2003;56:262 - 8.

12. Gage BF, Waterman AD, Shannon W, Boechler M, Rich MW, Radford MJ. Validation of clinical classification schemes for predicting stroke: results from the national registry of atrial fibrillation. J Am Med Assoc 2001;285:2864-70.

13. Fuster V, Ryden LE, Asinger RW, Cannom DS, Crijns HJ, Frye RL et al. ACC/AHA/ ESC guidelines for the management of patients with atrial fibrillation. A report of the American college of cardiology/American heart association task force on practice guidelines and the European society of cardiology committee for practice guidelines and policy conferences (committee to develop guidelines for the man- agement of patients with atrial fibrillation) developed in collaboration with the north American society of pacing and electrophysiology. Eur Heart J 2001;22:1852 - 923.

14. Chimowitz MI, Lynn MJ, Howlett-Smith H, Stern BJ, Hertzberg VS, Frankel MR et al. Comparison of warfarin and aspirin for symptomatic intracranial arterial stenosis. N Engl J Med 2005;352:1305-16.

15. Friberg J, Gislason GH, Gadsboll N, Rasmussen JN, Rasmussen S, Abildstrom SZ et al. Temporal trends in the prescription of vitamin $\mathrm{k}$ antagonists in patients with atrial fibrillation. J Intern Med 2006;259:173-8.

16. Smith NL, Psaty BM, Furberg CD, White R, Lima JA, Newman AB et al. Temporal trends in the use of anticoagulants among older adults with atrial fibrillation. Arch Intern Med 1999;159:1574-8.

17. Lip G, Nieuwlaat R, Pisters R, Lane D, Crijns H. Refining clinical risk stratification for predicting stroke and thromboembolism in atrial fibrillation using a novel risk factor based approach: the euro heart survey on atrial fibrillation. Chest 2010;137: $263-272$.

18. Gorin L, Fauchier L, Nonin E, de Labriolle A, Haguenoer K, Cosnay P et al. Antith- rombotic treatment and the risk of death and stroke in patients with atrial fibrilla- tion and a chads2 score $=1$. Thromb Haemost 2010; online publish-ahead-of-print 2 February 2010, doi:10.1160/TH09-10-0746. 
19. Healey JS, Hart RG, Pogue J, Pfeffer MA, Hohnloser SH, De Caterina R et al. Risks and benefits of oral anticoagulation compared with clopidogrel plus aspirin in patients with atrial fibrillation according to stroke risk: the atrial fibrillation clopi- dogrel trial with irbesartan for prevention of vascular events (active-w). Stroke 2008;39:1482 - 6.

20. Risk factors for stroke and efficacy of antithrombotic therapy in atrial fibrillation. Analysis of pooled data from five randomized controlled trials. Arch Intern Med 1994;154:1449 - 57.

21. Mant J, Hobbs FD, Fletcher K, Roalfe A, Fitzmaurice D, Lip GY et al. Warfarin versus aspirin for stroke prevention in an elderly community population with atrial fibrillation (the birmingham atrial fibrillation treatment of the aged study, bafta): a randomised controlled trial. Lancet 2007;370:493 - 503.

22. Man-Son-Hing M, Nichol G, Lau A, Laupacis A. Choosing antithrombotic therapy for elderly patients with atrial fibrillation who are at risk for falls. Arch Intern Med 1999;159:677 - 85.

23. Gage BF, Birman-Deych E, Kerzner R, Radford MJ, Nilasena DS, Rich MW. Inci- dence of intracranial hemorrhage in patients with atrial fibrillation who are prone to fall. Am J Med 2005;118:612 - 7.

24. Hylek EM, Go AS, Chang Y, Jensvold NG, Henault LE, Selby JV et al. Effect of intensity of oral anticoagulation on stroke severity and mortality in atrial fibrilla- tion. N Engl J Med 2003;349:1019 - 26. 


\title{
Guidelines for antithrombotic therapy in atrial fibrillation: understanding the reasons for non- adherence and moving forwards with simplifying risk stratification for stroke and bleeding
}

\author{
Laurent Fauchier ${ }^{1,2^{*}}$ and Gregory Y.H. Lip ${ }^{3}$
}

Service Cardiologie B et Laboratoire d’Electrophysiologie Cardiaque, Po^le Cœur Thorax Vasculaire, Centre Hospitalier Universitaire Trousseau, Tours 37044, France; Faculte de Me decine, Universite Francois Rabelais, Tours 37032, France; and University of Birmingham Centre for Cardiovascular Sciences, City Hospital, Birmingham B18 7QH, UK

This editorial refers to 'The likelihood of decreasing strokes in atrial fibrillation patients by strict application of guidelines' by R. Pisters et al., doi:10.1093/europace/ euq080

Randomized trials in patients with atrial fibrillation (AF) have con- sistently demonstrated that compared with placebo, adjusted-dose vitamin $\mathrm{K}$ antagonists (VKAs) reduce the incidence of stroke by $65 \%$, whereas antiplatelet agents reduce stroke by $\sim 20 \%{ }^{1}$ Despite existing evidence and guidelines, several observational studies have demonstrated suboptimal use of oral anticoagulation in clinical practice. For example, the Euro Heart Survey in AF reported that although the application rate of VKAs had generally improved, antithrombotic drug therapy was only modestly tailored to guidelines. ${ }^{2}$ Appreciation that adherence to guidelines is subop- timal is one thing; understanding the reasons for this situation and its consequences and finally attempting at better adherence to guidelines are a different issue.

In this issue of the Journal, Pisters et al. ${ }^{3}$ report that many patients with known AF admitted for ischaemic stroke to a university medical center did not receive adequate antithrombotic treatment on admission and $51 \%$ patients with known AF who were eligible for VKA did not actually receive it. Indeed, an improved antithrombotic guideline adherence could have potentially pre- vented $22 \%$ of the ischaemic strokes. Moreover, at least $10 \%$ of patients at discharge were still insufficiently protected against recurrent stroke.

These observations are even more alarming than those from the Euro Heart Survey on AF in whom participating centers chose to include or not their patients on an individual basis, ${ }^{2}$ thus resulting in a possible bias. Nevertheless, these findings represent a systematic analysis of a 'real world' cohort of patients. Additional analyses of the factors leading to undertreatment would have been of interest, because the parameters associated with under- treatment may be broadly classified in two categories: those related to the patient and those (unfortunately) related to the physician. 
Older age and renal failure are recognized risk factors for bleeding and are commonly associated with undertreatment. ${ }^{4,5}$ Patients whose only risk factor is their greater age are less often treated with anticoagulants and this reflects the continued reluctance to treat elderly patients with VKAs. The pattern of AF (permanent or non-permanent) and/or time spent in AF (or 'AF burden') should not influence the decision to prescribe an anticoagulant, in the presence of risk factors. However, it is not an uncommon finding that the prescription rates of VKAs are lower rate in paroxysmal compared with permanent $A F$, or in persistent AF once sinus rhythm has been achieved. Indeed, patients with permanent AF are more often treated with VKAs than those with paroxysmal $A F,{ }^{4,5}$ perhaps as a result of the erroneous belief that paroxysmal AF would lead to fewer embolic events.

A take-home message from the paper by Pisters et al. ${ }^{3}$ is that almost $25 \%$ of strokes might have been prevented by guideline adherence. This finding is not the result of a direct comparison of two medical managements as in usual clinical research, but an evaluation, based on what is known from medical literature, of what would have been the benefit with an appropriate management of the AF patients in whom the guidelines were not applied, while there was no reason not to apply them. Such a method remains somewhat speculative but should probably be used more often. The calculation of the benefit-a $65 \%$ reduction in risk of stroke if VKA was used instead of no antithrombotic agent and a $40 \%$ reduction in risk if VKA was used instead of an antiplatelet agent-might not be accurate for all subgroups of patients or on an individual basis. However, there is no reason to think it is an inappropriate viewpoint since the benefit of VKAs in terms of relative risk reduction is similar in the different groups of patients at low, medium, and high risk of thromboembolic events. ${ }^{6}$ It is possible that the benefit obtained with a better guideline adherence was rather underestimated in the work by Pisters et al., ${ }^{3}$ since at least $20 \%$ of the reasons not to prescribe VKA could be considered invalid.

Interestingly, the AF patients who were classified as low risk of thromboembolism accounted for a substantial part of the whole population with stroke. This observation does not support a less vigorous antithrombotic regimen in these seemingly 'low risk' patients because their risk of ischaemic stroke is, in fact, high and aspirin does not provide a sufficient protection on a population basis. In patients with $\mathrm{AF}$ and a $\mathrm{CHADS}_{2}$ score of 1 , a lower incidence of stroke and/or death from all causes has been found among patients treated with VKAs when compared with other patients. ${ }^{5,6}$ In contrast, prescription of an antiplatelet agent was not associated with a lower risk of events compared with no antithrombotic therapy. ${ }^{5}$ In most cases, an antiplatelet strategy runs a similar risk of major bleeding as oral anticoagulant therapy, and it is also associated with a much lower benefit in reducing death and stroke. Such 'not so low risk' patients should be treated with oral anticoagulant whenever possible unless there is a high risk of haemorrhagic event. 
In patients with the $\mathrm{CHADS}_{2}$ score $\geq 2$, anticoagulant should then systematically be prescribed. Even so, most published stroke risk stratification systems are of modest value in predicting patients at high risk of thromboembolism. A paradigm shift is needed in the primary prevention of stroke in AF, whereby identification of the "low risk' category is improved so these patients should be truly low risk. This has been achieved with the $\mathrm{CHA}_{2} \mathrm{DS}_{2}$-VASc, [cardiac failure, hypertension, age $\geq 75$ (doubled), diabetes, stroke (doubled)-vascular disease, age 65 - 74, and sex category (female)] schema, which is based on a point system in which two points are assigned for a history of stroke or TIA, or age $\geq 75$ and one point each is assigned for age 6574 years, a history of hyper- tension, diabetes, recent cardiac failure, vascular disease [myocardial infarction, complex aortic plaque, and peripheral arterial disease (PAD), including prior revascularization, amputation due to PAD or angiographic evidence of PAD, etc], and female gender ${ }^{7}$ (Table 1). This schema improves on the $\mathrm{CHADS}_{2}$ schema, classifies a low proportion of subjects into the 'moderate risk' category, and helps better determine the truly 'low risk' patients who have very low event rates and no need for anticoagulation.

Nonetheless, most physicians seem more concerned with a greater risk of bleeding, whereas the patients' major concern is thromboembolic stroke. ${ }^{8}$ Patients who are at high risk of stroke due to AF (i.e. those with a previous thromboembolic event) accept anticoagulation, despite its increased risk of bleeding, to avoid stroke. What is more concerning, is that higher thrombotic stroke risk, defined by $\mathrm{CHADS}_{2}$ score, is also coupled with significant bleeding risk.

Until recently, bleeding risk has been less well stratified due to the lack of available validated and user-friendly bleeding risk stratification systems. Indeed, a simple bleeding risk predictor schema would assist physicians in making decisions about commencing anticoagulation therapy. There are currently four published bleeding risk score systems (only two of which have been validated in AF populations) but their major drawback is that they have dissimilar characteristics and (sometimes) complex scoring systems, which hamper their usage in daily clinical practice. ${ }^{9}$

Recently, a new simple bleeding risk score (acronym HAS-BLED: Hypertension, Abnormal renal/liver function, Stroke, Bleeding history or predisposition, Labile INR, Elderly (>65), Drugs/ alcohol concomitantly) has been derived and validated in a European cohort ${ }^{10}$ (Table 1). Application of this new simple bleeding risk score (HASBLED) gave similar c-statistics to other published schema in the overall cohort for major bleeding (0.72) but in some patient subgroups, who received antiplatelet agents alone or no antithrombotic therapy, there was even superior predictive ability for major bleeding (with c-statistics of 0.91 and 0.85 , respectively). A HAS-BLED score of $\geq 3$ indicates 'high risk' of bleeding and some caution (rather than contraindication) is needed, following initiation of oral anticoagulation therapy or aspirin, given the same rates of major bleeding with the latter, especially in the elderly. 
Table 1 - Stroke and bleeding risk assessment

\begin{tabular}{|c|c|c|}
\hline Letter & Clinical characteristic & Points awarded \\
\hline \multicolumn{3}{|c|}{$\begin{array}{l}\text { The CHA2DS2-VASc schema for } \\
\text { stroke risk assessment }\end{array}$} \\
\hline C & Congestive heart failure/LV dysfunction & 1 \\
\hline $\mathbf{H}$ & Hypertension & 1 \\
\hline A & Age $\geq 75$ & 2 \\
\hline D & Diabetes mellitus & 1 \\
\hline $\mathbf{S}$ & Stroke/TIA/TE & 2 \\
\hline $\mathbf{v}$ & $\begin{array}{l}\text { Vascular disease (prior myocardial infarction, } \\
\text { peripheral artery disease, aortic } \\
\text { plaque) }\end{array}$ & 1 \\
\hline A & Age 65-74 & 1 \\
\hline Sc & Sex category (i.e. Female gender) & 1 \\
\hline \multicolumn{3}{|c|}{ The HAS-BLED bleeding risk scorea } \\
\hline $\mathrm{H}$ & Hypertension & 1 \\
\hline A & Abnormal renal and liver function (one point each) & 1 or 2 \\
\hline S & Stroke & 1 \\
\hline B & Bleeding & 1 \\
\hline $\mathrm{L}$ & Labile INRs & 1 \\
\hline E & Elderly (age .65) & 1 \\
\hline \multirow[t]{2}{*}{ D } & Drugs or alcohol (one point each) & 1 or 2 \\
\hline & & $\begin{array}{l}\text { Maximum nine } \\
\text { points }\end{array}$ \\
\hline
\end{tabular}

In patients with thyrotoxicosis, antithrombotic therapy should be chosen based on the presence of other stroke risk factors, as listed above. 'Vascular disease' refers to myocardial infarction, complex aortic plaque, and $P A D$, including prior revascularization, amputation due to PAD or angiographic evidence of $P A D$, etc. LV, left ventricular; TE, thromboembolic event; TIA, transient ischaemic attack.

a Hypertension is defined as systolic blood pressure $>160 \mathrm{mmHg}$. Abnormal kidney function is defined as the presence of chronic dialysis or renal transplantation or serum creatinine $\mathbf{2 0 0} \mathbf{m m o l} / \mathrm{L}$. Abnormal liver function is defined as chronic hepatic disease (e.g. cirrhosis) or biochemical evidence of significant hepatic derangement (e.g. bilirubin $\mathbf{2} \mathbf{2 X}$ upper limit of normal, in association with AST/ALT/ALP > $\mathbf{3 X}$ upper limit normal, etc). Bleeding refers to previous bleeding history and/or predisposition to bleeding, e.g. bleeding diathesis, anaemia, etc. Labile INRs refers to unstable/high INRs or poor time in therapeutic range (e.g. <60\%). Drugs/alcohol use also refers to concomitant use of drugs, such as antiplatelet agents, non-steroidal anti-inflammatory drugs, etc.

Clearly, the relationship between stroke and bleeding risks factors and thromboembolic events and major bleeding now have to be examined prospectively in AF cohort. This will help to establish the best bleeding risk index and finally a unifying consensus on how to treat AF patients, particularly those with a relatively low risk of thromboembolic event.

Given the availability of innovative oral anticoagulant drugs which may have a better stroke prevention effect than VKAs and a lower risk of bleeding, ${ }^{11}$ simplification of the approach to stroke prevention is overdue. With the $\mathrm{CHA}_{2} \mathrm{DS}_{2}-\mathrm{VASc}$ score, those $\geq 2$ are clearly high risk and should receive oral anticoagulation (whether with 
a VKA or new agents, such as dabigatran), whereas those with a $\mathrm{CHA}_{2} \mathrm{DS}_{2}$-VASc score of 1 are at moderate risk and while 'oral anticoagulation or aspirin' is recommended, oral anticoagulation is probably preferred. ${ }^{5}$ Finally, those with a $\mathrm{CHA}_{2} \mathrm{DS}_{2}$ VASc score of 0 are so low risk that no antithrombotic therapy is a possible approach, given the lack of evidence for the effectiveness (and possible harm, from bleeding) with aspirin in these patients. ${ }^{12}$ This paradigm shift leads to a 'yes/no' approach for anticoagulation based on the $\mathrm{CHA}_{2} \mathrm{DS}_{2}$-VASc score, whereby a $\mathrm{CHA}_{2} \mathrm{DS}_{2}$-VASc score $\geq 1$ means 'prescribe oral anticoagulation', whereas those at low risk (score $=0$ ) may not need antithrombo- tic therapy. Such a simplification would improve guideline adherence and our approach to thromboprophylaxis in AF patients.

Conflict of interest: none declared.

\section{REFERENCES}

1. Hart RG, Pearce LA, Aguilar MI. Meta-analysis: antithrombotic therapy to prevent stroke in patients who have nonvalvular atrial fibrillation. Ann Intern Med 2007; 146:857 - 67.

2. Nieuwlaat R, Olsson SB, Lip GY, Camm AJ, Breithardt G, Capucci A et al. Guideline-adherent antithrombotic treatment is associated with improved out- comes compared with undertreatment in high-risk patients with atrial fibrillation. The Euro Heart Survey on Atrial Fibrillation. Am Heart J 2007;153:1006- 12 .

3. Pisters R, van Oostenbrugge RJ, Knottnerus ILH, de Vos CB, Boreas A, Lodder J et al. The likelihood of decreasing strokes in atrial fibrillation patients by strict application of guidelines. Europace 2010; advance access publication 26 March 2010, doi:10.1093/europace/euq080.

4. Waldo AL, Becker RC, Tapson VF, Colgan KJ, NABOR Steering Committee. Hos- pitalized patients with atrial fibrillation and a high risk of stroke are not being pro- vided with adequate anticoagulation. J Am Coll Cardiol 2005;46:1729-36.

5. Gorin L, Fauchier L, Nonin E, Labriolle A, Haguenoer K, Cosnay P et al. Antith- rombotic treatment and the risk of death and stroke in patients with atrial fibrilla- tion and a CHADS2 score 1/4 1. Thromb Haemost 2010;103:683-5.

6. Healey JS, Hart RG, Pogue J, Pfeffer MA, Hohnloser SH, De Caterina R et al. Risks and benefits of oral anticoagulation compared with clopidogrel plus aspirin in patients with atrial fibrillation according to stroke risk: the atrial fibrillation clopi- dogrel trial with irbesartan for prevention of vascular events (ACTIVE-W). Stroke 2008;39:1482 - 6.

7. Lip G, Nieuwlaat R, Pisters R, Lane D, Crijns H. Refining clinical risk stratification for predicting stroke and thromboembolism in atrial fibrillation using a novel risk factor based approach: the Euro Heart Survey on Atrial Fibrillation. Chest 2010; 137:263 - 72.

8. Devereaux PJ, Anderson DR, Gardner MJ, Putnam W, Flowerdew GJ, Brownell BF et al. Differences between perspectives of physicians and patients on anticoagula- tion in patients with atrial fibrillation: observational study. BMJ 2001;323: $1218-22$.

9. Tay $\mathrm{KH}$, Lane D, Lip GYH. Bleeding risks with combination of oral anticoagulation plus antiplatelet therapy: is clopidogrel any safer than aspirin when combined with warfarin? Thromb Haemostat 2008;100:955-7. 
10. Pisters R, Lane D, Nieuwlaat R, Crijns H, Lip GYH. A novel user-friendly score to assess one-year risk of major bleeding in atrial fibrillation. Chest 2010. Published online ahead of print 18 March 2010, doi:10.1378/chest.10-0134.

11. Connolly SJ, Ezekowitz MD, Yusuf S, Eikelboom J, Oldgren J, Parekh A et al. Dabi- gatran versus warfarin in patients with atrial fibrillation. N Engl J Med 2009;361: $1139-51$.

12. Sato H, Ishikawa K, Kitabatake A, Ogawa S, Maruyama Y, Yokota Y et al., Japan Atrial Fibrillation Stroke Trial Group. Low-dose aspirin for prevention of stroke in low-risk patients with atrial fibrillation: Japan Atrial Fibrillation Stroke Trial. Stroke 2006;37:447 - 51. 


\section{Chapter 5 \\ Use and Underuse of Oral Anticoagulation for Stroke Prevention in Atrial Fibrillation: Old and New Paradigms}

Ron Pisters, M.D., ${ }^{1}$ Cees B. de Vos, M.D., ${ }^{1}$ Robby Nieuwlaat, Ph.D., ${ }^{1}$ and Harry J. G. M. Crijns, M.D., Ph.D. ${ }^{1}$

${ }^{1}$ Department of Cardiology, Maastricht University Medical Centre, Maastricht, The Netherlands.

Semin Thromb Hemost. 2009 Sep;35(6):554-9. 


\section{ABSTRACT}

Atrial fibrillation (AF) is the most common sustained arrhythmia of the Western world. The increased ischemic stroke risk of the AF patient is one of the most important clinical issues to manage. Despite the well-known benefit of oral anticoagulation in high- risk AF patients, these drugs are widely underused in daily practice all over the world. We describe old and new paradigms of the use of oral anticoagulation. In the future, increased comprehensibility of stroke risk scores, development of a validated clinical bleed risk score, and new patient and physician user-friendly antithrombotic medication may contribute to improved adequate use of oral anticoagulation in AF patients.

Keywords: Atrial fibrillation, oral anticoagulation, stroke prevention 


\section{INTRODUCTION}

Atrial fibrillation (AF) is independently associ- ated with an increased risk of stroke and systemic arterial occlusion. ${ }^{1}$ The stroke risk is also independent of the clinical AF type $^{2-4}$ and believed to be mainly caused by thrombogenic remodeling of the atrial wall and stasis of blood in the atrium, in particular in the atrial appendage. ${ }^{5}$ In addition, large population studies demonstrate that concomitant cardiovascular disease make patients with AF more vulnerable for stroke. ${ }^{6}$ As a result, many of these highrisk $A F$ patients should receive oral anticoagulation, which reduces the risk of stroke with $60 \%{ }^{7}$

Despite the overwhelming evidence on its superior stroke risk reduction, in clinical practice, oral anti- coagulation is underused in high-risk patients. ${ }^{8-10}$ In this article we report on clinical paradigms determining underuse of oral anticoagulation in $\mathrm{AF}$ and their potential clinical consequences.

\section{Use of oral anticoagulation}

Until the beginning of the 1990s, prescription of antithrombotic medication among AF patients was virtually restricted to those with a prosthetic heart valve, rheumatic heart disease, or a previous stroke.1 Then, the so-called big five clinical trials demonstrated superiority of oral anticoagulation over aspirin and placebo as primary stroke prevention in high-risk AF patients. ${ }^{11-15} \mathrm{~A}$ few years later, the European Atrial Fibrillation Trial (EAFT) showed similar benefit of oral anticoagulation (OAC) in secondary stroke prevention. $^{16}$

The evidence just cited contributed to the emergence of many stroke risk classification schemes. Because risk classification depends on the scheme used, ${ }^{17}$ the proportion of patients classified as high, intermediate, or low risk varies per study. Focusing on reported percentages therefore harbors the inherent risk of overestimating the accurate use of oral anticoagulation. With this in mind, we should consider the reported use of OAC. The use of OAC ranged from 20 to $40 \%$ in the early 1990 s to $65 \%$ about 2005 , increasing to $80 \%$ in some of the most recent surveys. ${ }^{18}$ Nevertheless, recent studies report that even now significant numbers of high-risk AF patients are insufficiently protected against (recurrent) stroke. ${ }^{8,9}$

Once AF is detected, physicians should consider antithrombotic treatment. Rational use of oral antico- agulation is enhanced by application of one or another stroke risk classification schemes. Over time, several risk schemes have been developed and validated in different settings, incorporating various known thromboembolism (TE) risk factors. ${ }^{6,19-21}$ Recent reports underline that the plethora of schemes with all their inherent differences cause confusion and conflicting stroke risk classi- 
fication, and that this generates over- and under- use. ${ }^{17,22}$ In addition, old clinical paradigms preclude proper application of OAC in many cases. ${ }^{18}$

\section{Clinical Type of Atrial Fibrillation}

When assessing the need for antithrombotic treatment in AF patients, wrong assumptions based on misconceptions play a role. For instance, the fact that AF patients have a fourfold increased stroke risk compared with patients in chronic sinus rhythm renders the presence of $A F$ itself a risk factor for many clinicians. As a consequence, the continuous presence of AF in permanent AF patients or, conversely, its predominant absence in infrequent paroxysmal $A F$ is taken as a reason to install or avoid OAC, respectively. However, type of AF, actual presence or absence of AF, or burden of AF do not play a role in any of the risk schemes. The old clinical paradigm is that paroxysmal AF because of the brevity of the attacks is not thrombogenic, whereas persistent and permanent are. This probably is the basis for increased stroke rate, especially in paroxysmal AF patients under- going cardioversion. $^{3}$ Thus clinical AF type unfortunately has remained-up and until these days-a significant determinant for OAC prescription in clinical practice $e^{8,9}$ despite long available, convincing evidence, ${ }^{2}$ which was recently reinforced. ${ }^{3,4,23}$

\section{(Electrical) Cardioversion}

Another acting old paradigm, and a very appealing one, is that anticoagulation is indicated around electrical cardioversion because recovery of atrial contraction after electrical cardioversion of persistent AF may drive thrombus from the left atrial appendage to the systemic circulation. However, Virchow's triad indicates that high flow-as seen with a well-contracting atrium-reduces risk of thrombus formation. Therefore, thrombogenic atrial wall remodeling and increased intravascular coagulation factors are most important in causing strokes after cardioversion rather than atrial contraction propelling thrombi from the appendage. In how far clinicians believe that the electrical countershock itself plays a role here because it might induce atrial stunning is uncertain. From the Euro Heart Survey on AF it appeared that OAC was considered less urgent around pharmacological cardioversion than around electrical cardioversion, certainly a concept that is not based on solid data. The stunning seen after electrical cardioversion (and which indeed may cause thrombi for lack of atrial contraction and intra-atrial flow) is due to AF-related thrombogenic remodeling of the atrial wall rather than the instantaneous action of the electrical energy itself. These new concepts need further substantiation before they will be accepted by the clinical community.

Another strong but false paradigm is that cardioversion or catheter ablation may obviate the need for OAC. Indeed, the perspective of being able to stop OAC is 
frequently used to convince patients to undergo these interventions. How incorrect this paradigm is was demonstrated by the large rhythm versus rate control studies showing that strokes-if anything-were more prevalent under rhythm control. ${ }^{24,25}$ At this time it is uncertain whether effective means of rhythm control that maintains patients permanently in sinus rhythm would keep the stroke risk away.

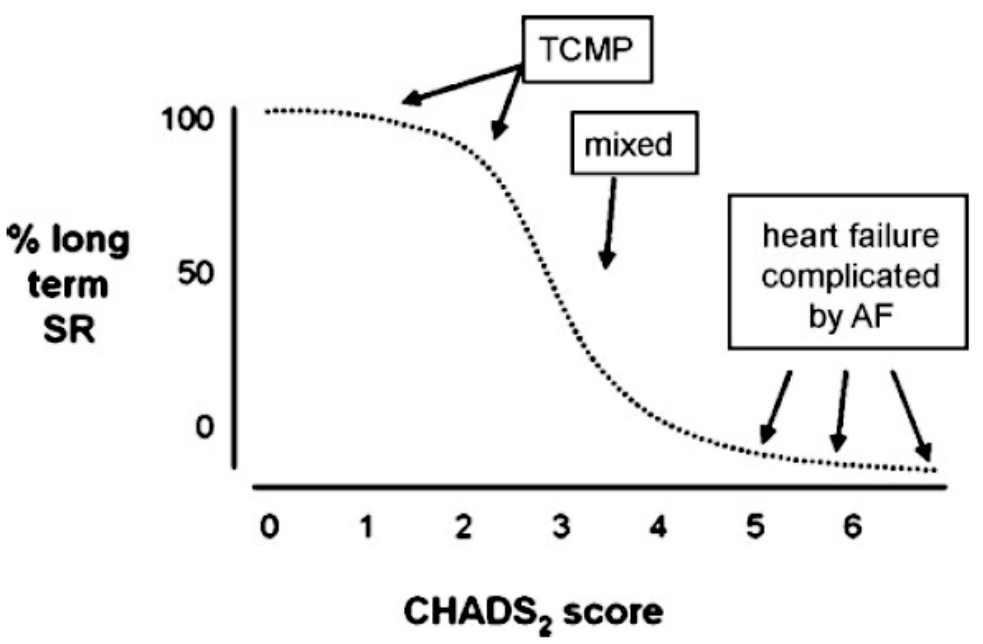

Figure 1 - Hypothetical relation between stroke risk and success rhythm (SR) control. The figure illustrates the hypothetical relationship between stroke risk represented by the CHADS2 stroke risk score and the success rhythm control (i.e., long-term sinus rhythm after intervention). The CHADS2 risk score is used to guide antithrombotic treatment. The score runs from 0 (no risk factor) to 6 (cumulative score with each CHADS condition including previous Congestive heart failure, Hypertension, Age $>75$ years, and diabetes mellitus receiving 1 point and previous Stroke receiving 2 points). In fact, the CHADS2 stroke risk scoring system may be used to guide rhythm control strategy. A score of _2 should trigger avoiding intensive rhythm control. In addition, the figure illustrates that atrial fibrillation (AF) associated with heart failure but without significant other associated disease as indicated by a low CHADS2 score of 1 presumably is associated with a good arrhythmia outcome because underlying atrial remodeling will be limited. These patients probably suffer from tachycardiomyopathy (TCMP) rather than AF as a complication of heart failure. The latter is the case for AF plus heart failure in patients with a high CHADS2 score. In those patients rhythm control will not be successful at all, and these patients should continue oral anticoagulation lifelong.

For now, we cannot sell cardioversion or catheter ablation to the patient with the argument that OAC can be stopped. This relates to the fact that the risk factors for stroke are almost the same as those predicting recurrence of AF after intervention. In other words, stroke risk and recurrence risk, like stroke risk and bleeding risk, go hand in hand. Fig. 1 illustrates this graphically. In recent years it has been shown that heart failure patients with AF may be successfully ablated. Up until now it is unsettled whether these patients may stop OAC. We suggest that this is the case only in patients in whom (focal) AF is complicated by heart failure and in whom the heart failure may subside completely after effective AF elimination. However, pa- 
tients with heart failure complicated by AF should continue OAC life- long even if the ablationist suggests the patient is cured from the arrhythmia. This relates to the fact that heart failure complicated by AF is associated with thrombogenic atrial remodeling that may not be abolished by ablation and represents persistence of both AF recurrence risk as well as stroke risk.

\section{Bleed Risk and Oral Anticoagulation Use}

If stroke risk indicates use of oral anticoagulation, individual bleeding risk needs to be addressed because use of vitamin $\mathrm{K}$ antagonists leaves the hemostatic system severely compromised due to functional elimination of key proteins. In daily practice, this means that patients have a realistic chance of bleeding on OAC. This increased risk is explained by the generally not well-appreciated fact that stroke and bleeding risk go hand in hand. ${ }^{26}$ This is further exemplified by mutual incorporation of the same risk factors into stroke $\left(\mathrm{CHADS}_{2}\right.$ index [Cardiac failure, Hypertension, Age, Diabetes, and stroke, doubled]) ${ }^{20}$ and bleeding (HEMOR ${ }_{2}$ RHAGES [Hepatic or renal disease, Ethanol abuse, Malignancy, Older (age $\geq 75$ years), Reduced platelet count or function, Hypertension (uncontrolled), Anemia, Genetic factors, Excessive fall risk, and Stroke) $)^{27}$ risk schemes.

Considering the high prevalence of bleeds among AF patients using oral anticoagulation, it is important to concentrate on the major bleedings with the highest mortality: intracerebral hemorrhage $(\mathrm{ICH}) .{ }^{28}$ Although contemporary reports demonstrate an increased risk of ICH among AF patients using oral anticoagulation compared with those not taking vitamin $\mathrm{K}$ antagonists, the bleeding risk still is low because the incidence is as low as $0.4 \% .{ }^{29,30}$ Known risk factors for $\mathrm{ICH}$ are an excessively high international normalized ratio (INR) $(>4.0),{ }^{31}$ very old age (>85 years), ${ }^{32}$ uncontrolled hypertension, ${ }^{33}$ the initiation period, ${ }^{34}$ and previous stroke. ${ }^{35}$

Excessive INR values result from the narrow therapeutic window of vitamin $\mathrm{K}$ antagonists and war- rant intensive monitoring to prevent harm. In some countries physicians have specialized anticoagulation clinics at their disposal. In these clinics, specially trained and dedicated staff use software algorithms to monitor (AF) patients treated with oral anticoagulation to facilitate time spent in target range. Physicians not supported by an anticoagulation monitoring clinic are less likely to prescribe OAC to high-risk AF patients, compared with those who do have such a clinic at their disposal.9 Certainly, the self-check of INR is an excellent tool to enhance INR stability obviating the need for monitoring in anticoagulation clinics.

Patients living in an area without an anticoagulation clinic more often receive both antiplatelet therapy and oral anticoagulation, ${ }^{9}$ probably associated with institution of OAC at subtherapeutic levels. Fear of excessive INR values (>4.0), being one of the major risk factors of $\mathrm{ICH}^{31}$ is hypothetically the most likely explanation for low OAC dosing. However, inadequate INR values are known to provide insuffi- 
cient protection against stroke ${ }^{36}$ and result in a higher stroke-related mortality ${ }^{31}$ and are associated with an ICH risk similar to seen with INR values in the therapeutic range. ${ }^{32}$ Furthermore, the combination of antiplatelet therapy with OAC has proven to be related with an even higher $\mathrm{ICH}$ risk, especially in the elderly. ${ }^{37,38}$

In contrast to stroke risk stratification, none of the bleeding risk schemes ${ }^{27,39-41}$ have been incorporated into the latest guidelines. ${ }^{5}$ This may relate to the fact that the bleeding risk schemes focus on all major bleeds instead of $\mathrm{ICH}$ alone and to compromised user friendliness by inclusion of genetic factors and laboratory tests. ${ }^{27}$ Also, contemporary bleed risk schema incorporate rather less important and risk and old age. Especially the latter risk factor should trigger installing rather than circumventing OAC.

Fall risk is used as a reason to avoid oral anti- coagulation in large numbers of AF patients. The risks of falling are vastly overestimated because traumatic subdural hematoma in patients using oral anticoagulation has a far lower impact than stroke and is much less frequent. ${ }^{42,43}$ Above all, it is important to search for a potentially reversible cause of falling. Cessation of benzodiazepines, referral to the ophthalmologist, or advice to use walking aids may free the way to oral anti-coagulation by reducing the fall risk. These new paradigms still have a long way to go.

Old age, despite the increased intracranial bleeding risk compared with lower age categories, can no longer be seen as a contraindication for OAC use considering the results of the Birmingham Atrial Fibrillation Treatment of the Aged (BAFTA) study. This randomized controlled trial demonstrated that AF patients age 75 years treated with warfarin suffered significantly fewer strokes (both ischemic and hemorrhagic) and had a similar number of major bleeds compared with those who received aspirin. ${ }^{44}$ Furthermore, a recent study demonstrated that with aging the protective effect of antiplatelet therapy decreases, whereas the benefit of oral anticoagulation remains constant. ${ }^{45}$ These are all strong arguments favoring use of oral anticoagulation in the elderly instead of considering old age a bleeding risk factor or considering it a reason to exchange OAC for aspirin.

Lacking consensus and clinical tools for bleeding risk stratification makes it difficult for the average physician to correctly assess the individual AF patients' indication for OAC. This is reflected by the EXAMINE- AF study, a survey among Netherlands general practitioners (GPs), general internists, and cardiologists on antithrombotic management of AF patients in daily practice. The survey demonstrated that cardiologists did best on guideline adherence (78\%), with no difference between internists (55\%) and GPs (58\%). ${ }^{10}$ In the Euro Heart Survey on AF, OAC use was highest in enrolled participants where the arrhythmia was the sole reason for seeking medical attention; if AF was a secondary diagnosis, the rate was lower. ${ }^{9}$ This possibly indicates that even general cardiologists have difficulty correctly choosing antithrombotic management in AF patients. 


\section{Consequences of antithrombotic undertreatment}

Beside reducing overall mortality with $26 \%$, OAC de- creases relative stroke risk, both ischemic and hemorrhagic, with $60 \%$ of patients. ${ }^{7}$ This is especially important because AF-related strokes are associated with both higher mortality and morbidity. ${ }^{46}$ The first study to point out true clinical consequences of antithrombotic undertreatment of AF patients was a subanalysis from the Euro Heart Survey on AF. Nieuwlaat et al. demonstrated that antithrombotic undertreatment in AF patients was associated with a worse cardiovascular prognosis compared with their guideline-adherent treated counterparts, already after 1 year of follow- up. ${ }^{47}$ Perhaps even more striking was that overtreatment was not significantly associated with increased bleeding risk. ${ }^{47}$ In a hospital-based cross-sectional study, we estimated the number of preventable strokes if OAC was administered according to the guidelines.48 We calculated that in the Netherlands alone, one stroke per day could have been prevented by simply following current guidelines. Of note, additional cases of OAC- associated ICH were already taken into account in the just mentioned number of preventable strokes. ${ }^{48}$ Recently, Gladstone et al. demonstrated a similar disappointing percentage of appropriate use of OAC in AF patients admitted with stroke. $^{49}$ On top of that, they showed that only $10 \%$ of the AF patients who received OAC had an INR value within the therapeutic range. ${ }^{49}$ This underlines the importance of the qualitative aspect of antithrombotic undertreatment and highly anticipated release of new antithrombotic drugs with properties that will redress this issue. Strokes could also be prevented if patients were not managed with rhythm control without effective anticoagulation. Especially paroxysmal AF patients undergoing cardioversion suffer avoidable strokes because of insufficient OAC. ${ }^{3}$

\section{CONCLUSION}

Suboptimal use of OAC is still a major clinical issue. Complexity of guidelines, medication-inherent hurdles, and lack of consensus among physicians seem to be key barriers. The issues mentioned here call for guidelines whose role and power need to lie in increasing both comprehensiveness as well as discriminative power regarding quality and general applicability of research articles. New patient- and physician user-friendly antithrombotic medication associated with a low bleeding risk will strengthen physician confidence to institute OAC. A practical and validated bleed risk schema will facilitate guideline adherence, subsequently increase OAC use, and thereby maximize stroke prevention. 


\section{REFERENCES}

1. Wolf PA, Abbott RD, Kannel WB. Atrial fibrillation as an independent risk factor for stroke: the Framingham Study. Stroke 1991;22(8):983-988.

2. Hart RG, Pearce LA, Rothbart RM, McAnulty JH, Asinger RW, Halperin JL; Stroke Prevention in Atrial Fibrillation Investigators. Stroke with intermittent atrial fibrillation: incidence and predictors during aspirin therapy. J Am Coll Cardiol 2000;35(1):183-187.

3. Nieuwlaat R, Dinh T, Olsson SB, et al; Euro Heart Survey Investigators. Should we abandon the common practice of withholding oral anticoagulation in paroxysmal atrial fibril- lation? Eur Heart J 2008;29(7):915-922.

4. Lip GY. Paroxysmal atrial fibrillation, stroke risk and thromboprophylaxis. Thromb Haemost 2008;100(1):11-13 after transient ischaemic attack or minor stroke. Lancet 1993;342(8882):1255126217.

5. Fuster V, Ryden LE, Cannom DS, et al. European Heart Rhythm Association; Heart Rhythm Society; American College of Cardiology; American Heart Association Task Force on Practice Guidelines European Society of Cardiology Committee for Practice Guidelines Writing Committee to Revise the 2001 Guidelines for the Management of Patients With Atrial Fibrillation. ACC/AHA/ESC 2006 guidelines for the management of patients with atrial fibrillation-executive summary: a report of the American College of Cardiology/ American Heart Association Task Force on Practice Guide- lines and the European Society of Cardiology Committee for Practice Guidelines (Writing Committee to Revise the 2001 Guidelines for the Management of Patients With Atrial Fibrillation). J Am Coll Cardiol 2006;48(4):854-906 2870.

6. Risk factors for stroke and efficacy of antithrombotic therapy in atrial fibrillation. Analysis of pooled data from five randomized controlled trials. Arch Intern Med 1994; 154(13):1449-1457.

7. Hart RG, Pearce LA, Aguilar MI. Meta-analysis: antith- rombotic therapy to prevent stroke in patients who have nonvalvular atrial fibrillation. Ann Intern Med 2007;146(12): 857-867.

8. Waldo AL, Becker RC, Tapson VF, Colgan KJ; NABOR Steering Committee. Hospitalized patients with atrial fibrillation and a high risk of stroke are not being provided with adequate anticoagulation. J Am Coll Cardiol 2005; 46(9):1729-1736.

9. Nieuwlaat R, Capucci A, Lip GY, et al; Euro Heart Survey Investigators. Antithrombotic treatment in real-life atrial 2161 fibrillation patients: a report from the Euro Heart Survey on Atrial Fibrillation. Eur Heart J 2006;27(24):3018-3026.

10. Dinh T, Nieuwlaat R, Tieleman RG, et al. Antithrombotic drug prescription in atrial fibrillation and its rationale among general practitioners, internists and cardiologists in The Netherlands-The EXAMINE-AF study. A questionnaire survey. Int J Clin Pract 2007;61(1):24-31.

11. The Boston Area Anticoagulation Trial for Atrial Fibrillation Investigators. The effect of low-dose warfarin on the risk of stroke in patients with nonrheumatic atrial fibrillation. $\mathrm{N}$ Engl J Med 1990;323(22):1505-1511.

12. Stroke Prevention in Atrial Fibrillation Study. Final results. Circulation 1991;84(2):527-539.

13. Petersen P, Boysen G, Godtfredsen J, Andersen ED, Andersen B. Placebo-controlled, randomised trial of warfarin and aspirin for prevention of thromboembolic complications in chronic atrial fibrillation. The Copenhagen AFASAK study. Lancet 1989;1(8631):175-179.

14. Connolly SJ, Laupacis A, Gent M, Roberts RS, Cairns JA, Joyner C. Canadian Atrial Fibrillation Anticoagulation (CAFA) study. J Am Coll Cardiol 1991;18(2):349-355.

15. Ezekowitz MD, Bridgers SL, James KE, et al; Veterans Affairs Stroke Prevention in Nonrheumatic Atrial Fibrilla- tion Investigators. Warfarin in the prevention of stroke associated with nonrheumatic atrial fibrillation. N Engl J Med 1992;327(20):1406-1412.

16. EAFT (European Atrial Fibrillation Trial) Study Group. Secondary prevention in non-rheumatic atrial fibrillation after transient ischemic attack or minor stroke. Lancet 1993;342(8882):1225-1262. 
17. Stroke Risk in Atrial Fibrillation Working Group. Comparison of 12 risk stratification schemes to predict stroke in patients with non-valvular atrial fibrillation. Stroke 2008;39(6):1901-1910.

18. Nieuwlaat R. Management of Atrial Fibrillation in Europe [dissertation]. Maastricht, the Netherlands: Maastricht University; 2007.

19. Hart RG, Pearce LA, McBride R, Rothbart RM, Asinger RW; The Stroke Prevention in Atrial Fibrillation (SPAF) Investigators. Factors associated with ischemic stroke during aspirin therapy in atrial fibrillation: analysis of 2012 participants in the SPAF I-III clinical trials. Stroke 1999; 30(6):1223-1229.

20. Gage BF, Waterman AD, Shannon W, Boechler M, Rich MW, Radford MJ. Validation of clinical classification schemes for predicting stroke: results from the National Registry of Atrial Fibrillation. JAMA 2001;285(22):2864-2870.

21. Wang TJ, Massaro JM, Levy D, et al. A risk score for predicting stroke or death in individuals with new-onset atrial fibrillation in the community: the Framingham Heart Study. JAMA 2003;290(8):1049-1056.

22. Fang MC, Go AS, Chang Y, Borowsky L, Pomernacki NK, Singer DE; ATRIA Study Group. Comparison of risk stratification schemes to predict thromboembolism in people with nonvalvular atrial fibrillation. J Am Coll Cardiol 2008; 51(8):810-815.

23. Hohnloser SH, Pajitnev D, Pogue J, et al; ACTIVE W Investigators. Incidence of stroke in paroxysmal versus sustained atrial fibrillation in patients taking oral anti- coagulation or combined antiplatelet therapy: an ACTIVE W Substudy. J Am Coll Cardiol 2007;50(22):2156-2161.

24. Van Gelder IC, Hagens VE, Bosker HA, et al; Rate Control versus Electrical Cardioversion for Persistent Atrial Fibrilla- tion Study Group. A comparison of rate control and rhythm control in patients with recurrent persistent atrial fibrillation. N Engl J Med 2002;347(23):1834-1840.

25. Wyse DG, Waldo AL, DiMarco JP, et al; Atrial Fibrillation Follow-up Investigation of Rhythm Management (AFFIRM) Investigators. A comparison of rate control and rhythm control in patients with atrial fibrillation. N Engl J Med 2002;347(23):1825-1833.

26. Poli $D$, Antonucci $E$, Marcucci $R$, et al. Risk of bleeding in very old atrial fibrillation patients on warfarin: relationship with ageing and CHADS2 score. Thromb Res 2007;121(3):347-352.

27. Gage BF, Yan Y, Milligan PE, et al. Clinical classification schemes for predicting hemorrhage: results from the National Registry of Atrial Fibrillation (NRAF). Am Heart J 2006; 151(3):713-719.

28. Fang $M C$, Go AS, Chang $Y$, et al. Death and disability from warfarin-associated intracranial and extracranial hemor- rhages. Am J Med 2007;120(8):700-705.

29. Chimowitz MI, Lynn MJ, Howlett-Smith H, et al; Warfarin- Aspirin Symptomatic Intracranial Disease Trial Investigators. Comparison of warfarin and aspirin for symptomatic intra- cranial arterial stenosis. N Engl J Med 2005;352(13):1305-1316.

30. Go AS, Hylek EM, Chang Y, et al. Anticoagulation therapy for stroke prevention in atrial fibrillation: how well do randomized clinical trials translate into clinical practice? JAMA 2003;290(20):26852692.

31. Hylek EM, Go AS, Chang Y, et al. Effect of intensity of oral anticoagulation on stroke severity and mortality in atrial fibrillation. N Engl J Med 2003;349(11):1019-1026.

32. Fang $M C$, Chang $\mathrm{Y}$, Hylek EM, et al. Advanced age, anticoagulation intensity, and risk for intracranial hemor- rhage among patients taking warfarin for atrial fibrillation. Ann Intern Med 2004;141(10):745-752.

33. Perry HM Jr, Davis BR, Price TR, et al. Effect of treating isolated systolic hypertension on the risk of developing various types and subtypes of stroke: the Systolic Hyper- tension in the Elderly Program (SHEP). JAMA 2000;284(4): 465-471.

34. Hylek EM, Evans-Molina C, Shea C, Henault LE, Regan S. Major hemorrhage and tolerability of warfarin in the first year of therapy among elderly patients with atrial fibrillation. Circulation 2007;115(21):2689-2696.

35. Hylek EM, Singer DE. Risk factors for intracranial hemorrhage in outpatients taking warfarin. Ann Intern Med 1994;120(11):897-902. 
36. Hylek EM, Skates SJ, Sheehan MA, Singer DE. An analysis of the lowest effective intensity of prophylactic anticoagula- tion for patients with nonrheumatic atrial fibrillation. N Engl J Med 1996;335(8):540-546.

37. Shireman TI, Howard PA, Kresowik TF, Ellerbeck EF. Combined anticoagulant-antiplatelet use and major bleeding events in elderly atrial fibrillation patients. Stroke 2004; 35(10):2362-2367.

38. Hart RG, Benavente O, Pearce LA. Increased risk of intracranial hemorrhage when aspirin is combined with warfarin: a meta-analysis and hypothesis. Cerebrovasc Dis 1999;9(4):215-217.

39. Beyth RJ, Quinn LM, Landefeld CS. Prospective evaluation of an index for predicting the risk of major bleeding in outpatients treated with warfarin. Am J Med 1998;105(2): 91-99.

40. Kuijer PM, Hutten BA, Prins MH, Bu ller HR. Prediction of the risk of bleeding during anticoagulant treatment for venous thromboembolism. Arch Intern Med 1999;159(5): 457-460.

41. Kearon C, Ginsberg JS, Kovacs MJ, et al; Extended Low- Intensity Anticoagulation for ThromboEmbolism Investi- gators. Comparison of low-intensity warfarin therapy with conventional-intensity warfarin therapy for long-term pre- vention of recurrent venous thromboembolism. N Engl J Med 2003;349(7):631-639.

42. Man-Son-Hing M, Nichol G, Lau A, Laupacis A. Choosing antithrombotic therapy for elderly patients with atrial fibrillation who are at risk for falls. Arch Intern Med 1999; 159(7):677-685.

43. Garwood CL, Corbett TL. Use of anticoagulation in elderly patients with atrial fibrillation who are at risk for falls. Ann Pharmacother 2008;42(4):523-532.

44. Mant J, Hobbs FD, Fletcher K, et al; BAFTA investiga- torsMidland Research Practices Network (MidReC). Warfarin versus aspirin for stroke prevention in an elderly community population with atrial fibrillation (the Birming- ham Atrial Fibrillation Treatment of the Aged Study, BAFTA): a randomised controlled trial. Lancet 2007; 370(9586):493-503.

45. van Walraven C, Hart RG, Connolly S, et al. Effect of Age on Stroke Prevention Therapy in Patients With Atrial Fibrillation: The Atrial Fibrillation Investigators. Stroke 2009;40(4):1410-1416.

46. Marini C, De Santis F, Sacco S, et al. Contribution of atrial fibrillation to incidence and outcome of ischemic stroke: results from a population-based study. Stroke 2005;36(6):1115-1119.

47. Nieuwlaat R, Olsson SB, Lip GY, et al; Euro Heart Survey InvestigatorsThe Euro Heart Survey on Atrial Fibrillation. Guideline-adherent antithrombotic treatment is associated with improved outcomes compared with undertreatment in high-risk patients with atrial fibrillation. Am Heart J 2007; 153(6):1006-1012.

48. Pisters R, Knottnerus I, Crijns HJ, et al. Antithrombotic guideline adherence in atrial fibrillation patients admitted with stroke. Do we use our safety-belt? Paper presented at: Annual meeting of the European Society of Cardiology; September 2, 2007; Vienna, Austria.

49. Gladstone DJ, Bui E, Fang J, et al. Potentially preventable strokes in high-risk patients with atrial fibrillation who are not adequately anticoagulated. Stroke 2009;40(1):235-240. 



\section{Chapter 6}

\section{Improving Antithrombotic Management in Patients with Atrial Fibrillation: Current Status and Perspectives}

Marcel Levi, M.D., Ph.D., ${ }^{1}$ F. D. Richard Hobbs, M.D., ${ }^{2}$ Alan K. Jacobson, M.D., ${ }^{3}$ Ron Pisters, M.D., ${ }^{4}$ Domenico Prisco, M.D., ${ }^{5}$ Artur Bernardo, M.D., ${ }^{6}$ Markus Haas, Ph.D., ${ }^{7}$ Jens Heidrich, Ph.D., ${ }^{8}$ Matt Rosenberg, M.D., ${ }^{9}$ Jørn Dalsgaard Nielsen, M.D., ${ }^{10}$ and Walter A. Wuillemin, M.D., Ph.D. ${ }^{11}$

Department of Vascular Medicine and Internal Medicine, Academic Medical Center, University of Amsterdam, Amsterdam, The Netherlands; Primary Care Clinical Sciences, University of Birmingham, UK; Loma Linda University School of Medicine, Department of Anticoagulation Services, Cardiology Section, Loma Linda VA Medical Center, Loma Linda, CA, USA; Department of Cardiology, University Hospital of Maastricht, The Netherlands; Department of Medical and Surgical Critical Care, Thrombosis Centre, University Hospital Careggi, Florence, Italy; Department of Cardiology, Klinik Gais, Gais, Switzerland; Theresienkrankenhaus, Academic Hospital, Mannheim, Germany; Laboratory Dr. von Froreich \& Kollegen GmBH, Hamburg, Germany; General Practitioner, Jackson, Michigan, USA; Thrombosis Centre, Gentofte Hospital, Hellerup, Denmark; Division of Hematology, Luzerner Kantonsspital and University of Bern, Switzerland.

Semin Thromb Hemost. 2009;35:527-542 


\section{ABSTRACT}

Despite overwhelming evidence of the benefits of risk-adjusted oral anticoaguation on stroke reduction in patients with atrial fibrillation (AF), there is still considerable undertreatment. A multidisciplinary expert group was formed to discuss issues surrounding anticoagulant treatment of patients with AF to try and achieve consensus on various aspects of the implementation of guidelines on oral anticoagulation therapy in AF. Panel members were cardiologists, hematologists, and laboratory and primary care physicians with specific expertise from Europe and the United States. One of the most important conclusions of the meeting was to enhance guideline adherence by better communication of the data showing that the benefits of stroke reduction outweigh the risk of bleeding associated with treatment with vitamin $\mathrm{K}$ antagonists. Management of oral anticoagulation therapy by dedicated centers, such as anticoagulation clinics, or by patient self-management may improve the quality of anticoagulation and facilitate the management of these patients and thereby further facilitate optimal antithrombotic management in patients with AF.

Keywords: Atrial fibrillation, anticoagulation, warfarin, Coumadin, cerebrovascular thrombosis, thromboembolism, bleeding 


\section{INTRODUCTION}

Most patients with atrial fibrillation (AF) at a stage of their disease need to be treated with vitamin $\mathrm{K}$ antagonists (VKAs). Although current guidelines clearly define the indications for treatment, there are barriers among physicians and patients to the implementation of oral anticoagulation. The consensus meeting intended to delineate current international standards and to discuss strategies of how to implement and manage adequate VKA treatment.

The main reason for implementing anticoagulation is the higher risk of stroke and the associated higher mortality in AF patients who are not treated. Adjusteddose oral anticoagulation therapy reduces the risk for stroke efficiently, and this effect outweighs the risk for bleeding, particularly intracranial hemorrhage (ICH). ${ }^{1,2}$ $\mathrm{AF}$ prevalence is on the rise worldwide due to the increased elderly population. Therefore the number of elderly patients with AF who need VKA treatment will increase. When applying international guidelines such as the joint guidelines of the American College of Cardiology (ACC), the American Heart Association (AHA), and the European Society of Cardiology (ESC), 60 to $70 \%$ of AF patients should receive VKAs. ${ }^{1}$ However, most studies show underutilization of this effective treatment, irrespective of how patients are cared for.

\section{Epidemiology of atrial fibrillation}

AF represents the most common arrhythmia in clinical practice. An estimated 2.5 million people in the United States and $>6$ million European Union citizens have paroxysmal or persistent AF. ${ }^{1,3-5}$ Incidence and prevalence of AF is age dependent. Due to the demographic change and an increasing proportion of the aged population with and without underlying heart disease, prevalence of AF is increasing worldwide with a growth rate of $\sim 2 \%$ per year. In the United States, the number of patients with AF has been projected to be $\sim 3.0$ million by 2020, increasing to 5.6 million by $2050 .^{3,4}$ Following an analysis from the Mayo Clinic in the Midwest, an increase of the number of adults with AF to 12.1 million has been projected and to as many as $\mathbf{1 5 . 9}$ million assuming a continued increase in the incidence of AF. ${ }^{6}$

The prevalence of $A F$ correlates with age, affecting 0.4 to $1 \%$ of the entire population and increasing to $8 \%$ of the population $>80$ years of age. ${ }^{1} \mathrm{AF}$ prevalence varies considerably between countries, although this may partly be a function of the methods of collecting the data and the demographics of the population investigated. In some countries, no specific epidemiological data have been reported. Prevalence of $A F$ is $~ 1 \%$ in Denmark, increasing with age up to $6 \%$ in those patients $\geq 80$ years of age. In Germany, the estimated number of patients with AF is 900,000 (diagnosed in 680,000). ${ }^{7,8}$ Based on the Echocardiographic Heart of England Screen- 
ing study cohort, point prevalence in the UK general population is $1.7 \%$ in persons $>45$ years of age, with a maximum of $12 \%$ in subjects $>84$ years of age. ${ }^{9}$ In the United States, overall prevalence of diagnosed AF was estimated as $1.0 \%$ in the Anticoagulation and Risk Factors in Atrial Fibrillation study. ${ }^{3}$ It increases with older age, ranging from $0.1 \%$ among persons $<55$ years to $3.8 \%$ among persons $\geq 60$ years and $9.0 \%$ among persons $\geq 80$ years. In the Netherlands, overall prevalence of $A F$ is $5.5 \%$, increasing from $0.7 \%$ at 55 to 59 years of age up to $17.8 \%$ at $\geq 85$ years of age. ${ }^{10}$ According to unpublished data from the Italian Longitudinal Study of Aging study, the prevalence ranges from $2.2 \%$ (65 to 69 years of age) to $5.4 \%$ ( 80 to 84 years of age). ${ }^{11}$ In a survey of 51 general practitioners in Northern Italy, a prevalence of $1.75 \%$ in 41,050 subjects $>40$ years of age has been found. ${ }^{12}$ According to an Italian survey on 9712 subjects 34 to 74 years of age, AF prevalence in men is $0.8 \%$ and $0.7 \%$ in women. $^{13}$

Like prevalence, incidences of AF increase continually with age at the rate of $0.1 \%$ per year for those $<40$ years of age and $>1.5 \%$ per year for those $>80$ years of age. ${ }^{1}$ Overall incidence in Germany is reported $\sim 0.2 \%$, and overall incidence in the Netherlands is $1 \%$, increasing with age up to $2.1 \%$ in patients $\geq 85$ years of age. ${ }^{10}$

\section{Consensus statement:}

AF is a highly prevalent rhythm disturbance of the heart mainly affecting older people. Due to an aging population, the personal and economic burden of the disease is expected to increase in Europe and the United States.

\section{Efficacy and safety of oral anticoagulation therapy in atrial fibrillation}

$\mathrm{AF}$ is a major contributor to stroke risk in the elderly. Ischemic stroke rate in patients with nonvalvular $A F$ is up to 7 times that of people without $A F$, and the risk increases with age. ${ }^{14,15} \mathrm{AF}$ increases risk of stroke approximately fivefold, 15 to $20.3 \%$ of all acute stroke patients have $A F$, and $36 \%$ of acute stroke patients $>80$ years of age have $A F .{ }^{16}$ In many stroke patients, AF is first diagnosed at the time of the event. Although 18 to $21 \%$ of patients with AF are asymptomatic, ${ }^{17,18}$ they have an increased risk of stroke. Stroke is a leading cause of serious long-term disability in the United States with 15 to $30 \%$ being permanently disabled and $20 \%$ requiring institutional care at 3 months after onset. ${ }^{19}$ Furthermore, AF increases mortality of stroke by $70 \%$, it doubles severity of stroke and increases stroke morbidity as evidenced by more stroke patients with AF in a bedridden state than stroke patients without $A F$, and it is associated with a higher recurrence rate and with an increase of silent cerebral infarcts. ${ }^{16,20,21}$ Taken together, untreated AF is associated with an increased mortality. ${ }^{21-23}$ 
Rates of stroke and hemorrhagic events are of primary interest in patients receiving oral anticoagulation therapy. Once the targeted intensity of oral anticoagulation is achieved, it must be maintained be- cause this protocol is directly related to its derived benefit. ${ }^{1,24}$ The most recognized way to measure the therapeutic effectiveness of oral anticoagulation therapy is to measure international normalized ratio (INR) values. Time in therapeutic range, that is, the percentage of values in the targeted therapeutic range once a therapeutic INR has been established, correlates with the main clinical outcomes of bleeding or thrombosis but also represents a research tool for the evaluation of quality of overall care in these patients. ${ }^{24,25}$

Maintaining the intensity of anticoagulation is crucial to achieve effective stroke prevention as well as to avoid bleeding complications, particularly in elderly patients $^{2}$ (Fig. 1). For optimal outcomes it is essential to treat underlying heart disease such as coronary artery disease in addition to anticoagulation control in AF patients. $^{1}$

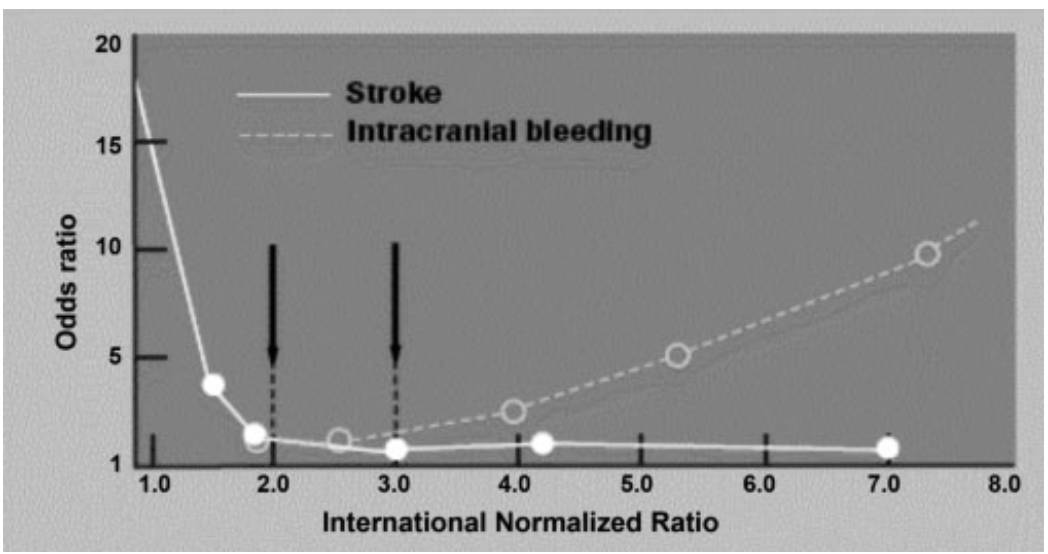

Figure 1 - Significant increase in stroke risk with international normalized ratio (INR) values $<2.0$ and in intracranial bleeding risk with INR values over the range of 3.5 to $4.0 .^{2}$

\section{Reduction of stroke risk}

The superiority of a risk-adjusted oral anticoagulation with VKAs compared with placebo or an aspirin-based therapy on stroke reduction has been clearly demonstrated by many prospective trials (Fig. 2). Oral anti- coagulation reduces stroke events of any cause, not only embolic stroke, and it is also associated with a decrease of peripheral embolism. ${ }^{26}$ Most trials of anticoagulation in AF were terminated earlier due to overwhelming results in favor of anticoagulation. A metaanalysis of six major trials has demonstrated a risk reduction of stroke (both ischemic and hemorrhagic) by $62 \%$ and of all-cause mortality by $26 \%{ }^{27}$ Benefits of 
oral anti- coagulation therapy may even have been underestimated because between $25 \%$ and $93 \%$ of patients were excluded in landmark trials on oral anticoagulation therapy in $\mathrm{AF}$ patients (e.g., patients with previous stroke).

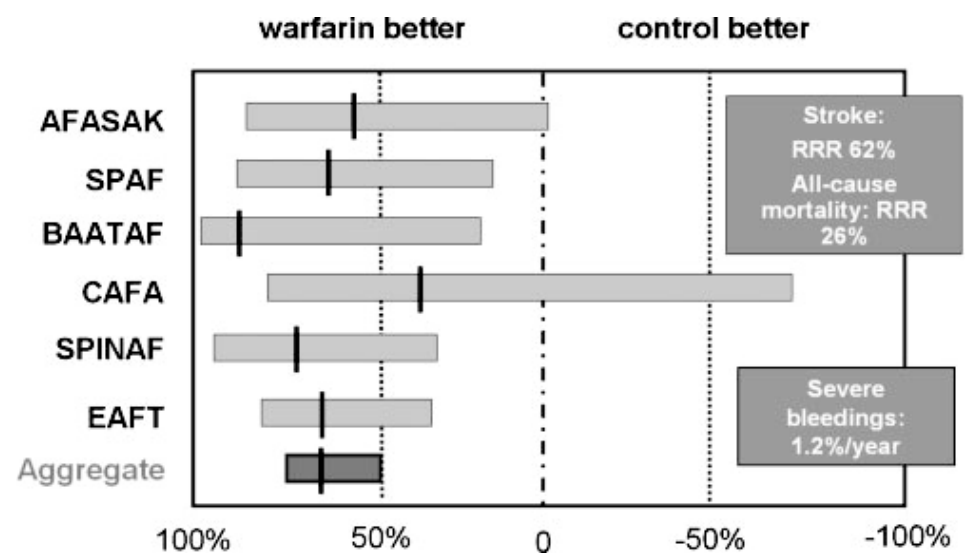

Figure 2 - Reduction of stroke risk by oral anticoagulation therapy in prospective atrial fibrillation trials. Adapted from Hart et al. ${ }^{27}$ AFASAK, Atrial Fibrillation, Aspirin, and Anticoagulation study; BAATAF, The Boston Area Anticoagulation Trial for Atrial Fibrillation; CAFA, Canadian Atrial Fibrillation Anticoagulation study; EAFT, European Atrial Fibrillation Trial; RRR, relative risk reduction; SPAF, Stroke Prevention in Atrial Fibrillation study; SPINAF, Stroke Prevention in Nonrheumatic Atrial Fibrillation study.

In a pooled analysis of five large randomized controlled trials, oral anticoagulation with warfarin de- creased the risk of stroke by $68 \%$ in patients with $\mathrm{AF}$, from $4.5 \%$ in the control group (placebo) to $1.4 \%$ in the warfarin group. ${ }^{28}$ Stroke reduction was more pronounced in women compared with men. In a more recent meta-analysis by Hart et al. ${ }^{29}$ that included 29 randomized, controlled studies with a total of $\sim 28,000$ patients, oral anticoagulation with a coumarin derivative was shown to reduce the risk of a stroke by $64 \%$ compared with the control group in patients with nonvalvular AF. ${ }^{29}$ Warfarin efficacy is consistent across AF trials with 32 patients needed to treat for 1 year to prevent one stroke in primary prevention and 12 patients in secondary prevention. Oral anticoagulation may be most beneficial for AF patients at higher intrinsic thromboembolic risk. ${ }^{1}$

In addition to superiority over placebo, there is clear evidence of the efficacy of adjusted-dose oral anti- coagulants to reduce stroke, disabling stroke, and other major vascular events for those with nonvalvular AF when compared with antiplatelet therapy. ${ }^{2,27,30-41}$ Finally, we now also have data on the superiority of warfarin in the elderly in a primary care setting. In the Birmingham Atrial Fibrillation in the Aged (BAFTA) trial, patients $\geq 75$ ( $n=973$ ) were either treated with $75 \mathrm{mg} /$ day aspirin or warfarin targeting an INR of 2.5 (range, 2.0 to 3.0).42 There was a significant benefit of warfarin over aspirin treatment in terms of stroke prevention (1.8\% versus $3.8 \%$ annually). This benefit was maintained in all subgroups of AF patients. 
Adherence to warfarin was less than adherence to aspirin in the BAFTA trial. Warfarin's relative superiority over aspirin for prevention of ischemic stroke is maintained in paroxysmal AF, prior stroke or transient ischemic attack (TIA), hypertension, heart failure, and diabetes. It possibly is more effective in women and people $<75$ years of age. ${ }^{31}$

\section{Safety of oral anticoagulation}

Overall bleeding risk is increased with warfarin when compared with placebo, and hemorrhage is the major complication of VKA treatment. The rates of major bleeding, however, defined as bleeding severe enough to require hospitalization, blood transfusion, or surgery, were not significantly worsened in AF trials when comparing adjusted-dose warfarin with placebo. ${ }^{27,28,43} \mathrm{ICH}$, the most feared and devastating bleeding complication, ${ }^{44}$ is uncommon. In a meta-analysis of six trials conducted by Hart et al, ${ }^{27}$ the rate of $\mathrm{ICH}$ in adjusted- dose warfarin was moderately higher among those taking warfarin $(0.3 \%$ per year) versus those not taking warfarin $(0.1 \%$ per year) without reaching statistical difference (Fig. 3). The relative risk for major extracranial hemorrhage was 2.4 (95\% confidence interval [Cl], 1.2 to 4.6 ), an absolute increase of $0.3 \% /$ year for warfarin patients. ${ }^{27}$

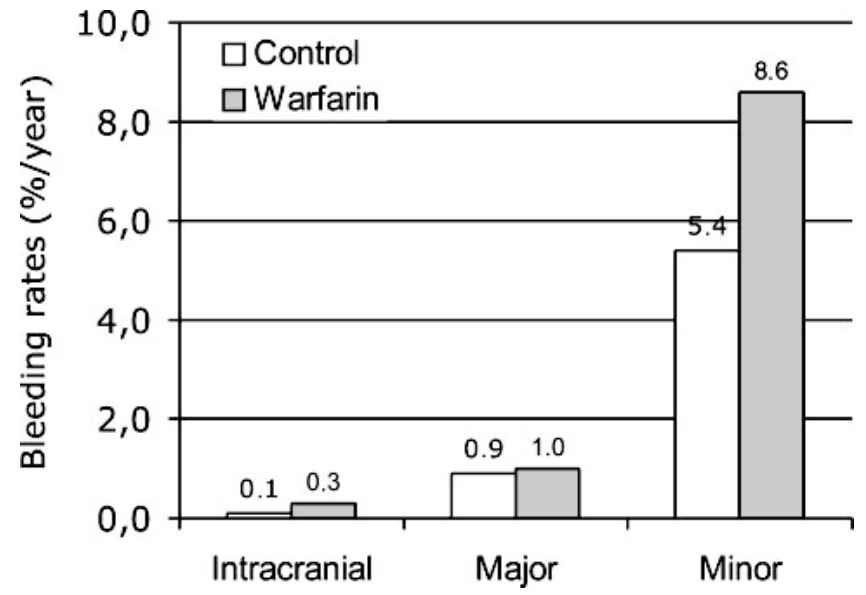

Figure 3 - Bleeding rates in atrial fibrillation trials. ${ }^{28,43}$

However, there were concerns that the bleeding risk with warfarin was understated because many of the main trials excluded large numbers of patients from randomization, including those perceived to have higher bleed risk. ${ }^{45}$ Exclusion from studies would therefore result in a different risk-benefit ratio for these patients than in a real-world setting. ${ }^{45}$ Furthermore, observational data from the major warfarin ver- 
sus aspirin trials suggested that the bleeding risks with warfarin were higher in the elderly, eliciting cautionary notes for warfarin use in those $>75$ years of age in clinical guide- lines. ${ }^{31}$ Importantly, the BAFTA trial was designed to test these concerns by randomizing patients $>75$ years of age with minimal ineligibility criteria and demonstrated the bleeding risk with warfarin was the same as for aspirin. ${ }^{42}$ These analogous bleeding findings are con- firmed in the meta-analysis update. ${ }^{46}$

The risk of major hemorrhage and $\mathrm{ICH}$ in AF patients is mainly related to inadequate oral anticoagulation therapy. Overtreatment with persistent INR values $\geq 4$ is associated with an increased risk of major hemorrhage, especially among older patients. ${ }^{2,47}$ There- fore, dedicated monitoring of INR values helps to prevent ICH among patients with AF receiving oral anticoagulation therapy.

\section{Consensus position:}

- Risk-adjusted oral anticoagulation therapy in AF significantly reduces stroke rates, whereas major bleeding rates are not increased compared with placebo or aspirin within the therapeutic range of INR 2.0 to 3.0.

- In high-risk patients the benefit of stroke reduction outweighs the risk of bleeding associated with treatment with VKAs.

- Avoiding excessive INR values $>4$ by way of dedicated monitoring helps to prevent ICH among AF patients.

\section{Guidelines on the implementation of antithrombotic therapy in atrial fibrillation}

Practice guidelines such as the 2006 ACC/AHA/ESC Guidelines for the Management of Patients with Atrial Fibrillation ${ }^{1}$ or the Seventh American College of Chest Physicians (ACCP) 2004 guidelines ${ }^{24}$ provide detailed recommendations relating to antithrombotic therapy in patients with AF. National guidelines such as those from the United Kingdom, ${ }^{48}$ Italy, ${ }^{49}$ or Switzerland ${ }^{50}$ are mainly based on the ACC/AHA/ESC or ACCP guidelines. Despite substantial differences among published schemes, ${ }^{51}$ scoring systems for stratifying stroke risk in patients with nonvalvular AF provide some guidance for implementation of oral anticoagulation therapy. The 2006 ACC/AHA/ESC guidelines apply a risk-based approach using the clinical $\mathrm{CHADS}_{2}$ (cardiac failure, hypertension, age, diabetes, and stroke [doubled]) scoring system. ${ }^{52}$ In $\mathrm{CHADS}_{2}$, prior stroke or TIA is the strongest independent predictor of stroke followed by diabetes mellitus, history of hypertension, current or history of heart failure, and advanced age. ${ }^{1,28,53}$ Studies have identified INR $>4,54$ age $>80$ years, ${ }^{55}$ elevated blood pressure, ${ }^{56}$ prior ischemic stroke, ${ }^{54}$ and short-term tolerability of oral anticoagulants ${ }^{47}$ as major risk factors for intracranial bleeding (Table 1). Especially the latter two risk factors underline the need for adequate initiation of oral antico- 
agulation in high-risk AF patients. Anticoagulation of elderly patients with AF should be accompanied by tight control of hypertension because modest reductions in blood pressure considerably reduce the risk of $\mathrm{ICH}^{57}$

Table 1 - Clinical Risk Factors for Major Hemorrhage during Oral Anticoagulation Therapy*

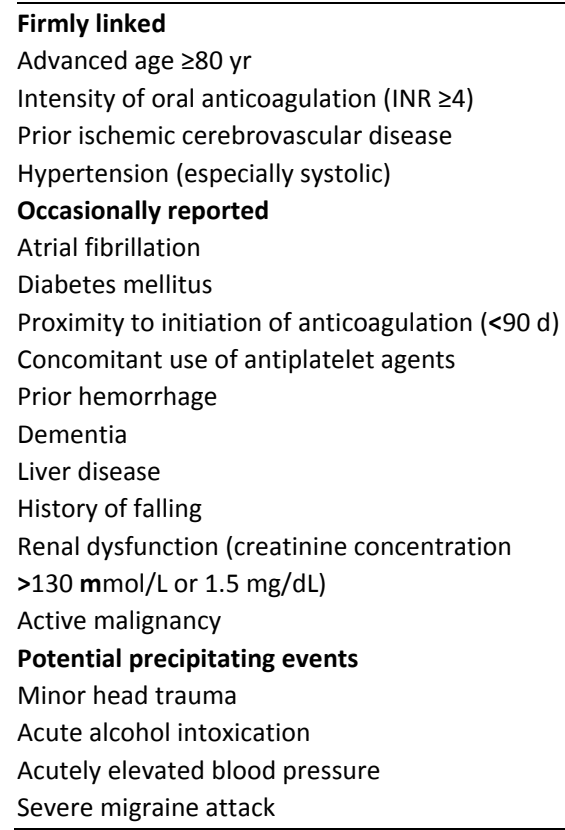

\section{Current recommendations}

According to the ACC/AHA/ESC guidelines, patients with prior stroke, TIA, other thromboembolism, or with rheumatic heart disease are at highest risk for stroke and clearly need oral anticoagulation. The guidelines specify when risk factors indicate that aspirin is sufficient for antithrombotic treatment and when risk factors suggest a patient is a candidate for oral anticoagulation therapy (Table 2). VKAs are indicated if a patient has one high- risk factor or more than one moderate risk factor. Aspirin is sufficient in a patient with no other risk factors for stroke. If there is one moderate stroke risk factor, either aspirin or VKAs can be used, according to patient and physician preference. 
Table 2 - Summary of Recommendations for Antithrombotic Therapy in Patients with Atrial Fibrillation Dependent on Risk Group and Definition of the Risk Groups

\begin{tabular}{lll}
\hline Risk Groups & Recommended Therapy & \\
\hline No risk factors & Aspirin $81-325 \mathrm{mg} / \mathrm{d}$ & \\
One moderate risk factor & $\begin{array}{l}\text { Aspirin } 81-325 \mathrm{mg} / \mathrm{d} \text { or } \\
\text { Oral anticoagulation } \\
\text { (INR 2.0-3.0; target value: } 2.5)\end{array}$ & \\
& Oral anticoagulation \\
A high-risk factor or $>1$ moderate risk factor & (INR 2.0-3.0; target value: 2.5$)$ & \\
Less Validated or Less Important Risk Factors & Moderate Risk Factors & High Risk Factors \\
Female gender & Age $\geq 75$ yr & Previous stroke \\
Age 65-74 yr & Hypertension & TIA or thromboembolism \\
Thyroid hyperfunction (thyreotoxicosis) & Heart failure & Mitral stenosis \\
& Left ventricular function $\leq 35 \%$ & Mechanical valve \\
& & replacement* \\
\hline
\end{tabular}

*For mechanical valve replacement, target INR >2.5. INR, international normalized ratio; TIA, transient ischemia attack. Adapted from 60.

Oral anticoagulation is considered monotherapy for AF patients. The concomitant use of an antiplatelet agent and oral anticoagulation has proven not to be beneficial over oral anticoagulation monotherapy but rather seems to increase ICH risk in the elderly. ${ }^{61}$ Awaiting the results of the Atrial Fibrillation Clopidogrel Trial With Irbesartan for Prevention of Vascular Events-A trial, recent data from a post hoc subgroup analysis of the Clopidogrel for High Atherothrombotic Risk and Ischemic Stabilization, Management, and Avoidance trial indicate the same holds true for dual antiplatelet therapy in low-risk patients. ${ }^{62}$ In anticoagulated patients with concomitant stents, antiplatelet therapy is managed according to stent guidelines and intensity of oral anticoagulation remains unchanged (INR, 2.0 to 3.0; target value, 2.5). In these patients, anticoagulation monitoring needs to be performed at an increased frequency.

Little data are available on the thromboembolic risk of the patient with atrial flutter. However, based on evidence that the thromboembolic risk is elevated compared with sinus rhythm patients but slightly lower than that of AF patients, ${ }^{63}$ the antithrombotic regimen is the same for both arrhythmias, atrial flutter and AF.

Except in AF patients with mechanical valves, the target INR should be 2.5 (range, 2.0 to 3.0). This is based on data demonstrating an INR $<2$ is not associated with a lower ICH risk in elderly AF patients compared with INR values between 2.0 and $3.0,{ }^{64}$ but both the risk for ${ }^{65}$ and mortality of ischemic stroke ${ }^{2}$ do increase when the INR drops below 2.0. In the Euro- Heart Survey on AF, guideline-adherent antithrombotic treatment of high-risk patients was associated with improved outcomes compared with a higher chance of thromboembolism in undertreated patients. ${ }^{66}$ In 
this survey, overtreatment was not associated with a higher chance of major bleeding (Fig. 4).

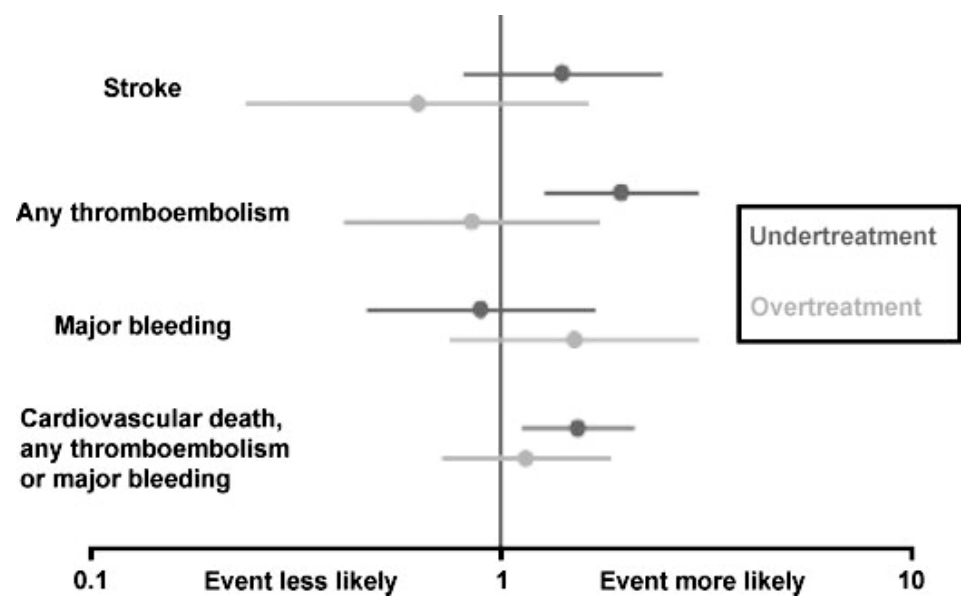

Figure 4 - Multivariable effect of antithrombotic guideline deviance on 1-year outcome. Results are reported as odds ratio (OR) with $95 \%$ confidence interval compared with the reference group "guideline adherence" $(\mathrm{OR}, 1) .^{66}$

Referral of AF patients to a specialist one time is strongly recommended when initiating antithrombotic therapy. For implementation and management of oral anticoagulation, therapy determination of INR is preferable over expressing the results as prothrombin time (PT) or Quick \%.

\section{Consensus position:}

- International practice guidelines such as the 2006 ACC/AHA/ESC guidelines provide helpful guidance on how to manage oral anticoagulation therapy in patients with AF.

- The antithrombotic treatment of patients with atrial flutter is the same as that for AF patients.

- Physicians should first evaluate stroke risk and bleeding risk in a given patient. Then risks and benefits of oral anticoagulation therapy should be discussed.

- If appropriate, oral anticoagulation should be initiated when one high-risk factor or more than one moderate risk factor are present.

- Oral anticoagulation therapy should be used as mono- therapy in AF patients. The only exceptions are AF patients requiring concomitant clopidogrel treatment during the first 9 to 12 months after coronary stenting.

- Determination of INR is preferable over expressing the results as prothrombin time (PT) or Quick \%. The target INR value should be 2.5 (range, 2.0 to 3.0). 


\section{Implementation of anticoagulation guidelines in clinical practice}

Although AF is highly prevalent in general practice and guidelines are in place, many patients are still under- treated or not treated at all. It has been estimated that worldwide an average of only $30 \%$ of patients with AF are treated with oral anticoagulation, ${ }^{67}$ whereas an estimated 60 to $70 \%$ should be. ${ }^{1}$ In Germany and the Netherlands, $\sim 60 \%$ of patients are treated according to guidelines; in Denmark, $\sim 75 \%{ }^{7,14,60}$ Guideline adherence in Italy is not clearly known but may be $10 \%$ in a series of AF patients admitted to hospital with a first-ever stroke ${ }^{68}$ to $<50 \%{ }^{69}$ In a single-center study from Italy among 255 patients with nonvalvular AF admitted to an internal medicine ward from 2001 to 2005, 85\% of them high-risk patients, 62\% received VKAs, but a fourth of these patients were undercoagulated. Among the high- risk patients, only $47.2 \%$ were adequately anticoagulated, $17.9 \%$ were undercoagulated, $23.4 \%$ received aspirin, and $11.5 \%$, no antithrombotic treatment. ${ }^{69}$ But patients not only are undertreated: In the Netherlands, overtreatment has been reported in as many as $18 \%$ of anti- coagulated AF patients, ${ }^{14,66}$ exposing them to an increased risk of bleeding. Whereas many high-risk AF patients are not anticoagulated adequately, it has been clearly demonstrated that guideline-adherent treatment is associated with improved outcomes. ${ }^{66,70}$ Several barriers to implementation of oral anticoagulation therapy exist.

\section{Awareness and estimate of true risk}

Strong evidence indicates that physicians underestimate the risk of stroke in their patients with AF and over- estimate the risk of severe bleeding, particularly in the elderly. ${ }^{70-73}$ Unfortunately, stroke prevention as a positive result of oral anticoagulation cannot be perceived by physicians directly. In contrast, major bleeding as a side effect of anticoagulation therapy can be experienced by physicians. Positive reinforcement pointing out the effectiveness of oral anticoagulation therapy is absent. As a consequence, physicians tend to ascribe stroke events to the disease itself and bleeding to treatment, and they fear iatrogenic complications but not stroke as the more frequent complication of AF. Accordingly, it has been shown that a physician's experience with bleeding events associated with oral anticoagulation therapy reduced warfarin prescribing, whereas the experience of stroke in a patient while not on warfarin did not affect subsequent prescribing. ${ }^{74}$

In another study, $15.8 \%$ of 596 general practitioners reported having a patient with $\mathrm{AF}$ experience an $\mathrm{ICH}$ with anticoagulation, and $45.8 \%$ had a patient with known AF experience a stroke without anticoagulation. ${ }^{75}$ However, only $45.6 \%$ of the physicians selected an anticoagulant in the presence of a minor falls risk when presented with a patient at "very high risk" of stroke, and $17.1 \%$ would anticoagu- 
late if the patient had a treated peptic ulcer. ${ }^{75}$ Family physicians with less decisional conflict and those who were more experienced were more likely to endorse anticoagulation.

Among very elderly AF patients, the decision to prescribe oral anticoagulants is strongly influenced by contraindications. Hemorrhage, falls, and patient refusal or history of nonadherence to treatment constituted nearly $80 \%$ of the physician-cited reasons for not pre- scribing warfarin in AF patients who had been considered for anticoagulation therapy in one study. ${ }^{59}$

For many patients with AF, physicians' fears of the risk of bleeding related to anticoagulant therapy are often exaggerated and unfounded. Physicians should be aware of the impact of $\mathrm{AF}$ and the devastating consequences of not treating it adequately. They should also be able to discern absolute from relative contraindications. Strategies to optimize the management of AF should address psychological barriers to using anticoagulation as well. The key issue in selecting patients with AF for oral anticoagulation therapy is accurately estimating their stroke risk, with risk of hemorrhage during anticoagulation a lesser issue, relevant to only a few patients.

\section{Access to guidelines}

Better access to the evidence base should enable clinicians to advise their patients appropriately. Often guidelines are too large and complex and, as a result, even specialists may not have consensus on treatment decisions (e.g., in patients presenting with high INR levels). Moreover, international guidelines are available only in English and not in local languages. What is more, few guidelines on oral anticoagulation therapy aim at the needs of general practitioners, which may include topics such as bleeding risk stratification, bridging therapy, or dual treatment with anticoagulants and antiplatelets. Because AF only represents a small part of a general practitioner's job, these physicians need simple guidance and suggestions for clear-cut decisions. This is critical to counter the concerns over treatment risk and perceived complications of oral anticoagulation therapy for some physicians. In some countries, the average general physician may not be well trained in treating AF but should be confident, as a minimum, about screening patients for AF and identifying those patients who need treatment. Special referral guidelines would also be of particular interest for general practitioners. They should help the physician to decide on when to refer the patient to specialist evaluation and treatment and to identify the "red flags" of oral anti- coagulation therapy monitoring. Factors to consider include prevalence and costs; definition and symptoms; impact on patients, such as the risk of death and disability in stroke; diagnosis and assessment; and treatment options. 
International and national guidelines should be harmonized and also be published and diffused in local languages and adapted to local practice patterns. Short and simple guideline versions should be prepared for use in primary care medicine. In addition to the complete paper version, an updated backup guideline Web site could be implemented. Guideline versions in electronic formats such as for personal digital assistants and personal computers as well as easy-to-use calculator tools should assist in balancing the benefits and risks of oral anticoagulation therapy for the individual patient.

\section{Educational issues}

Physician specialty is an important determinant for VKA use. In a Dutch study, cardiologists showed best guideline adherence, whereas general practitioners were less adherent to guidelines. ${ }^{76}$ Similarly, in the Stroke and Atrial Fibrillation Ensemble II study, factors independently associated with prescription of oral anticoagulation were mainly related to the characteristics of the practitioner. ${ }^{77}$ Being followed up by a cardiologist or a younger general practitioner were the strongest predictors of VKA treatment. Underutilization of oral anticoagulation therapy as well as differences between treatment by general practitioners and specialists may therefore not only result from inappropriate perceptions of stroke and bleeding risks and consequences. Other reasons may be insufficient education, resulting in a lack of knowledge about oral anticoagulation therapy, and avoidance of responsibility for the patient.

Living with anticoagulants has become more demanding for patients than just taking the medication prescribed by the doctor. Patients therefore need to take responsibility by getting involved. The reward is control of the therapy in contrast to letting the therapy control the patients' lives. ${ }^{78}$ According to studies such as the West Birmingham Atrial Fibrillation Project, ${ }^{79}$ how- ever, many patients with AF possess limited knowledge of $A F$, its consequences, and therapies. Most patients (61\%) believed AF was "not serious," and many patients were not aware that AF predisposed to stroke. Only 52\% were aware of the reason for anticoagulation treatment, whereas the rest of the patients started therapy just because their "doctor told them to." A minority felt that their physician provided adequate information regarding warfarin therapy. ${ }^{79}$ Poor patient adherence to treatment is potentially a major source for poor anti- coagulation control even among patients being treated in dedicated management systems where the importance of adherence is continually emphasized. ${ }^{80}$ The key to success is to communicate with patients to meet their requirements and improve their quality of life. Care of anticoagulated patients means to diagnose, educate, and treat them. Adherence rates are also related to access to INR testing and the burden of monitoring. ${ }^{81,82}$ In this regard 
point-of-care testing may offer advantages to physicians because rapidly available results enable them to communicate their treatment decision immediately to the patient.

Educational intervention programs improve knowledge about and/or control of oral anticoagulation therapy for AF. ${ }^{83-85}$ Such programs may include regular teaching sessions, information booklets, workbooks, or slide presentations and can be addressed to individuals or groups of patients. However, education of the anticoagulated patient is time consuming for physicians and stuffed with learning content for patients, and therefore often neglected. Thus educational programs should attempt to maximize office efficiency by delegating this task to physician extenders, nurses, pharmacists, or perhaps an office-based computer. ${ }^{84}$ When written in- formation is applied, the patient's reading skills have to be considered because the patient's reading abilities may be lower than the readability of the written information. It is important to have information that is understand- able and culturally relevant to prevent the outcome of internal bleeding. ${ }^{86}$ Despite the practical value of making the patient as knowledgeable as possible, the best strategy for educating patients about anticoagulation is yet to be determined. ${ }^{84}$

\section{Consensus position:}

- International and national guidelines should be harmonized and be published and diffused in local languages and adapted to local practice patterns. Short and simple guideline versions should be prepared for use in primary care medicine.

- In addition to the complete paper version of guidelines, an updated backup Web site may be prepared. It would be helpful to provide an easy-to-use calculator for balancing and checking benefits and risks of oral anticoagulation therapy in the individual patient in electronic formats.

- General physicians need better education on the management of oral anticoagulation and to be aware of the importance of $\mathrm{AF}$ and the consequences of not treating it adequately. Special referral guidelines may help them decide when to refer the patient to specialist evaluation and treatment and to identify the "red flags" of oral anticoagulation therapy monitoring.

\section{Impact of underutilization of anticoagulation in patients with atrial fibrillation}

When patients with AF do not receive any or no adequate oral anticoagulation therapy, the risk of stroke and death is increased. ${ }^{2}$ In a Swiss study, $16 \%$ of stroke patients who had a history of AF were not on oral anticoagulation, providing evidence that for many of the stroke patients AF is diagnosed first at the time of stroke. In another study, $31 \%$ of unselected AF patients without contraindications were not 
treated with oral anticoagulants. ${ }^{70}$ If these patients had been treated according to guidelines, an estimated event rate of $4.9 \%$ per year could have been prevented. A meta- analysis of nine studies using a target conventional INR of 2.0 to 3.0, the overall odds ratio for ischemic stroke for patients with INR $<2$ as compared with INR $\geq 2$ was 5.07 (95\% Cl, 2.92 to 8.80$).{ }^{87}$ This means that undercoagulated patients with $\mathrm{AF}$ are significantly more likely to have stroke than those maintained within the recommended INR range (Fig. 5).

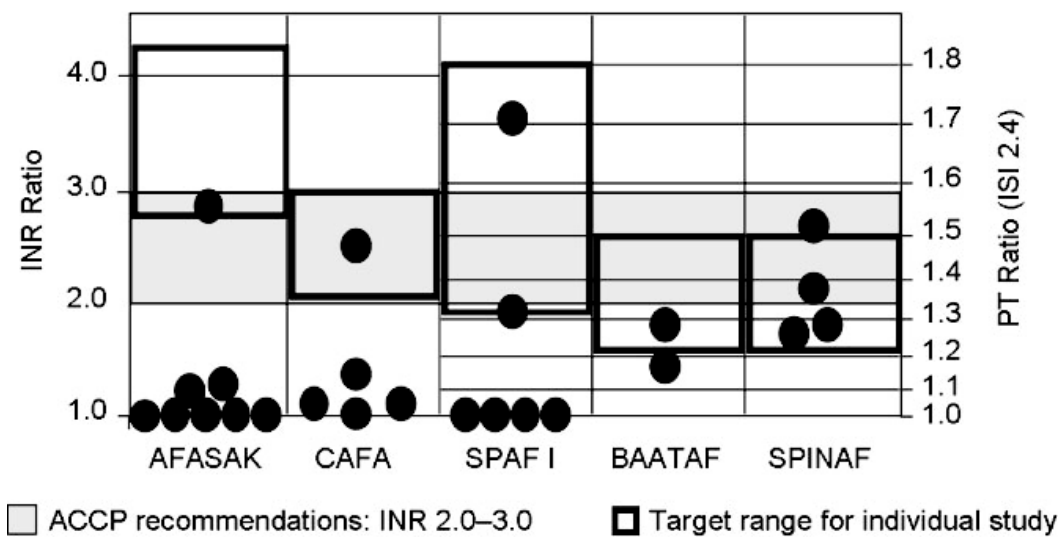

Figure 5 - Intensity of anticoagulation when stroke occurred in patients assigned to warfarin in atrial fibrillation trials. ${ }^{32,88-92}$

Undercoagulated patients are more prone to have stroke (black balls). ACCP, American College of Chest Physicians; AFASAK, Atrial Fibrillation, Aspirin, and Anticoagulation Study; BAATAF, The Boston Area Anticoagulation Trial for Atrial Fibrillation; CAFA,Canadian Atrial Fibrillation Anticoagulation study; INR, international normalized ratio; ISI, international sensitivity index; PT, prothrombin time; SPAF, Stroke Prevention in Atrial Fibrillation study; SPINAF, Stroke Prevention in Nonrheumatic Atrial Fibrillation.

\section{Economic aspects}

AF represents a considerable cost burden on health-care systems due to therapeutic interventions associated with increased AF morbidity and mortality. ${ }^{93}$ In the United States, the number of hospitalizations related to AF almost increased threefold in 2000 compared with 20 years ago. ${ }^{94}$ Fig. 6 shows the annual estimated costs of care and health resource utilization for the management of AF according to data from the United King- dom, ${ }^{95}$ France, ${ }^{96}$ and the United States. ${ }^{97}$ In the UK- based survey, an increase of the National Health Service budget, from 0.6 to $1.2 \%$ in 1995 to 0.9 to $2.4 \%$ by 2000 , has been observed. ${ }^{95}$ 


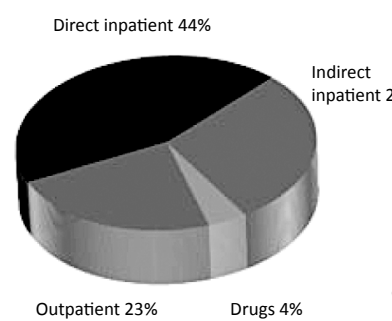

US: US\$6,650 million

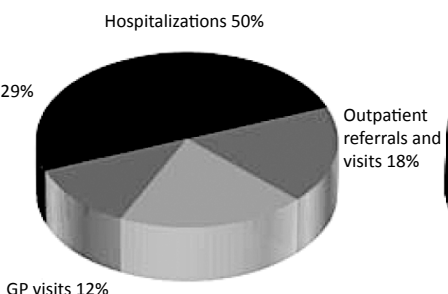

Drugs $20 \%$

UK: US\$803 million

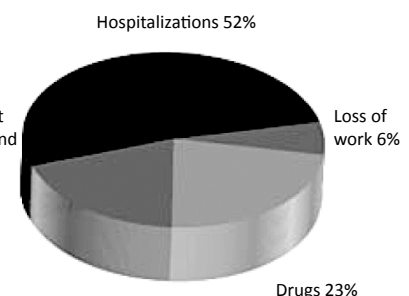

Consultations $19 \%$

France: US\$2,605 million

Figure 6 - Estimated annual costs of atrial fibrillation in the United States, ${ }^{97}$ United Kingdom, ${ }^{95}$ and France. ${ }^{96} \mathrm{GP}$, general practitioner.

Costs attributable to AF have to be considered in the context of different management strategies. In a pharmacoeconomic review, Szucs and Bramkamp showed that treatment with warfarin is highly cost effective both compared with aspirin or no therapy in patients with AF at moderate-to-high risk of stroke. ${ }^{98}$ The cost effectiveness of anticoagulation therapy is driven by the achieved risk reduction rather than the potential benefits estimated from clinical trials. Failure to maintain optimal anticoagulation places patients at risk of complications such as stroke, the management of which is a significant cost driver. ${ }^{98}$ Undertreatment with INR values outside the target range increases hospitalization rates. ${ }^{19,99}$ A Canadian and a U.S. study showed that INR monitoring led to fewer complications as well as to lower costs for health-care professionals. ${ }^{100,101}$ However, only a small amount of the potential anticoagulation cost-saving benefit is currently attained due to undertreatment with VKAs. The U.S. study presented that if half of the AF patients in routine medical care currently receiving oral anticoagulation were optimally anticoagulated, $\$ 1.3$ billion would have been saved in 2004. Oral anticoagulation for stroke prevention, in addition to an optimized anticoagulation care, could even have saved up to \$2.4 billion.

\section{Anticoagulation management}

Anticoagulation management should consider various aspects of anticoagulation therapy that are addressed differently by different methods of anticoagulation management (Table 3). Not all management strategies work the same for all patients, and the physician should evaluate what works best for the individual patient for major convenience. A major problem for oral anticoagulation control independent from the strategy used is the instability of lifestyle of a patient as well as the loss of patients or lack of adherence ${ }^{80}$ during treatment. Anti- coagulation management may also be complicated (e.g., by interacting drugs, diet, or traveling). Another major influence on INR variation results from the time point of testing, particularly 
when treating a patient with a sub- stance having a short half-life such as acenocoumarol. $^{102}$

Table 3 - Elements of Anticoagulation Management

\begin{tabular}{ll}
\hline Elements & Options \\
\hline Management style & Formal, structured anticoagulation management \\
Informal, unstructured anticoagulation management \\
Method of INR testing & $\begin{array}{l}\text { Venipuncture, laboratory } \\
\text { Professional point-of-care testing }\end{array}$ \\
& Point-of-care testing by patient or surrogate \\
Supervision of adjustments and decision making & Health-care professional patient or surrogate \\
Frequency of testing & Historically once a month (4-6 wk) \\
& More frequent in selected situations \\
& Individually determined for each patient \\
\hline
\end{tabular}

INR, international normalized ratio

\section{Elements of anticoagulation management}

Basically there are two styles of anticoagulation management: In the informal style, oral anticoagulation is managed by the individual practitioner who cares for the patient. In this essentially unstructured "usual care" option, patients may show up once per month. In contrast, a formal approach to anticoagulation management promotes systematic, structured care of the patients. The persons involved in structured care adopt an active attitude. The formal approach meets the requirements of "high quality anticoagulation monitoring" and is the preferred management style where available. $^{103}$

INR testing can be performed in different ways. Blood may be sampled by venipuncture or by simple fingerstick, and INR values can be measured in a central laboratory or by point-of-care coagulometers. INR testing may be performed either by health-care professionals or by the patient or a surrogate at home (e.g., a nurse visiting older patients who are not able to manage self-testing on their own). All methods of INR testing are accurate and capable of providing reliable results. Anticoagulant dose may be adjusted by health-care professionals, as in the usual care or patient self-testing (PST) options, or by the patient or a surrogate, as in patient selfmanagement (PSM). In any of these options, competency is needed to ensure correct dose adjustments.

Because factors such as medications, diet, and concurrent diseases can alter the pharmacokinetics of VKAs, frequent INR monitoring is necessary to ensure that a patient remains within therapeutic range. ${ }^{104}$ Health-care providers should assess their performance by monitoring INR regularly using a consistent method- ology. Historically, oral anticoagulation therapy has been monitored once a month. Testing 
not only allows for dose adjustments but is also important for reassurance of the patients in terms of avoidance of bleeding. INR testing should be performed at least every 4 to 6 weeks, and more frequent testing of no longer than 2 weeks is required in selected situations such as unstable patients. ${ }^{24}$ Special considerations that may warrant more frequent testing are a huge bleeding risk or periods of instability. The International Self-Monitoring Association for Oral Anticoagulation 2005 guidelines recommend a testing interval of no longer than 4 weeks for stable patients and weekly testing for PST and PSM. ${ }^{105}$ Computerized decision support algorithms, which calculate monitoring intervals based on prior results, provide the optimum method for achieving good anti- coagulation control, ${ }^{106-109}$ but they are not available everywhere.

\section{Anticoagulation management modalities}

Traditionally four strategies of oral anticoagulation therapy management have been established: "usual" care by general practitioners or specialists, anticoagulation clinics, PST, and PSM. In the usual care option, patients are cared for, along with all other patients, by their personal physician. Table 4 presents an overview of the advantages and disadvantages of different anticoa- gulation management modalities.

When compared with usual care, coagulation monitoring in dedicated anticoagulation clinics shows a $59 \%$ reduction in major hemorrhagic events and $68 \%$ reduction in thrombotic events when compared with usual care ${ }^{110}$ due to improvements in INR time in a range ${ }^{111}$ leading to reduced bleeding events. ${ }^{112}$ Several studies have shown that PSM of oral anticoagulation using point-of-care coagulometers improves the quality of anticoagulation, thus reducing complication rates and mortality compared with usual care and that it is at least as good as or even slightly better than management in anticoagulation clinics. ${ }^{113-115}$ Accordingly, the current ACCP guidelines advocate PSM and PST for the management of patients with AF. ${ }^{1}$ Better INR control by PSM than by usual care translates into better out- comes of the patients. $^{116}$ 
Table 4 - Synopsis of Advantages and Disadvantages of Anticoagulation Management Modalities

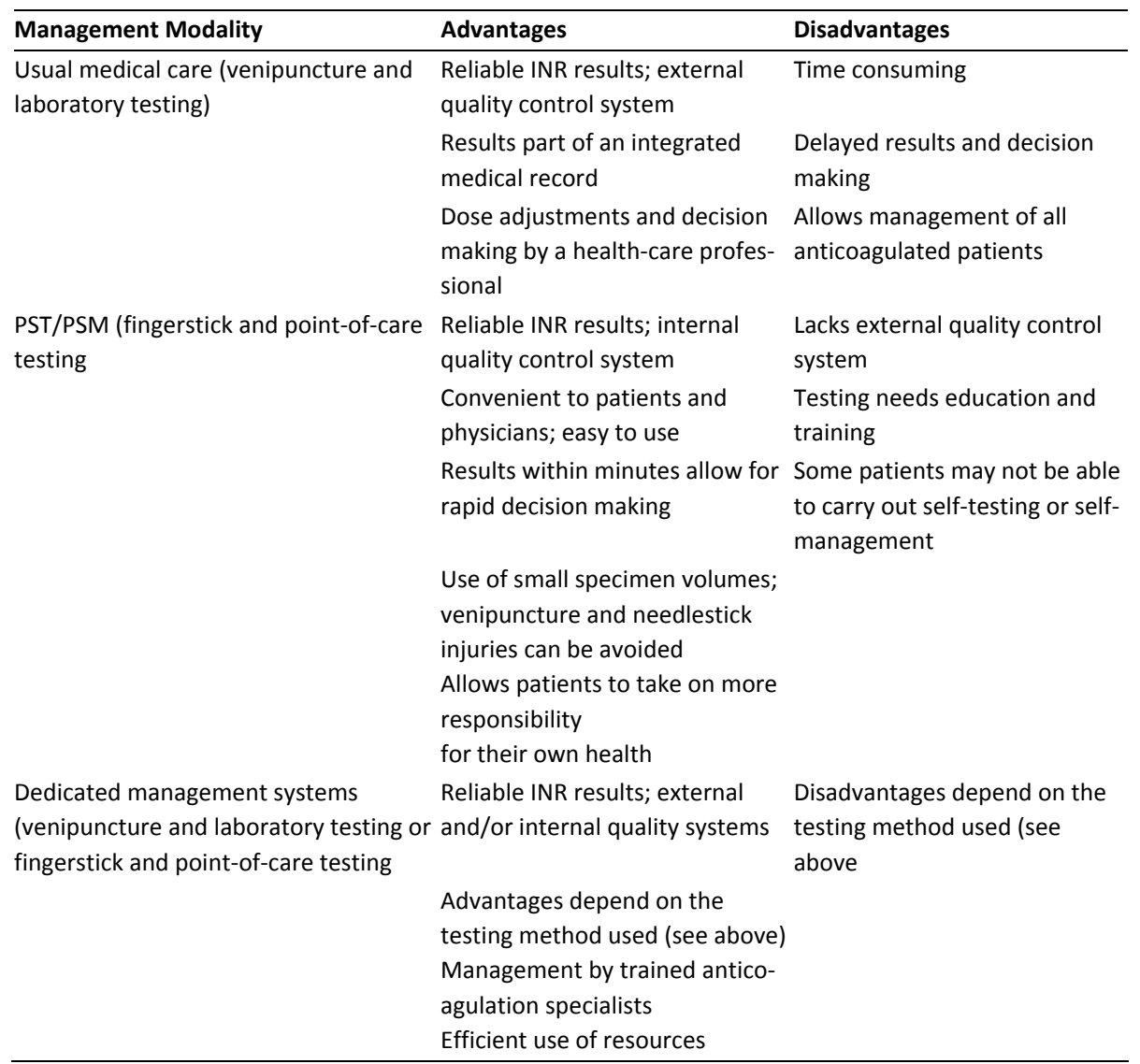

INR, international normalized ratio; PST, patient self-testing; PSM, patient self-management.

Currently, the Department of Veterans Affairs Cooperative Study 481, "The Home INR Study" (THINRS), is underway to compare anticoagulation management with frequent PST using a point-of-care device to high-quality anticoagulation management implemented by an anticoagulation service with conventional monitoring of prothrombin time by INR on major health outcomes. ${ }^{117}$ To assess the effect of PST frequency on oral anticoagulation outcomes, patients randomized to PST are assigned in a substudy of THINRS to weekly, twice-weekly, or once-every- 4-weeks testing. The results will help to determine the exact place of self-testing versus dedicated care in oral anticoagulation monitoring.

There are regional differences in oral anticoagulation management strategies. In the Netherlands, formal anticoagulation management predominates. Blood is in general drawn by venipuncture, and anticoagulation is managed by anticoagulation clinics. Moreover, pharmacists are integrated in the management of the patients. In Italy, $75 \%$ of the patients are formally managed by their general practitioners but 
often are self-managed without any formal education. In the United States, healthcare environments are extremely diverse, so PSM currently is not applicable. Usually patients are referred to venipuncture, but caring of the patients is informal. In Germany, a sophisticated PSM training system exists. Furthermore, there are important regional differences concerning re- imbursement by health insurances: In Germany, where self-management is reimbursed for patients with mechanical heart valves and on a single-case basis also for patients with atrial fibrillation, $<100,000$ patients per-form PSM, whereas point-of-care testing by physicians is not adequately reimbursed. In the United Kingdom, test strips needed for point-of-care testing are reimbursed, but not the devices; in Switzerland, a sophisticated PSM training system exists comparable to Germany and $\sim 50$ to $90 \%$ of PSM costs are reimbursed by health insurance companies; in Denmark, $\sim 4 \%$ of patients perform PSM with full reimbursement and 50 to $60 \%$ of INR measurements at general practitioners are performed with point-of-care devices and reimbursed.

\section{Consensus position:}

- Reliable access to accurate INR monitoring is important for optimal management of oral anticoagulation therapy. A formal, structured management style is preferable when available. The frequency of testing has to be determined for each individual patient.

- All methods of INR testing are capable of providing reliable results.

- Dose adjustments of anticoagulants require competency (i.e., trained professionals or educated patients/ surrogates).

\section{REFERENCES}

1. Fuster V, Ryden LE, Cannom DS, et al. American College of Cardiology/American Heart Association Task Force on Practice Guidelines; European Society of Cardiology Committee for Practice Guidelines; European Heart Rhythm Association; Heart Rhythm Society. ACC/ AHA/ESC 2006 Guidelines for the Management of Patients with Atrial Fibrillation: a report of the American College of Cardiology/American Heart Association Task Force on Practice Guidelines and the European Society of Cardiology Committee for Practice Guidelines (Writing Committee to Revise the 2001 Guidelines for the Management of Patients With Atrial Fibrillation): devel- oped in collaboration with the European Heart Rhythm Association and the Heart Rhythm Society. Circulation 2006; 114(7):e257-e354.

2. Hylek EM, Go AS, Chang $Y$, et al. Effect of intensity of oral anticoagulation on stroke severity and mortality in atrial fibrillation. N Engl J Med 2003;349(11):1019-1026.

3. Go AS, Hylek EM, Phillips KA, et al. Prevalence of diagnosed atrial fibrillation in adults: national implications for rhythm management and stroke prevention: the AnTi- coagulation and Risk Factors in Atrial Fibrillation (ATRIA) Study. JAMA 2001;285(18):2370-2375.

4. Kannel WB, Benjamin EJ. Status of the epidemiology of atrial fibrillation. Med Clin North Am 2008; 92(1):17-40; ix 
5. Feinberg WM, Blackshear JL, Laupacis A, Kronmal R, Hart RG. Prevalence, age distribution, and gender of patients with atrial fibrillation. Analysis and implications. Arch Intern Med 1995;155(5):469-473.

6. Miyasaka Y, Barnes ME, Gersh BJ, et al. Secular trends in incidence of atrial fibrillation in Olmsted County, Minne- sota, 1980 to 2000, and implications on the projections for future prevalence. Circulation 2006;114(2):119-125.

7. WHO Monica Study. Decision resources. Availableat:www. klt.Fi/monica.

8. StatistischesBundesamt.2007.Availableat:www.destatis.de

9. Davies M, Hobbs F, Davis R, et al. Prevalence of left- ventricular systolic dysfunction and heart failure in the Echocardiographic Heart of England Screening study: a population based study. Lancet 2001;358(9280):439-444.

10. Heeringa J,van der Kuip DA, Hofman A, et al.Prevalence, incidence and lifetime risk of atrial fibrillation: the Rotterdam study. Eur Heart J 2006;27(8):949-953 11.

11. Di Carlo A, Baldereschi M, Gandolfo C, et al; ILSA Working Group; The Italian Longitudinal Study on Aging. Stroke in an elderly population: incidence and impact on survival and daily function. Cerebrovasc Dis 2003;16(2):141-150.

12. Filippi A, Bettoncelli G, Zaninelli A. Detected atrial fibrillation in north Italy: rates, calculated stroke risk and proportion of patients receiving thrombo-prophylaxis. Fam Pract 2000;17(4):337-339.

13. National Center of Epidemiology Surveillance and Health Promotion, Italian Institute of Health. . The Italian Cardiovascular Epidemiological Observatory. Ital Heart J 2004;5(suppl 3):29S-92S 14.

14. Nieuwlaat R, Capucci A, Camm AJ, et al; European Heart Survey Investigators. Atrial fibrillation management: a prospective survey in ESC member countries: the Euro Heart Survey on Atrial Fibrillation. Eur Heart J 2005;26(22):2422-2434.

15. Friberg J, Scharling H, Gadsbøll N, Truelsen T, Jensen GB; Copenhagen City Heart Study. Comparison of the impact of atrial fibrillation on the risk of stroke and cardiovascular death in women versus men (The Copenhagen City Heart 2448Study). Am J Cardiol 2004;94(7):889-894.

16. Wolf PA, Abbott RD, Kannel WB. Atrial fibrillation as an independent risk factor for stroke: the Framingham Study. Stroke 1991;22(8):983-988.

17. Page RL, Tilsch TW, Connolly SJ, et al; Azimilide Supraventricular Arrhythmia Program (ASAP) Investiga- tors. Asymptomatic or "silent" atrial fibrillation: frequency in untreated patients and patients receiving azimilide. Circulation 2003;107(8):1141-1145

18. Kerr C, Boone J, Connolly S, et al. Follow-up of atrial fibrillation: the initial experience of the Canadian Registry of Atrial Fibrillation. Eur Heart J 1996;17(suppl C):48-51.

19. American Heart Association. Heart disease and stroke statistics. Update. 2008. Available at: www.americanheart. org/presenter.jhtml.

20. Dulli DA, Stanko H, Levine RL. Atrial fibrillation is associated with severe acute ischemic stroke. Neuroepidemi- ology 2003;22(2):118-123.

21. Lin HJ, Wolf PA, Kelly-Hayes M, et al. Stroke severity in atrial fibrillation. The Framingham Study. Stroke 1996; 27(10):1760-1764.

22. Kannel WB, Abbott RD, Savage DD, McNamara PM. Epidemiologic features of chronic atrial fibrillation: the Framingham study. N Engl J Med 1982;306(17):1018- 1022.

23. Vidaillet $\mathrm{H}$, Granada JF, Chyou $\mathrm{PH}$, et al. A population- based study of mortality among patients with atrial fibrillation or flutter. Am J Med 2002;113(5):365-370.

24. Ansell J, Hirsh J, Poller L, Bussey H, Jacobson A, Hylek E. The pharmacology and management of the vitamin $\mathrm{K}$ antagonists: the Seventh ACCP Conference on Antithrom- botic and Thrombolytic Therapy. Chest 2004;126(3, suppl): 204S-233S.

25. White HD, Gruber M, Feyzi J, et al. Comparison of outcomes among patients randomized to warfarin therapy according to anticoagulant control: results from SPORTIF III and V. Arch Intern Med 2007;167(3):239-245. 
26. Go AS, Hylek EM, Chang Y, et al. Anticoagulation therapy for stroke prevention in atrial fibrillation: how well do randomized trials translate into clinical practice? JAMA 2003;290(20):2685-269.

27. Hart RG, Benavente O, McBride R, Pearce LA. Antith- rombotic therapy to prevent stroke in patients with atrial fibrillation: a meta-analysis. Ann Intern Med 1999;131(7): 492-501.

28. Risk factors for stroke and efficacy of antithrombotic therapy in atrial fibrillation. Analysis of pooled data from five randomized controlled trials. Arch Intern Med 1994;154(13):1449-1457.

29. Hart RG, Pearce LA, Aguilar MI. Meta-analysis: anti- thrombotic therapy to prevent stroke in patients who have nonvalvular atrial fibrillation. Ann Intern Med 2007;146(12):857-867.

30. Aguilar MI, Hart R, Pearce LA. Oral anticoagulants versus antiplatelet therapy for preventing stroke in patients with non-valvular atrial fibrillation and no history of stroke or transient ischemic attacks. Cochrane Database Syst Rev 2007;(3):CD006186.

31. van Walraven C, Hart RG, Singer DE, et al. Oral anticoagulants vs aspirin in nonvalvular atrial fibrillation: an individual patient meta-analysis. JAMA 2002;288(19):2441-2448.

32. Petersen P, Boysen G, Godtfredsen J, Andersen ED, Andersen B. Placebo-controlled, randomised trial of war- farin and aspirin for prevention of thromboembolic complications in chronic atrial fibrillation. The Copenhagen AFASAK study. Lancet 1989;1(8631):175-179.

33. Gull $\varnothing v$ AL, Koefoed BG, Petersen $P$, et al. Fixed minidose warfarin and aspirin alone and in combination vs adjusted- dose warfarin for stroke prevention in atrial fibrillation: Second Copenhagen Atrial Fibrillation, Aspirin, and Anti- coagulation Study. Arch Intern Med 1998;158(14):1513-1521.

34. Warfarin versus aspirin for prevention of thromboembolism in atrial fibrillation: Stroke Prevention in Atrial Fibrillation II Study. Lancet 1994;343(8899):687-691.

35. EAFT (European Atrial Fibrillation Trial) Study Group. Secondary prevention in non-rheumatic atrial fibrillation after transient ischaemic attack or minor stroke. Lancet 1993;342(8882):1255-1262.

36. Rash A, Downes T, Portner R, Yeo WW, Morgan N, Channer KS. A randomised controlled trial of warfarin versus aspirin for stroke prevention in octogenarians with atrial fibrillation (WASPO). Age Ageing 2007;36(2):151-156.

37. Healey JS, Hart RG, Pogue J, et al. Risks and benefits of oral anticoagulation compared with clopidogrel plus aspirin in patients with atrial fibrillation according to stroke risk: the atrial fibrillation clopidogrel trial with irbesartan for prevention of vascular events (ACTIVE-W). Stroke 2008; 39(5):14821486.

38. Hu DY, Zhang HP, Sun YH, Jiang LQ; Antithrombotic Therapy in Atrial Fibrillation Study Group. The rando- mized study of efficiency and safety of antithrombotic therapy in nonvalvular atrial fibrillation: warfarin compared with aspirin [in Chinese]. Zhonghua Xin Xue Guan Bing Za Zhi 2006;34(4):295-298.

39. Hellemons BS, Langenberg M, Lodder J, et al. Primary prevention of arterial thromboembolism in non-rheumatic atrial fibrillation in primary care: randomised controlled trial comparing two intensities of coumarin with aspirin. BMJ 1999;319(7215):958-964.

40. Pe rez-Go mez F, Alegr a E, Berjo $n \mathrm{~J}$, et al; NASPEAF Investigators. Comparative effects of antiplatelet, antico- agulant, or combined therapy in patients with valvular and nonvalvular atrial fibrillation: a randomized multicenter study. J Am Coll Cardiol 2004;44(8):1557-1566.

41. Morocutti C, Amabile G, Fattapposta F, et al. Indobufen versus warfarin in the secondary prevention of major vascular events in nonrheumatic atrial fibrillation. SIFA (Studio Italiano Fibrillazione Atriale). Investigators. Stroke 1997;28:1015-1021.

42. Mant J, Hobbs FD, Fletcher K, et al; BAFTA investigators; Midland Research Practices Network (MidReC). Warfarin versus aspirin for stroke prevention in an elderly community population with atrial fibrillation (the Birmingham Atrial Fibrillation Treatment of the Aged Study, BAFTA): a randomised controlled trial. Lancet 2007; 370(9586):493-503.

43. Atwood JE, Albers GW. Anticoagulation and atrial fibrillation. Herz 1993;18(1):27-38.

44. Fang MC, Go AS, Chang $Y$, et al. Death and disability from warfarin-associated intracranial and extracranial hem- orrhages. Am J Med 2007;120(8):700-705. 
45. Levi M, Hovingh GK, Cannegieter SC, Vermeulen M, Bu ller HR, Rosendaal FR. Bleeding in patients receiving vitamin $\mathrm{K}$ antagonists who would have been excluded from trials on which the indication for anticoagulation was based. Blood 2008;111(9):4471-4476.

46. van Walraven C, Hart RG, Singer DE, Koudstaal PJ, Connolly S. Oral anticoagulants vs. aspirin for stroke prevention in patients with non-valvular atrial fibrillation: the verdict is in. Card Electrophysiol Rev 2003;7(4):374- 378.

47. Hylek EM, Evans-Molina C, Shea C, Henault LE, Regan S. Major hemorrhage and tolerability of warfarin in the first year of therapy among elderly patients with atrial fibrilla- tion. Circulation 2007;115(21):2689-2696.

48. National Collaborating Centre for Chronic Conditions. Atrial Fibrillation: National Clinical Guideline for Management in Primary and Secondary Care. London, United Kingdom: Royal College of Physicians; 2006.

49. Albers GW, Dalen JE, Laupacis A, Manning WJ, Petersen P, Singer DE. Antithrombotic therapy in atrial fibrillation. Chest 2001;119(1, suppl):194S-206S.

50. Fumeaux T, Cornuz J, Polikar R, et al. Guidelines for the clinical management of atrial fibrillation: a practical perspective. Swiss Med Wkly 2004;134(17-18):235-247.

51. Stroke Risk in Atrial Fibrillation Working Group. Com- parison of 12 risk stratification schemes to predict stroke in patients with nonvalvular atrial fibrillation. Stroke 2008; 39(6):1901-1910.

52. Hart RG, Halperin JL. Atrial fibrillation and thromboembo- lism: a decade of progress in stroke prevention. Ann Intern Med 1999;131(9):688-695.

53. Gage BF, Waterman AD, Shannon W, Boechler M, Rich MW, Radford MJ. Validation of clinical classification schemes for predicting stroke: results from the National Registry of Atrial Fibrillation. JAMA 2001;285(22):2864- 2870.

54. Hylek EM, Singer DE. Risk factors for intracranial hemorrhage in outpatients taking warfarin. Ann Intern Med 1994;120(11):897-902.

55. Fihn SD, Callahan CM, Martin DC, McDonell MB, Henikoff JG, White RH; The National Consortium of Anticoagulation Clinics. The risk for and severity of bleeding complications in elderly patients treated with warfarin. Ann Intern Med 1996;124(11):970-979.

56. Hart RG, Boop BS, Anderson DC. Oral anticoagulants and intracranial hemorrhage. Facts and hypotheses. Stroke 1995;26(8):1471-1477.

57. Hart RG, Aguilar MI. Anticoagulation in atrial fibrillation: selected controversies including optimal anticoagulation intensity, treatment of intracerebral hemorrhage. J Thromb Thrombolysis 2008;25(1):26-32.

58. Levine MN, Raskob G, Beyth RJ, Kearon C, Schulman S. Hemorrhagic complications of anticoagulant treatment: the Seventh ACCP Conference on Antithrombotic and Thrombolytic Therapy. Chest 2004;126(3, suppl):287S-310S 59.

59. Hylek EM, D'Antonio J, Evans-Molina C, Shea C, Henault LE, Regan S. Translating the results of random- ized trials into clinical practice: the challenge of warfarin candidacy among hospitalized elderly patients with atrial fibrillation. Stroke 2006;37(4):1075-1080.

60. Fuster V, Ryde $\mathrm{L}$ LE, Asinger RW, et al; American College of Cardiology; American Heart Association; European Society of Cardiology; North American Society of Pacing and Electrophysiology. ACC/AHA/ESC guidelines for the management of patients with atrial fibrillation. A report of the American College of Cardiology/American Heart Association Task Force on Practice Guidelines and the European Society of Cardiology Committee for Practice Guidelines and Policy Conferences (Committee to develop guidelines for the management of patients with atrial fibrillation) developed in collaboration with the North American Society of Pacing and Electrophysiology. Eur Heart J 2001;22(20):1852-1923.

61. Hart RG, Benavente O, Pearce LA. Increased risk of intracranial hemorrhage when aspirin is combined with warfarin: a meta-analysis and hypothesis. Cerebrovasc Dis 1999;9(4):215-217. 
62. Hart RG, Bhatt DL, Hacke W, et al; CHARISMA Investigators. Clopidogrel and aspirin versus aspirin alone for the prevention of stroke in patients with a history of atrial fibrillation: subgroup analysis of the CHARISMA randomized trial. Cerebrovasc Dis 2008;25(4):344-347.

63. Biblo LA, Yuan Z, Quan KJ, Mackall JA, Rimm AA. Risk of stroke in patients with atrial flutter. Am J Cardiol 2001; 87(3):346-349, A9.

64. Fang MC, Chang Y, Hylek EM, et al. Advanced age, anticoagulation intensity, and risk for intracranial hemor- rhage among patients taking warfarin for atrial fibrillation. Ann Intern Med 2004;141(10):745-752.

65. Hylek EM, Skates SJ, Sheehan MA, Singer DE. An analysis of the lowest effective intensity of prophylactic anticoagulation for patients with nonrheumatic atrial fibrillation. $N$ Engl J Med 1996;335(8):540-546.

66. Nieuwlaat R, Olsson SB, Lip GY, et al; Euro Heart Survey Investigators; The Euro Heart Survey on Atrial Fibrillation. Guideline-adherent antithrombotic treatment is associated with improved outcomes compared with undertreatment in high-risk patients with atrial fibrillation. Am Heart J 2007; 153(6):1006-1012.

67. Ang SY, Peterson GM, Friesen WT, Vial JH. Review of antithrombotic drug usage in atrial fibrillation. J Clin Pharm Ther 1998;23(2):97-106.

68. Paciaroni M, Agnelli G, Caso V, et al. Atrial fibrillation in patients with first-ever stroke: frequency, antithrombotic treatment before the event and effect on clinical outcome. J Thromb Haemost 2005;3(6):1218-1223.

69. Ferro D, Loffredo L, Polimeni L, Violi F. Underuse of oral anticoagulants in patients with nonvalvular atrial fibrillation in Italy. Intern Emerg Med 2007;2(1):24-28.

70. Zehnder BS, Schaer BA, Jeker U, Cron TA, Osswald S. Atrial fibrillation: estimated excess rate of stroke due to lacking adherence to guidelines. Swiss Med Wkly 2006; 136(47-48):757-760.

71. Beyth RJ, Antani MR, Covinsky KE, et al. Why isn't warfarin prescribed to patients with nonrheumatic atrial fibrillation? J Gen Intern Med 1996;11(12):721-728.

72. Chang HJ, Bell JR, Deroo DB, Kirk JW, Wasson JH. Physician variation in anticoagulating patients with atrial fibrillation. Dartmouth Primary Care COOP Project. Arch Intern Med 1990;150(1):83-86.

73. Partington SL, Abid S, Teo K, Oczkowski W, O'Donnell MJ. Pre-admission warfarin use in patients with acute ischemic stroke and atrial fibrillation: the appropriate use and barriers to oral anticoagulant therapy. Thromb Res 2007;120(5):663-669.

74. Choudhry NK, Anderson GM, Laupacis A, Ross-Degnan D, Normand SL, Soumerai SB. Impact of adverse events on prescribing warfarin in patients with atrial fibrillation: matched pair analysis. BMJ 2006;332(7534):141-145.

75. Gattellari M, Worthington J, Zwar N, Middleton S. Barriers to the use of anticoagulation for nonvalvular atrial fibrillation: a representative survey of Australian family physicians. Stroke 2008;39(1):227-230.

76. Dinh T, Nieuwlaat R, Tieleman RG, et al. Antithrombotic drug prescription in atrial fibrillation and its rationale among general practitioners, internists and cardiologists in The Netherlands-The EXAMINE-AF study. A ques- tionnaire survey. Int J Clin Pract 2007;61(1):24-31.

77. Deplanque D, Leys D, Parnetti L, et al; SAFE II Investigators. Stroke prevention and atrial fibrillation: reasons leading to an inappropriate management. Main results of the SAFE II study. Br J Clin Pharmacol 2004; 57(6):798-806.

78. Hasenkamp JM, Sygehus S. Living with anticoagulants. Paper presented at: World Congress of Cardiology; 2006; Barcelona, Spain.

79. Lip GY, Golding DJ, Nazir M, Beevers DG, Child DL, Fletcher RI. A survey of atrial fibrillation in general practice: the West Birmingham Atrial Fibrillation Project. Br J Gen Pract 1997;47(418):285-289.

80. Kimmel SE, Chen Z, Price M, et al. The influence of patient adherence on anticoagulation control with warfarin: results from the International Normalized Ratio Adherence and Genetics (IN-RANGE) Study. Arch Intern Med 2007; 167(3):229-235. 
81. Nieuwlaat R, Capucci A, Lip GY, et al; Euro Heart Survey Investigators. Antithrombotic treatment in real-life atrial fibrillation patients: a report from the Euro Heart Survey on Atrial Fibrillation. Eur Heart J 2006;27(24):3018-3026.

82. Arnsten JH, Gelfand JM, Singer DE. Determinants of compliance with anticoagulation: a case-control study. Am J Med 1997;103(1):11-17.

83. Lane DA, Ponsford J, Shelley A, Sirpal A, Lip GY. Patient knowledge and perceptions of atrial fibrillation and anti- coagulant therapy: effects of an educational intervention programme. The West Birmingham Atrial Fibrillation Project. Int J Cardiol 2006;110(3):354-358.

84. Wofford JL, Wells MD, Singh S. Best strategies for patient education about anticoagulation with warfarin: a systematic review. BMC Health Serv Res 2008;8:40.

85. Sawicki PT; Working Group for the Study of Patient Self- Management of Oral Anticoagulation. A structured teach- ing and self-management program for patients receiving oral anticoagulation: a randomized controlled trial. JAMA 1999;281(2):145-150.

86. Wilson FL, Racine E, Tekieli V, Williams B. Literacy, readability and cultural barriers: critical factors to consider when educating older African Americans about anticoagulation therapy. J Clin Nurs 2003;12(2):275-282 87.

87. Reynolds MW, Fahrbach K, Hauch O, et al. Warfarin anticoagulation and outcomes in patients with atrial fibrillation: a systematic review and meta-analysis. Chest 2004;126(6):1938-1945 88.

88. Stroke Prevention in Atrial Fibrillation Study. Final results. Circulation 1991;84(2):527-539 89.

89. The Boston Area Anticoagulation Trial for Atrial Fibrillation Investigators. The effect of low-dose warfarin on the risk of stroke in patients with nonrheumatic atrial fibrillation. $\mathrm{N}$ Engl J Med 1990;323(22):1505-1511.

90. Connolly SJ, Laupacis A, Gent M, Roberts RS, Cairns JA, Joyner C. Canadian Atrial Fibrillation Anticoagulation (CAFA) Study. J Am Coll Cardiol 1991;18(2):349-355.

91. Ezekowitz MD, Bridgers SL, James KE, et al; Veterans Affairs Stroke Prevention in Nonrheumatic Atrial Fibrilla- tion Investigators. Warfarin in the prevention of stroke associated with nonrheumatic atrial fibrillation. N Engl J Med 1992;327(20):1406-1412.

92. Hirsh J, Dalen JE, Deykin D, Poller L. Oral anticoagulants. Mechanism of action, clinical effectiveness, and optimal therapeutic range. Chest 1992;102(4, suppl):312S-326S.

93. Bajpai A, Savelieva I, Camm AJ. Epidemiology and economic burden of atrial fibrillation. US Cardiovasc Dis 2007;1:14-17.

94. Wattigney WA, Mensah GA, Croft JB. Increasing trends in hospitalization for atrial fibrillation in the United States, 1985 through 1999: implications for primary prevention. Circulation 2003;108(6):711-716.

95. Stewart S, Murphy NF, Murphy N, Walker A, McGuire A, McMurray JJ. Cost of an emerging epidemic: an economic analysis of atrial fibrillation in the UK. Heart 2004;90(3): 286-292.

96. Le Heuzey JY, Paziaud O, Piot O, et al. Cost of care distribution in atrial fibrillation patients: the COCAF study. Am Heart J 2004;147(1):121-126.

97. Coyne KS, Paramore C, Grandy S, Mercader M, Reynolds M, Zimetbaum P. Assessing the direct costs of treating nonvalvular atrial fibrillation in the United States. Value Health 2006;9(5):348-356.

98. Szucs TD, Bramkamp M. Pharmacoeconomics of anti- coagulation therapy for stroke prevention in atrial fibrillation: a review. J Thromb Haemost 2006;4(6):1180-1185.

99. Jones M, McEwan P, Morgan CL, Peters JR, Goodfellow J, Currie CJ. Evaluation of the pattern of treatment, level of anticoagulation control, and outcome of treatment with warfarin in patients with non-valvar atrial fibrillation: a record linkage study in a large British population. Heart 2005;91(4):472-477.

100. Regier DA, Sunderji R, Lynd LD, Gin K, Marra CA. Cost- effectiveness of self-managed versus physician-managed oral anticoagulation therapy. CMAJ 2006;174(13):1847-1852.

101. Caro JJ. An economic model of stroke in atrial fibrillation: the cost of suboptimal oral anticoagulation. Am J Manag Care 2004;10(14, suppl):S451-S458; discussion S458-S461. 
102. van Geest-Daalderop JH, Hutten BA, Pe que riaux NC, Haas FJ, Levi M, Sturk A. The influence on INRs and coagulation factors of the time span between blood sample collection and intake of phenprocoumon or acenocoumarol: consequences for the assessment of the dose. Thromb Haemost 2007;98(4):738-746.

103. Phillips KW, Ansell J. Outpatient management of oral vitamin K antagonist therapy: defining and measuring high- quality management. Expert Rev Cardiovasc Ther 2008; 6(1):57-70.

104. Bernardo A, Vo ller H. Arbeitsgemeinschaft Selbstkontrolle der Antikoagulation (ASA) [Guidelines for "coagulation self-management"]. Dtsch Med Wochenschr 2001;126(12): 346-351.

105. Ansell J, Jacobson A, Levy J, Vo ller H, Hasenkam JM; International Self-Monitoring Association for Oral Anti- coagulation. Guidelines for implementation of patient self- testing and patient selfmanagement of oral anticoagulation. International consensus guidelines prepared by International Self-Monitoring Association for Oral Anticoagulation. Int J Cardiol 2005;99(1):37-45.

106. Fihn SD, McDonell MB, Vermes D, et al; National Consortium of Anticoagulation Clinics. A computerized intervention to improve timing of outpatient follow-up: a multicenter randomized trial in patients treated with warfarin. J Gen Intern Med 1994;9(3):131-139.

107. Fitzmaurice DA, Hobbs FD, Delaney BC, Wilson S, McManus R. Review of computerized decision support systems for oral anticoagulation management. Br J Haema- tol 1998;102(4):907-909.

108. Fitzmaurice DA, Hobbs FD, Murray ET, Holder RL, Allan TF, Rose PE. Oral anticoagulation management in primary care with the use of computerized decision support and near-patient testing: a randomized, controlled trial. Arch Intern Med 2000;160(15):2343-2348.

109. Manotti C, Moia M, Palareti G, Pengo V, Ria L, Dettori AG. Effect of computer-aided management on the quality of treatment in anticoagulated patients: a prospective, randomized, multicenter trial of APROAT (Automated PRogram for Oral Anticoagulant Treatment). Haemato- logica 2001;86(10):1060-1070.

110. Ansell JE. Optimizing the efficacy and safety of oral anticoagulant therapy: high-quality dose management, anticoagulation clinics, and patient self-management. Semin Vasc Med 2003;3(3):261270.

111. Ansell J, Hollowell J, Pengo V, Martinez-Brotons F, Caro J, Drouet L. Descriptive analysis of the process and quality of oral anticoagulation management in real-life practice in patients with chronic non-valvular atrial fibrillation: the international study of anticoagulation management (ISAM). J Thromb Thrombolysis 2007; 23(2):83-91.

112. Nichol MB, Knight TK, Dow T, et al. Quality of anticoagulation monitoring in nonvalvular atrial fibrillation patients: comparison of anticoagulation clinic versus usual care. Ann Pharmacother 2008;42(1):62-70.

113. Cromheecke ME, Levi M, Colly LP, et al. Oral anti- coagulation self-management and management by a specialist anticoagulation clinic: a randomised cross-over comparison. Lancet 2000;356(9224):97-102.

114. Voller H, Glatz J, Taborski U, Bernardo A, Dovifat C, Heidinger K. Self-management of oral anticoagulation in nonvalvular atrial fibrillation (SMAAF study). Z Kardiol 2005;94(3):182-186.

115. Heneghan C, Alonso-Coello P, Garcia-Alamino JM, Perera R, Meats E, Glasziou P. Self-monitoring of oral anti- coagulation: a systematic review and meta-analysis. Lancet 2006;367(9508):404-411.

116. Mene ndez-Ja ndula B, Souto JC, Oliver A, et al. Comparing self-management of oral anticoagulant therapy with clinic management: a randomized trial. Ann Intern Med 2005; 142(1):1-10.

117. Matchar DB, Jacobson AK, Edson RG, et al. The impact of patient self-testing of prothrombin time for managing anticoagulation: rationale and design of VA Cooperative Study \#481-the Home INR Study (THINRS). J Thromb Thrombolysis 2005;19(3):163-172 



\section{Chapter 7}

\section{Clinical Correlates of Immediate Success and Outcome at One Year Follow-up of Real World Cardioversion of Atrial Fibrillation: The Euro Heart Survey}

Ron Pisters ${ }^{*}{ }^{\dagger}$, Robby Nieuwlaat ${ }^{\ddagger}$, Martin H Prins ${ }^{\S}$, Jean-Yves Le Heuzey ${ }^{\prime \prime}$, Aldo P Maggioni", A John Camm ${ }^{\#}$ and Harry JGM Crijns ' + ; for the Euro Heart Survey Investigators.

*Department of Cardiology, Maastricht University Medical Centre, the Netherlands ${ }^{\dagger}$ Cardiovacular Research Institute Maastricht, Maastricht, the Netherlands

${ }^{\ddagger}$ Department of Cardiology, Population Health Research Institute, Hamilton, Canada

${ }^{\S}$ Department of Clinical Epidemiology, Maastricht University Medical Centre, the Netherlands

IIDepartment of Cardiology, Georges Pompidou Hospital, René Descartes University, Paris, France

"ANMCO Research Centre, Florence, Italy

"British Heart Foundation, Professor of Clinical Cardiology, Division of of Clinical Sciences, St. George's University, London, United Kingdom

Europace 2012 Jan 5. [Epub ahead of print]. PMID: 22222085 


\section{ABSTRACT}

Aims: In atrial fibrillation (AF) cardioversion is the cornerstone of the rhythm management strategy despite the lack of contemporary data on acute and long-term success. We aim to describe present-day cardioversion of AF and identify characteristics associated with immediate and long-term outcome.

Methods and Results: Based on the 5,333 AF patients enrolled in the multi-centre prospective Euro Heart Survey on AF we selected the 1,801 patients undergoing cardioversion at enrollment. Sinus rhythm (SR) was restored in 630/712 (88\%), $458 / 643(71 \%)$ and $333 / 446(75 \%)(p<.001)$ of the electrical $(E C V)$, intravenous (ivCCV) and oral (oCCV) chemical cardioversions, respectively at the cost of few (4.2\%) major complications. In multivariate analysis, absence of chronic obstructive pulmonary disease (COPD) $(p<0.001)$, presence of paroxysmal AF (PAF) $(p=0.013)$ and use of biphasic waveform $(p=0.018)$ were predictors of successful ECV. For ivCCV PAF $(p<0.001)$, absence of valvular heart disease $(p=0.004)$ and heart failure $(p=0.009)$, the presence of hypertension $(p=0.018)$ and coronary artery disease $(p=0.007)$ were predictive. Success of oCCV was driven by PAF $(p<0.001)$ and a smaller left atrial dimension ( $p=0.001$ ). At one year follow-up 893/1,271 (70\%) patients were in SR. Multivariate analysis revealed PAF $(p<0.001)$, shorter total AF history $(p<.001)$, continuous use of class Ic drugs or amiodarone during follow-up $(p<0.001)$, absence of COPD $(p=0.003)$, younger age $(p=0.004)$ and smaller left atrial dimension $(p=0.005)$ as independent predictors of $S R$ at one year follow-up.

Conclusions: Contemporary cardioversion of AF is routinely successfully and safely performed with a high proportion of patients in sinus rhythm at one year follow-up.

Keywords: Atrial fibrillation - cardioversion - rhythm control 


\section{INTRODUCTION}

Atrial fibrillation (AF) is responsible for a significant health care burden in the Western world due to its high and growing prevalence ${ }^{1,2}$, incidence ${ }^{3,4}$, chronic nature and potentially life-threatening complications. ${ }^{5,6}$

In AF management, rate control is not inferior to rhythm control regarding mortality or cardiovascular morbidity. ${ }^{7-9}$ Therefore, the rate control is the recommended initial treatment strategy for symptomatic individuals. ${ }^{10}$ Nevertheless, many AF patients are symptomatic or experience symptoms in daily practice despite rate control and they therefore receive rhythm control. ${ }^{11}$ This makes it an important and widely applied strategy.

Since their introduction several decades ago, electrical ${ }^{12}$ and pharmacological cardioversion ${ }^{13}$ have become important components of the rhythm control strategy for AF management. More recently, catheter ablation of AF has emerged as an attractive approach ${ }^{14}$, possibly becoming a first line rhythm control treatment in subgroups of patients. ${ }^{15}$

However, despite these developments and their common application, contemporary direct and long-term success rates of cardioversion of AF outside a randomized controlled setting are lacking. We therefore aim to provide insight into presentday cardioversion of AF in 'real-life' patients, and identify predictors for both immediate and long-term success.

\section{METHODS}

The study protocol was submitted to the institutional review board or ethical committee of all participating centers and approved or waived for the requirement of formal approval being an observational survey. The Euro Heart Survey on Atrial Fibrillation was a registry that only evaluated daily clinical practice, meaning patients were not required to undergo additional tests. As such the regulatory authorities waived the necessity of informed consent.

The design, data collection and validation, main $^{11}$ and general follow-up ${ }^{16}$ results and used definitions of the survey have been described previously. Briefly, between September 2003 and July 2004182 cardiology practices across 35 member countries of the European Society of Cardiology consecutively enrolled 5,333 ambulatory and hospitalized AF patients. Patients needed to be above 18 years of age and have a qualifying electrocardiogram or Holter recording of AF within the preceding 12 months. Patient characteristics and treatment were collected both at baseline and at clinical follow-up one year after the qualifying visit / admission. Absence or presence of AF at follow-up was electrocardiographically confirmed. 
For the present analysis we selected only patients undergoing a cardioversion at the time of enrollment. This amounted to 1,801 study subjects: $712 \mathrm{AF}$ patients underwent an electrical cardioversion (ECV), 643 patients had an intravenous pharmacological cardioversion (ivCCV) and in 446 patients an attempt to restore sinus rhythm by oral pharmacological cardioversion (oCCV) was made.

\section{Definitions}

Success of pharmacological cardioversion (CCV) was defined as restoration of sinus rhythm within 24 hours after the onset of pharmacological treatment. Successful ECV was defined as achieving and maintaining sinus rhythm for at least 10 minutes after shock. Failed electrical cardioversion was classified either as (a) no sinus rhythm obtained, (b) immediate recurrence of AF (IRAF) defined as a recurrence within two minutes after the last shock, or (c) an acute AF recurrence, defined as a recurrence later than two minutes but within ten minutes after the last shock. Pharmacological agents used to restore sinus rhythm were grouped according to the Vaughan-Williams classification ${ }^{17}$ and appropriateness of use was checked(10). From a clinical perspective, all used CCV drugs without cardioversion properties digitalis, magnesium, class II (betablockers, not including sotalol) and class IV (diltiazem, verapamil) agents were defined as non-antiarrhythmic drugs. This allowed evaluation of differences in short and long-term success between an approach using true antiarrhythmic drugs compared to use of non-antiarrhythmic drugs. Furthermore, beside the standard clinical classification of AF type, the present AF episode was termed 'breakthrough' when antiarrhythmic drugs were in use during the onset of this episode. Rhythm control during follow-up was defined as the use of a Vaughan-Williams Class I or III antiarrhythmic drug or an attempt at cardioversion at any time during the follow-up period. Major complications following cardioversion consisted of the previously defined major adverse events ${ }^{16}$ as well as sick sinus syndrome, asystole, syncope, torsade des pointes, ventricular tachycardia or ventricular fibrillation occurring within 14 days after enrollment, leading to hospitalization following the outpatient consultation or prolonged hospital admission. The above mentioned events occurring beyond 14 days were considered to be follow-up events.

\section{Statistical analysis}

SPSS statistical software version 17.0 (SPSS Inc., Chicago, Illinois) was used to perform data analysis. Continuous variables are reported as mean (SD) or median $\left(25^{\text {th }}\right.$ $-75^{\text {th }}$ percentiles) and categorical variables as number of observed patients (percentage). When comparing categorical variables between groups Fisher's exact test was used. Student's t test and ANOVA were utilized for comparison of normally 
distributed continuous variables between, respectively, two and three groups. When the continuous variable did not follow a normal distribution the MannWhitney or Kruskal-Wallis test was employed when comparing between two and three groups, respectively.

Identifying predictors of success of cardioversion and long-term maintenance of sinus rhythm was done by incorporating all biologically plausible variables with a significant univariate relationship ( $p$ value $<0.10$ ) after non-parametric testing for correlation, into a logistic regression model with stepwise reduction of the model. For these analyses, paroxysmal AF was compared with persistent/permanent AF. All variables in the final model with a $p$ value $<0.05$ were considered significant independent predictors and were tested for interactions. In order to maximize patients included in the multivariate analysis we used the average values of total AF history and the duration of the current AF episode within the respective cardioversion groups and the average values of the echocardiographic measures from the entire cohort (5,333 patients) to replace missing values.

\section{RESULTS}

Between September 2003 and July 2004 a total of 1,801 patients underwent a cardioversion at the time of enrollment into the survey. 1,271/1,801 (71\%) of these had a known rhythm status at follow-up. The last follow-up took place on December 18,2005 . Overall, the majority of patients were male (59\%) and had a mean age of 64.1 (SD, 12.6) years. Patients were mainly enrolled from the cardiology ward (70\%), outpatient clinic (19\%) or emergency department (6\%).Table 1 depicts patient baseline characteristics according to cardioversion strategy and Table 2 procedural characteristics. In general, patients of the oCCV strategy more often suffered from cardiovascular disease and patients undergoing ECV had a longer current AF episode.

Patients lost to follow-up had similar rates of successful cardioversion and differed in that they were more often female ( 46 vs. $39 \%, p=0.009$ ) and diabetic (20 vs. $16 \%, p=0.02$ ), had a shorter AF history (median [interquartile range] 0.09 [0.0-1.2] vs. $0.28[0.01-0.28]$ years, $p=0.002)$ and less often suffered from a prior stroke or transient ischemic attack ( 6 vs. $10 \%, p=0.02$ ) and hypertension ( 60 vs. $65 \%, p=0.04$ ). 
Table 1 - Patient baseline characteristics ${ }^{*}$

\begin{tabular}{|c|c|c|c|c|c|c|}
\hline & $\begin{array}{l}\text { ECV } \\
(n=712)\end{array}$ & $\begin{array}{l}\text { Intravenous PCV } \\
(n=643)\end{array}$ & $\begin{array}{l}\text { Oral PCV } \\
(n=446)\end{array}$ & $\begin{array}{l}\text { P } \\
\text { Value }^{+}\end{array}$ & $\begin{array}{l}\text { P } \\
\text { Value }^{\ddagger}\end{array}$ & $\begin{array}{l}\text { P } \\
\text { Value }^{\S}\end{array}$ \\
\hline \multicolumn{7}{|l|}{ Demographics } \\
\hline Age, mean (SD), y & $64.5(12.0)$ & $64.5(13.2)$ & $63.0(12.6)$ & .96 & .055 & .035 \\
\hline Women & 249/712 (35) & $286 / 643(45)$ & $211 / 446(47)$ & $<.001$ & .39 & $<.001$ \\
\hline Body Mass Index, mean (SD) & $28.0(7.0)(n=673)$ & $28.0(7.1)(n=609)$ & $27.3(14.3)(n=437)$ & .37 & .11 & .13 \\
\hline Type of AF & $(n=697)$ & $(n=637)$ & $(n=443)$ & & & \\
\hline First detected AF & $130(19)$ & $240(38)$ & $123(28)$ & $<.001$ & .001 & $<.001$ \\
\hline Paroxysmal AF & $156(22)$ & $271(45)$ & $204(46)$ & $<.001$ & .26 & $<.001$ \\
\hline Persistent AF & $411(59)$ & $126(20)$ & $116(26)$ & $<.001$ & .014 & $<.001$ \\
\hline Breakthrough episode & $282 / 683(42)$ & $156 / 608(26)$ & $133 / 427(31)$ & $<.001$ & .057 & .001 \\
\hline $\begin{array}{l}\text { Total AF history, } \\
\text { median (IQR), days }{ }^{\prime \prime}\end{array}$ & $331(59-1568)(n=381)$ & $\begin{array}{l}4(0-257) \\
(n=438)\end{array}$ & $\begin{array}{l}87(1-1499) \\
(n=296)\end{array}$ & $<.001^{11}$ & $<.001^{11}$ & $<.001^{11}$ \\
\hline $\begin{array}{l}\text { Duration present episode, } \\
\text { median (IQR), days }\end{array}$ & $30(3-90)(n=378)$ & $0.5(0.2-2)(n=508)$ & $2(0.4-14)(n=320)$ & $<.001^{11}$ & $<.001^{\prime \prime}$ & $<.001^{\prime \prime}$ \\
\hline $\begin{array}{l}\text { Admission duration, } \\
\text { median (IQR), days }\end{array}$ & $1(0-5)(n=704)$ & $2(0-6)(n=632)$ & $4(1-9)(n=442)$ & $<.001^{\prime \prime}$ & $<.001^{11}$ & $<.001^{11}$ \\
\hline Previous PCV & $169 / 710(24)$ & $290 / 643(45)$ & $296 / 446(66)$ & $<.001$ & $<.001$ & $<.001$ \\
\hline Previous ECV & $313 / 711(44)$ & $70 / 641(11)$ & $18 / 445$ (18) & $<.001$ & .001 & $<.001$ \\
\hline $\mathrm{CHADS}_{2}$ score & $(n=700)$ & $(n=634)$ & $(n=443)$ & & & \\
\hline $0-1$ & $434(62)$ & $374(59)$ & $257(58)$ & .26 & .75 & .19 \\
\hline 2 & $161(23)$ & $151(24)$ & $100(23)$ & .75 & .66 & .89 \\
\hline$>2$ & $105(15)$ & 109 (17) & 86 (19) & .30 & .38 & .061 \\
\hline AF symptoms" & $526 / 711(74)$ & $595 / 643(93)$ & $408(92)$ & $<.001$ & .57 & $<.001$ \\
\hline \multicolumn{7}{|l|}{ Patient history } \\
\hline Hypertension & $432 / 711(61)$ & $422 / 643(66)$ & $295 / 446(66)$ & .071 & .90 & .070 \\
\hline Coronary artery disease & $167 / 708(24)$ & $235 / 639(37)$ & $154 / 440(35)$ & $<.001$ & .56 & $<.001$ \\
\hline Diabetes mellitus & $106 / 711(15)$ & $127 / 641(20)$ & $71 / 446(16)$ & .017 & .11 & .68 \\
\hline Valvular heart disease & $178 / 710(25)$ & $134 / 631(21)$ & $95 / 444(21)$ & .11 & 1.0 & .16 \\
\hline Cerebrovascular accident/TIA & $51 / 707(7)$ & $43 / 638(7)$ & $65 / 445(15)$ & .75 & $<.001$ & $<.001$ \\
\hline Heart Failure & $188 / 708(27)$ & $169 / 640(26)$ & $122 / 444(28)$ & 1.00 & .73 & .73 \\
\hline COPD & 74/711 (10) & $89 / 641(14)$ & $88 / 440(20)$ & .054 & .009 & $<.001$ \\
\hline Pacemaker & $42 / 712(6)$ & $12 / 640(2)$ & $6 / 445(1)$ & $<.001$ & .63 & $<.001$ \\
\hline Major bleeding & $10 / 709(1)$ & $6 / 641(1)$ & $12 / 444(3)$ & .46 & .030 & .13 \\
\hline LVEF, mean (SD) & $51.1(14.7)(n=457)$ & $51.6(14.7)(n=447)$ & $48.7(14.6)(n=354)$ & .62 & .006 & .023 \\
\hline LA dimension, mean (SD), mm & $46.5(8.0)(n=555)$ & $43.5(7.2)(n=496)$ & $42.3(7.2)(n=378)$ & $<.001$ & .015 & $<.001$ \\
\hline \multicolumn{7}{|l|}{ Medication in use } \\
\hline Vitamin $\mathrm{K}$ antagonist & $569 / 693(82)$ & $143 / 579(25)$ & $167 / 419(40)$ & $<.001$ & $<.001$ & $<.001$ \\
\hline Aspirin & $11 / 694(21)$ & $245 / 583(47)$ & $166 / 422(32)$ & $<.001$ & .40 & $<.001$ \\
\hline Antiarrhythmic drug & $327 / 694(47)$ & $192 / 583(33)$ & $177 / 422(42)$ & $<.001$ & .004 & .094 \\
\hline Amiodarone & $209(30)$ & $107(18)$ & $103(24)$ & $<.001$ & .023 & .039 \\
\hline Sotalol & $58(8)$ & $34(6)$ & $32(8)$ & .083 & .30 & .73 \\
\hline Flecainide & $22(3)$ & $8(1)$ & $7(2)$ & .041 & .79 & .17 \\
\hline Propafenone & $41(6)$ & $38(7)$ & $31(7)$ & .73 & .62 & .38 \\
\hline Disopyramide & $3(0.4)$ & $2(0.3)$ & $3(0.7)$ & 1.0 & .66 & .69 \\
\hline Quinidine & $0(0)$ & $4(1)$ & $8(2)$ & .043 & .14 & $<.001$ \\
\hline
\end{tabular}




\begin{tabular}{|c|c|c|c|c|c|c|}
\hline & $\begin{array}{l}\text { ECV } \\
(n=712)\end{array}$ & $\begin{array}{l}\text { Intravenous PCV } \\
(n=643)\end{array}$ & $\begin{array}{l}\text { Oral PCV } \\
(n=446)\end{array}$ & $\begin{array}{l}\text { P } \\
\text { Value }^{+}\end{array}$ & $\begin{array}{l}\text { P } \\
\text { Value }^{\ddagger}\end{array}$ & $\begin{array}{l}\text { P } \\
\text { Value }^{\S}\end{array}$ \\
\hline Rate control drug ${ }^{\#}$ & $266 / 694(38)$ & $185 / 583(32)$ & $144 / 422(34)$ & .016 & .45 & .16 \\
\hline ARB or ACE inhibitor & $415 / 693(60)$ & $324 / 583(56)$ & $251 / 422(60)$ & .13 & .22 & .90 \\
\hline Statin $^{* *}$ & $170 / 694(25)$ & $148 / 583(25)$ & $80 / 422$ (19) & .75 & .018 & .032 \\
\hline
\end{tabular}

Abbreviations: $A C E$, angiotensin-converting enzyme; $A F$, atrial fibrillation; $A R B$, angiotensin II receptor blocker; COPD, chronic obstructive pulmonary disease; ECV, electrical cardioversion; LA, left atrial; LVEF, left ventricular ejection fraction; IQR, interquartile range; PCV, pharmacological cardioversion; TIA, transient ischemic attack. The CHADS2 score is a measure of the risk of stroke in patients with atrial fibrillation, with scores ranging from 0 to 6 and higher scores indicating a greater risk.(54) Congestive heart failure, hypertension, an age of 75 years or older, and diabetes are each assigned 1 point, and previous stroke or transient ischemic attack is assigned 2 points; the score is calculated by summing all the points for a given patient.

"Data are presented as No. (\%) unless otherwise specified. Fisher exact test for comparison of categorical outcomes. Unless otherwise specified Students t-test and ANOVA one-way variance analysis for continuous outcomes, respectively between two and three groups.

${ }^{\dagger} \mathrm{P}$ value between electrical and intravenous pharmacological cardioversion.

${ }^{\ddagger} \mathrm{P}$-value between intravenous and oral pharmacological cardioversion.

${ }^{\S} \mathrm{P}$-value between electrical and oral pharmacological cardioversion.

IIMann-Whitney and Kruskal-Wallis one-way variance analysis for continuous outcomes, respectively between two and three groups.

"The following were considered AF symptoms: palpitations, shortness of breath, fatigue, dizziness, syncope and chest pain.

"Combined or single use of a betablocker (no sotalol), digitalis, diltiazem or verpamil.

${ }^{* *}$ Statin are defined here as 3-hydroxy-3-methylglutaryl-coenzyme A reductase inhibitors.

\section{Success of cardioversion}

In 630 (88\%) of the ECV patients the procedure was successful. Procedural success was similar when using handheld paddles 469/527 (89\%) compared to adhesive pads $143 / 166(86 \%)(p=0.33)$ and in an antero-posterior compared to an anterolateral paddle position, respectively, $158 / 176$ (90\%) vs. 431/493 (87\%), $p=0.29$. Biphasic wave form was more successful than monophasic waveform, respectively, $387 / 424$ (91\%) vs. 218/260 (84\%), $p=0.003$.

Restoration of sinus rhythm within 24 hours after administration of the CCV drug was accomplished in $458 / 643$ (71\%) of the ivCCV patients vs. $333 / 446$ (75\%) of the oCCV, $p=0.21$. No antiarrhythmic drug-specific differences in success rate were observed. CCV using non-antiarrhythmic drugs was successful in 98/113 (87\%) oCCVs compared to 30/52 (58\%) ivCCVs, $p<0.001$.

Success of cardioversion was equal in the breakthrough compared to the antiarrhythmic drug free patients for ECVs, ivCCVs and oCCVs: $253 / 282(90 \%)$ vs. $377 / 430$ (88\%) $p=0.47,106 / 156$ (68\%) vs. $352 / 487$ (72\%) $p=0.31$ and $99 / 133$ (74\%) vs. $234 / 313(75 \%) p=1.0$, respectively.

In all strategies, patients with a current AF episode of unknown duration or $\geq 48$ hours were less likely to convert compared to patients with a current episode of $<48$ 
hours: $537 / 616(87 \%)$ vs. $93 / 96$ (97\%), p=0.003, 118/217 (54\%) vs. 340/426 (80\%), $\mathrm{p}<0.001$ and $181 / 272(67 \%)$ vs. $152 / 174(87 \%), p<0.001$, for ECVs, ivCCVs and oCCVs, respectively.

$41 / 630$ (7\%) ECVs, $15 / 458$ (3\%) ivCCVs and 17/333 (5\%) oCCVs that were successful were associated with a relapse to AF or atrial flutter prior to discharge. Taking this into account, the 'net success rate' for ECV, ivCCV and oCCV was $81 \%, 67 \%$ and $70 \%$, respectively.

Table 3, shows the univariately associated and independent determinants of successful cardioversion. After multivariate analysis absence of chronic obstructive pulmonary disease (COPD) $(p<0.001)$, paroxysmal AF $(p=0.01)$ and the use of a biphasic waveform device $(p=0.02)$ remained associated with success of ECV. For ivCCVs significant factors were paroxysmal AF $(p<0.001)$, absence of valvular heart disease $(p=0.004)$, absence of heart failure $(p=0.009)$ and the presence of hypertension $(p=0.02)$ and coronary artery disease (CAD) $(p=0.007)$. Sinus rhythm in oCCVs was driven by paroxysmal AF $(p<0.001)$ and a smaller left atrial dimension $(p=0.001)$.

\section{Complications}

Except for four patients who died following a non-sudden cardiovascular cause, all were discharged alive. Overall, 76/1,801 (4.2\%) of the patients undergoing cardioversion suffered a major complication with a similar event rate in breakthrough compared to antiarrhythmic drug free patients, respectively, $29 / 571$ (5.1\%) vs. $47 / 1,230$ (3.8\%), $p=0.26$. A complete overview of all major complications is displayed in Table 2. Patients with a current AF episode of $<48$ hours had a equal number of major complications compared to those with an episode of unknown duration or $\geq 48$ hours, $24 / 657$ (3.7\%) vs. $52 / 1086$ (4.8\%) p=0.28, respectively. 
Table 2 - (Peri)procedural characteristics ${ }^{*}$

\begin{tabular}{|c|c|c|c|c|}
\hline \multicolumn{3}{|c|}{ Pharmacological cardioversion } & \multirow{2}{*}{$\begin{array}{l}\text { Electrical cardioversion } \\
(\mathrm{n}=712)\end{array}$} & \\
\hline Drug & $\begin{array}{l}\text { Intravenous } \\
(n=643)\end{array}$ & Oral $(n=446)$ & & \\
\hline VW class III & $426(66)$ & $156(35)$ & Anesthesiologist present & $474 / 711(67)$ \\
\hline VW class Ic & $143(22)$ & $134(30)$ & Pre ECV pacemaker check & $94 / 161(61)$ \\
\hline Other AAD & $22(3)$ & $43(10)$ & Serum potassium check & $634 / 706$ (89) \\
\hline Amiodarone & $402(63)$ & $136(31)$ & Number of shocks & $(n=687)$ \\
\hline Dose, mg & $(n=401)$ & $(n=135)$ & Median & 1 \\
\hline Median & 900 & 1000 & IQR & $1-2$ \\
\hline IQR & $450-1200$ & $400-2000$ & Energy first shock, Joule & $(n=688)$ \\
\hline Sotalol & $3(1)$ & $20(5)$ & Median & 200 \\
\hline Dose, mg & $(n=3)$ & $(n=19)$ & IQR & $100-200$ \\
\hline Median & 40 & 160 & Energy final shock, Joule & $(n=621)$ \\
\hline IQR & $40-$ & $80-240$ & Median & 200 \\
\hline Ibutilide & $21(3)$ & Not applicable & IQR & $125-300$ \\
\hline Dose, mg & $(n=11)$ & Not applicable & External cardioversion & $698 / 709(98)$ \\
\hline Median & 1 & Not applicable & Biphasic waveform & $424 / 686(60)$ \\
\hline IQR & $1-2$ & & Handheld paddles & $527 / 693(74)$ \\
\hline Propafenone, $\mathrm{mg}$ & $86(13)$ & $113(25)$ & Antero-lateral paddle position & $493 / 682(69)$ \\
\hline Dose & $(n=83)$ & $(n=113)$ & Post ECV pacemaker check & $90 / 161(56)$ \\
\hline Median & 140 & 600 & Failure to achieve sinus rhythm & $54 / 82(66)$ \\
\hline IQR & $140-225$ & $450-600$ & IRAF & $8 / 82(10)$ \\
\hline Flecainide, mg & $57(9)$ & $21(5)$ & Acute recurrence & $20 / 82(24)$ \\
\hline Dose & $(n=54)$ & $(n=21)$ & & \\
\hline Median & 150 & 200 & & \\
\hline IQR & 137.5-150 & $200-300$ & & \\
\hline Non-AAD & $52(8)$ & $113(25)$ & & \\
\hline Digitalis & $28 / 52(54)$ & $22 / 113(20)$ & & \\
\hline Beta blocker $^{\dagger}$ & $10 / 52(19)$ & $51 / 113(45)$ & & \\
\hline Verapamil & $8 / 52(15)$ & 21/113 (19) & & \\
\hline Diltiazem & $3 / 52(6)$ & $17 / 113(15)$ & & \\
\hline Magnesium & $3 / 52(6)$ & Not applicable & & \\
\hline
\end{tabular}




\section{PCV}

ECV

Management following failed cardioversion

\begin{tabular}{|c|c|c|}
\hline AF accepted & $51 / 290(18)$ & $40 / 77(52)$ \\
\hline PCV & $81 / 290(28)$ & $6 / 77(8)$ \\
\hline ECV & $146 / 290(50)$ & $22 / 77(29)$ \\
\hline Other procedure to treat $A$ & $12 / 290(4)$ & $9 / 77(12)$ \\
\hline \multicolumn{3}{|l|}{ Major complications } \\
\hline Non-sudden cardiac death & $1(0.1)$ & $2(0.3)$ \\
\hline Sick sinus syndrome & $5(0.5)$ & $5(0.7)$ \\
\hline Ventricular tachycardia & $2(0.2)$ & $6(0.8)$ \\
\hline Torsades de Pointes & $3(0.3)$ & $1(0.1)$ \\
\hline Ventricular fibrillation & 0 & $3(0.4)$ \\
\hline Asystole & $7(0.7)$ & $2(0.3)$ \\
\hline Cardiac syncope & $8(0.8)$ & $1(0.1)$ \\
\hline Pulmonary embolism & $1(0.1)$ & 0 \\
\hline Myocardial infarction $^{\ddagger}$ & $4(0.4)$ & 0 \\
\hline Transient ischemic attack & $13(1.3)$ & $2(0.3)$ \\
\hline Non-hemorrhagic stroke & $1(0.1)$ & $2(0.3)$ \\
\hline Heart failure ${ }^{\S}$ & $9(1.0)$ & $7(1.1)$ \\
\hline Major bleeding & $10(1.0)$ & $9(1.3)$ \\
\hline
\end{tabular}

Abbreviations: $A F$, atrial fibrillation; $A A D$, antiarrhythmic drug; $E C V$, electrical cardioversion; IRAF, immediate recurrence of atrial fibrillation; IQR, interquartile range; PCV, pharmacological cardioversion; VW, Vaughan-Williams.

"Data are presented as No. (\%) of events within the cardioversion group unless otherwise specified.

${ }^{+}$Not including sotalol.

${ }^{\ddagger}$ The $n=58$ patients presenting with acute myocardial infarction on admission were excluded from this specific analysis.

${ }^{\S}$ The $n=271$ patients presenting with heart failure on admission were excluded from this specific analysis.

\section{Appropriate procedural anticoagulation and antiarrhythmic drug use}

Figure 1 provides details on the antithrombotic treatment. Anticoagulant use at the time of cardioversion because of an AF episode of unknown duration or $\geq 48$ hours was $90 \%, 42 \%$ and $52 \%$ in ECVs, ivCCVs and oCCVs, respectively. Discharge anticoagulation use increased to $93 \%$ for ECV and $61 \%$ for both ivCCV and oCCV patients. 


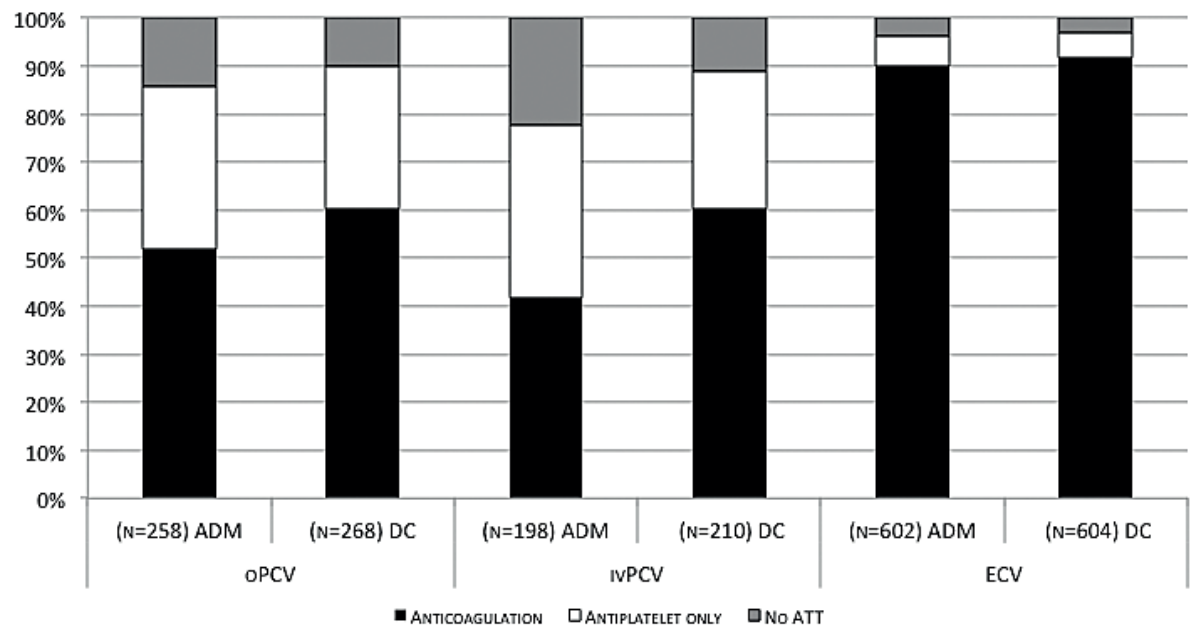

Figure 1 - Antithrombotic regimen by cardioversion strategy in patients with AF of unknown duration or $\geq 48$ hours. ADM, admission; AF, atrial fibrillation; ATT, antithrombotic treatment; DC, discharge; ECV, electrical cardioversion; oCCV, oral pharmacological cardioversion; ivCCV, intravenous pharmacological cardioversion.

In total, 399/712 (56\%) ECV and 684/1,089 (63\%) CCV patients either had coronary artery disease, heart failure or echo- or electrocardiographic evidence of left ventricular hypertrophy, i.e. a contra-indication to the use of class Ic drugs or sotalol. However, despite the presence of such a contra-indication these drugs were used prior to admission in 48/399 (12.0\%) ECV and 81/684 (11.8\%) CCV patients. Furthermore, in $126 / 1.089$ (11.6\%) of the CCV patients with a contra-indication a class Ic drug was used to attempt cardioversion and in 73/1,089 (6.7\%) CCV patients digitalis or sotalol were used. This brings the total number of CCVs using a nonrecommended antiarrhythmic drug to $199 / 1,089$ (18.2\%). CCVs using nonrecommended antiarrhythmic drugs had success and complications rates similar to the other CCVs, $138 / 199$ (69\%) vs. 653/890 (73\%), $p=0.25$ and $9 / 199$ (4.5\%) vs. $67 / 1,602$ (4.2\%), $p=0.84$, respectively.

\section{Outcome and rhythm status at one year follow-up}

During the median follow-up period of 374 (range, 363 - 410) days a total of $28 / 1,271(2 \%)$ patients died. No statistically significant difference in follow-up duration or death was observed between cardioversion strategies, $p=0.1$ and $p=1.0$, respectively. However, non-recommended antiarrhythmic drugs use at discharge was associated with more cardiovascular deaths compared to appropriate use, respectively, $5 / 133(3.8 \%)$ vs. $6 / 619$ (1.0\%), $p=0.03$. Major cardiac or cerebrovascular events occurred in $5.7 \%, 9.4 \%$ and $13.6 \%$ of the ECV, ivCCV and oCCV patients, respectively (for all comparisons $p<.001$, except when comparing ivCCV and oCCV, 
$\mathrm{p}=0.01$ ). For the ECV, intravenous and oral CCV patients the events consisted of an acute coronary syndrome in $2.4 \%, 6.3 \%$ and $8.1 \%(p=0.001)$ of patients respectively; thromboembolism in, respectively, $1.7 \%, 2.7 \%$ and $4.2 \%(p=0.08)$ and major bleeding in, respectively, $1.8 \%, 0.7 \%$ and $1.6 \%(p=0.33)$.

At follow-up, 157/529 (30\%) ECV, 115/409 (28\%) ivCCV and 106/295 (36\%) oCCV patients had AF symptoms.

\section{Predictors of sinus rhythm at follow-up}

In total, $893 / 1,271$ (70\%) of the patients were in sinus rhythm at follow-up consisting of 331 (61\%) ECV and 562 (77\%) CCV patients, $p<0.001$, without a difference between patients in the intravenous and oral CCV groups, respectively 330 (79\%) vs. $232(75 \%), p=0.29$. Overall, a rhythm control strategy during follow-up was applied in $804 / 1,052(63 \%)$ of the patients of which $600 / 804(47 \%)$ used an antiarrhythmic drug at some point in time during follow-up. The rhythm control strategy had a tendency to increase maintenance of sinus rhythm when compared to no rhythm control: 572/804 (71\%) vs. $165 / 248$ (67\%), p=0.18. Patients discharged with nonrecommended antiarrhythmic drugs had a similar rate of sinus rhythm at follow-up compared to those receiving recommended antiarrhythmic drugs, respectively, $102 / 144$ (71\%) vs. 429/612 (70\%), p=0.92.

Univariate and independent predictors of sinus rhythm at follow-up after multivariate logistic analysis are shown in Table 3. Logistic regression revealed paroxysmal AF ( $p<0.001)$, shorter total AF history $(p<0.001)$, continuous use of class Ic or amiodarone during follow-up $(p<0.001)$, absence of COPD $(p=0.003)$, younger age $(p=0.004)$ and smaller left atrial dimension $(p=0.005)$ as independent predictors of sinus rhythm at follow-up.

\section{Discussion}

The multicenter, prospective Euro Heart Survey on AF demonstrated that contemporary cardioversion of AF in real-life patients was widely applied in both symptomatic and asymptomatic individuals, had a high success rate and achieved maintenance of sinus rhythm at one year follow-up in a moderate proportion, at the cost of few major complications, for all strategies. 
Table 3 - Determinants of sinus rhythm

\begin{tabular}{|c|c|c|c|}
\hline & $\begin{array}{l}\text { Univariate } \\
P \text { value }\end{array}$ & $\begin{array}{l}\text { Multivariate } \\
\text { P value }\end{array}$ & $\begin{array}{l}\text { Odds ratio } \\
(95 \% \mathrm{Cl})\end{array}$ \\
\hline \multicolumn{4}{|l|}{ Following ECV (672/712) } \\
\hline Chronic obstructive pulmonary disease & $<.001$ & $<.001$ & $0.23(0.13-0.41)$ \\
\hline Paroxysmal atrial fibrillation & .014 & .014 & $2.04(1.15-3.61)$ \\
\hline Biphasic waveform & .003 & .020 & $1.79(1.10-2.91)$ \\
\hline Total AF history, per year & .039 & .078 & $0.96(0.92-1.01)$ \\
\hline Current duration of AF episode, per month & .001 & .62 & $1.01(0.99-1.03)$ \\
\hline \multicolumn{4}{|l|}{ Following intravenous PCV $(620 / 643)^{*}$} \\
\hline Paroxysmal atrial fibrillation & $<.001$ & $<.001$ & $3.01(2.00-4.51)$ \\
\hline Valvular heart disease & .002 & .004 & $0.52(0.34-0.81)$ \\
\hline Coronary artery disease & .029 & .007 & $1.76(1.16-2.67)$ \\
\hline Heart failure & .001 & .009 & $0.56(0.37-0.87)$ \\
\hline Hypertension & .002 & .018 & $1.60(1.09-2.37)$ \\
\hline Left atrial dimension, per millimeter & .002 & .13 & $0.98(0.95-1.01)$ \\
\hline Current duration AF episode, per month & $<.001$ & .26 & $0.96(0.89-1.03)$ \\
\hline Total AF history, per year & .002 & .73 & $1.01(0.94-1.09)$ \\
\hline \multicolumn{4}{|l|}{ Following oral PCV $(402 / 446)^{*}$} \\
\hline Paroxysmal atrial fibrillation & $<.001$ & $<.001$ & $5.11(3.07-8.49)$ \\
\hline Left atrial dimension, per millimeter & $<.001$ & .001 & $0.94(0.90-0.97)$ \\
\hline Amiodarone as PCV drug & .009 & .069 & $0.61(0.36-1.04)$ \\
\hline Thyroid disease & .021 & .073 & $0.50(0.23-1.07)$ \\
\hline Renal failure & .061 & .25 & $0.51(0.17-1.59)$ \\
\hline Current duration of AF episode, per month & $<.001$ & .25 & $0.97(0.93-1.02)$ \\
\hline Valvular heart disease & .024 & .27 & $0.71(0.38-1.31)$ \\
\hline Left ventricular ejection fraction, per percent & .028 & .50 & $1.01(0.99-1.03)$ \\
\hline Amiodarone at baseline & .038 & .76 & $1.13(0.55-2.53)$ \\
\hline Total AF history, per year & $<.001$ & .84 & $0.99(0.92-1.07)$ \\
\hline Age, per year & .071 & .84 & $1.00(0.98-1.02)$ \\
\hline \multicolumn{4}{|l|}{ At one-year follow-up $(1,210 / 1,271)^{*}$} \\
\hline Age, per year & $<.001$ & .004 & $0.98(0.97-0.99)$ \\
\hline Paroxysmal atrial fibrillation & $<.001$ & $<.001$ & $6.32(4.71-8.48)$ \\
\hline Total AF history, per year & $<.001$ & $<.001$ & $0.92(0.89-0.97)$ \\
\hline Left atrial dimension, per millimeter & $<.001$ & .005 & $0.92(0.95-0.99)$ \\
\hline Continuous use of $A \mathrm{AD}^{\dagger}$ during follow-up & $<.001$ & $<.001$ & $2.11(1.56-2.86)$ \\
\hline Heart failure & $<.001$ & .090 & $0.76(0.55-1.04)$ \\
\hline Chronic obstructive pulmonary disease & $<.001$ & .003 & $0.54(0.36-0.81)$ \\
\hline Left ventricular ejection fraction, per percent & .047 & .61 & $1.00(0.99-1.01)$ \\
\hline Diabetes mellitus & .091 & .83 & $0.96(0.66-1.40)$ \\
\hline Valvular heart disease & .068 & .99 & $1.00(0.71-1.41)$ \\
\hline Renal failure & .002 & .32 & $0.71(0.37-1.38)$ \\
\hline
\end{tabular}

Abbreviations: $A A D$, antiarrhythmic drugs; $A F$, atrial fibrillation; $\mathrm{Cl}$, confidence interval; $\mathrm{ECV}$, electrical cardioversion; PCV, pharmacological cardioversion.

*Number of patients in multivariate analysis.

${ }^{\dagger}$ Vaughan-Williams class Ic drug or amiodarone. 


\section{Electrical cardioversion}

The high success of ECV is within the range reported previously ${ }^{18-21}$, taking into account differences in patient characteristics ${ }^{22}$, duration of $\mathrm{AF}$ and technical aspects. Although the study was not designed to address optimum technical aspects of ECV a biphasic was clearly better than a monophasic waveform ${ }^{23}$. The benefit of an antero-posterior position ${ }^{24}$ was likely cancelled out by predominant use of selfadhesive pads in this position ${ }^{25}$ (data not shown). After multivariate analysis, biphasic waveform remained an independent predictor of success together with paroxysmal AF and COPD. The importance of trans thoracic resistance - largely driven by chest size - in success of cardioversion ${ }^{26}$ together with the pathophysiological changes, the observed influence of COPD is biologically plausible. Finally, the strong association between paroxysmal AF and successful ECV is not surprising since, by definition, this arrhythmia tends to convert spontaneously.

\section{Pharmacological cardioversion}

For both oral and intravenous administration, the observed success rates of pharmacological cardioversion with amiodarone and class Ic drugs are in line with the reports of randomized clinical trials $(\mathrm{RCTs})^{27-33}$, keeping in mind that our study could not identify differences in the time to conversion.

Interestingly, oCCV was frequently attempted and underlying heart disease appeared to have a less dramatic negative effect on success than expected in patients with the 'pill-in-the-pocket ${ }^{33}$ (or here, the perhaps more appropriate ${ }^{34}$ 'pill-in-thehospital') approach. .

Remarkable is the number and success of CCV using non-antiarrhythmic drugs, likely reflecting the known occurrence of spontaneous conversion of recent onset AF. However, even more concerning is the observation that a considerable number of patients received contra-indicated antiarrhythmic therapy prior to admission, at discharge and even as cardioversion drug. ${ }^{10,35}$

Data on predictors of pharmacologic cardioversion is scarce and conflicting. However, shorter duration of AF and smaller left atrial dimension are probably most consistently identified as predictors of successful $\mathrm{CCV}^{29,36-42}$. Multivariate analysis revealed paroxysmal AF to be the strongest independent predictor of success in $\mathrm{CCV}$, followed by shorter AF duration and smaller left atrial size in oral CCVs. Strikingly, we observed both hypertension and coronary artery disease to be positively associated with ivCCV success as opposed to heart failure and valvular heart disease. Possibly, the former two conditions are markers of a more early disease state and prompt presentation. 


\section{Complications}

Although cardioversion is potentially life-threatening, no patients died from sudden cardiac or thrombo-embolic causes. Despite the antithrombotic under-treatment the thrombo-embolic rate observed in this study is in line with the study by Gallagher et $\mathrm{al}^{43}$ However, considering the time-dependent occurrence of thromboembolic complications post-cardioversion, the true rate may have been underestimated. ${ }^{44}$ Based on a similar rate of major complications, cardioversion of recent onset compared to more persistent AF does not appear to be safer.

\section{Long term outcome}

Although substantial, the number of deaths and major cardiac or cerebrovascular events during follow-up were not surprising. The difference in events between ECV and CCV patients was largely driven by an increased number of acute coronary syndromes in the CCV group. However, inadequate anticoagulation and use of contraindicated antiarrhythmic drugs were strikingly high. It is unclear to what extend this contributed to the long term outcome and (peri)procedural complications. Altogether, these observations re-emphasize the importance of comprehensive treatment of AF patients rather than simply treating the electrocardiogram.

In all three groups, sinus rhythm at follow-up was promising at least, but perhaps most striking in the ECV group in light of previous studies. ${ }^{19,45-47}$ Beside rhythm control during follow-up and improved treatment of underlying heart disease, patient selection might be part of the explanation. The observed independent predictors of sinus rhythm at one year follow-up confirm what is known. ${ }^{19,46}$

As this is a subgroup analysis of the Euro Heart Survey on AF, consecutive inclusion of cardioversions cannot be guaranteed and careful data interpretation is warranted. Important to note, however, is that all reported peri-procedural details were pre-specified in the case record form and prospectively collected. Although missing rhythm status on follow-up excluded $32 \%$ of the cardioversions performed at baseline from the current analyses, significant differences from most of the presented data are unlikely considering that patient characteristics of those lost to follow-up were quite similar to those who were successfully followed. Inherent to the used definition of success, spontaneous conversion needs to be taken into consideration especially in recent onset and paroxysmal AF patients. ${ }^{30}$ Finally, as we used a single ECG at the follow-up visit to check for AF we underestimate the number of patients who still suffer from (paroxysmal) AF at one year follow-up. . 


\section{Clinical implications}

Potential clinical implications include emphasis on avoidance of non-guideline recommended drugs for CCV and long term rhythm control and on the importance of appropriate peri-procedural anticoagulation. Also, an initial (i.e. in the first 24 hours following the onset of $\mathrm{AF}$ ) pursuit of adequate rate control before attempting cardioversion might prove to be (cost-effectively) worthwhile. Finally, a biphasic waveform is always preferred, but especially in COPD patients.

Overall, our data provide a comprehensive, up-to-date overview of cardioversion of real-life AF patients, confirming its extensive successful implementation at the cost of few major complications.

\section{ACKNOWLEDGEMENTS}

We thank the Euro Heart Survey team, national coordinators, investigators, and data collection officers for performing the survey.

\section{Conflict of interests}

Dr Pisters reported receiving research grants from Bayer Health Care; consulting fees from Boehringer-Ingelheim, Bayer Health Care, Roche Diagnostics, and SanofiAventis; and lecture fees from Boehringer-Ingelheim. Dr Le Heuzey reported receiving research grants from Sanofi Aventis; consulting fees from Sanofi Aventis and Medapharma; and board membership fees from Sanofi Aventis and Medapharma. Dr Camm reported receiving consulting fees from Sanofi Aventis, Menarini, Richmond Pharmacology, Medtronic, Boston Scientific; expert testimony from Johnson and Johnson; research grants from Bayer Health Care, Boehringer Ingelheim, Sanofi Aventis, Servier and Daiichi-Sankyo; lecture fees from Menarini, Sanofi Aventis and Boehringer Ingelheim; fees for development of educational presentations from Merck; and royalties from Elsevier and Oxford University Press. Dr Crijns reported receiving consulting fees from Boehringer Ingelheim, Sanofi-Aventis, and AstraZeneca; grant support from St. Jude Medical, Boston Scientific, Boehringer Ingelheim, Sanofi-Aventis, Medapharma, and Merck; and honoraria from Medtronic, Sanofi-Aventis, Medapharma, Merck, Boehringer Ingelheim, and Biosense Webster. No other potential conflict of interest relevant to this article was reported. 


\section{REFERENCES}

1. Go AS, Hylek EM, Phillips KA, Chang Y, Henault LE, Selby JB, et al. Prevalence of diagnosed atrial fibrillation in adults: national implications for rhythm management and stroke prevention: the anTicoagulation and Risk Factors in Atrial Fibrillation (ATRIA) Study. JAMA. 2001 May 9;285(18):2370-5.

2. Heeringa J, van der Kuip DA, Hofman A, Kors JA, van Herpen G, Stricker BH, et al. Prevalence, incidence and lifetime risk of atrial fibrillation: the Rotterdam study. Eur Heart J. 2006 Apr;27(8):94953.

3. Lloyd-Jones DM, Wang TJ, Leip EP, Larson MG, Levy D, Vasan RS, et al. Lifetime risk for development of atrial fibrillation: the Framingham Heart Study. Circulation 2004;110:1042-6.

4. Miyasaka Y, Barnes ME, Gersh BJ, Cha SS, Bailey KR, Abhayaratna WP, et al. Secular trends in incidence of atrial fibrillation in Olmsted County, Minnesota, 1980 to 2000, and implications on the projections for future prevalence. Circulation. 2006 Jul 11;114(2):119-25. Epub 2006 Jul 3. Erratum in: Circulation. 2006 Sep 12;114(11):e498.

5. Risk factors for stroke and efficacy of antithrombotic therapy in atrial fibrillation. Analysis of pooled data from five randomized controlled trials. Arch Intern Med. 1994 Jul 11;154(13):1449-57. Erratum in: Arch Intern Med 1994 Oct 10;154(19):2254.

6. Stewart S, Hart CL, Hole DJ, McMurray JJ. A population-based study of the long-term risks associated with atrial fibrillation: 20-year follow-up of the Renfrew/Paisley study. Am J Med 2002;113:359-64.

7. Van Gelder IC, Hagens VE, Bosker HA, Kingma JH, Kamp O, Kingma T, et al. Rate Control versus Electrical Cardioversion for Persistent Atrial Fibrillation Study Group. A comparison of rate control and rhythm control in patients with recurrent persistent atrial fibrillation. N Engl J Med. 2002 Dec 5;347(23):1834-40.

8. The Atrial Fibrillation Follow-up Investigation of Rhythm Management (AFFIRM) Investigators. A comparison of rate control and rhythm control in patients with atrial fibrillation. N Engl J Med. 2002;347:1825-1833.

9. Roy D, Talajic M, Nattel S, Wyse DG, Dorian P, Lee KL, et al.; for the Atrial Fibrillation and Congestive Heart Failure Investigators. Rhythm control versus rate control for atrial fibrillation and heart failure. N Engl J Med. 2008 Jun 19;358(25):2667-77.

10. Fuster V, Rydén LE, Cannom DS, Crijns HJ, Curtis AB, Ellenbogen KA, et al. ACC/AHA/ESC 2006 guidelines for the management of patients with atrial fibrillation--executive summary: a report of the American College of Cardiology/American Heart Association Task Force on Practice Guidelines and the European Society of Cardiology Committee for Practice Guidelines (Writing Committee to Revise the 2001 Guidelines for the Management of Patients With Atrial Fibrillation). J Am Coll Cardiol. 2006 Aug 15;48(4):854-906. Erratum in: J Am Coll Cardiol. 2007 Aug 7;50(6):562.

11. Nieuwlaat R, Capucci A, Camm AJ, Olsson SB, Andresen D, Davies DW, et al.; for the European Heart Survey Investigators. Atrial fibrillation management: a prospective survey in ESC member countries: the Euro Heart Survey on Atrial Fibrillation. Eur Heart J. 2005 Nov;26(22):2422-34. Epub 2005 Oct 4.

12. Lown B, Amarasingham $R$ and Neuman $J$. New method for terminating cardiac arrhythmias. JAMA.1962, 182: 548.

13. W Frey; Ueber verhofflimmern bein menchen un seine beseitgung durch chinidin, Berklin Wochenschr 1918 (55):450-452.

14. Haïssaguerre M, Jaïs $P$, Shah DC, Takahashi A, Hocini M, Quiniou G, et al. Spontaneous initiation of atrial fibrillation by ectopic beats originating in the pulmonary veins. N Engl J Med. 1998 Sep 3;339(10):659-66.

15. Wilber DJ, Pappone C, Neuzil P, De Paola A, Marchlinski F, Natale A, et al.; for the ThermoCool AF Trial Investigators. Comparison of antiarrhythmic drug therapy and radiofrequency catheter ablation in patients with paroxysmal atrial fibrillation: a randomized controlled trial. JAMA. 2010 Jan 27;303(4):333-40. 
16. Nieuwlaat R, Prins MH, Le Heuzey JY, Vardas PE, Aliot E, Santini M, et al. Prognosis, disease progression, and treatment of atrial fibrillation patients during 1 year: follow-up of the Euro Heart Survey on atrial fibrillation. Eur Heart J. 2008 May;29(9):1181-9. Epub 2008 Apr 7.

17. Vaughan Williams EM. A classification of antiarrhythmic actions reassessed after a decade of new drugs. J Clin Pharmacol 1984;24:129-47.

18. Scott ME, Geddes JS, Patterson GC. The long term prognosis of atrial fibrillation following direct current conversion. Ulster Med J. 1968 Summer;37(2):155-61.

19. Van Gelder IC, Crijns HJ, Tieleman RG, Brügemann J, De Kam PJ, Gosselink AT, et al. Chronic atrial fibrillation. Success of serial cardioversion therapy and safety of oral anticoagulation. Arch Intern Med. 1996 Dec 9-23;156(22):2585-92.

20. Burton JH, Vinson DR, Drummond K, Strout TD, Thode HC, McInturff JJ. Electrical cardioversion of emergency department patients with atrial fibrillation. Ann Emerg Med. 2004 Jul;44(1):20-30. Erratum in: Ann Emerg Med. 2004 Sep;44(3):294.

21. Oral H, Brinkman K, Pelosi F, Flemming M, Tse HF, Kim MH, et al. Effect of electrode polarity on the energy required for transthoracic atrial defibrillation. Am J Cardiol. 1999 Jul 15;84(2):228-30, A8.

22. Van Gelder IC, Crijns HJ, Van Gilst WH, Verwer R, Lie KI. Prediction of uneventful cardioversion and maintenance of sinus rhythm from direct-current electrical cardioversion of chronic atrial fibrillation and flutter. Am J Cardiol. 1991 Jul 1;68(1):41-6.

23. Page RL, Kerber RE, Russell JK, Trouton T, Waktare J, Gallik D, et al; BiCard Investigators. Biphasic versus monophasic shock waveform for conversion of atrial fibrillation: the results of an international randomized, double-blindmulticenter trial. J Am Coll Cardiol. 2002 Jun 19;39(12):1956-63.

24. Kirchhof P, Eckardt L, Loh P, Weber K, Fischer RJ, Seidl KH, et al. Anterior-posterior versus anteriorlateral electrode positions for external cardioversion of atrial fibrillation: a randomised trial. Lancet. 2002 Oct 26;360(9342):1275-9.

25. Kirchhof P, Mönnig G, Wasmer K, Heinecke A, Breithardt G, Eckardt L, et al. A trial of self-adhesive patch electrodes and hand-held paddle electrodes for external cardioversion of atrial fibrillation (MOBIPAPA). Eur Heart J. 2005 Jul;26(13):1292-7.

26. Deale OC, Lerman BB. Intrathoracic current flow during transthoracic defibrillation in dogs. Transcardiac current fraction. Circ Res. 1990 Dec;67(6):1405-19.

27. Suttorp MJ, Kingma JH, Jessurun ER, Lie-A-Huen L, van Hemel NM, Lie KI. The value of class IC antiarrhythmic drugs for acute conversion of paroxysmal atrial fibrillation or flutter to sinus rhythm. J Am Coll Cardiol. 1990 Dec;16(7):1722-7.

28. Bianconi L, Boccadamo R, Pappalardo A, Gentili C, Pistolese M. Effectiveness of intravenous propafenone for conversion of atrial fibrillation and flutter of recent onset. Am J Cardiol. 1989 Aug 1;64(5):335-8.

29. Boriani G, Capucci A, Lenzi T, Sanguinetti M, Magnani B. Propafenone for conversion of recentonset atrial fibrillation. A controlled comparison between oral loading dose and intravenous administration. Chest. 1995 Aug;108(2):355-8.

30. Galve E, Rius T, Ballester R, Artaza MA, Arnau JM, Garcia-Dorado D, et al. Intravenous amiodarone in treatment of recent-onset atrial fibrillation: results of a randomized, controlled study. J Am Coll Cardiol. 1996 Apr;27(5):1079-82.

31. Chevalier P, Durand-Dubief A, Burri H, Cucherat M, Kirkorian G, Touboul P. Amiodarone versus placebo and class Ic drugs for cardioversion of recent-onset atrial fibrillation: a meta-analysis. J Am Coll Cardiol. 2003 Jan 15;41(2):255-62.

32. Azpitarte J, Alvarez M, Baún O, García R, Moreno E, Martin F, et al. Value of single oral loading dose of propafenone in converting recent-onset atrial fibrillation. Results of a randomized, double-blind, controlled study. Eur Heart J. 1997 Oct;18(10):1649-54.

33. Alboni P, Botto GL, Baldi N, Luzi M, Russo V, Gianfranchi L, Marchi P, Calzolari M, et al. Outpatient treatment of recent-onset atrial fibrillation with the "pill-in-the-pocket" approach. N Engl J Med. 2004 Dec 2;351(23):2384-91. 
34. Alboni P, Botto GL, Boriani G, Russo G, Pacchioni F, lori M, et al. Intravenous administration of flecainide or propafenone in patients with recent-onset atrial fibrillation does not predict adverse effects during 'pill-in-the-pocket' treatment. Heart. 2010 Apr;96(7):546-9.

35. Camm AJ, Kirchhof P, Lip GY, Schotten U, Savelieva I, Ernst S, et al. Guidelines for the management of atrial fibrillation: the Task Force for the Management of Atrial Fibrillation of the European Society of Cardiology (ESC). Eur Heart J 2010; Oct;31(19):2369-429.

36. Kochiadakis GE, Igoumenidis NE, Solomou MC, Kaleboubas MD, Chlouverakis GI, Vardas PE. Efficacy of amiodarone for the termination of persistent atrial fibrillation. Am J Cardiol. 1999 Jan 1;83(1):5861.

37. Ellenbogen KA, Stambler BS, Wood MA, Sager PT, Wesley RC Jr, Meissner MC, et al. . Efficacy of intravenous ibutilide for rapid termination of atrial fibrillation and atrial flutter: a dose-response study. J Am Coll Cardiol. 1996 Jul;28(1):130-6. Erratum in: J Am Coll Cardiol 1996 Oct;28(4):1082.

38. Reisinger J, Gatterer E, Lang W, Vanicek T, Eisserer G, Bachleitner T, et al. Flecainide versus ibutilide for immediate cardioversion of atrial fibrillation of recent onset. Eur Heart J. 2004 Aug;25(15):131824.

39. Vardas PE, Kochiadakis GE, Igoumenidis NE, Tsatsakis AM, Simantirakis EN, Chlouverakis GI. Amiodarone as a first-choice drug for restoring sinus rhythm in patients with atrial fibrillation: a randomized, controlled study. Chest. 2000 Jun;117(6):1538-45.

40. Tieleman RG, Gosselink AT, Crijns HJ, van Gelder IC, van den Berg MP, de Kam PJ, et al. Efficacy, safety, and determinants of conversion of atrial fibrillation and flutter with oral amiodarone. Am J Cardiol. 1997 Jan 1;79(1):53-7.

41. Stambler BS, Wood MA, Ellenbogen KA, Perry KT, Wakefield LK, VanderLugt JT. Efficacy and safety of repeated intravenous doses of ibutilide for rapid conversion of atrial flutter or fibrillation. Ibutilide Repeat Dose Study Investigators. Circulation. 1996 Oct 1;94(7):1613-21.

42. Weiner P, Ganam R, Ganem R, Zidan F, Rabner M. Clinical course of recent-onset atrial fibrillation treated with oral propafenone. Chest. 1994 Apr;105(4):1013-6.

43. Gallagher MM, Hennessy BJ, Edvardsson N, Hart CM, Shannon MS, Obel OA, et al. Embolic complications of direct current cardioversion of atrial arrhythmias: association with low intensity of anticoagulation at the time of cardioversion. J Am Coll Cardiol. 2002 Sep 4;40(5):926-33.

44. Berger M, Schweitzer P. Timing of thromboembolic events after electrical cardioversion of atrial fibrillation or flutter: a retrospective analysis. Am J Cardiol 1998;82:1545-7, A8.

45. Juul-Möller S, Edvardsson N, Rehnqvist-Ahlberg N. Sotalol versus quinidine for the maintenance of sinus rhythm after direct current conversion of atrial fibrillation. Circulation. 1990 Dec;82(6):19329.

46. Brodsky MA, Allen BJ, Capparelli EV, Luckett CR, Morton R, Henry WL. Factors determining maintenance of sinus rhythm after chronic atrial fibrillation with left atrial dilatation. Am J Cardiol. 1989 May 1;63(15):1065-8.

47. Singh BN, Singh SN, Reda DJ, Tang XC, Lopez B, Harris CL, et al; Sotalol Amiodarone Atrial Fibrillation Efficacy Trial (SAFE-T) Investigators. Amiodarone versus sotalol for atrial fibrillation. N Engl J Med. 2005 May 5;352(18):1861-72. 



\section{Chapter 8}

\section{Effect of Dronedarone on Clinical End Points in Patients with Atrial Fibrillation and Coronary Heart Disease: Insights from the ATHENA Trial}

Ron Pisters, $\mathrm{MD}^{*}$, Stefan H. Hohnloser, $\mathrm{MD}^{\dagger}$, Stuart J. Connolly, $\mathrm{MD}^{\ddagger}$, Christian TorpPedersen, $M D^{\S}$, Lisa Naditch-Brûlé, MD", Richard L Page, MD", Harry J.G.M. Crijns, $M D^{* *}$ for the ATHENA investigators

*Department of Cardiology, Maastricht University Medical Centre, Maastricht, the Netherlands; 'Department of Cardiology, J. W. Goethe University Hospital, Frankfurt, Germany; ${ }^{\ddagger}$ McMaster University, Population Health Research Institute, Hamilton, Ontario, Canada; ${ }^{\S}$ Gentofte Hospital, University of Copenhagen, Hellerup, Denmark; "Sanofi, Paris, France; University of Washington, Seattle, USA; **Department of Cardiology, Maastricht University Medical Centre, Maastricht, the Netherlands 


\section{ABSTRACT}

Objective: This study assessed safety and cardiovascular outcomes of dronedarone in patients with paroxysmal or persistent atrial fibrillation (AF) with coronary heart disease (CHD)

Background: $\mathrm{CHD}$ is prevalent among AF patients and limits antiarrhythmic druguse because of their potentially life-threatening ventricular proarrhythmic effects.

Methods: This post hoc analysis evaluated 1,405 patients with paroxysmal or persistent $\mathrm{AF}$ and CHD from the ATHENA trial. Follow-up lasted 2.5 years, during which patients received either dronedarone (400 mg twice daily) or a double-blind matching placebo. Primary outcome was time to first cardiovascular hospitalization or death. Secondary end points included first hospitalization due to cardiovascular events.

Results: The primary outcome occurred in 350/737 (47\%) placebo patients versus 252/668 (38\%) dronedarone patients (hazard ratio $[H R]=0.73$; 95\% confidence interval $[\mathrm{Cl}]=0.62$ to $0.86 ; \mathrm{p}=0.0002$ ) without a significant increase in number of adverse events. In addition, 42/668 patients receiving dronedarone suffered from a first acute coronary syndrome compared with $67 / 737$ patients from the placebo group ( $\mathrm{HR}=0.67 ; 95 \% \mathrm{Cl}=0.46$ to $0.99 ; \mathrm{p}=0.04$ ).

Conclusions: In this post hoc analysis, dronedarone on top of standard care in AF patients with CHD reduced cardiovascular hospitalization or death similar to that in the overall ATHENA population, and reduced a first acute coronary syndrome. Importantly, the safety profile in this subpopulation was also similar to that of the overall ATHENA population, with no excess in proarrhythmias. The mechanism of the cardiovascular protective effects is unclear and warrants further investigation.

Keywords: dronedarone; atrial fibrillation; coronary heart disease

\section{Abbreviations}

$\mathrm{AF}=$ atrial fibrillation; $\mathrm{ATHENA}=\mathrm{A}$ placebo controlled, double-blind, parallel arm Trial to assess the efficacy of dronedarone $400 \mathrm{mg}$ BID for the prevention of cardiovascular Hospitalization or death from any cause in patiENts with Atrial fibrillation/atrial flutter; $\mathrm{CHD}=$ coronary heart disease; $\mathrm{Cl}=$ confidence interval; ERATO = Efficacy and safety of dRonedArone for The cOntrol; HR = hazard ratio; PRP = pressure rate product; RACE $=$ Rate Control Efficacy in Permanent Atrial Fibrillation: a Comparison between Lenient versus Strict Rate Control; SD = standard deviation; $\mathrm{TEAE}=$ treatment-emergent adverse event. 


\section{INTRODUCTION}

Coronary heart disease (CHD) is common among patients with atrial fibrillation (AF (1). AF symptoms that do not respond to rate control frequently require rhythm control. Besides increasing the risk of cardiovascular events, CHD facilitates ventricular proarrhythmia of most antiarrhythmic drugs. Subsequently, the therapeutic options for rhythm control in patients with AF and CHD are limited. Although the use of amiodarone is recommended in patients with $\operatorname{AF}$ and $\operatorname{CHD}(2,3)$, the wellknown extracardiac side effects associated with this drug create an important tradeoff.

Recently, dronedarone, a multichannel-blocking antiarrhythmic drug pharmacologically related to amiodarone, proved to be effective in preventing recurrencein patients with persistent or paroxysmal AF (4). More recently, the ATHENA (A placebo controlled, double-blind, parallel arm Trial to assess the efficacy of dronedarone $400 \mathrm{mg}$ BID for the prevention of cardiovascular Hospitalization or death from any cause in patiENts with Atrial fibrillation/atrial flutter) study demonstrated that, in patients with persistent or paroxysmal $\mathrm{AF}$ and at least 1 risk factor for vascular events, dronedarone reduced the composite outcome of cardiovascular hospitalization or death. The observed benefit of dronedarone was not offset by an increased number of serious adverse events (5).

The current post hoc analysis from ATHENA therefore focuses on the safety and cardiovascular outcomes of dronedarone use in patients with AF and CHD.

\section{METHODS}

ATHENA's design, definitions, and main findings have been published previously $(4,5)$. In summary, patients with paroxysmal or persistent AF or atrial flutter who had both sinus rhythm and an arrhythmia documented in the previous 6 months and at least 1 additional risk factor for cardiovascular events, including age $\geq 75$ years or 70 years with 1 or more risk factors (hypertension, diabetes mellitus, prior stroke or transient ischemic attack, left atrial enlargement [ $\geq 50 \mathrm{~mm}]$, or depressed left ventricular ejection fraction $[\leq 0.40]$ ), were recruited. Prior to a study protocol amendment in the first year of the trial, patients younger than 70 years were also eligible, if they also did not meet any exclusion criterion, of which unstable hemodynamic situation, New York Heart Association class IV heart failure, and permanent AF were key. Patients were randomly allocated to a regimen of dronedarone 400 mg twice daily or double-blind matching placebo, and followed up every 3 months until a common termination point assuring a minimum follow-up of at least 1 year for the patient enrolled last (maximum of 2.5 and mean of 1.7 years). 
The primary study outcome was the first occurrence of cardiovascular hospitalization or death due to any cause. The secondary outcomes were death, cardiovascular death, and cardiovascular hospitalization. Deaths were categorized by a blinded adjudication committee into 4 categories: cardiac, arrhythmic; cardiac, nonarrhythmic; vascular, noncardiac; and nonvascular. Information on occurrence of acute coronary syndrome was collected from hospitalization and death report forms.

CHD is defined as a documented history of either ischemic dilated cardiomyopathy, evidenced by clinically significant left ventricular dilatation secondary to coronary artery disease, or coronary artery disease, which was defined as acute myocardial infarction and/or the following: significant ( $\geq 70 \%)$ coronary artery stenosis, history of revascularization procedure (percutaneous transluminal coronary angioplasty, stent implantation in a coronary artery, coronary artery bypass grafting, etc), positive exercise test, and positive nuclear scan of cardiac perfusion.

A treatment-emergent adverse event (TEAE) was defined as an adverse event occurring between first dose of the study drug and 10 days after the last dose. A serious TEAE was one that resulted in death, was life-threatening, required or prolonged hospitalization, was a medically important event, resulted in persistent, clinically significant disability or incapacity, or was a congenital anomaly or birth defect.

\section{Statistics}

Analyses were performed in the intention-to-treat population and the time to event was estimated according to the Kaplan-Meier method and compared using the logrank test. Hazard ratio was calculated using Cox's proportional hazard model with treatment group as covariate. The $\mathrm{p}$ value for interaction between treatment and CHD status was tested based on Cox regression model. The annual event rates (\% per year) were calculated by dividing the actual number of events by the total follow-up years. All p values were 2-tailed.

The trial was sponsored by Sanofi and designed by the steering committee in collaboration with the sponsor. Data management and statistical analysis were performed by the sponsor. The first draft of the report was written by the principal author, and subsequent drafts were revised and edited by all authors, who vouch for the accuracy and completeness of the data.

\section{RESULTS}

Of the 1,405/4,628 (30\%) patients in the entire ATHENA cohort with AF and CHD, 668 were randomized to receive dronedarone, and the remaining 737 to receive 
placebo. Apart from a similar prevalence of hypertension at baseline, in AF patients with $\mathrm{CHD}$, cardiovascular diseases and associated medications were significantly more common compared with their non-CHD counterparts (Table 1).

Table 1 - Baseline Characteristics of Patients With and Without Coronary Heart Disease (CHD)*

\begin{tabular}{|c|c|c|c|c|}
\hline & \multirow{3}{*}{$\begin{array}{l}\text { CHD } \\
\text { Placebo } \\
(n=737)\end{array}$} & \multicolumn{2}{|r|}{ No CHD } & \multirow{3}{*}{$\begin{array}{l}\text { Dronedarone (n } \\
=1633 \text { ) }\end{array}$} \\
\hline & & \multicolumn{2}{|c|}{ Dronedarone $(\mathrm{n}=$ Placebo } & \\
\hline & & 668) & $(n=1590)$ & \\
\hline Mean age, y (SD) & $73.5(8.2)$ & $73.1(7.7)$ & $70.8(9.3)$ & $70.9(9.3)$ \\
\hline Male gender & $485(65.8 \%)$ & $419(62.7 \%)$ & $804(50.6 \%)$ & $751(46 \%)$ \\
\hline Hypertension & $639(86.7 \%)$ & $593(88.8 \%)$ & 1357 (85.3\%) & $1406(86.1 \%)$ \\
\hline Hypercholesterolemia & $436(59.2 \%)$ & $416(62.3 \%)$ & $566(35.6 \%)$ & $618(37.8 \%)$ \\
\hline Diabetes mellitus & $199(27.0 \%)$ & $166(24.9 \%)$ & $264(16.6 \%)$ & $316(19.4 \%)$ \\
\hline Chronic renal failure & $38(5.2 \%)$ & $40(6.0 \%)$ & $45(2.8 \%)$ & $45(2.8 \%)$ \\
\hline Congestive heart failure & 287 (38.9\%) & $261(39.1 \%)$ & $406(25.5 \%)$ & $411(25.2 \%)$ \\
\hline NYHA class III & 67 (9.1\%) & $58(8.7 \%)$ & $42(2.6 \%)$ & $33(2.0 \%)$ \\
\hline LVEF $<35 \%$ & $58 / 723(8.0 \%)$ & $52 / 658(7.9 \%)$ & 29/1558 (1.9\%) & $40 / 1605$ (2.5\%) \\
\hline Oral anticoagulant & $436(59.2 \%)$ & $414(62.0 \%)$ & $948(59.6 \%)$ & $989(60.6 \%)$ \\
\hline Low dose of aspirin $(\leq 365 \mathrm{mg})$ & $413(56.0 \%)$ & 390 (58.4\%) & $606(38.1 \%)$ & $628(38.5 \%)$ \\
\hline Beta-blocking agents ${ }^{\ddagger}$ & $559(75.8 \%)$ & $534(79.9 \%)$ & $1082(68.1 \%)$ & $1094(67.0 \%)$ \\
\hline ARB or ACE inhibitor & $551(74.8 \%)$ & 495 (74.1\%) & 1051 (66.1\%) & 1119 (68.5\%) \\
\hline Statins $^{\ddagger}$ & 453 (1.5\%) & 429 (64.2\%) & 461 (29.0\%) & 449 (27.5\%) \\
\hline
\end{tabular}

*Data are numbers (\%) unless otherwise specified.

${ }^{\ddagger}$ Not including sotalol.

${ }^{\ddagger}$ Statins are defined as 3-hydroxy-3-methylglutaryl-coenzyme A reductase inhibitors.

$A C E$ = angiotensin-converting enzyme; $A R B=$ angiotensin $\|$ receptor blocker; $L V E F=$ left ventricular ejection fraction; NYHA = New York Heart Association.

Figure 1 shows that the composite primary outcome (first cardiovascular hospitalization or all-cause death) is similar in the cohort of AF patients with CHD (hazard ratio $[\mathrm{HR}]=0.73 ; 95 \%$ confidence interval $[\mathrm{Cl}]=0.62$ to $0.86 ; \mathrm{p}=0.0002$ ) and those without $\mathrm{CHD}(\mathrm{HR}=0.78 ; 95 \% \mathrm{Cl}=0.69$ to $0.88 ; \mathrm{p}<0.0001)$. Figure 2 shows that dronedarone significantly prevents the occurrence of a first acute coronary syndrome in $\mathrm{AF}$ patients with $\mathrm{CHD}(\mathrm{HR}=0.67 ; 95 \% \mathrm{Cl}=0.46$ to $0.99 ; \mathrm{p}=0.04)$. Table 2 presents the comparison of the effect of dronedarone across the 2 subgroups, those with $\mathrm{CHD}$ and those without CHD. For both the primary and secondary outcomes, dronedarone is as effective in AF patients with $\mathrm{CHD}$ as in those without ( $p$ value for interaction $=$ NS for all). 


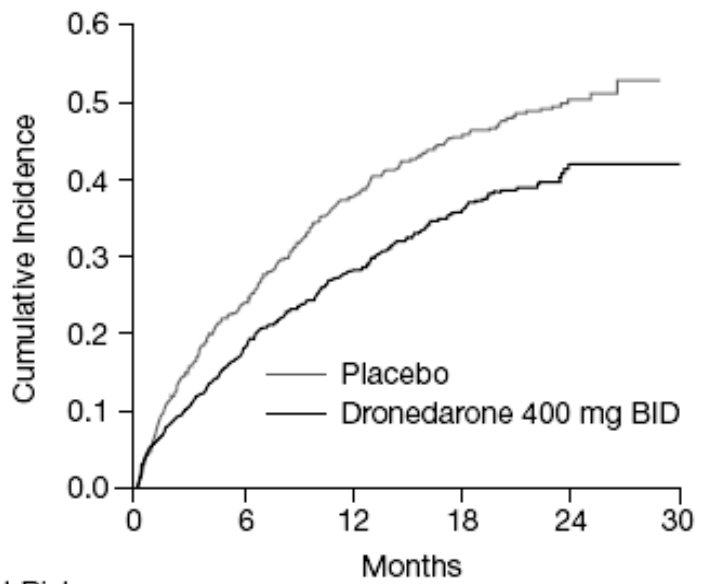

Number at Risk:

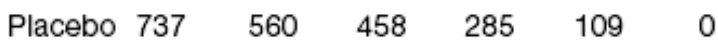

$\begin{array}{lllllll}\text { Dronedarone } 400 \mathrm{mg} \text { BID } & 668 & 545 & 480 & 298 & 88 & 1\end{array}$

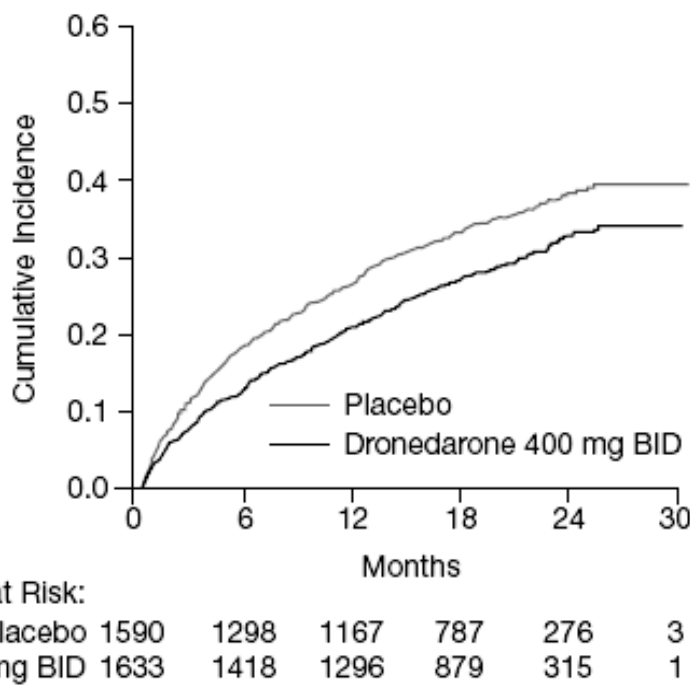

Figure 1 - Cumulative Risk of the Composite Outcome of First Cardiovascular Hospitalization or Death From Any Cause in Patients With (On top) and Without (Below) Coronary Heart Disease. BID = twice daily. 


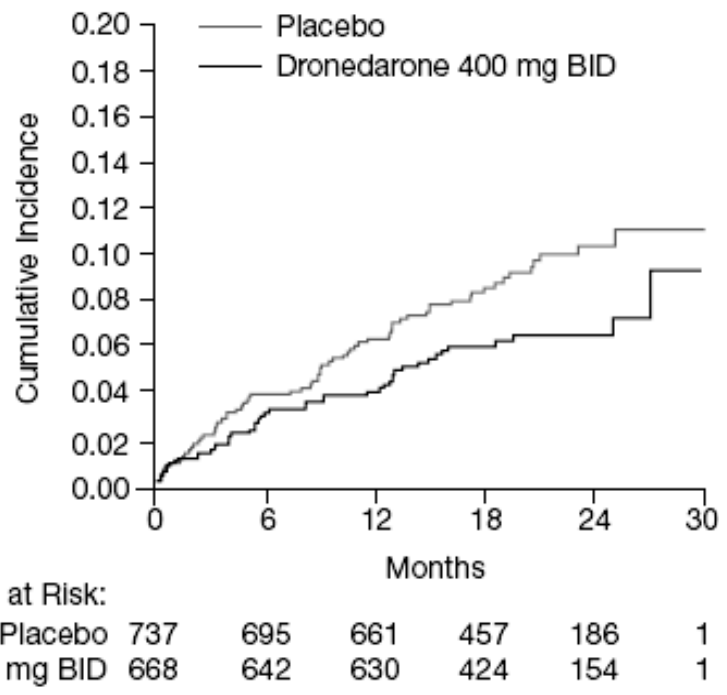

Figure 2 - Cumulative Risk of the Occurrence of First Acute Coronary Syndrome in Patients With Coronary Heart Disease. BID = twice daily.

Table 2 - Comparison of the Effect of Dronedarone Among Patients With and Without Coronary Heart Disease

\begin{tabular}{|c|c|c|c|c|c|}
\hline Outcome & CHD & $\begin{array}{l}\text { Placebo } \\
\text { n/N (\%) }\end{array}$ & $\begin{array}{l}\text { Dronedarone } \\
\mathrm{n} / \mathrm{N}(\%)\end{array}$ & $\begin{array}{l}\text { HR for Dronedarone } \\
{[95 \% \mathrm{Cl}]}\end{array}$ & p Value ${ }^{*}$ \\
\hline \multirow{2}{*}{$\begin{array}{l}\text { First cardiovascular } \\
\text { hospitalization or death } \\
\text { from any cause }\end{array}$} & Yes & $350 / 737$ (47.49) & $252 / 668(37.72)$ & $0.733[0.62$ to 0.86$]$ & 0.535 \\
\hline & No & $567 / 1,590(35.66)$ & $482 / 1,663(29.52)$ & 0.782 [0.69 to 0.88$]$ & \\
\hline \multirow[t]{2}{*}{ Cardiovascular death } & Yes & $47 / 737$ (6.38) & 26/668 (3.89) & $0.602[0.37$ to 0.97$]$ & 0.350 \\
\hline & No & $47 / 1,590$ (2.96) & $39 / 1,663$ (2.39) & $0.814[0.53$ to 1.24$]$ & \\
\hline \multirow[t]{2}{*}{ First ACS } & Yes & $67 / 737$ (9.09) & $42 / 668$ (6.29) & 0.671 [0.46 to 0.99$]$ & 0.429 \\
\hline & No & $29 / 1,590(1.82)$ & 26/1,633 (1.59) & 0.876 [0.52 to 1.49$]$ & \\
\hline \multirow{2}{*}{$\begin{array}{l}\text { First stroke, ACS or } \\
\text { cardiovascular death }\end{array}$} & Yes & 116/737 (15.74) & $67 / 668(10.03)$ & 0.615 [0.46 to 0.83$]$ & 0.272 \\
\hline & No & $101 / 1,590(6.35)$ & $81 / 1,633$ (4.96) & $0.778[0.58$ to 1.04$]$ & \\
\hline
\end{tabular}

${ }^{*} p$ Value of interaction between CHD status and treatment based on Cox regression model. $\mathrm{ACS}=$ acute coronary syndrome; $\mathrm{CHD}=$ coronary heart disease; $\mathrm{Cl}=$ confidence interval.

The effect of dronedarone on heart rate and systolic blood pressure is combined in Figure 3 , which shows the pressure rate product (PRP): (heart rate $\times$ systolic blood pressure)/1000. Although the mean (standard deviation [SD]) baseline PRP was similar in patients randomized to receive dronedarone (9.3 [2.4]) or placebo (9.2 [2.4]), during follow-up a mean decrease in PRP compared with baseline was observed only in the dronedarone patients $(-0.65 \mathrm{vs} .+0.15$ for dronedarone and placebo groups, respectively; difference of $-0.8 ; 95 \% \mathrm{Cl}=-0.98$ to -0.61$)$. The effect was 
more pronounced in the dronedarone patients who were in AF during the ontreatment period, where their mean (SD) baseline PRP of 11.2 (3.0) dropped on average 1.5 points during follow-up, compared with those in sinus rhythm during the on-treatment period where the mean (SD) baseline PRP of 8.6 (1.7) was reduced on average 0.5 points $(p<0.0001)$.

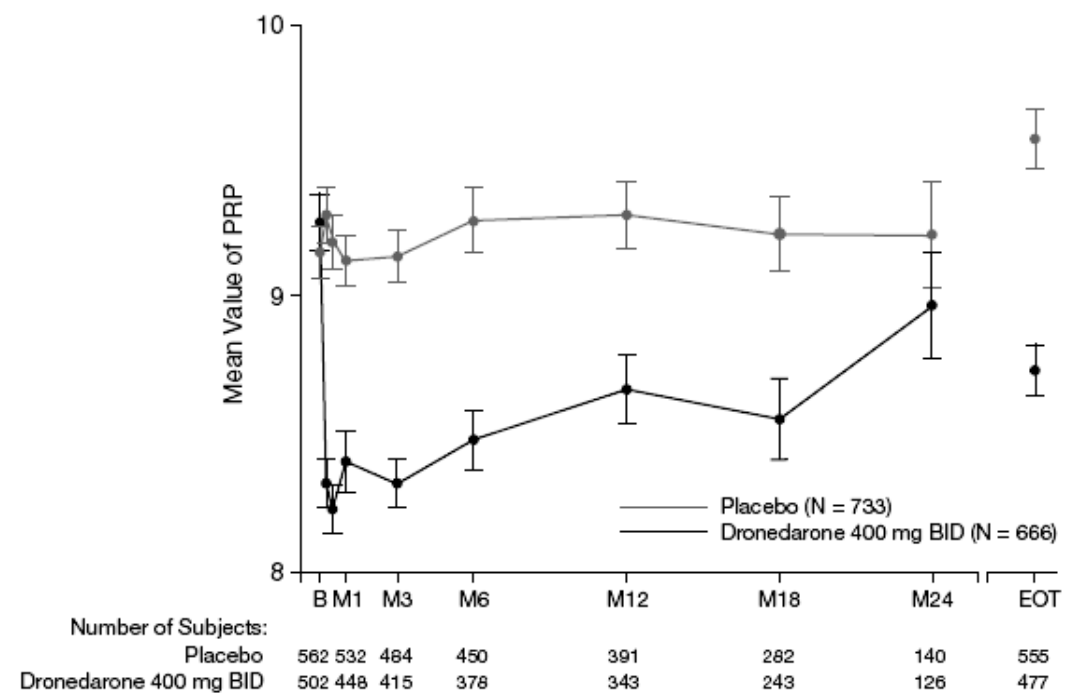

Figure 3 - Pressure Rate Product Over Time in Patients With Coronary Heart Disease. $\mathrm{B}$ = baseline; EOT = end of treatment; $\mathrm{M} 1=$ Month $1 ; \mathrm{PRP}=$ pressure rate product $=$ (heart rate $\times$ systolic blood pres sure)/1000.

A subgroup analysis was done to identify characteristics predictive of a reduced incidence of acute coronary syndromes in response to dronedarone treatment (Figure 4). The only significant interaction occurred in patients with a reduced left ventricular ejection fraction $(<35 \%)$, meaning they had a significantly greater effect with dronedarone compared with those patients with a preserved ejection fraction $(p=$ 0.008 for interaction).

In total, $510(76.6 \%)$ of the patients with $\mathrm{CHD}$ randomized to receive dronedarone and $538(73.4 \%)$ of the placebo patients experienced a TEAE; TEAEs resulted in premature discontinuation of study drug in 108 (16.2\%) and 70 (9.5\%) patients, respectively. In dronedarone patients the withdrawal was largely driven by gastrointestinal disorders (5.0\%), such as diarrhea and nausea, and QT interval prolongation (2.7\%). Serious TEAEs were reported in $22.7 \%$ of the dronedarone and $25.9 \%$ of the placebo patients. The occurrence and distribution of type of TEAEs are displayed in Table 3. Importantly, the expected increased occurrence of QTc interval prolongation $>500 \mathrm{~ms}$ in patients randomized to receive dronedarone compared with placebo did not lead to an increased number of serious (cardiac) TEAEs as shown in 
Table 4. Also, hepatic injury reported during treatment was similar between patients randomized to receive dronedarone (1.7\%) and placebo (1.9\%).

\begin{tabular}{|c|c|c|c|c|}
\hline Characteristic & $\mathbf{N}$ & Relative Risk [95\% Cl]* & p-valuet Dronedarone Better & Placebo Better \\
\hline \multicolumn{5}{|l|}{ Overall } \\
\hline ACS & 1405 & $0.67[0.46 ; 0.99]$ & & \\
\hline \multicolumn{5}{|c|}{ ACS by baseline covariates } \\
\hline \multicolumn{5}{|l|}{ Age (years) } \\
\hline$<65$ & 183 & $0.52[0.18 ; 1.49]$ & & - \\
\hline$\geq 65$ to $<75$ & 548 & $0.96[0.52 ; 1.73]$ & & - \\
\hline$\geq 75$ & 674 & $0.52[0.29 ; 0.95]$ & 0.317 & \\
\hline \multicolumn{5}{|l|}{ Gender } \\
\hline Male & 904 & $0.60[0.36 ; 1.00]$ & & \\
\hline Female & 501 & $0.77[0.43 ; 1.37]$ & 0.543 & - \\
\hline \multicolumn{5}{|l|}{ Diabetes } \\
\hline Yes & 365 & $0.62[0.29 ; 1.32]$ & & - \\
\hline No & 1040 & $0.69[0.44 ; 1.09]$ & 0.766 & \\
\hline \multicolumn{5}{|l|}{ Stroke/TIA } \\
\hline Yes & 212 & $0.64[0.27 ; 1.49]$ & & \\
\hline No & 1193 & $0.67[0.44 ; 1.03]$ & 0.905 & \\
\hline \multicolumn{5}{|l|}{ CHF } \\
\hline Yes & 548 & $0.73[0.43 ; 1.24]$ & & \\
\hline No & 857 & $0.62[0.35 ; 1.09]$ & 0.681 & \\
\hline \multicolumn{5}{|l|}{ LVEF (\%) } \\
\hline$<35$ & 110 & $0.13[0.03 ; 0.57]$ & $\rightarrow$ & \\
\hline$\geq 35$ & 1271 & $0.82[0.54 ; 1.24]$ & 0.008 & - \\
\hline \multicolumn{5}{|l|}{$\mathrm{CHADS}_{2}$ score } \\
\hline$\leq 1$ & 337 & $0.51[0.22 ; 1.17]$ & & \\
\hline$\geq 2$ & 1068 & $0.73[0.47 ; 1.13]$ & 0.452 & \\
\hline \multicolumn{5}{|l|}{ Hypertension } \\
\hline Yes & 1232 & $0.75[0.50 ; 1.12]$ & & \\
\hline \multirow[t]{3}{*}{ No } & 173 & $0.22[0.05 ; 1.01]$ & 0.093 & \\
\hline & & & 0.10 & $\overrightarrow{10.00}$ \\
\hline & & & Hazard & Scale) \\
\hline
\end{tabular}

Figure 4 - Specific Subgroup Analysis for Acute Coronary Syndrome (ACS) in Patients With Coronary Heart Disease. The $\mathrm{CHADS}_{2}$ score is a measure of the risk of stroke in patients with atrial fibrillation, with scores ranging from 0 to 6 and higher scores indicating a greater risk (13). Congestive heart failure (CHF), hypertension, an age of 75 years or older, and diabetes are each assigned 1 point, and previous stroke or transient ischemic attack is assigned 2 points; the score is calculated by summing all the points for a given patient. $\mathrm{Cl}$ = confidence interval; $\mathrm{LVEF}=$ left ventricular ejection fraction; $\mathrm{TIA}=$ transient ischemic attack; $\mathrm{RR}=$ relative risk. 
Table 3 - Occurrence and Distribution of Treatment-Emergent Adverse Events According to History of Coronary Heart Disease*

\begin{tabular}{|c|c|c|c|c|c|c|c|c|c|c|}
\hline \multirow[b]{3}{*}{ Prognostic Factor } & \multirow{2}{*}{\multicolumn{4}{|c|}{ Placebo $^{\dagger}$}} & \multirow{2}{*}{\multicolumn{3}{|c|}{$\begin{array}{l}\text { Dronedarone } 400 \mathrm{mg} \\
\text { BID }^{+}\end{array}$}} & \multicolumn{3}{|c|}{ Relative Risk* } \\
\hline & & & & & & & & \multicolumn{2}{|c|}{ Dronedarone/Placebo } & \multirow[b]{2}{*}{$\begin{array}{l}\text { p Val- } \\
\text { ue }^{\ddagger}\end{array}$} \\
\hline & Category & & $\mathbf{N}$ & $\%$ & $\mathbf{n}$ & $\mathbf{N}$ & $\%$ & $\begin{array}{l}\text { Relative } \\
\text { Risk }\end{array}$ & $95 \% \mathrm{Cl}$ & \\
\hline \multirow[t]{3}{*}{ TEAE } & Overall & 1,603 & 2,313 & 69.30 & 1,649 & 2,291 & 71.98 & 1.138 & [1.06 to 1.22$]$ & \\
\hline & $\mathrm{CHD}^{\S}$ & 538 & 733 & 73.40 & 510 & 666 & 76.58 & 1.197 & [1.06 to 1.35 ] & \\
\hline & No CHD & 1,065 & 1,580 & 67.41 & 1,139 & 1,625 & 70.09 & 1.123 & [1.03 to 1.22 ] & 0.38 \\
\hline \multirow[t]{3}{*}{ Serious TEAE } & Overall & 489 & 2,313 & 21.14 & 456 & 2,291 & 19.90 & 0.937 & [0.82 to 1.06$]$ & \\
\hline & $\mathrm{CHD}^{\S}$ & 190 & 733 & 25.92 & 151 & 666 & 22.67 & 0.900 & [0.73 to 1.11$]$ & \\
\hline & No CHD & 299 & 1,580 & 18.92 & 305 & 1,625 & 18.77 & 0.977 & [0.83 to 1.15$]$ & 0.54 \\
\hline \multirow{3}{*}{$\begin{array}{l}\text { AE leading to drug } \\
\text { discontinuation }\end{array}$} & Overall & 187 & 2,313 & 8.08 & 290 & 2,291 & 12.66 & 1.590 & [1.32 to 1.91$]$ & \\
\hline & $\mathrm{CHD}^{\S}$ & 70 & 733 & 9.55 & 108 & 666 & 16.22 & 1.772 & [1.31 to 2.39 ] & \\
\hline & No CHD & 117 & 1,580 & 7.41 & 182 & 1,625 & 11.20 & 1.519 & [1.20 to 1.92 ] & 0.43 \\
\hline
\end{tabular}

*Determined from Cox regression model

${ }^{\dagger} n=$ Number of patients with endpoint, $N=$ Number of patients, $\%=(n / N) * 100$

${ }^{\ddagger} \mathrm{p}$ Value of interaction between $\mathrm{CHD}$ at baseline and treatment based on Cox regression model.

${ }^{\S}$ Patients with CHD are defined as patients with history of coronary heart disease or ischemic dilated cardiomyopathy.

$\mathrm{AE}=$ adverse event; $\mathrm{CHD}=$ coronary heart disease $\mathrm{Cl}$ = confidence interval; $\mathrm{TEAE}=$ treatment-emergent $A E$.

Table 4 - Treatment-Emergent Adverse Events in AF Patients With CHD Treated With Dronedarone or Placebo

\begin{tabular}{llll}
\hline & Dronedarone (n= 666) & Placebo (n= 733) & p Value \\
\hline Any TEAE & $510(76.6 \%)$ & $538(73.4 \%)$ & \\
Any cardiac events & $83(12.5 \%)$ & $92(12.6 \%)$ & NS \\
$\quad$ Bradycardia & $29(4.4 \%)$ & $13(1.8 \%)$ & 0.007 \\
QT interval prolongation & $21(3.2 \%)$ & $5(0.7 \%)$ & $<0.001$ \\
Any respiratory events & $117(17.6 \%)$ & $129(17.6 \%)$ & NS \\
Any gastrointestinal events & $203(30.5 \%)$ & $183(25.0 \%)$ & 0.023 \\
$\quad$ Diarrhea & $78(11.7 \%)$ & $52(7.1 \%)$ & 0.003 \\
Any serious TEAE & $151(22.7 \%)$ & $190(25.9 \%)$ & NS \\
$\quad$ Cardiac events & $6(0.9 \%)$ & $6(0.8 \%)$ & \\
Other events of interest & & & NS \\
$\quad$ Hepatic events & $11(1.7 \%)$ & $14(1.9 \%)$ & $<0.001$ \\
Serum creatinine increase & $34(5.1 \%)$ & $10(1.4 \%)$ & NS \\
INR increase & $18(2.7 \%)$ & $15(2.0 \%)$ & \\
\hline
\end{tabular}

TEAE = treatment emergent adverse event; INR = international normalized ratio. 


\section{DISCUSSION}

In this post hoc analysis of the ATHENA study, the use of the multichannel-blocking antiarrhythmic drug dronedarone in patients with AF and CHD reduced mortality or cardiovascular hospitalization, an observation that is in line with the results of the overall population in the ATHENA trial (5). Furthermore, in this subgroup, fewer patients randomized to receive dronedarone were admitted to the hospital because of an acute coronary syndrome during follow-up compared with the placebo arm. Of note, the reduced mortality and cardiovascular hospitalization associated with the use of dronedarone occurs in a subgroup of patients with more extensive cardiovascular disease and who already receive established (secondary) cardiovascular preventive drugs, i.e., $\beta$-blockers, statins, angiotensin-converting enzyme inhibitors, and antithrombotic therapy.

The observed benefit:risk ratio of dronedarone in AF patients with CHD is of key importance for clinical practice. Ischemic heart disease creates a hazardous (electrical) milieu in which administration of most antiarrhythmic drugs is prohibited or not recommended due to their potential life-threatening ventricular proarrhythmic effects (7). As a result, the number of antiarrhythmic drugs that can be safely used to treat symptomatic AF patients with CHD is limited $(2,3)$. Because the use of dofetilide, a pure class III antiarrhythmic with a high proarrhythmic profile, is restricted to the United States, and sotalol is commonly contraindicated in AF patients with CHD (due to left ventricular hypertrophy), amiodarone is often the only option based on its multichannel properties, leading to a very low proarrhythmic profile $(2,3)$. However, because of its very long half-life, in conjunction with the well-known extracardiac side effects associated with its use and important interactions, it is not the ideal drug to prescribe to such a large group of patients. From this perspective, dronedarone could be an ideal alternative because its use minimizes the excess risk of the abovementioned serious side effects compared with placebo. In addition, in light of the recently raised concerns of hepatic toxicity associated with dronedarone use (8), it is important to note that the occurrence of hepatic events was similar in patients randomized to receive dronedarone and those who received placebo in this subgroup of patients with CHD as well as in the entire ATHENA cohort. However, this does not negate the recommendation to perform careful, systematic follow-up of the liver enzymes. A meta-analysis on the benefits and risks of amiodarone showed that the pooled reduction in all-cause death with the use of amiodarone was limited to an estimated $13 \%$ (odds ratio $=0.87 ;[95 \% \mathrm{Cl}=0.78$ to 0.99 ]; $\mathrm{p}=$ 0.030 ) based on classic fixed-effects meta-analysis, and to a nonsignificant $15 \%$ reduction ( 0.85 [0.71 to 1.02 ], $p=0.081$ ) using the more conservative randomeffects approach (9). Furthermore, a recent mixed treatment comparison analysis by Freemantle et al. (10) even suggests potential increased mortality associated 
with amiodarone use in contrast to a potential reduction of serious adverse events and proarrhythmia by dronedarone (10).

The reduced number of acute coronary syndromes in patients with AF and CHD who were randomized to dronedarone is probably not unexpected based on the observed decrease in the number of strokes reported by Connolly et al. (11). The precise mechanism(s) of the cardiovascular protective effects associated with the use of dronedarone in these patients are unclear. Hypothetically, in the setting of fixed coronary artery stenosis, a partial explanation could be the observed reduced rate pressure product in dronedarone patients, which relates to a decreased myocardial oxygen demand. This potential mechanism would mainly be driven by a decrease in heart rate, given the modest reduction in systolic blood pressure by dronedarone (5), but the clear prevention of AF (5) and reduction of ventricular rate seen in patients with permanent AF on top of other rate-controlling drugs in the Efficacy and safety of dRonedArone for The cOntrol (ERATO) trial (11). The available data from the recent Rate Control Efficacy in Permanent Atrial Fibrillation: a Comparison between Lenient versus Strict Rate Control (RACE) II study, however, do not support this. RACE II showed that after a 2-year follow-up period, the occurrence of the primary outcome (a composite of cardiovascular death and hospitalization for heart failure, and stroke systemic embolism, bleeding, and life-threatening arrhythmic events) was similar in permanent AF patients randomized to a strict ratecontrol target (resting heart rate $<80$ beats per minute and a heart rate $<110$ beats per minute during moderate exercise) compared with a more lenient one (resting heart rate $<110$ beats per minute) (13). Also considering amiodarone does not reduce stroke risk $(14,15,-16)$, it would be interesting to investigate any potential cardiovascular protective effect that antiarrhythmic drugs could harbor in future research.

\section{LIMITATIONS}

Potential limitations of this study are that it was retrospective, exploratory, and based on a small number of patients. The results of this post hoc analysis were not fully protected by randomization, but at the same time the double-blind study design minimizes bias and therefore strengthens the current analysis. Information on acute coronary syndromes was carefully collected as it was part of the primary end point (death and cardiovascular hospitalization), but these were not prespecified or centrally adjudicated, or reported as adverse events using a prespecified and systematic approach. 


\section{CONCLUSIONS}

The reduced mortality and cardiovascular hospitalization associated with dronedarone use, and the safety profile of dronedarone, are consistent with the results of the main ATHENA trial. Altogether, this makes dronedarone a welcome addition to the antiarrhythmic drug arsenal for patients with paroxysmal or persistent AF and CHD and a possible alternative to amiodarone therapy in this subgroup. The observed reduced number of acute coronary syndromes is interesting, and should therefore spark our thoughts on the underlying (preventive) mechanisms (i.e., hypothesis-generating), rather than to guide prescription of dronedarone.

\section{REFERENCES}

1. Nieuwlaat R, Capucci A, Camm AJ, et al; for the European Heart Survey Investigators. Atrial fibrillation management: a prospective survey in ESC member countries: the Euro Heart Survey on Atrial Fibrillation. Eur Heart J 2005;26:2422-34.

2. Camm AJ, Kirchhof P, Lip GY, et al. Guidelines for the management of atrial fibrillation: the Task Force for the Management of Atrial Fibrillation of the European Society of Cardiology (ESC). Eur Heart J 2010; Oct;31(19):2369-429.

3. Fuster V, Rydén LE, Cannom DS, et al. ACC/AHA/ESC 2006 guidelines for the management of patients with atrial fibrillation--executive summary: a report of the American College of Cardiology/American Heart Association Task Force on Practice Guidelines and the European Society of Cardiology Committee for Practice Guidelines (Writing Committee to Revise the 2001 Guidelines for the Management of Patients With Atrial Fibrillation). J Am Coll Cardiol 2006;48:854-906. Erratum in: J Am Coll Cardiol 2007;50:562.

4. Singh BN, Connolly SJ, Crijns HJ, et al; EURIDIS and ADONIS Investigators. Dronedarone for maintenance of sinus rhythm in atrial fibrillation or flutter. N Engl J Med 2007;357:987-99.

5. Hohnloser SH, Crijns HJGM, van Eickels M, et al. Effect of dronedarone on cardiovascular events in atrial fibrillation. N Engl J Med 2009;360:668-78.

6. Hohnloser SH, Connolly SJ, Crijns HJ, Page RL, Seiz W, Torp-Petersen C. Rationale and design of ATHENA: a placebo-controlled, double-blind, parallel arm Trial to assess the efficacy of dronedarone $400 \mathrm{mg}$ bid for the prevention of cardiovascular Hospitalization or death from any cause in patiENts with Atrial fibrillation/atrial flutter. J Cardiovasc Electrophysiol 2008;19:69-73.

7. Echt DS, Liebson PR, Mitchell LB, et al. Mortality and morbidity in patients receiving encainide, flecainide, or placebo. The Cardiac Arrhythmia Suppression Trial. N Engl J Med 1991;324:781-8.

8. Joghetaei N, Weirich G, Huber W, Büchler P, Estner H. Acute liver failure associated with dronedarone. Circ Arrhythm Electrophysiol 2011;4:592-3.

9. Effect of prophylactic amiodarone on mortality after acute myocardial infarction and in congestive heart failure: meta-analysis of individual data from 6500 patients in randomised trials. Amiodarone Trials Meta-Analysis Investigators. Lancet 1997;350:1417-24.

10. Freemantle N, Lafuente-Lafuente C, Mitchell S, Eckert L, Reynolds M. Mixed treatment comparison of dronedarone, amiodarone, sotalol, flecainide, and propafenone, for the management of atrial fibrillation. Europace 2011;13:329-45.

11. Connolly SJ, Crijns HJ, Torp-Pedersen C, et al; ATHENA Investigators. Analysis of stroke in ATHENA: a placebo-controlled, double-blind, parallel-arm trial to assess the efficacy of dronedarone $400 \mathrm{mg}$ BID for the prevention of cardiovascular hospitalization or death from any cause in patients with atrial fibrillation/atrial flutter. Circulation 2009;120:1174-80. 
12. Davy JM, Herold M, Hoglund C, et al; ERATO Study Investigators. Dronedarone for the control of ventricular rate in permanent atrial fibrillation: the Efficacy and safety of dRonedArone for the cOntrol of ventricular rate during atrial fibrillation (ERATO) study. Am Heart J 2008;156:527.e1-9.

13. Van Gelder IC, Groenveld HF, Crijns HJ, et al; RACE II Investigators. Lenient versus strict rate control in patients with atrial fibrillation. N Engl J Med 2010;362:1363-73.

14. Roy D, Talajic M, Nattel S, et al; for the Atrial Fibrillation and Congestive Heart Failure Investigators. Rhythm control versus rate control for atrial fibrillation and heart failure. $N$ Engl J Med 2008;358:2667-77.

15. Sherman DG, Kim SG, Boop BS, et al; National Heart, Lung, and Blood Institute AFFIRM Investigators. Occurrence and characteristics of stroke events in the Atrial Fibrillation Follow-up Investigation of Sinus Rhythm Management (AFFIRM) study. Arch Intern Med 2005;165:1185-91.

16. Gage BF, Waterman AD, Shannon W, Boechier M, Rich MW, Radford MJ. Validation of clinical classification schemes for predicting stroke: results from the National Registry of Atrial Fibrillation. JAMA 2001;285:2864-70. 
Discussion and Future Directions 


\section{Antithrombotic management of atrial fibrillation}

Atrial fibrillation (AF) is an extremely prevalent ${ }^{1}$ dynamic, chronic disease ${ }^{2}$ often associated with underlying heart disease ${ }^{3}$ making the management of AF challenging per se. ${ }^{4}$ Because of the significantly increased risk of thrombo-embolic events associated with the arrhythmia ${ }^{5}$, one of its most feared complications is the occurrence of an ischemic stroke. Despite existing knowledge on risk factors of stroke and bleeding as well as the availability of (very) effective agents ${ }^{6,7}$, the antithrombotic management is particularly challenging as it depends on the (adequate) assessment and understanding of both the risk of stroke and major bleeding.

Therefore, this thesis focuses on (the caveats of) the current use of antithrombotic medication in AF patients, provides (novel) user friendly tools for every day clinical practice in the antithrombotic management of AF patients. Furthermore, gained insights are shared and future avenues are portrayed regarding the potential of (unusual) suspects in the prevention of cardiovascular adverse events in general and thrombo-embolic complications in particular in patients with AF.

\section{Thrombo-embolism in atrial fibrillation}

\subsection{Stroke risk in Virchow's triad}

The mechanism responsible for the increased stroke risk associated with atrial fibrillation is unknown and perhaps does not even exist. Virchow's triad however plays an essential role in explaining and understanding the increased risk of thromboembolism which the AF patients carry. His hypothesis is that thrombus formation results from the (im)balance of blood constituents, (vascular) wall and hemodynamics. In the setting of valvular AF this is easy to imagine. The (severe) obstruction due to the mitral valve stenosis is responsible for a considerable left atrial hemodynamic overload which leads to - often prothrombotic - atrial remodeling and consequently consumption and/or release of (local) blood constituents; all together providing a thriving milieu for thrombus formation and subsequent embolization. This is reflected by the astounding thrombo-embolic risk of patients with valvular AF: being almost fivefold as high compared to their non-valvular counterparts. ${ }^{5}$ Considering rheumatic heart disease and (subsequent) valvular AF are, fortunately, extremely uncommon in the Western world I only focus on non-valvular AF in this thesis.

An altered, prothrombotic blood composition is confirmed by several studies which demonstrate increased (markers of) thrombosis in blood of AF patients compared to patients without the arrhythmia. ${ }^{8-11}$ The importance of, in this case the atrial, structural component of Virchow's triad is underscored by histological stud- 
ies. ${ }^{12-16}$ Considering atrial fibrillation can involve both atria in the electrical and structural remodeling, it seems logical to wonder whether right sided thrombus formation is of clinical importance? The answer comes in part from (transesophageal) echocardiographic studies which show a clear preference of atrial thrombi on the left side, in particular the left atrial appendage. ${ }^{17,18}$

The latter is probably a reflection of the third aspect of the triad: altered hemodynamics, considering the anatomy of the left atrial appendage and lower blood flow velocities in or nearby its opening (during AF). ${ }^{19-21}$ Echocardiography also exposes another (related) hemodynamic factor: spontaneous (dense) echo contrast (SEC). ${ }^{22}$ In the literature SEC is sometimes referred to as 'smoke' because of its characteristic appearance. It is believed to represent slurry rolling of the erythrocytes (due to lower blood flow velocities) and is associated with the presence of left atrial thrombus. ${ }^{23}$ Regarding the echocardiographic features it is important to realize that it represents a snap shot in which the image quality is also of importance. Apart from the timing aspect it is also crucial to note that the absence of echocardiographic thrombus does not equal the absence of cardiac thrombi. Given the trabecularization, the left atrium can easily harbor small thrombi which go unnoticed by (echocardiographic) imaging but which can have a profound clinical impact. $^{24}$

The importance of Virchow's hemodynamic component as a prothrombotic factor is also exemplified by the probably most important clinical temporary increase in thrombo-embolic risk associated with cardioversion. Predominantly based on case control studies this risk is believed to lie anywhere between $1-5 \% .{ }^{25-27}$ The accepted theory behind it has everything to do with so-called 'atrial stunning' ${ }^{28}$ Stunning relates to transient mechanical dysfunction of the left atrium and atrial appendage which occurs when AF converts to sinus rhythm. The stunning renders the atrium mechanically silent, which facilitates lowering of the blood flow velocity and subsequently causes stasis and thrombi formation. Next, after regaining (normal) atrial contraction, these thombi can be expelled into the circulation and potentially cause a clinically significant embolism. The theory is supported by the observed clustering of virtually all thrombo-embolic events within 10 days following the cardioversion. ${ }^{29}$ Is this stunning influenced by the way of conversion? No, not likely. The time of atrial stunning is in part dependent on the duration of the terminated AF episode and the use of action potential prolonging drugs or digitalis which 'poison' the atrial cells. $^{30}$ Furthermore, pre-existing - structural - atrial contractile dysfunction should also be considered to play a role in stunning. As the mode of conversion does not influence the time to restore 'normal' mechanical function. Therefore, it is important to note is that the mode of conversion, i.e. spontaneous, pharmacological or electrical, does not influence the thrombo-embolic risk. ${ }^{31,32}$ 


\subsection{Identifying risk factors of stroke}

In the nineties, recognition of the significantly increased stroke risk in patients with AF started the search for the optimal antithrombotic therapy. Several landmark trials were carried out comparing oral anticoagulation (OAC) - being vitamin $\mathrm{K}$ antagonists (VKAs) - with aspirin, the most used antiplatelet agent at that time. ${ }^{33-38}$ Consistently and convincingly, the so-called 'big six' demonstrated superiority in (secondary) stroke risk prevention of VKAs over aspirin in high risk AF patients: an estimated additional $40 \%$ relative risk reduction. ${ }^{39}$ Importantly, the control arms of these trials also provided data on risk factors for stroke, subsequently facilitating derivation of stroke risk assessment scores. ${ }^{40}$

The pooled data from the control arms receiving no antithrombotic therapy of the five large randomized trials on primary stroke prevention revealed the following risk factors for stroke: previous stroke or transient ischemic attack (relative risk (RR) 2.5), diabetes mellitus (RR 1.7), history of hypertension (RR 1.6), heart failure (RR 1.4) and advanced age (continuous, per decade RR 1.4). ${ }^{40}$ Apart from heart failure, these risk factors proved to be consistent, independent predictors of stroke in AF patients. A prior stroke or TIA is the undisputed 'champion' of risk factors of ischemic stroke in AF considering its independent predictive value in all trials in which it was studied. Of note, to this date, there is no such thing as a low risk AF patient with a previous TIA or stroke. ${ }^{41,42}$ Therefore it is of the utmost importance to diagnose the arrhythmia in patients with a prior stroke or TIA.

Another important and consistent stroke risk factor is age. Although nearly half of all AF related strokes occur in patients $\geq 75$ years of age, several studies recognize it as a non-static stroke risk factor with an average hazard ratio of approximately 1.5 per decade increase. ${ }^{5,43,44}$ Its predictive value is independent of the age-related increase of AF. Diabetes mellitus has also consistently proven to be an independent risk factor for stroke in AF patients. ${ }^{45}$ However, it is the weakest one. Given that in these trials limited to no attention was paid to discriminating factors, e.g. type I vs. II, it is very much conceivable that further (stronger) validation of this extremely prevalent cardiovascular disease as a risk factor for stroke in AF is possible.

Elevated blood pressure also proved to be of importance in predicting the occurrence of ischemic stroke in AF patients in most trials. ${ }^{34,40} \mathrm{~A}$ history of hypertension, to be more precise, is a predominant independent risk factor. A systolic blood pressure above $160 \mathrm{mmHg}$, however, belongs to the category of less well validated risk factors of stroke in AF patients. A partial explanation could lie in the fact that nearly always single office blood pressure measurements are used for such cut-offs. Presumably, most patients enrolled in these studies who have an increased (systolic) blood pressure suffer from so-called 'white coat hypertension' or demonstrate a physiologic stress response. Also, the presence of AF influences the result of the measurement. Considering this has not been systematically taken into account it blurs the predictive power of a blood pressure cut-off. 
Clinical heart failure might translate into a plausible pathophysiological mechanism of stasis of blood and subsequent thrombus formation, solid clinical evidence as a risk factor for stroke in AF patients is lacking. Some evidence exists which shows that a depressed left ventricular function and recent heart failure are independent predictors of stroke or surrogate markers of thromboembolism. ${ }^{41,46-48}$ Factors likely to contribute to the lesser validation of heart failure as a stroke risk factor in AF are the challenge to decipher the clinical presentation of the syndrome and the arrhythmia; the heterogeneity of causes of heart failure; and the even more divers phenotypic manifestation of each cause of heart failure.

Although the arrhythmia is slightly more common in men, not male but female gender proved to be a lesser validated stroke risk factor in AF patients based on a few cohort studies. ${ }^{40,47,49}$ Recently, we strengthened the supportive evidence of female gender as a risk factor for stroke in AF patients (Chapter 1). ${ }^{50}$ In a contemporary, 'real-life' cohort of some 1,000 non anticoagulated, non-valvular AF patients, female gender along with a history of stroke/TIA, hypertension, diabetes mellitus and vascular disease were found to be univariate predictors of stroke. Female gender was the only statistically significant independent predictor of stroke following multivariate analysis. ${ }^{50}$ We also found evidence pointing towards the additive value of vascular disease as a risk factor for stroke in AF patients (Chapter 1). Prior studies have linked coronary artery disease to stroke univariately ${ }^{40,51}$ and shown that complex aortic plaques on itself is highly thrombogenic. ${ }^{52}$ In our 'real-life' cohort vascular disease - defined as either prior myocardial infarction, peripheral artery disease or aortic plaque - was just short of being a statistically significant independent predictor of stroke $(p=0.064)$. The reason why the above mentioned variables proved to be (independent) predictors of stroke in AF patients in our cohort, likely relates to the setting. The majority of stroke risk factors in AF are derived from control arms of large randomized trials. ${ }^{40}$ This introduces a certain selection bias due to, for instance, the likelihood of men and women participating. But also because the in- and exclusion criteria translate into incomplete gathering of potential risk factors. When studying the real-life, uncontrolled world - although limitations are also present this kind of bias is somehow restricted. Furthermore, a time dependent factor reflecting (qualitative) improvement of care has to be considered responsible for such an effect.

\subsection{Stroke risk stratification schema's}

Along with the numerical growth of the various (established) risk factors of stroke in AF as studies appeared, the notion grew of the importance to provide overview. This led to the development of many stroke risk stratification attempts prior to the start of this thesis. ${ }^{6,40,41,51,53-59}$ Although all schema's aimed to provide optimal stroke risk assessment their roads (and thereby their 'success') differed. Use of 
different (trial) cohorts as blue print for the development, together with a (partial) consensus versus evidence based approach cause the used risk factors to not be identical. Most striking is the apparent lacking incorporation of prior stroke/TIA into the 2001 ACC/AHA/ESC practice guidelines. ${ }^{6}$ However, a closer look reveals that the writing committee did acknowledge the importance of previous thromboembolism and consequent indication for anticoagulation. This is illustrative of the importance of conveying not only the correct and complete message, but also to take the practical side into account. A positive effect of adding this dimension to the stroke risk schema setting is exemplified by the so-called $\mathrm{CHADS}_{2}$ index. ${ }^{59}$ Whereas all other stroke risk schema's chose a 'traditional' 2-3 strata risk categorization based on an impractical overview of risk factors, the $\mathrm{CHADS}_{2}$ index was the first scheme to take a more clinically oriented approach. The original format provided a stroke risk factor based scoring system resulting in 7 strata (scores). The acronym represents Congestive heart failure, $\underline{H}$ ypertension, $\underline{A g e} \geq 75$, $\underline{D}$ iabetes mellitus and previous $\underline{S}$ troke/TIA. Apart from the latter, worth 2 points, the presence of each of the other risk factors is awarded one point. Simple addition of these points results in the $\mathrm{CHADS}_{2}$ score, ranging from $0-6$, which correlates with a specific estimated annual stroke risk. Due to its user-friendliness it is probably the most known and widespread used stroke risk stratification schema for AF patients at present. However, despite these attractive improvements, $\mathrm{CHADS}_{2}$ has its shortcomings. This becomes apparent when considering the occurrence of thromboembolic events in nearly $2 \%$ (!) of the 'low risk' (score 0) patients and the vast number of patients classified as intermediate risk of stroke (score 1). ${ }^{59,60}$ Both shortcomings result from 'disregarding' the previously discussed lesser validated risk factors of stroke in AF patients and choosing a single, dichotomous cut-off for age ( $\geq 75$ years).

We therefore investigated whether 'fine-tuning' of the $\mathrm{CHADS}_{2}$ score would improve stroke risk stratification without substantial loss of user-friendliness (Chapter 1). ${ }^{50}$ Using the 2006 Birmingham/NICE stroke risk schema ${ }^{61}$ our first step was to reevaluate all established risk factors in the large, contemporary European cohort of the EHS-AF. This led to maintenance of the incorporated risk factors of CHADS, but in respect of age being a continuum - with a rearrangement of points awarded for age as a risk factor (age $64-75=1$ point, age $\geq 75=2$ points). Furthermore, as previously mentioned, female gender (Sc) and vascular disease (V) were found to be of importance and were added to the score, producing the acronym $\mathrm{CHA}_{2} \mathrm{DS}_{2}-\mathrm{VASc}$. Similar to the $\mathrm{CHADS}_{2}$ index addition of these points results in a $\mathrm{CHA}_{2} \mathrm{DS}_{2}-\mathrm{VASC}$ score, ranging from 0-9. However, opposed to the $\mathrm{CHADS}_{2}$ score, $\mathrm{CHA}_{2} \mathrm{DS}_{2}-\mathrm{VASC}$ proved to be superior in correctly identifying AF patients with a truly low stroke risk given the absence of thromboembolic complications during follow-up with $\mathrm{CHA}_{2} \mathrm{DS}_{2}$ VASc score $0 .^{50}$ This superiority also holds true when $\mathrm{CHA}_{2} \mathrm{DS}_{2}$-VASc was compared to the other available stroke risk schema's. Recently, the predictive value of $\mathrm{CHA}_{2} \mathrm{DS}_{2}$-VASc was strengthened in a nationwide Danish cohort of nearly $80,000 \mathrm{AF}$ 
patients with an extended follow-up period. ${ }^{62}$ Again, $\mathrm{CHA}_{2} \mathrm{DS}_{2}$-VASc proved to be superior compared to $\mathrm{CHADS}_{2}$ in identifying $\mathrm{AF}$ patients at truly low risk of stroke. Although this time the risk of thromboembolism was $0.78 \%$ with a $\mathrm{CHA}_{2} \mathrm{DS}_{2}$-VASc score of 0 compared to $1.67 \%$ for a similar $\mathrm{CHADS}_{2}$ score. Furthermore, the $\mathrm{CHA}_{2} \mathrm{DS}_{2}$-VASc score is superior in pinpointing which patients are at high risk of stroke compared to the $\mathrm{CHADS}_{2}$ score. ${ }^{62}$

\section{Major bleeding in atrial fibrillation}

Opposed to thromboembolism, the occurrence of major bleeding in AF patients is perceived to be iatrogenic by nature. Use of antithrombotic agents in general and oral anticoagulation in particular, leaves the hemostatic system severely compromised due to functional elimination of key proteins. In daily practice, this means that patients have a realistic chance of bleeding on VKAs and that individual bleeding risk needs to be addressed.

\subsection{Identifying risk factors of major bleeding}

Considering the high prevalence of bleeds among AF patients using oral anticoagulation it is important to focus on 'the right ones'. An initial reflex would be to disregard minor bleedings and concentrate on all major bleedings. However, the first pitfall is the fact that defining bleedings is not as 'easy' as defining an ischemic stroke. Even despite the availability of internationally accepted definitions of minor and major bleeding, it is important to realize that many are not so homogenous and straightforward as they appear at first glance. ${ }^{63}$ Even if the perfect definitions would exist and discrimination between minor and major bleeding would be perfect, it would not be the end of the clinical dilemma. This relates to a second pitfall: grading the (clinical) impact of a (major) bleeding. Here, AF related ischemic strokes have a head start because they are extremely disabling and deadly ${ }^{64}$ whereas most major bleedings are non-fatal. ${ }^{65}$ With risk stratification of major bleeding in AF patients at least two important aspects come into mind. First, are the risk factors for all different types of major bleedings the same? Perhaps a more valid question would be whether the answer is needed at present? Second, what is the ideal bleeding counterpart to compare to the risk of ischemic stroke to make a well-balanced decision regarding the clinical antithrombotic regimen? Unfortunately, we do not have clear cut answers to these questions because of both scarce and inconsistent data. Focus has (justifiably) been on the most lethal of all major bleedings: intracerebral hemorrhage $(\mathrm{ICH}) .{ }^{65}$ Known risk factors for $\mathrm{ICH}$ are an excessively high international normalized ratio (INR) (>4.0), very old age (>85 years), uncontrolled hypertension, the initiation period, and previous stroke. ${ }^{66-68}$ 


\subsection{Bleeding risk stratification schema's}

Still, attempts have been made to develop a schema which estimates the risk of major bleeding associated with use of VKA. ${ }^{69-72}$ However, this did not lead to an implementation success similar to that of the $\mathrm{CHADS}_{2}$ index exemplified by their lacking incorporation into the guidelines. ${ }^{7}$ This may relate to the fact that these schema's either do not focus on AF patients in particular or address a (very) specific subgroup among AF patients. Furthermore, all published schema are based on 'historic' cohorts of patients and consequently may not reflect advancements in medical care over time (for example, VKA monitoring) and treatment of underlying heart disease. The HEMORR ${ }_{2}$ HAGES score, from the same group as the $\mathrm{CHADS}_{2}$ index, is probably the best alternative. ${ }^{70} \mathrm{HEMORR}_{2} \mathrm{HAGES}$ is also an acronym based scoring system and represents $\underline{H}$ epatic or renal disease, Ethanol abuse, Malignancy, $\underline{\text { Older }}$ (age $>75$ years), Reduced platelet count or function, $\underline{R}$ e-bleeding risk (2 points), Hypertension (uncontrolled), Anemia, Genetic factors, Excessive fall and Stroke. Apart from a previous major bleeding (re-bleeding) presence of the other risk factors adds one point. The resulting maximum score is 12 and an increasing score relates to an increasing risk of major bleeding. However, the user-friendliness of $\mathrm{HEMORR}_{2}$ HAGES is far to seek given the incorporation of many routinely unavailable risk factors, which also overlap significantly with stroke risk factors. ${ }^{70}$

Therefore, we recently developed a novel scoring system called HASBLED (Chapter 3). ${ }^{73}$ The HASBLED scoring system is derived from a large, contemporary European cohort of nearly 3,500 non-valvular AF patients. During the 1 year followup period a total of 53 major bleedings occurred. We identified prior major bleeding, age $>65$, clopidogrel use and kidney failure as independent risk factors of major bleeding in this cohort. After incorporation of other recognized risk factors of major bleeding this led to the HASBLED score. One point is awarded for the presence of each incorporated risk factor, producing a score between 0 and 9 . The acronym stands for: Hypertension [uncontrolled, $>160 \mathrm{mmHg}$ systolic], Abnormal renal/liver function (1 point each), Stroke, Bleeding history or predisposition, Labile INR [i.e. therapeutic time in range $<60 \%$ ], Elderly (>65), Drugs/alcohol (1 point each) concomitantly. In the study population, HASBLED proved to be as good in predicting the occurrence of major bleeding within one year as its best competitor, the HEM$\mathrm{OR}_{2} \mathrm{RHAGES}$ scheme. Its predictive accuracy was the highest in patients receiving only antiplatelet agents or no antithrombotic therapy at all. Keeping in mind the lessons learned from the stroke risk classification it is also important to emphasize the superior user-friendliness of HASBLED over the HEMOR ${ }_{2}$ RHAGES scheme. The HASBLED risk factors are easier to memorize, more readily available and have less overlap with stroke risk factors. Furthermore, the potential of HASBLED as a clinically useful tool to assess the risk of major bleeding in AF patients has been recently strengthened. ${ }^{75,76}$ From the SPORTIF (Stroke Prevention Using an ORal Thrombin Inhibitor in Atrial Fibrillation) trials III and V a cohort of $>7,000$ non-valvular AF pa- 
tients receiving either warfarin or the direct thrombin inhibitor ximelagatran was selected. HASBLED was better in predicting the occurrence of major bleeding compared to the other available schema's with, again, its user-friendly potential. ${ }^{75} \mathrm{~A}$ large, nationwide, Danish study among $>118,000$ hospitalized non-valvular AF patients demonstrated the predictive power of HASBLED to be similar to that of HEM$\mathrm{OR}_{2} \mathrm{RHAGES}^{76}$ However, HASBLED has important advantages regarding its clinical user-friendliness. Although additional validation and fine-tuning is required, the HASBLED score provides an essential first step to improved assessment of the risk of major bleeding in AF patients.

\section{Antithrombotic management in clinical practice}

\subsection{Evolution of international guidelines on the antithrombotic management of AF}

In 2001 the first joined ACC/AHA/ESC guidelines on the management of AF were released. ${ }^{6}$ The recommendations on the antithrombotic regimen were a virtual copy of the knowledge derived from the big five. A few years later, in 2006, a second version of the international guidelines appeared. ${ }^{7}$ Most noteworthy was the emergence of reports on large scale antithrombotic undertreatment and the availability of more (fine tuned) stroke risk stratification schema's, in particular the $\mathrm{CHADS}_{2}$ index. ${ }^{59}$ Although data-wise not much had changed, the recommendations on the antithrombotic management did and perhaps more than expected. Opposed to the first version, the 2006 guidelines no longer recommended combined use of aspirin and oral anticoagulation in patients with coronary artery disease or diabetes mellitus. This is largely due to recognition that subtherapeutic (INR <1.5) VKA dosing in combination with aspirin adds little to nothing in stroke prevention compared to aspirin alone in AF patients. ${ }^{77,78}$ However, when higher INR values are targeted the combined regimen fails to proof superiority over VKA monotherapy, but it is associated with more bleedings, especially $\mathrm{ICH}$ in elderly patients. ${ }^{79}$ Another important change was the somehow contradictive support for a 'less liberal' oral anticoagulation policy, given the translation of the $\mathrm{CHADS}_{2}$ index into clinical practice. ${ }^{7}$ This created an opportunity for physicians and patients alike to 'bail-out' on the use of vitamin $\mathrm{K}$ antagonists in the majority of the cases. In hindsight it seems questionable whether this change in common practice was for the better. Especially, considering our observations of such a regimen in a retrospective analysis in all patients admitted because of an AF related ischemic stroke to our university teaching hospital between 2003-2006. (Chapter 4). ${ }^{80}$ It turned out that $163 / 1120$ ischemic strokes were AF related. In 89 (55\%) patients the arrhythmia was already known prior to admission and in 74 (45\%) AF was newly diagnosed during the index admission. In 
the known AF patients we studied the antithrombotic management on admission according to the patient's risk profile. We found that at least $51 \%$ of the patients was undertreated. Taking into account the additional cases of $\mathrm{ICH}$ associated with increased vitamin $\mathrm{K}$ antagonist use, optimal guideline adherence could have potentially prevented a net of 20/89 (22\%) strokes. Extrapolation of these data to the entire Netherlands would result in the net prevention of more than one stroke per day. ${ }^{80}$

Thus, it is questionable whether full adherence to the recommendations of the $2006 \mathrm{ACC} / \mathrm{AHA} / \mathrm{ESC}$ guidelines on the management of AF would prevent as much strokes as possible. In other words, how can we defend the seemingly fundamental changes in the overall approach and recommendations of the antithrombotic management in the ESC 2010 guidelines compared to the 2006 guidelines? ${ }^{81}$ These latest guidelines recommend no antithrombotic therapy at all in patients without risk factors (or 1 minor) and use of oral anticoagulation in all others, unless contraindicated. The latter refers to the premier recommendation to use a major bleeding risk assessment tool (HASBLED) in the antithrombotic management of AF patients.

\subsection{1 'Low' risk}

First of all, the overall stroke risk reduction by aspirin in AF patients is quite poor $(20 \%) .^{39}$ This is likely due to the fact that aspirin primarily prevents noncardioembolic stroke, whereas AF patients predominantly suffer from cardioembolic stroke. ${ }^{82}$ In low $\left(\mathrm{CHADS}_{2}\right.$ score 0 ) risk patients, the guidelines allow the choice between aspirin or nothing at all. ${ }^{7}$ Assuming this recommendation is based on a similar efficacy/safety assessment it leaves the physician in confusion, since it implies that for this particular group of patients, doing nothing is as good as prescribing aspirin in preventing stroke. Why give aspirin when its protective effect is close to nothing, but the risk of major (gastro-intestinal) bleeding is significant and that of ICH doubled compared to placebo ${ }^{39}$

\subsection{2 'Intermediate' risk}

For moderate $\left(\mathrm{CHADS}_{2}\right.$ score 1) risk AF patients the message that comes across is even more surprising. Here, the recommendation is to prescribe either aspirin or VKAs, suggesting comparable efficacy while the evidence for the superiority of VKAs over aspirin is overwhelming. At the same time, (identification of) a single additional stroke risk factor (i.e. $\mathrm{CHADS}_{2}$ score 2) renders choosing no longer an option. ${ }^{7}$ Fortunately, since the release of the 2006 guidelines, new evidence emerged. Among others, particularly helpful lessons can be learned from the Atrial Fibrillation Clopidogrel Trial with Irbesartan for Prevention of Vascular Events (ACTIVE) trials (W and A). ${ }^{83,84}$ The large randomized clinical trial ACTIVE W, was designed to address the question whether a combination of aspirin and clopidogrel could achieve stroke risk reduction equal to VKAs, at the cost of fewer complications. ${ }^{83}$ The study was prema- 
turely terminated as warfarin was clearly superior in preventing stroke and other cardiovascular events compared to the combination of aspirin and clopidogrel. Apart from this main lesson, regarding the inferiority of antiplatelet therapy for stroke prevention, ACTIVE W brought another important message forward via a post-hoc analysis. Healey et al. studied whether the superiority of warfarin was maintained in patients with a $\mathrm{CHADS}_{2}$ score of 1 vs. $>1$, in comparison with the combined treatment of clopidogrel and aspirin. Although the absolute event rates were low, the $\mathrm{CHADS}_{2}$ score 1 patients had significantly less strokes when using warfarin compared to dual antiplatelet therapy without an increased risk of major

bleeding. ${ }^{85}$ Recently, another study reinforced the finding that $\mathrm{CHADS}_{2}$ score 1 patients are better off treated with VKAs, considering they had a better prognosis (combined end-point of stroke and all-cause mortality) compared to those treated only with antiplatelet agents. ${ }^{86}$

\subsubsection{Balancing the risk of stroke and bleeding}

Absence of recommendations or guidance on what to do in case of a (perceived) high risk of major bleeding characterizes the 2001 and 2006 guidelines and distinguishes them from the 2010 ESC guidelines. ${ }^{6,7,81}$ Two things are important in this matter. First, are there reasonable alternatives to oral anticoagulation? Considering aspirin alone provides a modest protective effect, but on the other hand also has a lower risk of major bleeding one would therefore like to evaluate the effect of combined antiplatelet regimens to achieve this goal. This was exactly the study aim of the ACTIVE A trial, where AF patients with a least one risk factor of stroke who were deemed unsuitable to use VKA were randomized to either receive aspirin alone or combined with clopidogrel. ${ }^{84}$ The main results are that clopidogrel on top of aspirin provides superior stroke protection over aspirin alone, but at an increased risk of major bleeding, almost as high as with the use of VKA. ${ }^{84}$ Thus, from the ACTIVE W it appears that clopidogrel on top of aspirin is inferior to VKA, while both ACTIVE W and $A$ show that the associated risk of major bleeding is similar to that of VKA use. 83,84

Because a suitable alternative is lacking at present, the second question becomes even more important: how to identify and deal with patients at high risk of bleeding in general and in the ACTIVE A study in particular? An important concern with the selection of patients (Chapter 2 ) $^{87}$ is the fact that only $25 \%$ of the enrolled patients of the ACTIVE A trial actually had an established risk factor of major bleeding. ${ }^{84}$ The remaining $75 \%$ of the patients were included because of physician or patient preference not to use VKA, remarkably in the absence of specific, established risk factors of major bleeding. True, use of VKA is troublesome. However, experience drives skills. True, patients could have a tendency to be unwilling to use VKA. However, they can just as easy be persuaded in the opposite direction. True, the ruling 2006 guidelines at that time, mainly due to the lack of tools, did not pro- 
vide (sufficient) guidance on assessing the risk of major bleeding or outweighing the risk/benefit of VKA use for the individual AF patient. However, these enrolled subjects were free of all 'accepted' major risk factors of bleeding, leaving only less validated reasons and clinical paradigms. ${ }^{87}$ True, stroke and bleeding risk go hand in hand. Should this result in not prescribing VKA to patients who would substantially benefit from it? Likely not. Even if risk factors of major bleeding are present. This is exactly the idea behind the - first time ever - recommendation of the use of a clinical tool (HASBLED) to assess the risk of major bleeding in AF patients with an indication for oral anticoagulation by the 2010 ESC guidelines. ${ }^{81}$ It illustrates that the HASBLED score in its current form is not intended to be used in a simple mathematical equation $\left(\mathrm{CHA}_{2} \mathrm{DS}_{2}\right.$-VASC $-\mathrm{HASBLED}>0=$ oral anticoagulation; $\mathrm{CHA}_{2} \mathrm{DS}_{2}$-VASc HASBLED $<0=$ antiplatelet therapy). Instead it should trigger physicians to carefully evaluate whether the incorporated potential risk factors of major bleeding are present. Even more important, if this is the case, physician and patient need to combine their efforts in order to reverse and optimize each of the risk factors throughout time (ideally preventing their occurrence!). For example, more strict INR control (in the initiation phase); strict (systolic) blood pressure control; improved medical guidance regarding pain relief (avoidance of non-steroidal anti-inflammatory drugs). Also, the presence of previous ischemic stroke on the list of risk factors of major bleeding - and especially ICH - should be an eye-opener for clinicians to, again, emphasize the importance of primary stroke prevention.

Altogether, the changes which resulted in the latest guidelines seem very much defendable. The focus of the antithrombotic management of AF patients shifted from deciding which drug to use, to identifying those at truly low risk of ischemic stroke and relatively low risk of major bleeding. Whether these 'simple' adjustments also improve stroke prevention needs to be awaited, in part because of established clinical paradigms.

\subsection{Clinical paradigms}

When assessing the need for antithrombotic treatment in AF patients, wrong assumptions based on misconceptions play a role (Chapters $\mathbf{5}$ and 6). For instance, the risk of falling. Fall risk is used as a reason to avoid oral anticoagulation in large numbers of AF patients. ${ }^{84,88,89}$ The risks of falling are vastly overestimated because traumatic subdural hematoma in patients using oral anticoagulation has a far lower impact than stroke and is much less frequent. Furthermore, it has been estimated that a patient almost has to fall on a daily basis for the potential harm of warfarin to outweigh its benefit. ${ }^{90,91}$ Above all, it is important to search for a potentially reversible cause of falling (similar to 'true' risk factors of major bleeding). Cessation of benzodiazepines, referral to the ophthalmologist, or advice to use walking aids may free the way to oral anticoagulation by reducing the fall risk. 
Another important paradigm is old age ${ }^{92}$ which, despite the increased intracranial bleeding risk compared with lower age categories, can no longer be seen as a contraindication for VKA use. ${ }^{93,94}$ First of all because many studies have shown the importance of considering age as continuous risk factor starting age 65. Second, considering the results of the Birmingham Atrial Fibrillation Treatment of the Aged (BAFTA) study. ${ }^{95}$ This randomized controlled trial demonstrated that AF patients age $\geq 75$ years treated with warfarin suffered significantly fewer strokes (both ischemic and hemorrhagic) and had a similar number of major bleeds compared with those who received aspirin. ${ }^{95}$ Furthermore, a recent study demonstrated that with aging the protective effect of antiplatelet therapy decreases, whereas the benefit of oral anticoagulation remains constant. ${ }^{96}$ These are all strong arguments favoring use of oral anticoagulation in the elderly instead of considering old age a bleeding risk factor or considering it a reason to exchange VKA for aspirin.

Finally, the fact that AF patients have a fourfold increased stroke risk compared with patients in chronic sinus rhythm renders the presence of AF itself a risk factor for many clinicians. As a consequence, the continuous presence of AF in permanent $A F$ patients or, conversely, its predominant absence in infrequent paroxysmal $A F$ is taken as a reason to install or avoid VKA, respectively. ${ }^{97,}{ }^{98}$ However, type of AF, actual presence or absence of $A F$, or burden of $A F$ do not play a role in any of the risk schemes. The clinical paradigm is that paroxysmal AF because of the brevity of the attacks is not thrombogenic, whereas persistent and permanent are. This probably is the basis for increased stroke rates, especially in paroxysmal AF patients undergoing cardioversion. Not primarily because of lacking VKA prior to cardioversion, but more so because of omission at discharge. Thus clinical AF type unfortunately has remained-up and until these days-a significant determinant for VKA prescription in clinical practice despite long available, convincing evidence, which was recently reinforced. ${ }^{53,99,100}$

\subsection{Specific situations}

\subsubsection{Cardioversion}

The temporary increased stroke risk peri-cardioversion has led to one of the consistent and most straight forward recommendations in the AF guidelines. ${ }^{6,7,81}$ In patients with an episode of $A F \geq 48$ hours or of unknown duration adequate oral anticoagulation is recommended 3 and 4 consecutive weeks, respectively, prior and following elective cardioversion. However, that 'sense and simplicity' does not equal successful implementation in every day clinical practice is demonstrated in Chapter 7. Here we described all primary cardioversions performed during enrolment in the Euro Heart Survey on AF. In total 1,801 cardioversions were performed. Although the immediate 'success' was reassuring at least, with sinus rhythm restoration in $630 / 712(88 \%)$ of the electrical, $458 / 643(71 \%)$ of the intravenous and $333 / 446$ 
(75\%) of the oral pharmacological cardioversions, the same could not be said for the antithrombotic management. In patients with $\mathrm{AF} \geq 48$ hours or of unknown duration adequate anticoagulation in use at time of cardioversion was $90 \%, 42 \%$ and $52 \%$, respectively, in electrical, intravenous and oral pharmacological cardioversion. Important to note that this already disappointingly low rate would actually drop even more considering we could not account for the 3 preceding weeks. Furthermore, this only covers the quantitative aspect of anticoagulation. Qualitative undertreatment, i.e. INR value<2.0), is another important issue which was beyond our scope but likely to contribute additional cases of antithrombotic undertreatment in this setting. However, considering the thrombo-embolic safety of cardioversion with dabigatran ${ }^{26}$, the qualitative undertreatment is probably a non-issue in the nearby future. More alarming is the observation that at discharge of the aforementioned patients adequate anticoagulation only rose to $93 \%$ in the electrical and $61 \%$ in both pharmacological cardioversion groups. This relates to the clinical focus on terminating the arrhythmia and forgetting about the stroke risk. Unfortunately, patients undergoing cardioversion for acute atrial fibrillation or flutter are also not considered for chronic anticoagulation following the procedure even if they have significant stroke risk factors. Despite the fact that our study was not designed to draw solid conclusions on the outcome of antithrombotic undertreatment, we did observe a trend towards more thrombo-embolic events in the patients who underwent pharmacological vs. electrical cardioversion. Nevertheless, key is that in a time where awareness of the importance of patient education and empowerment is growing it shows there is still a lot to be gained on the side of the health care professionals, even in seemingly straight forward scenarios. To avoid a 'wild west practice' such recommendations should either be critically reviewed or properly communicated and endorsed.

\subsubsection{Preventing (secondary) coronary thrombo-embolism}

An interesting and challenging aspect of the antithrombotic treatment of AF patients is the use of antithrombotic agents in the setting of a percutaneous coronary intervention with stent implantation (PCl-S). Underlying heart disease, such as coronary artery disease, is extremely prevalent among AF patients and not uncommonly results in acute coronary syndromes (ACS)., ${ }^{3,4}$ Current guidelines on $\mathrm{PCl}$ recommend a combination of clopidogrel and aspirin following $\mathrm{PCl}^{101}$ However, as previously addressed, this regimen is inferior to VKAs in moderate to high risk AF (CHADS $_{2}$ score $\geq 2$ ) patients regarding stroke prevention. Therefore the challenging question rises whether, and if so how, addition of this antiplatelet regimen can be justified in these AF patients.

An important (first) step to justify the use of clopidogrel plus aspirin on top of warfarin, i.e. triple therapy, in $\mathrm{CHADS}_{2}$ score $\geq 2$ patients, is to assess its antithrombotic effect against the concurrent bleeding risks. The limited available evidence 
indicates that triple therapy, compared to the combination of warfarin and aspirin, results in less thromboembolism in general, and stroke and myocardial infarction in particular, occurring in, respectively, $0.8 \%$ vs. $15.2 \%, 2.8 \%$ vs. $8.8 \%$, and $8.5 \%$ vs. $18.2 \%$ of the patients. ${ }^{102}$ Data on the efficacy of the combination warfarin and clopidogrel instead of aspirin is even more scarce, but studies by Karjalainen et al. and Nguyen et al. suggest that a combination with clopidogrel is more beneficial. ${ }^{102,}$ 103

Intuitively and partly based on trial results, one expects triple therapy to further increase the risk of major bleeding and one should therefore consider this before justifying its use. Indeed, a recent systematic review reveals an increased - but with a highly variable incidence - risk of, predominantly gastro-intestinal, major bleeding. Risk factors for bleeding were excessive INR values, periprocedural heparin and intravenous platelet inhibitor administration. ${ }^{104,105}$ Duration also appears to be of importance as short term triple therapy (limited to 30 days) relates to less major bleedings compared to longer term application (6-12 months), with a pooled incidence of, respectively, 4.6 vs. $10.3 \%$. All three available studies comparing safety of triple therapy to the guideline recommended combination of aspirin and clopidogrel demonstrate a significant, almost fivefold increased risk of major bleeding up to 9 months of treatment in the triple therapy group. ${ }^{104,105}$ However, the limited number of patients receiving warfarin in combination with either clopidogrel or aspirin in these trials, does not allow reliable interpretation of the results and therefore, at present, no reliable conclusions on their respective safety profile can be made.

Expert consensus justifies the use of triple therapy using VKA with INR target 23, clopidogrel $75 \mathrm{mg} /$ day and aspirin in AF patients with a moderate to high thromboembolic risk $\left(\mathrm{CHADS}_{2}\right.$ score $\left.\geq 2\right)$, during the initial critical period of (re)endothelization post $\mathrm{PCl}(-\mathrm{S}) .^{104,105}$ Because the increased risk of major bleeding associated with triple therapy rises even further during long term therapy, one should indeed confine triple therapy for the shortest possible duration. Moreover, one must consider the patient's bleeding risk beforehand also taking into consideration the preferred type of $\mathrm{PCl}$ for this individual. The latter has to do with the fact that differences in the recommended period of dual antiplatelet use - and thus in these cases triple therapy - are considerable and also depend on the type of drug eluting stent (DES) (at least 3 vs. 6 months, respectively, for a sirolimus compared to a paclitaxel coated stent). ${ }^{101}$ This is also the reason why expert consensus advices restrictive use of DES in this specific population and, in case a patient has a high risk of major bleeding, exclusive use of a bare metal stent combined with reducing the period of triple therapy to 2 weeks. Furthermore, in all cases where triple therapy is instituted one should maximize opportunities to prevent major bleeding. As excessive INR values are associated with major bleeding during triple therapy, strategies to reduce variation in INR's are important, involving lifestyle adjustment if necessary (diet and drinking habits, co-medication), more frequent INR monitoring or change 
of VKA preparation - if possible - , e.g. from a short to a longer acting preparation. Obviously, new drugs may appear more appropriate than VKA in this respect. Since the majority of major bleeding involves the gastro-intestinal tract, measures to protect the gastric surface could be recommended such as use of a proton pomp inhibitor and restriction, or even prohibition, of concomitant (chronic) use of nonsteroidal anti-inflammatory drugs. Finally, peri-procedural bleeding could be minimized by choosing a radial access site, considering to perform the procedure while the patient is effectively anticoagulated (INR 2-3), opposed to heparin bridging, and restrictive use of additional intravenous platelet inhibitors.

Protection against late complications after this initial period is also of importance. The $\mathrm{PCl}$ guidelines recommend all ACS patients to use clopidogrel and aspirin up to one year following the event. ${ }^{101}$ However, considering the long term risk of major bleeding associated with triple therapy, this regimen is no option for the moderate to high thromboembolic risk AF patients. Instead, the current best alternative is to choose between adding aspirin or clopidogrel to warfarin. Evidence arguing against the use of a combination of VKA with aspirin is the observed increased risk of major bleeding opposed to no improved stroke protection over VKA monotherapy. ${ }^{79}$ Also, the maximum beneficial effect of aspirin appears to be restricted to the early period after myocardial infarction. ${ }^{106}$ On the other hand, the above mentioned trials are outdated in that PCl-S was not routine care at that time and thus extrapolation of the results to the current population is probably not correct.

Evidence favoring clopidogrel on top of warfarin does exist, but is limited due to the low number of evaluated patients as well as the marginal reported benefit. In spite of that, a combination of VKA with a thienopyridine derivative received preferential recommendation over aspirin. ${ }^{7,104,105}$ However, it is expert consensus that in light of the lack of evidence from randomized clinical trials - warfarin combined with aspirin in combination with gastro-intestinal protection, i.e. a proton pump inhibitor can be considered. Safeguarding the occurrence of thromboembolic events in AF patients with a moderate to high thromboembolic risk $\left(\mathrm{CHADS}_{2}\right.$ score $\left.\geq 2\right)$ beyond one year following the event, is restricted to VKA (INR 2-3) monotherapy. ${ }^{104,}$ 105

To answer the initially raised question: yes, triple therapy is required - and therefore justified - to be used in the above discussed setting. Unfortunately, a similar clear cut answer to the how cannot be given due to the complexity of (individual) bleeding risk assessment and lacking, convincing evidence.

Recently, the novel multichannel blocking antiarrhythmic drug dronedarone was tested in the randomized clinical trial ATHENA (A placebo-controlled, doubleblind, parallel-arm Trial to assess the efficacy of dronedarone $400 \mathrm{mg}$ BID for the prevention of cardiovascular Hospitalization or death from any cause in patiENts with Atrial fibrillation/atrial flutter). ${ }^{107}$ ATHENA demonstrated in patients with per- 
sistent or paroxysmal AF and at least 1 risk factor for vascular events, that dronedarone reduced the composite outcome of cardiovascular hospitalization or death. ${ }^{107}$ Although the main result was already unique, being the first antiarrhythmic drug associated with less death and cardiovascular hospitalization - the observations of the subsequent post-hoc analyses on thromboembolic events were, if possible, even more surprising. First, Connolly et al. demonstrated that treatment with dronedarone on top of usual care resulted in less strokes compared to placebo. ${ }^{108}$ Second, in Chapter 8 we performed a post-hoc analysis on the safety and efficacy of dronedarone among patients with both AF and coronary heart disease. Here, next to similar main results in this subgroup compared to the ATHENA population, we observed less first acute coronary syndromes in patients with both $\mathrm{AF}$ and coronary heart disease receiving dronedarone compared to placebo. Full comprehension of these effects is difficult and lacking at present. Still, it is extremely interesting to explain and exploit any potential cardiovascular protective effect which antiarrhythmic drugs could harbor in future research.

\section{Future directions}

What will the future of antithrombotic management of AF (seemingly) bring and what is needed? New oral anticoagulants? Undoubtedly and soon. Dabigatran, rivaroxaban and apixaban are coming. ${ }^{109-112}$ They collectively, to my opinion, revolutionize the antithrombotic treatment of (AF) patients in particular and fuel debate on treatment (changes) in general, such as cost, (patient) empowerment, compliance and personalized medicine. Are these new drugs needed? Absolutely. Strokes, and particularly AF related ones, are a numerical and socio-economical threat on both a micro- and macro level. All the available evidence up to now shows an unacceptably high rate of antithrombotic undertreatment among AF patients. ${ }^{80,97,113,114}$ This is largely believed to be due to the (inherent) inconveniences of VKAs, resulting in reluctance from patient and physicians alike to use the drug. Also, the almost mystical - unfounded ${ }^{112}$ - trust in aspirin (especially in its 'benign' bleeding profile) should not be forgotten as an important determinant of antithrombotic undertreatment. The new breed of oral anticoagulants, which lack most of the inconveniences of VKAs and considerably contribute to the downfall of aspirin's heroic status, should therefore rid the AF world of the term 'antithrombotic undertreatment' (both quantitative and qualitative). However, at the same time it is questionable whether this will be the case, as all (new) things come at a cost. Personally, I believe that true success in the treatment of (AF) patients depends on integrated approach, accepted preconditions, outside expertise and willingness to challenge all current aspects of the health care system, i.e. redefining ( $A F$ related) health care. ${ }^{115}$ 
Unusual suspects? Likely. However, given the recently raised safety issues associated with the use of dronedarone in patients with permanent AF (numerical increased number of deaths and cardiovascular hospitalizations) the initial excitement for a quick win here is damped. Still, (animal) studies which increase our mechanistic understanding should continue as it may lead the way to the holy grail of conventional antithrombotic drug therapy: restoring normal hemostasis, i.e. no excess risk of (major) bleeding. Is it needed? Yes, most of the usual suspects (i.e. coagulation factors) have been detained or are in the process of being arrested. Yet, the stroke cartel and the significant collateral damage remain to exist. Perhaps a steady state antithrombotic poly pill might have potential.

Improved risk stratification? You have my word. It is important to realize that the increased stroke rate in AF is not fully attributable to cardio-embolism ${ }^{116}$ and that risk of stroke and bleeding go hand-in-hand. ${ }^{117,}{ }^{118}$ Hence, AF should really be considered a 'vascular' disease and this approach also helps us to understand why stroke risk refinement with $\mathrm{CHA}_{2} \mathrm{DS}_{2}-\mathrm{VASc}$ is successful, considering more wellknown cardiovascular risk factors are taken into account compared to $\mathrm{CHADS}_{2}{ }^{119}$ Although these clinical risk factors improve the overall stroke risk stratification of $A F$ patients, many of them do not (fully) relate to true cardio-embolic stroke. Therefore, we need to learn more about the presence of local - cardiac/left atrial - abnormalities (or its surrogates) of what is going on in the left atrium. ${ }^{120}$ The observation of a beneficial effect of adding echocardiographic parameters to clinical schema is therefore plausible and less surprising. ${ }^{48}$ In fact, it exemplifies the power of echocardiography - or any imaging modality for that matter - which is to visualize the scene of calamity: in this case, the left atrium. This raises the question: "What and how to visualize best?" Increased atrial dimensions, or more specifically atrial growth over time, is bad news in general ${ }^{121}$ and associated with increased risk of stroke in particular. ${ }^{122}$ However, it is important to realize that most of the available evidence concerns 'simple' quantification of the left atrium. Such measurements are outdated and there is a lot to be gained if they are at least expanded with left atrial area measurement using the apical four chamber view and, preferably, volumes. Perhaps cardiac MRI will become the way to go once atrial inflammation and fibrosis can be reliably quantified. ${ }^{123}$ Going even one step further, we could even consider performing a cerebral MRI in patients with 'score 0 or 1 ' to reveal clinically silent cerebral infarctions ${ }^{124-126}$ or small vessel disease, and thereby re-classifying them from low to high stroke risk patients. This also creates the possibility to potentially fine-tune existing bleeding risk schema ${ }^{73}$ by concomitant screening of, for instance, cerebral micro-bleeds. Finally, given the vascular nature of AF, it is also important to note that a lot can be gained by continued efforts to further breakdown already incorporated clinical risk factors such as diabetes mellitus and to investigate other potentially relevant ones, such as renal impairment. The need seems 
obvious: low risk patients still suffer from stroke and the answer is unknown as to which patients benefit from more rigorous secondary stroke prevention?

Improving identification of AF? You can take it to the bank. Not in the least because of the new oral anticoagulants. The most apparent hurdles are the asymptomatic and paroxysmal nature of the arrhythmia in a substantial number of patients. ${ }^{127}$ The most likely subgroup to start with - who are currently subject of numerous studies - are TIA/stroke patients. ${ }^{128}$ Apart from the technical aspect, it also touches upon the (atrial) characterization of patients, i.e. determining those who are at risk of developing AF. ${ }^{129}$ Similar to other risk stratification systems, a combination of clinical and ((semi-)invasive) imaging modalities will provide significant insights. Increasing the detection of AF is very much necessary as the undetected become the 'new antithrombotic undertreated'. Even more so, failure to increase our efforts of improved AF detection raises more ethical concerns than ever before.

\section{Conclusions}

The antithrombotic management of patients with $\mathrm{AF}$ is and remains a challenge despite, or perhaps in part due, significant (future) changes in both risk stratification and therapeutic armamentarium. However, if we recognize AF as a (marker of) cardiovascular disease and dare to defy current cardiovascular care we should consider (this) challenge as an indicator of (significant) room for improvement.

\section{REFERENCES}

1. Heeringa J, van der Kuip DA, Hofman A, Kors JA, van Herpen G, Stricker BH, Stijnen T, Lip GY, Witteman JC. Prevalence, incidence and lifetime risk of atrial fibrillation: the Rotterdam study. Eur Heart J 2006;27:949-953.

2. de Vos CB, Pisters R, Nieuwlaat R, Prins MH, Tieleman RG, Coelen RJ, van den Heijkant AC, Allessie MA, Crijns HJ. Progression from paroxysmal to persistent atrial fibrillation clinical correlates and prognosis. J Am Coll Cardiol 55:725-731.

3. Nieuwlaat R, Capucci A, Camm AJ, Olsson SB, Andresen D, Davies DW, Cobbe S, Breithardt G, Le Heuzey JY, Prins MH, Levy S, Crijns HJ. Atrial fibrillation management: a prospective survey in ESC member countries: the Euro Heart Survey on Atrial Fibrillation. Eur Heart J 2005;26:2422-2434.

4. Nieuwlaat R, Prins MH, Le Heuzey JY, Vardas PE, Aliot E, Santini M, Cobbe SM, Widdershoven JW, Baur LH, Levy S, Crijns HJ. Prognosis, disease progression, and treatment of atrial fibrillation patients during 1 year: follow-up of the Euro Heart Survey on atrial fibrillation. Eur Heart J 2008;29:11811189.

5. Wolf PA, Abbott RD, Kannel WB. Atrial fibrillation as an independent risk factor for stroke: the Framingham Study. Stroke 1991;22:983-988. 
6. Fuster V, Ryden LE, Asinger RW, Cannom DS, Crijns HJ, Frye RL, Halperin JL, Kay GN, Klein WW, Levy S, McNamara RL, Prystowsky EN, Wann LS, Wyse DG. ACC/AHA/ESC guidelines for the management of patients with atrial fibrillation. A report of the American College of Cardiology/American Heart Association Task Force on Practice Guidelines and the European Society of Cardiology Committee for Practice Guidelines and Policy Conferences (Committee to develop guidelines for the management of patients with atrial fibrillation) developed in collaboration with the North American Society of Pacing and Electrophysiology. Eur Heart J 2001;22:1852-1923.

7. Fuster V, Ryden LE, Cannom DS, Crijns HJ, Curtis AB, Ellenbogen KA, Halperin JL, Le Heuzey JY, Kay GN, Lowe JE, Olsson SB, Prystowsky EN, Tamargo JL, Wann S, Smith SC, Jr., Jacobs AK, Adams CD, Anderson JL, Antman EM, Hunt SA, Nishimura R, Ornato JP, Page RL, Riegel B, Priori SG, Blanc JJ, Budaj A, Camm AJ, Dean V, Deckers JW, Despres C, Dickstein K, Lekakis J, McGregor K, Metra M, Morais J, Osterspey A, Zamorano JL. ACC/AHA/ESC 2006 guidelines for the management of patients with atrial fibrillation--executive summary: a report of the American College of Cardiology/American Heart Association Task Force on Practice Guidelines and the European Society of Cardiology Committee for Practice Guidelines (Writing Committee to Revise the 2001 Guidelines for the Management of Patients With Atrial Fibrillation). J Am Coll Cardiol 2006;48:854-906.

8. Marin F, Roldan V, Climent VE, Ibanez A, Garcia A, Marco P, Sogorb F, Lip GY. Plasma von Willebrand factor, soluble thrombomodulin, and fibrin D-dimer concentrations in acute onset non-rheumatic atrial fibrillation. Heart 2004;90:1162-1166.

9. Kahn SR, Solymoss S, Flegel KM. Nonvalvular atrial fibrillation: evidence for a prothrombotic state. Cmaj 1997;157:673-681.

10. Mitusch R, Siemens HJ, Garbe M, Wagner T, Sheikhzadeh A, Diederich KW. Detection of a hypercoagulable state in nonvalvular atrial fibrillation and the effect of anticoagulant therapy. Thromb Haemost 1996;75:219-223.

11. Inoue H, Nozawa T, Okumura K, Jong-Dae L, Shimizu A, Yano K. Prothrombotic activity is increased in patients with nonvalvular atrial fibrillation and risk factors for embolism. Chest 2004;126:687692.

12. Kumagai K, Fukuchi M, Ohta J, Baba S, Oda K, Akimoto H, Kagaya Y, Watanabe J, Tabayashi K, Shirato $\mathrm{K}$. Expression of the von Willebrand factor in atrial endocardium is increased in atrial fibrillation depending on the extent of structural remodeling. Circ $J$ 2004;68:321-327.

13. Nakamura Y, Nakamura K, Fukushima-Kusano K, Ohta K, Matsubara H, Hamuro T, Yutani C, Ohe T. Tissue factor expression in atrial endothelia associated with nonvalvular atrial fibrillation: possible involvement in intracardiac thrombogenesis. Thromb Res 2003;111:137-142.

14. Yamashita T, Sekiguchi A, Iwasaki YK, Sagara K, Hatano S, linuma H, Aizawa T, Fu LT. Thrombomodulin and tissue factor pathway inhibitor in endocardium of rapidly paced rat atria. Circulation 2003;108:2450-2452.

15. Dudley SC, Jr., Hoch NE, McCann LA, Honeycutt C, Diamandopoulos L, Fukai T, Harrison DG, Dikalov $\mathrm{SI}$, Langberg J. Atrial fibrillation increases production of superoxide by the left atrium and left atrial appendage: role of the NADPH and xanthine oxidases. Circulation 2005;112:1266-1273.

16. Kaireviciute D, Blann AD, Balakrishnan B, Lane DA, Patel JV, Uzdavinys G, Norkunas G, Kalinauskas G, Sirvydis V, Aidietis A, Lip GY. Characterisation and validity of inflammatory biomarkers in the prediction of post-operative atrial fibrillation in coronary artery disease patients. Thromb Haemost 104:122-127.

17. Jaber WA, Prior DL, Thamilarasan M, Grimm RA, Thomas JD, Klein AL, Asher CR. Efficacy of anticoagulation in resolving left atrial and left atrial appendage thrombi: A transesophageal echocardiographic study. Am Heart J 2000;140:150-156.

18. Stoddard MF, Dawkins PR, Prince CR, Ammash NM. Left atrial appendage thrombus is not uncommon in patients with acute atrial fibrillation and a recent embolic event: a transesophageal echocardiographic study. J Am Coll Cardiol 1995;25:452-459.

19. Pollick C, Taylor D. Assessment of left atrial appendage function by transesophageal echocardiography. Implications for the development of thrombus. Circulation 1991;84:223-231. 
20. Agmon Y, Khandheria BK, Gentile F, Seward JB. Echocardiographic assessment of the left atrial appendage. J Am Coll Cardiol 1999;34:1867-1877.

21. Kamp O, Verhorst PM, Welling RC, Visser CA. Importance of left atrial appendage flow as a predictor of thromboembolic events in patients with atrial fibrillation. Eur Heart J 1999;20:979-985.

22. Bernhardt $P$, Schmidt $H$, Hammerstingl C, Luderitz B, Omran $H$. Patients with atrial fibrillation and dense spontaneous echo contrast at high risk a prospective and serial follow-up over 12 months with transesophageal echocardiography and cerebral magnetic resonance imaging. J Am Coll Cardiol 2005;45:1807-1812.

23. Black IW. Spontaneous echo contrast: where there's smoke there's fire. Echocardiography 2000;17:373-382.

24. Black IW, Fatkin D, Sagar KB, Khandheria BK, Leung DY, Galloway JM, Feneley MP, Walsh WF, Grimm RA, Stollberger $C$, et al. Exclusion of atrial thrombus by transesophageal echocardiography does not preclude embolism after cardioversion of atrial fibrillation. A multicenter study. Circulation 1994;89:2509-2513.

25. Arnold AZ, Mick MJ, Mazurek RP, Loop FD, Trohman RG. Role of prophylactic anticoagulation for direct current cardioversion in patients with atrial fibrillation or atrial flutter. J Am Coll Cardiol 1992;19:851-855.

26. Nagarakanti R, Ezekowitz MD, Oldgren J, Yang S, Chernick M, Aikens TH, Flaker G, Brugada J, Kamensky G, Parekh A, Reilly PA, Yusuf S, Connolly SJ. Dabigatran versus warfarin in patients with atrial fibrillation: an analysis of patients undergoing cardioversion. Circulation 123:131-136.

27. Naccarelli GV, Dell'Orfano JT, Wolbrette DL, Patel HM, Luck JC. Cost-effective management of acute atrial fibrillation: role of rate control, spontaneous conversion, medical and direct current cardioversion, transesophageal echocardiography, and antiembolic therapy. Am J Cardiol 2000;85:36D45D.

28. Fatkin D, Kuchar DL, Thorburn CW, Feneley MP. Transesophageal echocardiography before and during direct current cardioversion of atrial fibrillation: evidence for "atrial stunning" as a mechanism of thromboembolic complications. J Am Coll Cardiol 1994;23:307-316.

29. Berger M, Schweitzer P. Timing of thromboembolic events after electrical cardioversion of atrial fibrillation or flutter: a retrospective analysis. Am J Cardiol 1998;82:1545-1547, A1548.

30. Manning WJ, Silverman DI, Katz SE, Riley MF, Doherty RM, Munson JT, Douglas PS. Temporal dependence of the return of atrial mechanical function on the mode of cardioversion of atrial fibrillation to sinus rhythm. Am J Cardiol 1995;75:624-626.

31. Antonielli E, Pizzuti A, Bassignana A, Tanga M, Baralis G, Rovere ME, Di Leo M. Transesophageal echocardiographic evidence of more pronounced left atrial stunning after chemical (propafenone) rather than electrical attempts at cardioversion from atrial fibrillation. Am J Cardiol 1999;84:10921096, A1099-1010.

32. Falcone RA, Morady F, Armstrong WF. Transesophageal echocardiographic evaluation of left atrial appendage function and spontaneous contrast formation after chemical or electrical cardioversion of atrial fibrillation. Am J Cardiol 1996;78:435-439.

33. The effect of low-dose warfarin on the risk of stroke in patients with nonrheumatic atrial fibrillation. The Boston Area Anticoagulation Trial for Atrial Fibrillation Investigators. N Engl J Med 1990;323:1505-1511.

34. Stroke Prevention in Atrial Fibrillation Study. Final results. Circulation 1991;84:527-539.

35. Secondary prevention in non-rheumatic atrial fibrillation after transient ischaemic attack or minor stroke. EAFT (European Atrial Fibrillation Trial) Study Group. Lancet 1993;342:1255-1262.

36. Petersen P, Boysen G, Godtfredsen J, Andersen ED, Andersen B. Placebo-controlled, randomised trial of warfarin and aspirin for prevention of thromboembolic complications in chronic atrial fibrillation. The Copenhagen AFASAK study. Lancet 1989;1:175-179.

37. Connolly SJ, Laupacis A, Gent M, Roberts RS, Cairns JA, Joyner C. Canadian Atrial Fibrillation Anticoagulation (CAFA) Study. J Am Coll Cardiol 1991;18:349-355. 
38. Ezekowitz MD, Bridgers SL, James KE, Carliner NH, Colling CL, Gornick CC, Krause-Steinrauf H, Kurtzke JF, Nazarian SM, Radford MJ, et al. Warfarin in the prevention of stroke associated with nonrheumatic atrial fibrillation. Veterans Affairs Stroke Prevention in Nonrheumatic Atrial Fibrillation Investigators. N Engl J Med 1992;327:1406-1412.

39. Hart RG, Pearce LA, Aguilar MI. Meta-analysis: antithrombotic therapy to prevent stroke in patients who have nonvalvular atrial fibrillation. Ann Intern Med 2007;146:857-867.

40. Risk factors for stroke and efficacy of antithrombotic therapy in atrial fibrillation. Analysis of pooled data from five randomized controlled trials. Arch Intern Med 1994;154:1449-1457.

41. Hart RG, Pearce LA, McBride R, Rothbart RM, Asinger RW. Factors associated with ischemic stroke during aspirin therapy in atrial fibrillation: analysis of 2012 participants in the SPAF I-III clinical trials. The Stroke Prevention in Atrial Fibrillation (SPAF) Investigators. Stroke 1999;30:1223-1229.

42. van Latum JC, Koudstaal PJ, Venables GS, van Gijn J, Kappelle LJ, Algra A. Predictors of major vascular events in patients with a transient ischemic attack or minor ischemic stroke and with nonrheumatic atrial fibrillation. European Atrial Fibrillation Trial (EAFT) Study Group. Stroke 1995;26:801806.

43. Moulton AW, Singer DE, Haas JS. Risk factors for stroke in patients with nonrheumatic atrial fibrillation: a case-control study. Am J Med 1991;91:156-161.

44. Boysen G, Nyboe J, Appleyard M, Sorensen PS, Boas J, Somnier F, Jensen G, Schnohr P. Stroke incidence and risk factors for stroke in Copenhagen, Denmark. Stroke 1988;19:1345-1353.

45. van Walraven C, Hart RG, Singer DE, Laupacis A, Connolly S, Petersen P, Koudstaal PJ, Chang Y, Hellemons $B$. Oral anticoagulants vs aspirin in nonvalvular atrial fibrillation: an individual patient meta-analysis. Jama 2002;288:2441-2448.

46. Echocardiographic predictors of stroke in patients with atrial fibrillation: a prospective study of 1066 patients from 3 clinical trials. Arch Intern Med 1998;158:1316-1320.

47. Stollberger C, Chnupa P, Kronik G, Brainin M, Finsterer J, Schneider B, Slany J. Transesophageal echocardiography to assess embolic risk in patients with atrial fibrillation. ELAT Study Group. Embolism in Left Atrial Thrombi. Ann Intern Med 1998;128:630-638.

48. Providencia R, Botelho A, Trigo J, Quintal N, Nascimento J, Mota P, Leitao-Marques A. Possible refinement of clinical thromboembolism assessment in patients with atrial fibrillation using echocardiographic parameters. Europace.

49. Diener HC, Cunha L, Forbes C, Sivenius J, Smets P, Lowenthal A. European Stroke Prevention Study. 2. Dipyridamole and acetylsalicylic acid in the secondary prevention of stroke. J Neurol Sci 1996;143:1-13.

50. Lip GY, Nieuwlaat R, Pisters R, Lane DA, Crijns HJ. Refining clinical risk stratification for predicting stroke and thromboembolism in atrial fibrillation using a novel risk factor-based approach: the euro heart survey on atrial fibrillation. Chest 137:263-272.

51. van Walraven C, Hart RG, Wells GA, Petersen P, Koudstaal PJ, Gullov AL, Hellemons BS, Koefed BG, Laupacis A. A clinical prediction rule to identify patients with atrial fibrillation and a low risk for stroke while taking aspirin. Arch Intern Med 2003;163:936-943.

52. Macleod MR, Amarenco P, Davis SM, Donnan GA. Atheroma of the aortic arch: an important and poorly recognised factor in the aetiology of stroke. Lancet Neurol 2004;3:408-414.

53. Hart RG, Pearce LA, Rothbart RM, McAnulty JH, Asinger RW, Halperin JL. Stroke with intermittent atrial fibrillation: incidence and predictors during aspirin therapy. Stroke Prevention in Atrial Fibrillation Investigators. J Am Coll Cardiol 2000;35:183-187.

54. Wang TJ, Massaro JM, Levy D, Vasan RS, Wolf PA, D'Agostino RB, Larson MG, Kannel WB, Benjamin EJ. A risk score for predicting stroke or death in individuals with new-onset atrial fibrillation in the community: the Framingham Heart Study. Jama 2003;290:1049-1056.

55. Predictors of thromboembolism in atrial fibrillation: I. Clinical features of patients at risk. The Stroke Prevention in Atrial Fibrillation Investigators. Ann Intern Med 1992;116:1-5.

56. Laupacis A, Albers G, Dalen J, Dunn MI, Jacobson AK, Singer DE. Antithrombotic therapy in atrial fibrillation. Chest 1998;114:579S-589S. 
57. Singer DE, Albers GW, Dalen JE, Go AS, Halperin JL, Manning WJ. Antithrombotic therapy in atrial fibrillation: the Seventh ACCP Conference on Antithrombotic and Thrombolytic Therapy. Chest 2004;126:429S-456S.

58. Lip GY, Lowe GD. ABC of atrial fibrillation. Antithrombotic treatment for atrial fibrillation. Bmj 1996;312:45-49.

59. Gage BF, Waterman AD, Shannon W, Boechler M, Rich MW, Radford MJ. Validation of clinical classification schemes for predicting stroke: results from the National Registry of Atrial Fibrillation. Jama 2001;285:2864-2870.

60. Hughes M, Lip GY. Stroke and thromboembolism in atrial fibrillation: a systematic review of stroke risk factors, risk stratification schema and cost effectiveness data. Thromb Haemost 2008;99:295304.

61. Lip GY, Lane D, Van Walraven C, Hart RG. Additive role of plasma von Willebrand factor levels to clinical factors for risk stratification of patients with atrial fibrillation. Stroke 2006;37:2294-2300.

62. Olesen JB, Lip GY, Hansen ML, Hansen PR, Tolstrup JS, Lindhardsen J, Selmer C, Ahlehoff O, Olsen AM, Gislason GH, Torp-Pedersen C. Validation of risk stratification schemes for predicting stroke and thromboembolism in patients with atrial fibrillation: nationwide cohort study. Bmj 342:d124.

63. Schulman S, Kearon C. Definition of major bleeding in clinical investigations of antihemostatic medicinal products in non-surgical patients. J Thromb Haemost 2005;3:692-694.

64. Steger C, Pratter A, Martinek-Bregel M, Avanzini M, Valentin A, Slany J, Stollberger C. Stroke patients with atrial fibrillation have a worse prognosis than patients without: data from the Austrian Stroke registry. Eur Heart J 2004;25:1734-1740.

65. Fang MC, Go AS, Chang Y, Hylek EM, Henault LE, Jensvold NG, Singer DE. Death and disability from warfarin-associated intracranial and extracranial hemorrhages. Am J Med 2007;120:700-705.

66. Fang MC, Chang Y, Hylek EM, Rosand J, Greenberg SM, Go AS, Singer DE. Advanced age, anticoagulation intensity, and risk for intracranial hemorrhage among patients taking warfarin for atrial fibrillation. Ann Intern Med 2004;141:745-752.

67. Hylek EM, Evans-Molina C, Shea C, Henault LE, Regan S. Major hemorrhage and tolerability of warfarin in the first year of therapy among elderly patients with atrial fibrillation. Circulation 2007;115:2689-2696.

68. Hylek EM, Singer DE. Risk factors for intracranial hemorrhage in outpatients taking warfarin. Ann Intern Med 1994;120:897-902.

69. Beyth RJ, Quinn LM, Landefeld CS. Prospective evaluation of an index for predicting the risk of major bleeding in outpatients treated with warfarin. Am J Med 1998;105:91-99.

70. Gage BF, Yan Y, Milligan PE, Waterman AD, Culverhouse R, Rich MW, Radford MJ. Clinical classification schemes for predicting hemorrhage: results from the National Registry of Atrial Fibrillation (NRAF). Am Heart J 2006;151:713-719.

71. Shireman TI, Howard PA, Kresowik TF, Ellerbeck EF. Combined anticoagulant-antiplatelet use and major bleeding events in elderly atrial fibrillation patients. Stroke 2004;35:2362-2367.

72. Kuijer PM, Hutten BA, Prins MH, Buller HR. Prediction of the risk of bleeding during anticoagulant treatment for venous thromboembolism. Arch Intern Med 1999;159:457-460.

73. Pisters R, Lane DA, Nieuwlaat R, de Vos CB, Crijns HJ, Lip GY. A novel user-friendly score (HAS-BLED) to assess 1-year risk of major bleeding in patients with atrial fibrillation: the Euro Heart Survey. Chest 138:1093-1100.

74. Pisters R, Lane DA, Nieuwlaat R, de Vos CB, Crijns HJ, Lip GY. A novel user-friendly score (HAS-BLED) to assess one-year risk of major bleeding in atrial fibrillation patients: The Euro Heart Survey. Chest.

75. Lip GY, Frison L, Halperin JL, Lane DA. Comparative validation of a novel risk score for predicting bleeding risk in anticoagulated patients with atrial fibrillation: the HAS-BLED (Hypertension, Abnormal Renal/Liver Function, Stroke, Bleeding History or Predisposition, Labile INR, Elderly, Drugs/Alcohol Concomitantly) score. J Am Coll Cardiol 57:173-180. 
76. Olesen JB, Lip GY, Hansen PR, Lindhardsen J, Ahlehoff O, Andersson C, Weeke P, Hansen ML, Gislason $\mathrm{GH}$, Torp-Pedersen C. Bleeding risk in 'real world' patients with atrial fibrillation: comparison of two established bleeding prediction schemes in a nationwide cohort. J Thromb Haemost 9:14601467.

77. Hylek EM, Skates SJ, Sheehan MA, Singer DE. An analysis of the lowest effective intensity of prophylactic anticoagulation for patients with nonrheumatic atrial fibrillation. N Engl J Med 1996;335:540546.

78. Hylek EM, Go AS, Chang Y, Jensvold NG, Henault LE, Selby JV, Singer DE. Effect of intensity of oral anticoagulation on stroke severity and mortality in atrial fibrillation. N Engl J Med 2003;349:10191026.

79. Hart RG, Benavente O, Pearce LA. Increased risk of intracranial hemorrhage when aspirin is combined with warfarin: A meta-analysis and hypothesis. Cerebrovasc Dis 1999;9:215-217.

80. Pisters R, van Oostenbrugge RJ, Knottnerus IL, de Vos CB, Boreas A, Lodder J, Prins MH, Crijns HJ, Tieleman RG. The likelihood of decreasing strokes in atrial fibrillation patients by strict application of guidelines. Europace 12:779-784.

81. Camm AJ, Kirchhof P, Lip GY, Schotten U, Savelieva I, Ernst S, Van Gelder IC, Al-Attar N, Hindricks G, Prendergast B, Heidbuchel H, Alfieri O, Angelini A, Atar D, Colonna P, De Caterina R, De Sutter J, Goette A, Gorenek B, Heldal M, Hohloser SH, Kolh P, Le Heuzey JY, Ponikowski P, Rutten FH. Guidelines for the management of atrial fibrillation: the Task Force for the Management of Atrial Fibrillation of the European Society of Cardiology (ESC). Eur Heart J 31:2369-2429.

82. Hart RG, Pearce LA, Miller VT, Anderson DC, Rothrock JF, Albers GW, Nasco E. Cardioembolic vs. noncardioembolic strokes in atrial fibrillation: frequency and effect of antithrombotic agents in the stroke prevention in atrial fibrillation studies. Cerebrovasc Dis 2000;10:39-43.

83. Connolly S, Pogue J, Hart R, Pfeffer M, Hohnloser S, Chrolavicius S, Pfeffer M, Hohnloser S, Yusuf S. Clopidogrel plus aspirin versus oral anticoagulation for atrial fibrillation in the Atrial fibrillation Clopidogrel Trial with Irbesartan for prevention of Vascular Events (ACTIVE W): a randomised controlled trial. Lancet 2006;367:1903-1912.

84. Connolly SJ, Pogue J, Hart RG, Hohnloser SH, Pfeffer M, Chrolavicius S, Yusuf S. Effect of clopidogrel added to aspirin in patients with atrial fibrillation. N Engl J Med 2009;360:2066-2078.

85. Healey JS, Hart RG, Pogue J, Pfeffer MA, Hohnloser SH, De Caterina R, Flaker G, Yusuf S, Connolly SJ. Risks and benefits of oral anticoagulation compared with clopidogrel plus aspirin in patients with atrial fibrillation according to stroke risk: the atrial fibrillation clopidogrel trial with irbesartan for prevention of vascular events (ACTIVE-W). Stroke 2008;39:1482-1486.

86. Gorin L, Fauchier L, Nonin E, de Labriolle A, Haguenoer K, Cosnay P, Babuty D, Charbonnier B. Antithrombotic treatment and the risk of death and stroke in patients with atrial fibrillation and a CHADS2 score=1. Thromb Haemost 103:833-840.

87. Pisters R, Dinh T, Crijns HJ. Clopidogrel plus aspirin in atrial fibrillation. N Engl J Med 2009;361:1312; author reply 1314-1315.

88. Gattellari M, Worthington J, Zwar N, Middleton S. Barriers to the use of anticoagulation for nonvalvular atrial fibrillation: a representative survey of Australian family physicians. Stroke 2008;39:227230.

89. Deplanque D, Leys D, Parnetti L, Schmidt R, Ferro J, De Reuck J, Mas JL, Gallai V. Stroke prevention and atrial fibrillation: reasons leading to an inappropriate management. Main results of the SAFE II study. Br J Clin Pharmacol 2004;57:798-806.

90. Man-Son-Hing M, Nichol G, Lau A, Laupacis A. Choosing antithrombotic therapy for elderly patients with atrial fibrillation who are at risk for falls. Arch Intern Med 1999;159:677-685.

91. Gage BF, Birman-Deych E, Kerzner R, Radford MJ, Nilasena DS, Rich MW. Incidence of intracranial hemorrhage in patients with atrial fibrillation who are prone to fall. Am J Med 2005;118:612-617.

92. Riva N, Smith DE, Lip GY, Lane DA. Advancing age and bleeding risk are the strongest barriers to anticoagulant prescription in atrial fibrillation. Age Ageing. 
93. Poli D, Antonucci E, Grifoni E, Abbate R, Gensini GF, Prisco D. Bleeding risk during oral anticoagulation in atrial fibrillation patients older than 80 years. J Am Coll Cardiol 2009;54:999-1002.

94. Man-Son-Hing M, Laupacis A. Anticoagulant-related bleeding in older persons with atrial fibrillation: physicians' fears often unfounded. Arch Intern Med 2003;163:1580-1586.

95. Mant J, Hobbs FD, Fletcher K, Roalfe A, Fitzmaurice D, Lip GY, Murray E. Warfarin versus aspirin for stroke prevention in an elderly community population with atrial fibrillation (the Birmingham Atrial Fibrillation Treatment of the Aged Study, BAFTA): a randomised controlled trial. Lancet 2007;370:493-503.

96. van Walraven C, Hart RG, Connolly S, Austin PC, Mant J, Hobbs FD, Koudstaal PJ, Petersen P, PerezGomez F, Knottnerus JA, Boode B, Ezekowitz MD, Singer DE. Effect of Age on Stroke Prevention Therapy in Patients With Atrial Fibrillation. The Atrial Fibrillation Investigators. Stroke 2009.

97. Nieuwlaat R, Capucci A, Lip GY, Olsson SB, Prins MH, Nieman FH, Lopez-Sendon J, Vardas PE, Aliot E, Santini $M$, Crijns HJ. Antithrombotic treatment in real-life atrial fibrillation patients: a report from the Euro Heart Survey on Atrial Fibrillation. Eur Heart J 2006;27:3018-3026.

98. Nieuwlaat R, Olsson SB, Lip GY, Camm AJ, Breithardt G, Capucci A, Meeder JG, Prins MH, Levy S, Crijns HJ. Guideline-adherent antithrombotic treatment is associated with improved outcomes compared with undertreatment in high-risk patients with atrial fibrillation. The Euro Heart Survey on Atrial Fibrillation. Am Heart J 2007;153:1006-1012.

99. Nieuwlaat R, Dinh T, Olsson SB, Camm AJ, Capucci A, Tieleman RG, Lip GY, Crijns HJ. Should we abandon the common practice of withholding oral anticoagulation in paroxysmal atrial fibrillation? Eur Heart J 2008;29:915-922.

100. Pisters R, Nieuwlaat R, de Vos CB, Crijns HJ. Comprehensive upstream treatment for atrial fibrillation, when and how? Europace 2009;11:397-399.

101. Silber S, Albertsson P, Aviles FF, Camici PG, Colombo A, Hamm C, Jorgensen E, Marco J, Nordrehaug JE, Ruzyllo W, Urban P, Stone GW, Wijns W. Guidelines for percutaneous coronary interventions. The Task Force for Percutaneous Coronary Interventions of the European Society of Cardiology. Eur Heart J 2005;26:804-847.

102. Karjalainen PP, Porela P, Ylitalo A, Vikman S, Nyman K, Vaittinen MA, Airaksinen TJ, Niemela M, Vahlberg T, Airaksinen KE. Safety and efficacy of combined antiplatelet-warfarin therapy after coronary stenting. Eur Heart $\mathrm{J}$ 2007; 28:726-732.

103. Nguyen MC, Lim YL, Walton A, Lefkovits J, Agnelli G, Goodman SG, Budaj A, Gulba DC, Allegrone J, Brieger D. Combining warfarin and antiplatelet therapy after coronary stenting in the Global Registry of Acute Coronary Events: is it safe and effective to use just one antiplatelet agent? Eur Heart J 2007;28:1717-1722.

104. Rubboli A, Halperin JL, Airaksinen KE, Buerke M, Eeckhout E, Freedman SB, Gershlick AH, Schlitt A, Tse HF, Verheugt FW, Lip GY. Antithrombotic therapy in patients treated with oral anticoagulation undergoing coronary artery stenting. An expert consensus document with focus on atrial fibrillation. Ann Med 2008;40:428-436.

105. Lip GY, Andreotti F, Fauchier L, Huber K, Hylek E, Knight E, Lane DA, Levi M, Marin F, Palareti G, Kirchhof P, Collet JP, Rubboli A, Poli D, Camm J. Bleeding risk assessment and management in atrial fibrillation patients: a position document from the European Heart Rhythm Association, endorsed by the European Society of Cardiology Working Group on Thrombosis. Europace 13:723-746.

106. Baigent C, Collins R, Appleby P, Parish S, Sleight P, Peto R. ISIS-2: 10 year survival among patients with suspected acute myocardial infarction in randomised comparison of intravenous streptokinase, oral aspirin, both, or neither. The ISIS-2 (Second International Study of Infarct Survival) Collaborative Group. Bmj 1998;316:1337-1343.

107. Hohnloser SH, Crijns HJ, van Eickels M, Gaudin C, Page RL, Torp-Pedersen C, Connolly SJ. Effect of dronedarone on cardiovascular events in atrial fibrillation. N Engl J Med 2009;360:668-678. 
108. Connolly SJ, Crijns HJ, Torp-Pedersen C, van Eickels M, Gaudin C, Page RL, Hohnloser SH. Analysis of stroke in ATHENA: a placebo-controlled, double-blind, parallel-arm trial to assess the efficacy of dronedarone $400 \mathrm{mg}$ BID for the prevention of cardiovascular hospitalization or death from any cause in patients with atrial fibrillation/atrial flutter. Circulation 2009;120:1174-1180.

109. Connolly SJ, Ezekowitz MD, Yusuf S, Eikelboom J, Oldgren J, Parekh A, Pogue J, Reilly PA, Themeles E, Varrone J, Wang S, Alings M, Xavier D, Zhu J, Diaz R, Lewis BS, Darius H, Diener HC, Joyner CD, Wallentin L. Dabigatran versus warfarin in patients with atrial fibrillation. $N$ Engl J Med 2009;361:1139-1151.

110. Patel MR, Mahaffey KW, Garg J, Pan G, Singer DE, Hacke W, Breithardt G, Halperin JL, Hankey GJ, Piccini JP, Becker RC, Nessel CC, Paolini JF, Berkowitz SD, Fox KA, Califf RM. Rivaroxaban versus warfarin in nonvalvular atrial fibrillation. N Engl J Med 365:883-891.

111. Granger CB, Alexander JH, McMurray JJ, Lopes RD, Hylek EM, Hanna M, Al-Khalidi HR, Ansell J, Atar D, Avezum A, Bahit MC, Diaz R, Easton JD, Ezekowitz JA, Flaker G, Garcia D, Geraldes M, Gersh BJ, Golitsyn S, Goto S, Hermosillo AG, Hohnloser SH, Horowitz J, Mohan P, Jansky P, Lewis BS, LopezSendon JL, Pais P, Parkhomenko A, Verheugt FW, Zhu J, Wallentin L. Apixaban versus warfarin in patients with atrial fibrillation. N Engl J Med 365:981-992.

112. Connolly SJ, Eikelboom J, Joyner C, Diener HC, Hart R, Golitsyn S, Flaker G, Avezum A, Hohnloser SH, Diaz R, Talajic M, Zhu J, Pais P, Budaj A, Parkhomenko A, Jansky P, Commerford P, Tan RS, Sim KH, Lewis BS, Van Mieghem W, Lip GY, Kim JH, Lanas-Zanetti F, Gonzalez-Hermosillo A, Dans AL, Munawar M, O'Donnell M, Lawrence J, Lewis G, Afzal R, Yusuf S. Apixaban in patients with atrial fibrillation. N Engl J Med 364:806-817.

113. Pisters R, de Vos CB, Nieuwlaat R, Crijns HJ. Use and underuse of oral anticoagulation for stroke prevention in atrial fibrillation: old and new paradigms. Semin Thromb Hemost 2009;35:554-559.

114. Waldo AL, Becker RC, Tapson VF, Colgan KJ. Hospitalized patients with atrial fibrillation and a high risk of stroke are not being provided with adequate anticoagulation. I Am Coll Cardiol 2005;46:1729-1736.

115. Hendriks JL, Nieuwlaat R, Vrijhoef HJ, de Wit R, Crijns HJ, Tieleman RG. Improving guideline adherence in the treatment of atrial fibrillation by implementing an integrated chronic care program. Neth Heart J 18:471-477.

116. Watson T, Shantsila E, Lip GY. Mechanisms of thrombogenesis in atrial fibrillation: Virchow's triad revisited. Lancet 2009;373:155-166.

117. Poli D, Testa S, Antonucci E, Grifoni E, Paoletti O, Lip GY. Bleeding and Stroke Risk in a Real-world Prospective Primary Prevention Cohort of Patients With Atrial Fibrillation. Chest 140:918-924.

118. Poli D, Antonucci E, Marcucci R, Fatini C, Alterini B, Mannini L, Falciani M, Abbate R, Gensini GF, Prisco D. Risk of bleeding in very old atrial fibrillation patients on warfarin: relationship with ageing and CHADS2 score. Thromb Res 2007;121:347-352.

119. Lip G, Nieuwlaat R, Pisters R, Lane D, Crijns H. Refining clinical risk stratification for predicting stroke and thromboembolism in atrial fibrillation using a novel risk factor based approach: The Euro Heart Survey on Atrial Fibrillation. Chest 2009.

120. Pisters R, Crijns HJ. Atrial fibrillation: A risk score for AF-burning the haystack to find the needle. Nat Rev Cardiol 2009;6:394-395.

121. Osranek M, Bursi F, Bailey KR, Grossardt BR, Brown RD, Jr., Kopecky SL, Tsang TS, Seward JB. Left atrial volume predicts cardiovascular events in patients originally diagnosed with lone atrial fibrillation: three-decade follow-up. Eur Heart J 2005;26:2556-2561.

122. Aronow WS, Gutstein H, Hsieh FY. Risk factors for thromboembolic stroke in elderly patients with chronic atrial fibrillation. Am J Cardiol 1989;63:366-367.

123. Oakes RS, Badger TJ, Kholmovski EG, Akoum N, Burgon NS, Fish EN, Blauer JJ, Rao SN, DiBella EV, Segerson NM, Daccarett M, Windfelder J, McGann CJ, Parker D, MacLeod RS, Marrouche NF. Detection and quantification of left atrial structural remodeling with delayed-enhancement magnetic resonance imaging in patients with atrial fibrillation. Circulation 2009;119:1758-1767. 
124. Feinberg WM, Seeger JF, Carmody RF, Anderson DC, Hart RG, Pearce LA. Epidemiologic features of asymptomatic cerebral infarction in patients with nonvalvular atrial fibrillation. Arch Intern Med 1990;150:2340-2344.

125. Kempster PA, Gerraty RP, Gates PC. Asymptomatic cerebral infarction in patients with chronic atrial fibrillation. Stroke 1988;19:955-957.

126. Petersen P, Madsen EB, Brun B, Pedersen F, Gyldensted C, Boysen G. Silent cerebral infarction in chronic atrial fibrillation. Stroke 1987;18:1098-1100.

127. Pisters R, de Vos CB, Dennert R, Crijns HJ. Undetected paroxysmal atrial fibrillation in chronic heart failure patients: is it clinically relevant to catch the atrial phantom? Europace 2009;11:1257-1259.

128. Tayal AH, Tian M, Kelly KM, Jones SC, Wright DG, Singh D, Jarouse J, Brillman J, Murali S, Gupta R. Atrial fibrillation detected by mobile cardiac outpatient telemetry in cryptogenic TIA or stroke. Neurology 2008;71:1696-1701.

129. Schnabel RB, Sullivan LM, Levy D, Pencina MJ, Massaro JM, D'Agostino RB, Sr., Newton-Cheh C, Yamamoto JF, Magnani JW, Tadros TM, Kannel WB, Wang TJ, Ellinor PT, Wolf PA, Vasan RS, Benjamin EJ. Development of a risk score for atrial fibrillation (Framingham Heart Study): a communitybased cohort study. Lancet 2009;373:739-745. 



\section{Summary / Samenvatting}

\section{Summary}

The introduction portrays the profile of one of the most wanted cardiovascular serial killers: atrial fibrillation (AF). The arrhythmia has all it takes to maintain this position: several ten millions of victims worldwide, deadly sequelae - in particular stroke - and the act of a wolf in sheep's clothing.

Fortunately, we have a trump card backing up our pursuit to drastically minimize casualties by this international fugitive: oral anticoagulation. Still, up to now we failed to play this card right, leaving the arrhytmia to have the upper hand.

This thesis reflects the problem (Chapters 2, 4, 5 and 7), proposes guerrilla tactics (Chapters 1 and 3) and future avenues (Chapters 6 and 8 ) in order to regain control and make the (citizen's) arrest.

\section{Samenvatting}

De introductie schildert het profiel van een van de meest gezochte cardiovasculaire serie moordenaars: atrium fibrilleren. De ritmestoornis heeft alles in huis om deze positie te behouden: wereldwijd tientallen miljoenen slachtoffers, dodelijke gevolgen - met name beroertes - en het gedrag van een wolf in schaapskleren.

Gelukkig hebben we een troef achter de hand om het aantal slachtoffers van deze internationale voortvluchtige drastisch te beperken: orale antistolling. Helaas hebben we tot op heden onze kaarten niet juist gespeeld waardoor de ritmestoornis de bovenhand heeft.

Dit proefschrift schetst het probleem (Hoofdstukken 2, 4, 5, en 7), stelt guerrilla tactieken voor (Hoofdstuk 1 en 2) en toont toekomstige mogelijkheden om de controle terug te krijgen en tot (burger)arrest over te gaan. 



\section{Dankwoord}

Het schrijven van dit laatste, het dankwoord, doet me denken aan het begin van mijn onderzoekstraject: ik weet niet waar ik moet beginnen.

Misschien niet eens zo gek gezien de optelsom van de afgelopen 5 jaar: samenwerking met en steun van honderden collega's/vrienden + duizenden gekregen en gecreëerde mogelijkheden = oneindig daaruit voortgevloeide avonturen.

Daarnaast is in mijn ogen (eenmalig) bedanken in schrift significant inferieur aan dankbetuiging middels (dagelijkse) daden.

Hoe meer ik je help, hoe meer ik je waardeer en dankbaar ben.

You do the math ;D 



\section{Curriculum Vitae}

Ronny Pisters was born on Friday $27^{\text {th }}$ of August 1982 in Heerlen, the Netherlands. After completing his secondary school th the Sintermeertencollege (gymnasium) in Heerlen 2000, he started his medical training at the University of Maastricht. For his scientific work 'Apoptosis As Apocalyptic Adversary of Atherosclerosis', supervised by dr. Leonard Hofstra, during the final year of his training he received the Scientific Student of the Year (2006) award of the University of Maastricht, Faculty of Medicine.

Upon obtaining his medical degree in 2006 he started his work as a research fellow, under supervision of prof. dr. Harry J.G.M. Crijns, at the department of Cardiology at the University of Maastricht focussing on the antithrombotic management of patients with atrial fibrillation. He was allowed to present his work on many occasions at large international congresses and received the award for best clinical presentation at the Dutch Society of Cardiology in 2009. The scientific results obtained during that time form the basis of this thesis. Recently, he was awarded a grant by the Hein Wellens Foundation for a post-doc position, supervised by prof. dr. Gregory Y.H. Lip, at the Centre for Cardiovascular Sciences at the University of Birmingham, United Kingdom. Following his adventure abroad he looks forward to start his 'official' training in clinical cardiology, guided by prof.dr. Harry J.G.M. Crijns and dr. Emiel C. Cheriex, at the end of 2012. 



\section{List of Publications}

\section{Original research}

Pisters R, Nieuwlaat R, Prins MH, Le Heuzey JY, Maggioni AP, Camm AJ, Crijns HJ; for the Euro Heart Survey Investigators. Clinical correlates of immediate success and outcome at 1-year follow-up of real-world cardioversion of atrial fibrillation: the Euro Heart Survey. Europace 2012 Jan 5 [Epub ahead of print] PMID: 22222085.

Weijs B, Pisters R, Nieuwlaat R, Breithardt G, Le Heuzey JY, Vardas PE, Limantoro I, Schotten U, Lip GY, Crijns HJ. Idiopathic atrial fibrillation revisited in a large longitudinal clinical cohort. Europace. 2012 Feb;14(2):184-90.

Weijs B, de Vos CB, Tieleman RG, Pisters R, Cheriex EC, Prins MH, Crijns HJ. Clinical and echocardiographic correlates of intra-atrial conduction delay. Europace. 2011 Aug 15.

Dinh T, Baur LH, Pisters R, Kamp O, Verheugt FW, Smeets JL, Cheriex EC, Tieleman RG, Prins MH, Crijns HJ; for the TIARA pilot study group. Feasibility of TEE-guided stroke risk assessment in atrial fibrillation-background, aims, design and baseline data of the TIARA pilot study. Neth Heart J. 2011 May;19(5):214-222.

Pisters R, Lane DA, Nieuwlaat R, de Vos CB, Crijns HJ, Lip GY. A novel user-friendly score (HAS-BLED) to assess 1-year risk of major bleeding in patients with atrial fibrillation: the Euro Heart Survey. Chest. 2010 Nov;138(5):1093-100.

R Pisters, RJ van Oostenbrugge, ILH Knottnerus, CB de Vos, A Boreas, J Lodder, MH Prins, HJGM Crijns, RG Tieleman. The likelihood of decreasing strokes in atrial fibrillation patients by strict application of guidelines, Europace. 2010 Jun;12(6):779-84, DOI:10.1093/europace/euq080

CB de Vos, R Pisters, R Nieuwlaat, MH Prins, RG Tieleman, MA Allessie, HJGM Crijns. Progression from paroxysmal to persistent atrial fibrillation: clinical correlates and prognosis, JACC 2010, Feb 23;55(8):725-31, DOI: 10.1016/j.jacc.2009.11.040

De Vos CB, Pison L, Pisters R, Schotten U, Cheriex EC, Prins MH, Delhaas T, Crijns HJ, Tieleman RG. Atrial fibrillatory wall motion and degree of atrial remodeling in pa- 
tients with atrial fibrillation: a tissue velocity imaging study. J Cardiovasc Electrophysiol. 2009 Dec ;20(12):1374-81.

GYH Lip, R Nieuwlaat, R Pisters, DA Lane, HJ Crijns. Refining clinical risk stratification for predicting stroke and thromboembolism in atrial fibrillation using a novel risk factor based approach: The Euro Heart Survey on Atrial Fibrillation, Chest 2010, Feb;137(2):263-72, DOI 10.1378/chest.09-1584.

De Vos CB, Nieuwlaat R, Crijns HJ, Camm AJ, LeHeuzey JY, Kirchhof C, Capucci A, Breithardt G, Vardas P, Pisters R, Tieleman RG. Autonomic Trigger Patterns And Anti-Arrhythmic Treatment Of Paroxysmal Atrial Fibrillation: Data From The Euro Heart Survey. European Heart Journal. 2008 Mar;29(5):632-9

\section{Editorials/review}

R Pisters, JB Olesen, GYH Lip. The role of echocardiography in stroke risk assessment in patients with atrial fibrillation: it is it additive or does it simply echo clinical risk factors? Europace 2011.

R Pisters, R Nieuwlaat, CB de Vos, HJGM Crijns. Comprehensive upstream treatment for atrial fibrillation, when and how? Europace. 2009 Apr;11(4):397-9.

R Pisters, HJ Crijns. A risk score for AF - burning the haystack to find the needle. Nat Rev Cardiol. 2009 Jun;6(6):394-5

R Pisters, CB de Vos, R Dennert, HJ Crijns. Undetected atrial fibrillation in chronic heart failure patients: is it clinically relevant to catch the atrial phantom? Europace 2009, Oct;11(10):1257-9.

R Pisters, CB de Vos, R Nieuwlaat, HJ Crijns. Use and underuse of oral anticoagulation for stroke prevention in atrial fibrillation: old and new paradigms, Semin Thromb Hemost. 2009 Sep;35(6):554-9

Levi M, Hobbs FD, Jacobson AK, Pisters R, Prisco D, Bernardo A, Haas M, Heidrich J, Rosenberg M, Nielsen JD, Wuillemin WA. Improving antithrombotic management in patients with atrial fibrillation: current status and perspectives, Semin Thromb Hemost. 2009 Sep;35(6):527-42 


\section{Contribution to books}

R Pisters, $\mathrm{H}$ ten Cate, HJ Crijns. Particular challenges in atrial fibrillation; Karger, in press

\section{Editor of books}

HJGM Crijns, R Pisters, Stroke prevention in atrial fibrillation, Future Science Group, in preparation

\section{Correspondence}

Olesen JB, Pisters R, Roldans V, Marin F, Lane DA. Correspondence J Am Coll Cardiol 2012 Jan 10;59(20):194-5.

R Pisters, R Nieuwlaat, DA Lane, HJGM Crijns, GYH Lip. Chest. 2011 May;139(5):1248-9; author reply 1249-50.

R Pisters, R Nieuwlaat, DA Lane, HJGM Crijns, GYH Lip. Chest. 2011 May;139(5):1247-8; author reply 1248.

GYH Lip, R Nieuwlaat, R Pisters, DA Lane, HJGM Crijns. Chest. 2010 Oct;138(4):1020; author reply 1020-1.

R Pisters, R Nieuwlaat, DA Lane, HJGM Crijns, GYH Lip. Chest. 2010 Jul;138(1):239; author reply 239-40.

R Pisters, TD Dinh, HJ Crijns, correspondence. N Engl J Med. 2009 Sep 24;361(13):1312; author reply 1314-5.

\section{National publications}

R Pisters. Antithrombotische behandeling van atriumfibrilleren. FTO Online september 2011.

Willemsen RTA, Pisters R, Crijns HJGM, De Wit AAM. Implementatie van antitrombotische behandeling bij atriumfibrilleren. Huisarts Wet 2011;54(4):192-6 
R Pisters. Waarom moet ik naar de trombosedienst? Wetenswaardig; december 2010.

R Pisters, HJGM Crijns; Kan wat langer bestaand boezemfibrilleren zonder antistolling zonder risico medicamenteus geconverteerd worden? Cardiologen Vademecum. Jaargang 10, nr 1, februari 2007. 